
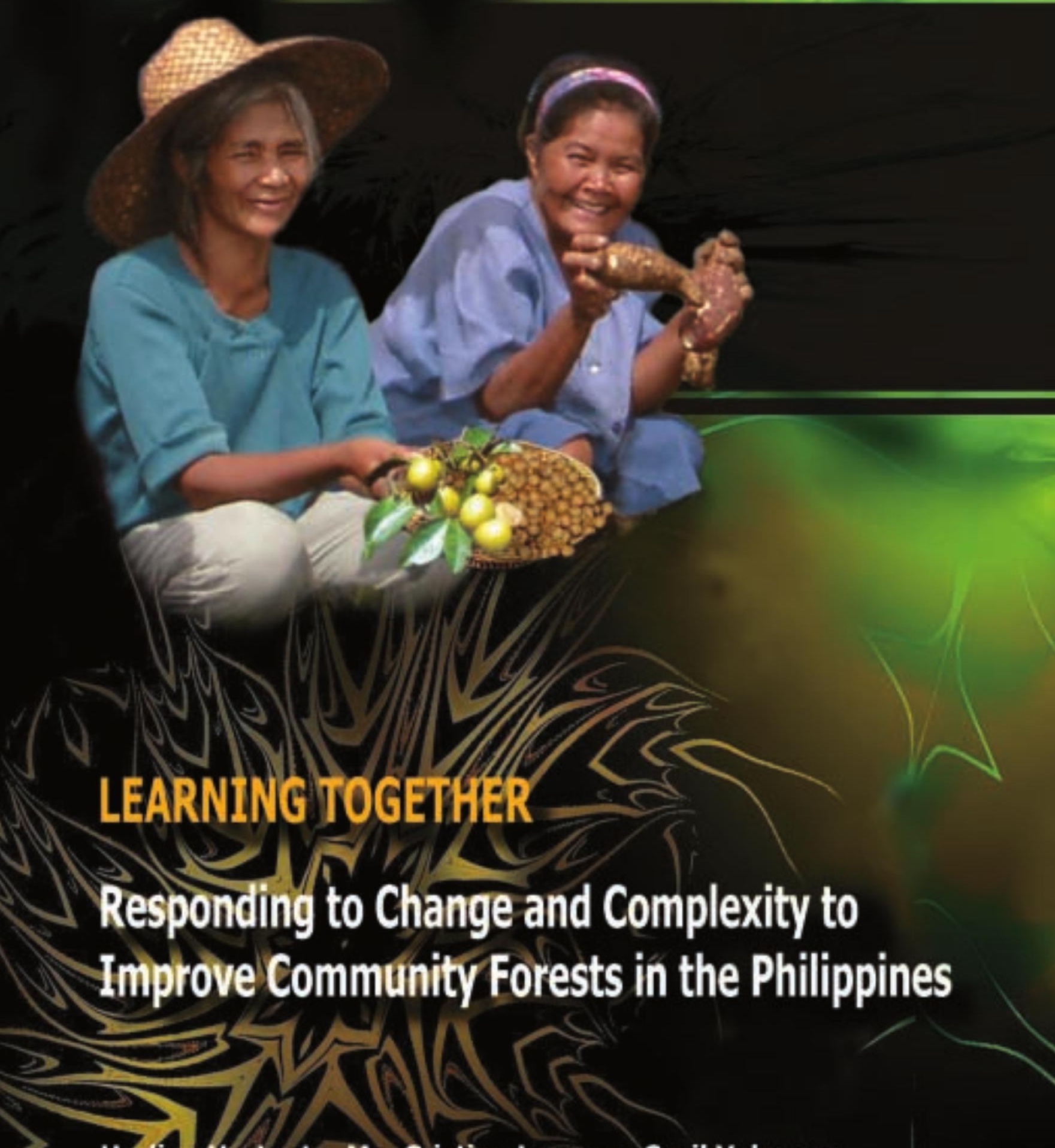

Herlina Hartanto, Ma. Cristina Lorenzo, Cecil Valmores, Lani Arda-Minas, Erlinda M. Burton, and Ravi Prabhu 


\section{LEARNING TOGETHER}

Responding to Change and Complexity to Improve Community Forests in the Philippines

Herlina Hartanto, Ma. Cristina Lorenzo, Cecil Valmores, Lani Arda-Minas, Erlinda M. Burton, and Ravi Prabu 
(C)2003 by Center for International Forestry Research

All rights reserved. Published in 2003

Printed by SMK Grafika Desa Putera, Indonesia

Cover design by Edwin Yulianto

Illustrations by Bernie Remoquillo

Photographs by ACM Philippine Team, Antonio Frio, Mt. Kitanglad Protected Area

Management Board, Ecosystems Research and Development Bureau, Carol Colfer,

Alain Compost, Christian Cossalter, Miriam van Heist, Esther Katz, Francis Ng, Yayat Ruchiat, Manuel Ruiz-Pérez, Plinio Sist, John Turnbull, Eva Wollenberg, and Linda Yuliani.

\section{ISBN 979-3361-10-7}

\section{Published by}

Center for International Forestry Research (CIFOR)

Mailing address: P.O. Box 6596 JKPWB, Jakarta 10065, Indonesia

Office address: Jl.CIFOR, Situ Gede, Sindang Barang

Bogor Barat 16880, Indonesia

Tel:+62 (0251) 622622 Fax:+62 (0251) 622100

E-mail: cifor@cgiar.org

Website: http://www.cifor.cgiar.org

with support from

Asian Development Bank

Manila, Philippines 


\section{TABLE OF CONTENTS}

List of Tables and Figures $\quad$ V

Foreword vi vi

Acknowledgements vii

Acronyms and A bbreviations $\quad x$

Chapter 1. Introduction $\quad 1$

O bjective of this book 3

W ho this book is for 3

Background of our research 4

Structure of this book 6

Chapter 2. Community Forestry in the Philippines 7

The CBFM programme 10

Who are involved in CBFM? 12

Devolution is not working 13

Partnershipshardly exist... $\quad 14$

... and challenges continue $\quad 14$

$\begin{array}{ll}\text { Chapter 3. What is ACM? } & 17\end{array}$

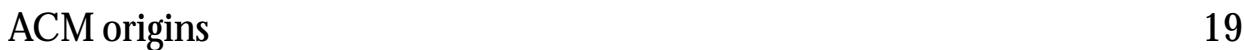

M ain elements of ACM $\quad 21$

Social learningin ACM $\quad 22$

What can ACM do for CBFM? 23

Chapter 4. The ACM Sites $\quad 25$

San Rafael, Tanabag, and C oncepcion villages: the Palawan site 27

Basac village: the Bukidnon site $\quad 30$

The CBFM stakeholders $\quad 32$

Biophysical conditions $\quad 35$

Forest management systems 38

Collaboration and adaptiveness $\quad 41$ 
Prioritisation and focusing on key local issues $\quad 47$

Key local priority issues $\quad 50$

W ho took part in addressing the local priority issues?

$\mathrm{H}$ ow ACM processes were activated and facilitated 51

M anaging a CBFM area boundary conflict $\quad 52$

Strengthening communication through newsletters 57

C reating better livelihood opportunities 61

$\mathrm{H}$ arnessing indigenous knowledge: The case for herbal medicine 68

Learning to improve organisational governance 77

ACM outcomes in Palawan and Bukidnon sites $\quad 85$

$\begin{array}{ll}\text { Spin-offs of ACM } & 91\end{array}$

Chapter 6. Constraints and Challenges 95

Chapter 7. Implications of ACM on CBFM 103

$\begin{array}{ll}\text { Chapter 8. Conclusion } & 111\end{array}$

ACM improves variousskills $\quad 113$

Conditions where ACM can be most effective 115

$\begin{array}{ll}\text { Annexes } & 117\end{array}$

Annex 1. A Guide on H ow to Implement ACM Processes 119

Annex 2. Effective Facilitation $\quad 151$

$\begin{array}{ll}\text { Endnotesand R eferences } & 155\end{array}$ 


\section{LIST OF TABLES AND FIGURES}

\section{Tables}

1. The main stakeholders in the ACM Palawan and Bukidnon sites

2. Monitoring form for herb garden

3. Outcomes of ACM in Palawan site

86

4. Outcomes of ACM in Bukidnon site

\section{Figures}

1. Evolution of the Philippine community forestry programme

2. The approval process of CBFM work plan documents

3. The ACM process in addressing a CBFM area boundary conflict

4. The ACM process in strengthening communication to enhance participation by the $\mathrm{PO}$ and community members in CBFM implementation

5. The ACM process in creating better livelihood options

6. The ACM process in creating better livelihood options (continuation)

7. The ACM process in addressing lack of medicines at the barangay health centre

8. The ACM process in improving local governance by addressing lack of information dissemination mechanisms

9. The ACM process in improving local governance by addressing lack of leadership and organisational skills

10. The ACM process in improving local governance by addressing weak implementation of ordinances

11. The ACM process in improving local governance by addressing lack of transparency in financial reporting system

12. Causal loop diagram showing the 'emergent' outcomes of ACM in reducing illegal resin extraction and trading in the Palawan site

13. Causal loop diagram showing the 'emergent' otcomes of ACM in making CBFM planning and decision making processes in the Palawan site more democratic 


\section{FOREWORD}

The Philippines has a long history of managing its forests. Several forest management schemes had been tried and implemented, but they had proved ineffective in preventing destructive forest practices. It was in the early '70s that the Government of the Philippines shifted to a participatory, rather than punitive approach, in solving the nation's forest problems. Since its inception, several people-oriented forestry programmes have been implemented to protect and manage our nation's forests. These programmes have now been integrated into the Community-Based Forest Management (CBFM).

To date, CBFM projects have been established in 4,956 sites covering an aggregate area of 5.7 million hectares of previously open access forests, and involving 496,165 households. A total of 727 People's Organisations have received tenure over a total of 905,000 hectares under the CBFM Agreement.

The success of CBFM prompted the Center for International Forestry Research (CIFOR), in coordination with the Department of Environment and Natural Resources (DENR), to publish this book which provides information on the concept, strategies and implementation of CBFM. Furthermore, the book also documents lesson learnt from the pilot studies on Adaptive Collaborative Management (ACM) as an approach to further strengthen CBFM in the Philippines.

Clearly managing a limited yet widely distributed resource with the participation of a large number of people is never going to be easy. Through CBFM, we are optimistic that this challenge can be addressed more effectively and equitably.

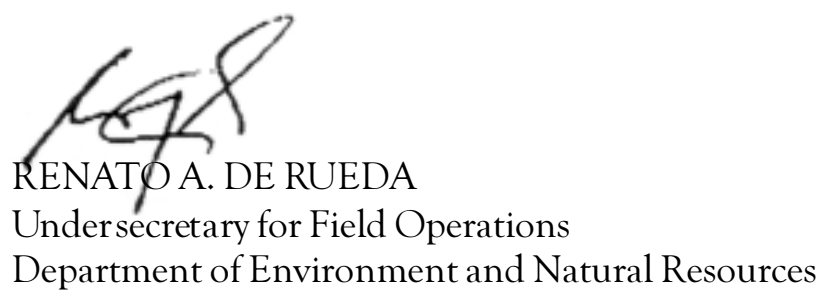




\section{ACKNOWLEDGEMENTS}

This book is one of the major outputs of the CIFOR project on "Planning for Sustainability of Forests through Adaptive Co-management" in the Philippines. We would like to express our gratitude to the Asian Development Bank who has generously extended the grant that has allowed us to conduct this research project, particularly to Muhammad A. Mannan and Sivaguru Sahajananthan for their guidance. The views and opinions expressed in this book, however, do not reflect the views and policies of the donor agency.

As a part of the global ACM research programme, our work in the Philippines benefited from the strategic guidance and intellectual contribution of our International Steering Committee. We would like to acknowledge Dr. Don Gilmour, Professor Peter Frost, Irene Guijt, Renato de Rueda (who is also the Chairman of our Philippine Steering Committee), K.B. Shrestha, and Dr. Yunita Winarto.

The ACM research activities in the Philippines were facilitated by the DENR. We are grateful for the support provided by Director Romeo T. Acosta and staff, in particular Remedios Evangelista and Domingo Bacalla, who have broadened our understanding of the situations and challenges of the community forestry in the country.

Throughout the implementation of our research project, we have enjoyed the valuable insights provided by our Philippine Steering Committee. Not only have they diligently reviewed the progress and provided inputs on how we can design our research so it would be most useful and applicable in the Philippine contexts, but they also have actively engaged in the discussions at the site level to directly address the problems faced by the communities and local stakeholders. We are indeed indebted to the Chairman and the Steering Committee members: Romeo T. Acosta, Dr. Celso P. Diaz, Ben S. Malayang, III., PhD., Alma A. dela Paz, Luz Lopez Rodriguez, Eduardo A. Sabio, PhD. and Dr. Marcelino V. Dalmacio.

In Palawan, we appreciate the efforts of the People's Organisation of San Rafael, Tanabag, Concepcion Multi-Purpose Cooperative, Inc. (STCMPC) and the communities to try out and apply ACM approach in managing their CBFM area. We recognize the active participation of the STCMPC Board of Directors, i.e. Eddie Canete, Jimmy Canete, Beatriz Dacles, Merlyn Lumbre, Jesus Maquillao, Rex Restar, Melquiades Rodriguez, Arturo Santos, and Euben Vargas.

Our sincere thanks go to Dennis Navarro, Veronica Flores, and Norma Cayatoc, community-level DENR officers; Emelita Cojamco, Felizardo Cayatoc, and Merlyn 
Blaza, provincial-level DENR officers; Josephine Matulac and Tex Racuya of the Palawan Council for Sustainable Development; Rogelio Daquer and Noel Ramos of City ENRO, Benny Postrado and Rowell Rodriguez of Budyong Rural Development Foundation, Inc., for their active participation and commitment. Lastly, we would like to sincerely acknowledge Eduarda Devanadera and Nelson Devanadera (Provincial Planning and Development Office) for their kind support and friendship.

In Lantapan, Bukidnon, we extend our great appreciation to the People's Organisation of Basac Upland Farmers' Association, Inc. (BUFAI), BUFAI Women's Association, Council of Elders, barangay captain Melanio Sulatan and his council, barangay health workers, and the communities of barangay Basac in general. We would like to thank Carlito Tiplohod (who welcomed us in his family during our research in Basac), Marlito Wacdas, Venus Gawingan, Tarciano Gawahan, Merlita Naguio, Letecia Gawahan, Nancy Gawingan, Christina Rita, Elizabeth Tamayo, Sergenia Gawingan and Purita Duki.

We also of fer our sincere thanks to the various organisations and institutions for their commitment, participation, and assistance in the ACM project. We owe a debt of gratitude to DENR-Integrated Protected Area System, particularly to Felix Mirasol (Protected Area Superintendent) and his staff, Edgar Agbayani, who have made it possible for us to jump-start our work in Bukidnon.

We likewise recognise the kind support of Mayor Narciso Rubio of Lantapan, DENR provincial staff Gina Narciso and Belino Epie, Alejandro Omaña of the Department of Agriculture, Dr. Dennis Garrity, Delia Catacutan, Glo Acaylar, Alex Tabbada of ICRAF, Heifer International, Dr. Alsula of the Municipal Health Office, Dr. Pinky Baclig, M.D. and the volunteer mothers of the Katingbanay Foundation. We wish to thank our colleagues at RIMCU, in particular Dr. Chona Echavez, and wish to appreciate the excellent administrative support provided by Marilou Tabor and Jessica Caharian.

There are many Philippine scientists and researchers who took part in our research at certain points and who have remained steadfast supporters of ACM. We would like to acknowledge the contribution of Azucena Estanol, Nelson Sapin, Dr. Antonio Contreras, Dr. Teodoro Villanueva, Dr. Guillermo Mendoza, Anita Frio, Emmanuel Esguerra, Elsa Santos, Pastor Malabrigo, and Dr. Donato del Castillo.

This book has benefited from substantive inputs provided by Dr. Celso P. Diaz, Dr. Doris Capistrano, Alma dela Paz, Dr. Alun M. Anderson, Glen Mulcahy, and Emerson Jacinto. Scientific names of the species mentioned in this book have been provided and checked by Dr. Aida Lapis (ERDB). Our deepest gratitude goes to Antonio Frio, our editorial consultant, for his excellent job in refining the materials and making sure that every section is simple and easy to understand, yet interesting 
and attractive, for the targeted readers. His commitment and dedication to this book are impeccable.

Within CIFOR, we would like to acknowledge Carol J.P.J. Colfer, who laid the foundation for ACM, continuously supported us, and critically reviewed this book; Cynthia McDougall, Linda Yuliani, and other ACM team members in Indonesia, Nepal, and other parts of the world who have enriched our perspectives, experience, and lives over the past three years. Last but not the least, our thanks to Edwin Yulianto, Gideon Suharyanto, Eko Prianto, and Rahayu Koesnadi for their assistance in the final layout and printing of this book.

Bogor, April 2003 


\section{ACRONYMS AND ABBREVIATIONS}

$\mathrm{ACM}$

AWP

BUFAI

BoD

BWA

CEI

CADC

CBFM

CIFOR

City ENRO

CRMF

DECS

DENR

ECC

ERDB

GPS

ICRAF

LGU

MOA

NGO

PAMB

PAR

$\mathrm{PhP}$

PO

STCMPC
Adaptive Collaborative Management

Annual Work Plan

Basac Upland Farmers Association Inc.

Board of Directors

BUFAI Women's Association

Criteria and Indicators

Certificate of Ancestral Domain Claim

Community-Based Forest Management

Center for International Forestry Research

City Environment and Natural Resources Office

Community Resource Management Framework

Department of Education, Culture, and Sports

Department of Environment and Natural Resources

Environmental Clearance Certificate

Ecosystems Research and Development Bureau

Global Positioning System

World Agroforestry Centre

Local Government Unit

Memorandum of Agreement

Non-Government Organisation

Protected Area Management Board

Participatory Action Research

Philippine Peso

People's Organisation

San Rafael, Tanabag and Concepcion Multi-Purpose

Cooperative, Inc. 


\section{INTRODUCTION}

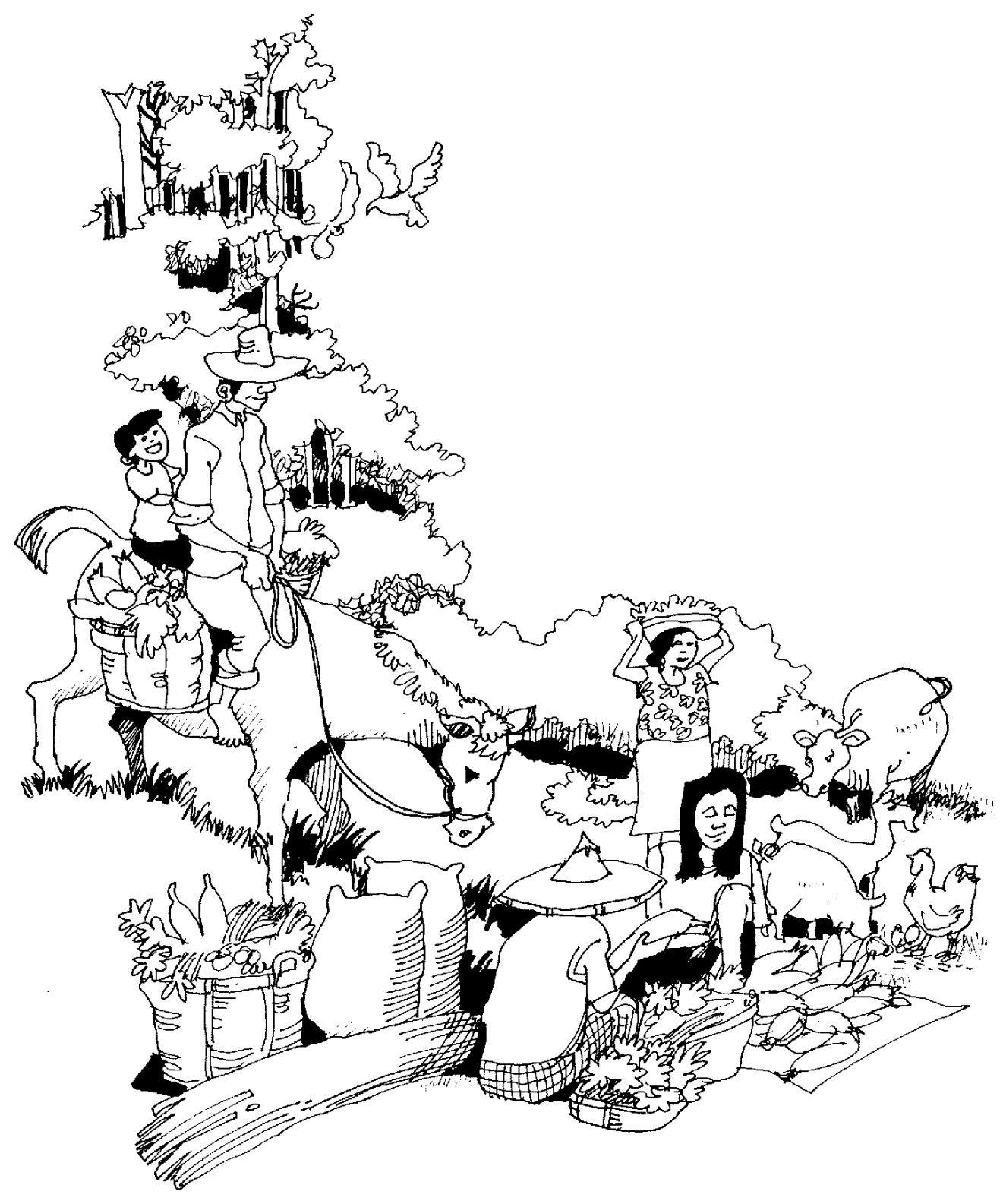




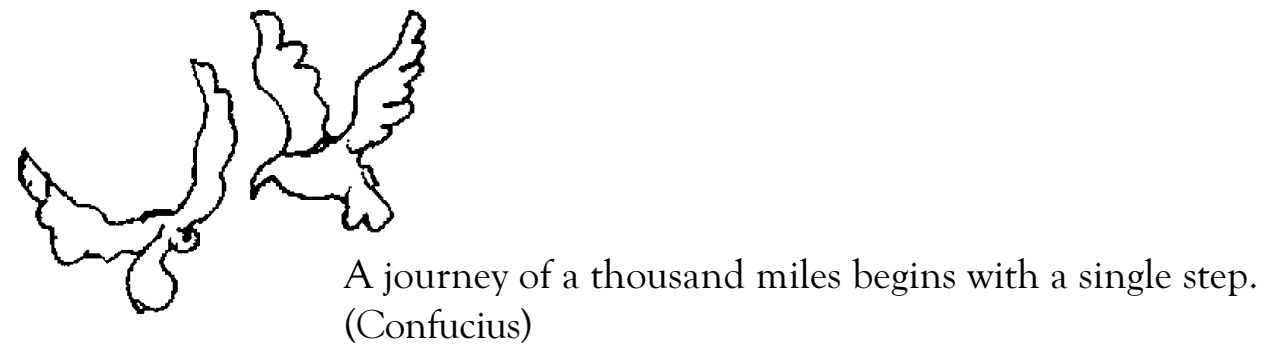




\section{Objective of this book}

A Philippine field worker seeking to improve the country's uplands and the livelihoods of forest communities is bound to ask:

- How can the communities best manage the forests in the complex and everchanging situations so that they can get the benefits they urgently need?

- How do we enhance the country's community-based forest management programmes to improve the lives of these communities?

This book attempts to help our fellow field workers answer these questions. We shall do this by sharing with them our research findings and experience. The results of our research in the Philippines have shown that an approach called adaptive collaborative management (ACM) is an effective approach that can help communities to better manage the forests.

From 1999 to 2002, our researchers from the Indonesia-based Center for International Forestry Research (CIFOR) joined the Philippines' efforts in enhancing the implementation of its community-based forest management (CBFM) programme.

We conducted a research project on ACM in Bukidnon province in Mindanao and Palawan province in Luzon. The research was funded by the Asian Development Bank and was also implemented in Indonesia and Nepal. Similar research projects funded by different donor agencies are currently underway in Zimbabwe, Cameroon, Ghana, Malawi, Bolivia, Brazil, and Krygyzstan.

\section{Who this book is for}

This book is intended for field-based non-governmental organisation (NGO) workers, extension workers, field officers of the Department of Environment and Natural Resources (DENR), local government units (LGUs), trainers, and others.

They are the ones who deal with community-based forest management programmes in their daily work and who are in need of new approaches, new references, and new ways of thinking about community forestry.

We hope that the reader will be able to get a clear picture of the ACM approach, its key elements, its added values to the existing community forestry programmes, and how ACM can be implemented in the areas they work in. 


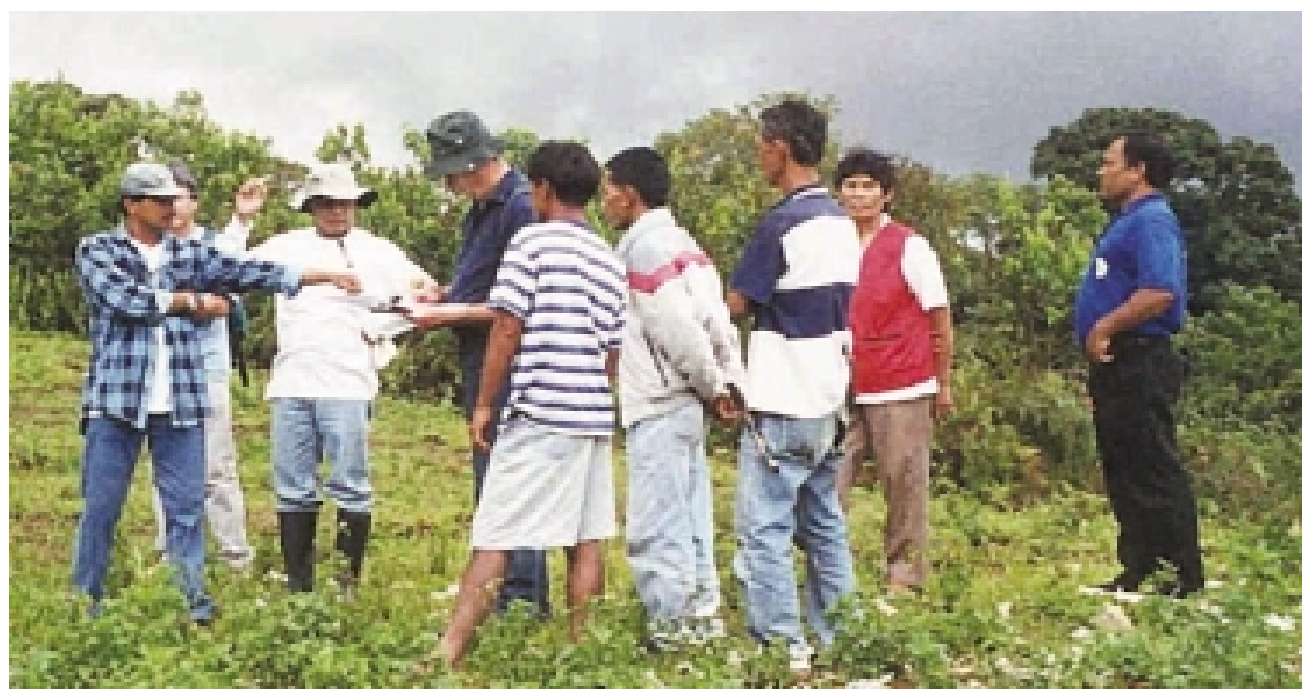

This book is about our research that shows ACM as an effective approach to enhance CBFM implementation. This approach can be applied by our fellow extensionists in promoting the goals of CBFM.

\section{Background of our research}

Community forestry in the Philippines has gone through a long process of change over the past 30 years.

Community forestry initiatives in the Philippines are considered to be among the best in the Asian region. ${ }^{1}$ But the communities, the concerned government departments and other stakeholders still face problems. They find it difficult to effectively implement community forestry programmes to fully meet their goals of improved forest conditions and improved lives of the communities who depend on the forest.

In 1995, the government institution responsible for the programme, the DENR, reviewed its past efforts. DENR critically analysed the factors that have hindered effective implementation and looked for new strategies and approaches. The process brought about the creation of the CBFM programme. CBFM calls for a new analytical framework and a paradigm shift to formulate programmes that are more responsive to the current and future conditions in the country.

In this context, we conducted our research on ACM. We aimed at finding suitable approaches, tools, and methods that could enhance community forest management. We argued that to be sustainable, community forest management must be collaborative and adaptive. We spell out what we mean by collaborative and adaptive below and in much more detail later in Chapter 3. 
In the Philippines, we translated ACM into an approach that would enhance collaboration between the People's Organisations (POs) and local stakeholders in planning and managing community forests.

At the same time, ACM would enhance their capabilities to learn, as a group, about the consequences of their management and adapt their strategies based on their learning, so that they can continuously improve their management efforts. Through collaboration and adaptation, we expected that ACM would strengthen CBFM initiatives in the Philippines.

Our research therefore, aimed at answering three questions:

1. Under what conditions can collaboration among stakeholders in forest management, enhanced by processes of conscious and deliberate social learning, lead to both improved human well-being and to the maintenance of forest cover?

2. What approaches, centred on social learning and collaborative action among diverse stakeholders, can be used to encourage sustainable use and management of forest resources?

3. In what ways do the processes and outcomes of ACM affect social, economic, political and ecological functioning and how do these effects reinforce or weaken forest management?

Preliminary results from our work are very promising. They showed us that indeed, ACM can help achieve stakeholders' goals in forest management. While the results

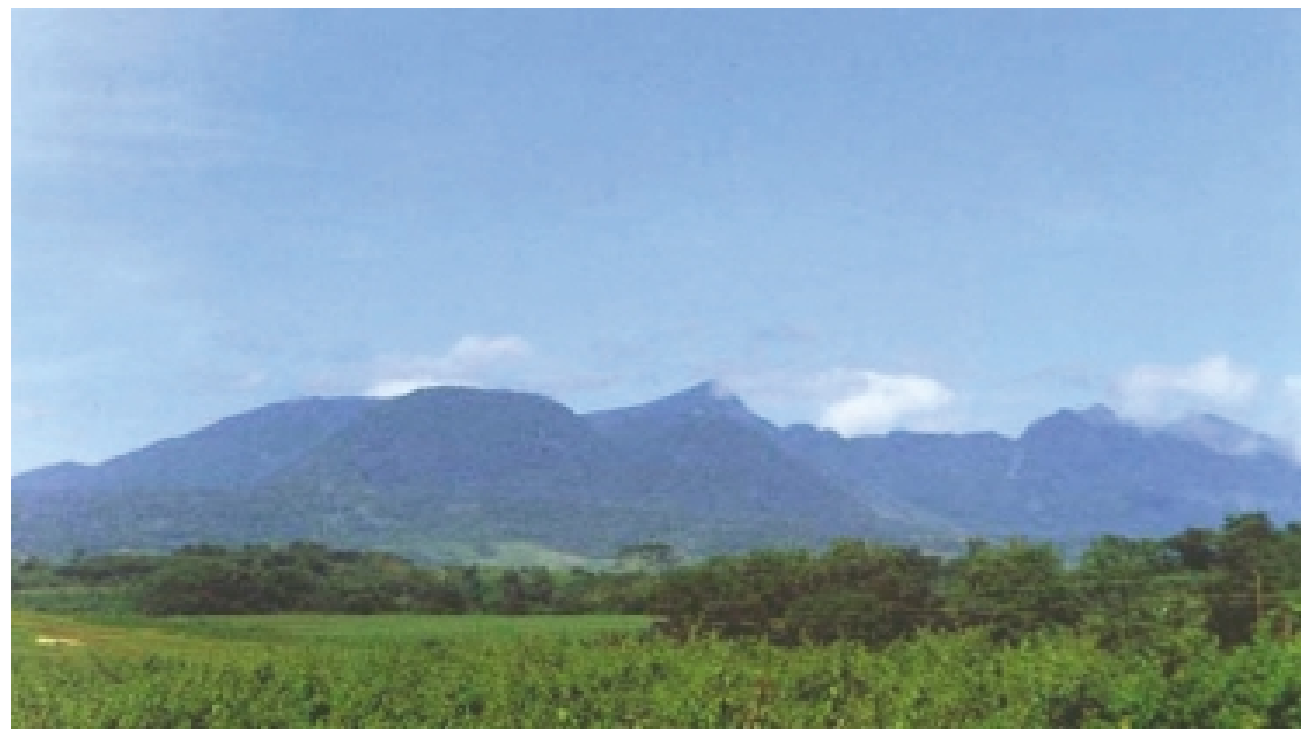

Mt. Kitanglad Range Natural Park in Bukidnon province, Philippines, is an area covered by the country's community-based forest management programme. 
came from only two CBFM sites over a three-year period, we obtained similar results in different countries in Asia. We also recognise the need to monitor whether or not these results are sustainable in the future. In any event, we encourage the field workers to apply and test our findings.

\section{Structure of this book}

In this chapter (Chapter 1), we introduce the ACM project, its objectives and provide some background information.

Chapter 2 describes a brief history of forest management in the country that led to the establishment of the CBFM programme. This chapter also provides a mosaic of power relationships among the communities represented by the PO, DENR, and LGUs in relation to community-based forest management. The challenges and problems that persist are also presented.

Chapter 3 illustrates the emerging concepts in natural resource management and the origins of ACM. It also explains the ACM approach and its key elements.

Chapter 4 describes the two CBFM areas where we applied the ACM approach, the communities and local stakeholders, their ways of living, the biophysical conditions of their environment, and how they have been managing the forests.

Chapter 5 illustrates how we and the stakeholders in the local communities used the ACM approach and processes to address local issues, the outcomes of the approach, and the challenges that remain.

In Chapter 6, we summarise the constraints and challenges of ACM, and the enabling conditions needed for ACM to be effective.

Chapter 7 highlights the implications of ACM in the overall implementation of CBFM in the Philippines.

In Chapter 8, we present our conclusions.

We put together a simple guide in Annex 1 so the readers will have a clear picture on how they can apply and incorporate the ACM approach in their work. Annex 2 highlights the important roles that field workers need to play in facilitating ACM processes, describes what facilitation means, and pinpoints various skills that facilitators should have.

Lastly, the endnotes and reference section provides further explanation on certain cited information and the reference materials we used in this book. 


\section{2}

\section{COMMUNITY FORESTRY IN THE PHILIPPINES}

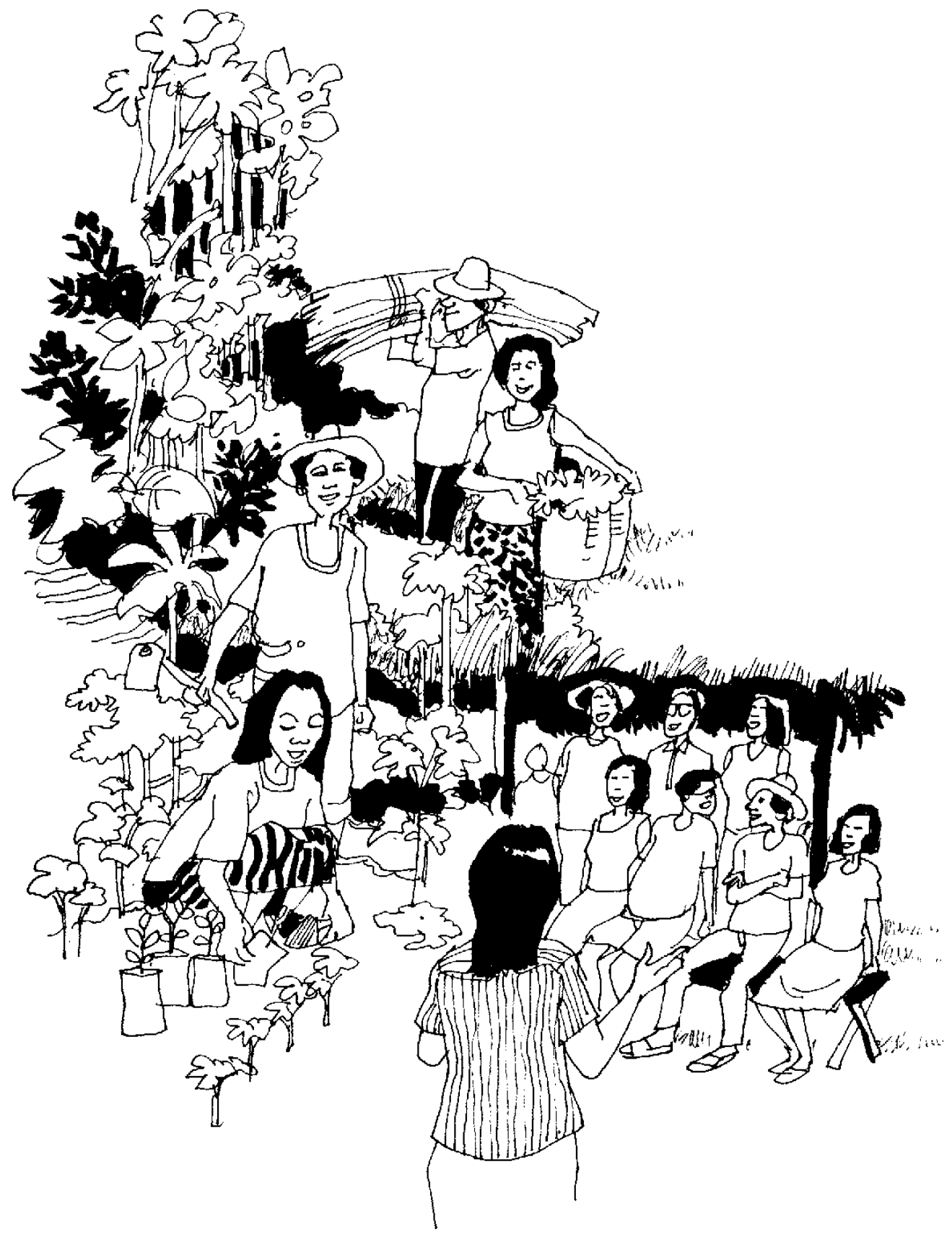




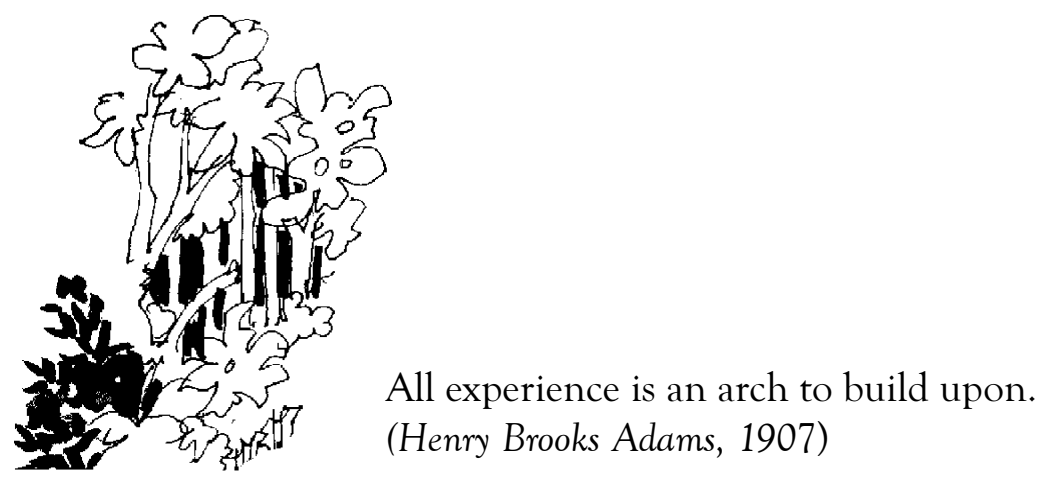


In this chapter, we describe a brief history of forest management in the Philippines that led to the development of its CBFM programme. We also portray a mosaic of power relationships among the communities, the DENR and other institutions. Then we show the challenges and problems that persist.

Community forestry is a concept that portrays people and forests and their relationship with one another. It is defined as organised groups of people who use and manage forests communally. ${ }^{2}$

In many parts of the world, community forestry programmes were developed by the state to give communities legitimate access to forest resources for their livelihood. These programmes also recognised the fact that forests could not be properly managed without active support from the local communities. ${ }^{3}$

In the Philippines, the recognition over the rights of the people evolved over time. During its colonial period, forests and forest management were put under the state's authority. Under the Spanish Regalian Doctrine, forestlands became part of the public domain. The centralised control continued under the American colonial period. This strengthened state control over the forests, but eroded the rights of the indigenous forest occupants and their long-term interest to manage forests in a sustainable manner. ${ }^{4}$

Human activities and development have been changing the country's landscape over the centuries. The clearing of vast forest areas started as early as the 18th century. Marshall McLennan described the years between 1800 and 1920 as 'the great era of forest clearance in the central plains of Luzon.' Demand for forestland and products, particularly timber and firewood for the sugar cane industries, increased rapidly throughout the 19th century. By the 1970s, agricultural productivity and self-sufficiency in rice also increased tremendously. At the same time, signs of forest degradation, such as soil erosion and downstream siltation of rivers, coasts, and dams, became more notable. ${ }^{5}$

The cause of upland degradation was largely blamed on kaingin (slash-and-burn shifting cultivation), although population growth and commercial timber harvesting contributed more significantly to this degradation. History shows that the state alone, represented by the then Philippine Bureau of Forestry, could not control and reduce the rate of forest degradation. In the 1970s, with increased discontent and a growing insurgency, greater recognition was given to the legitimacy of forest occupants and their potential roles in managing forests. ${ }^{6}$

Since then, community forestry in the Philippines began as a government 
programme. It took form in the following: Forest Occupancy Management, Communal Tree Farming, and Family Approach to Reforestation.

These early efforts, however, did not provide great authority or land tenure security to upland communities. The programmes aimed to rehabilitate open and cultivated areas, control local land use practices of the upland farmers within the forest zone, and contain occupancy, rather than to enhance local control over forest resources. Naturally, these failed to get the participation and support of the upland communities.

In 1982, the Integrated Social Forestry Programme was created through Letter of Instruction No. 1260 issued by the Office of the President which consolidated the three programmes. ${ }^{7}$ It gave greater emphasis on tenure security by providing forest occupants with a Certificate of Stewardship Contract. The contract lasts for 25 years and can be renewed for another 25 years. The contract holders were required, among others, to apply soil conservation measures, control forest fires, and maintain the forest growth in the tenured areas. ${ }^{8}$

The need to speed up the transfer of residual forest management to the community led to the proliferation of various programmes and tenure options in the following two decades (see Figure 1).

\section{The CBFM programme}

The confusion created by the emergence of various tenure options and the need for a more effective community forest management led the policy-makers to simplify the systems and develop a comprehensive programme called Community-Based Forest

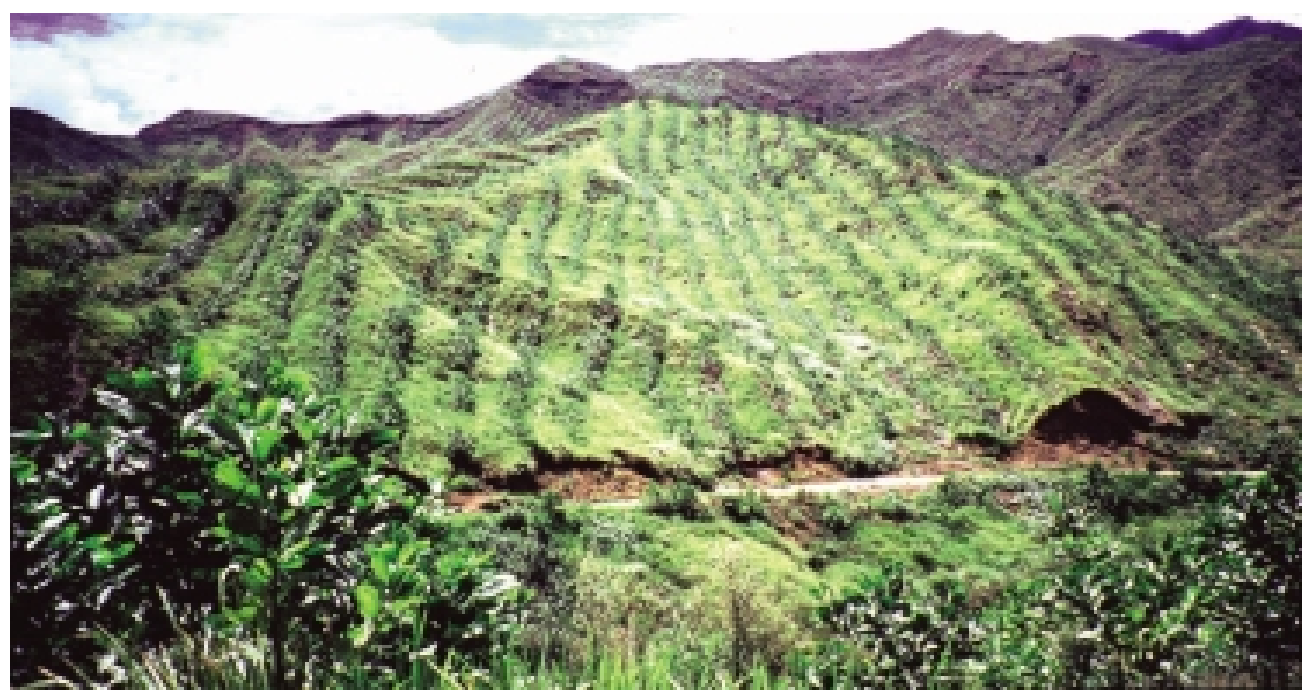

Community forestry started as a government-sponsored programme in the Philippines in the early seventies. It has evolved into the present community-based forest management programme. 
Figure 1. Evolution of the Philippine community forestry programme ${ }^{9}$

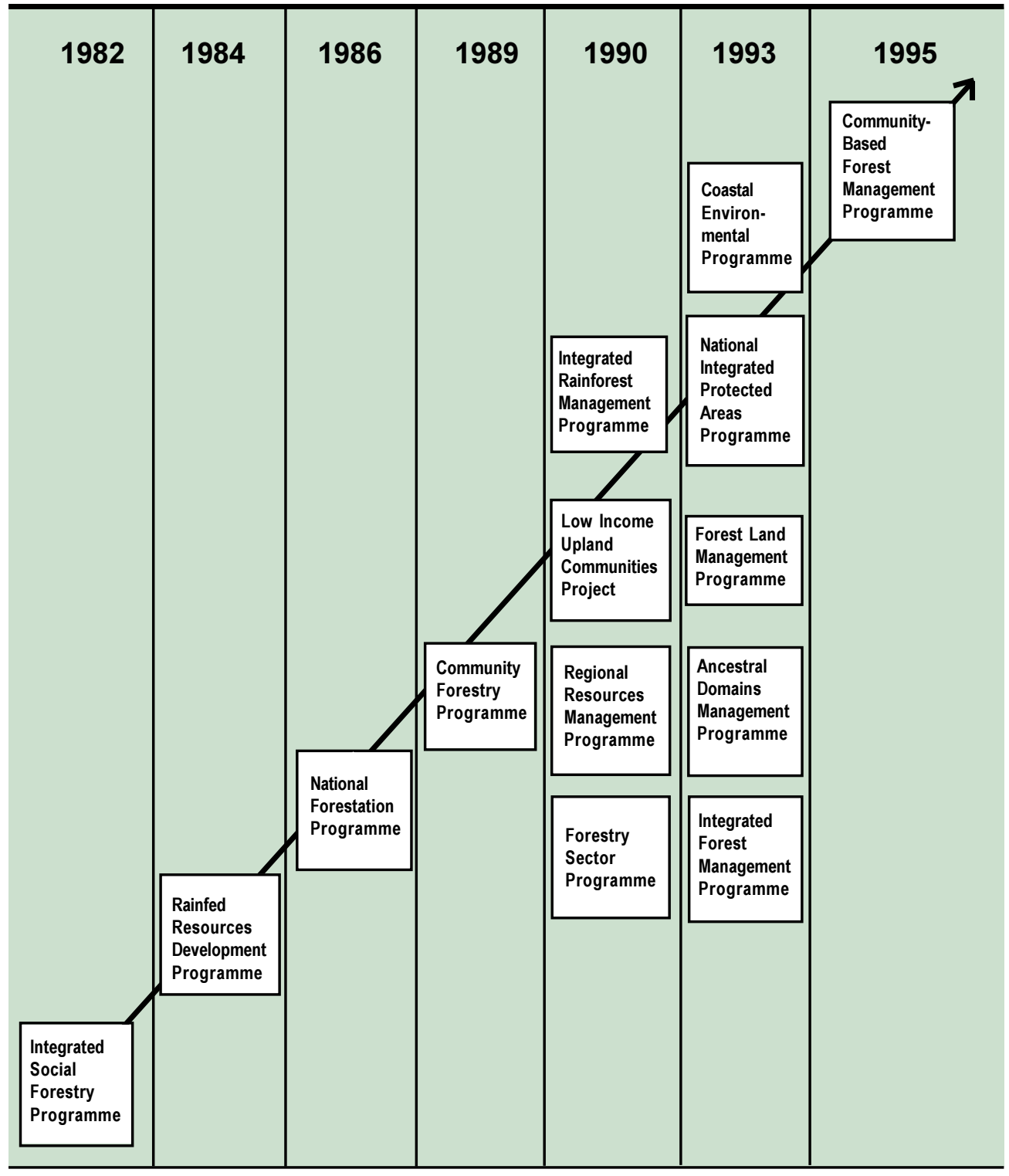

Management (CBFM). In 1995, Presidential Executive Order No. 263 proclaimed CBFM as the national strategy to ensure the sustainable development of the country's forestlands. ${ }^{10}$

CBFM integrates and unifies all people-oriented forestry programmes in the country. The aims of the programme are to promote social justice, improve the wellbeing of the local communities, and ensure sustainable forest management. CBFM is now in place in 4,956 sites in the country. It covers an aggregate area of 5.7 million hectares of previously open access forestlands. ${ }^{11}$ 


\section{Who are involved in CBFM?}

Local communities can participate in the CBFM programme and obtain the legal rights from the state to manage a piece of forestland, if they till a portion of the area within that forestland, traditionally depend on resources for livelihood, and reside within or adjacent to the area being proposed. They also have to organise themselves into People's Organisations. These are legally recognised organisations that are registered with the Securities and Exchange Commission or Cooperative Development Authority. In exchange for the rights to use the forest and its resources, the POs are responsible for managing, protecting, rehabilitating, conserving, preparing management plans, developing their organisations, and so on. ${ }^{12}$

The DENR oversees the implementation of CBFM in the country. It is only one of the many government agencies in the country, but the legal mandate provided by Executive Order No. $192^{13}$ gives the agency the authority to supervise and control the protection, management, utilisation, and development of the country's environment and natural resources, including the forestlands.

DENR is also expected to formulate, plan, coordinate, implement and monitor policies through its local field units. Operations at the site level are carried out by the regional environment and natural resources office, the provincial environment and natural resources office, and community environment and natural resources office.

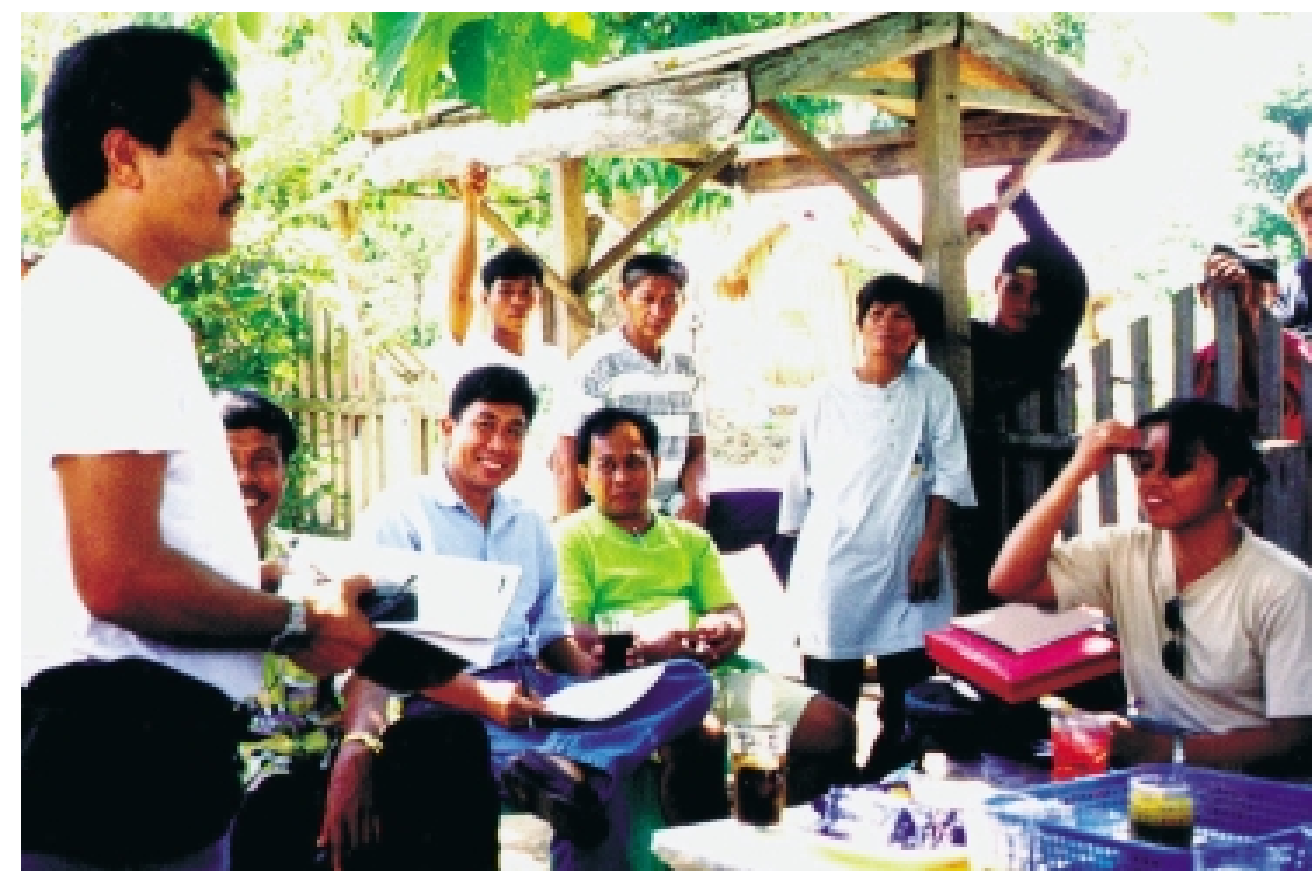

The DENR oversees implementation of CBFM in the country. Local governments are also given the authority to implement local CBFM programmes. 
Aside from the DENR, municipal and provincial governments play a role in local CBFM projects. The 1991 Local Government Code (Republic Act No. 7160) authorises Local Government Units to implement social forestry and reforestation programmes, manage communal forests under 5000 hectares, protect watersheds, and enforce forest laws. A special unit, called Environment and Natural Resource Office (ENRO), was established within provincial, municipal, and city government to handle the devolved functions. ${ }^{14}$ This law also gives LGUs the responsibilities and accountability for basic public services, such as in health, infrastructure, public works, agricultural extension, tourism, and investment programmes.

The Code is considered a significant turning point in the decentralisation and devolution of government powers. ${ }^{15}$ It is also probably one of the most innovative and impressive in the region. ${ }^{16}$

\section{Devolution is not working....}

Closer examination of devolved functions, however, indicates that CBFM implementation was often conditional, with DENR still in full control. The roles and responsibilities of LGUs vis-à-vis DENR remained ambiguous and were not clearly spelled out. ${ }^{17}$

The ambiguities in policies allowed the DENR to retain control over the larger areas of forestlands. LGUs were given the authority to manage and control only the small communal forests. ${ }^{18}$ Furthermore, only social forestry projects funded by national sources were devolved to LGUs while DENR still retained projects funded by foreign donor agencies. ${ }^{19}$

On the other hand, LGUs could not fully perform the devolved functions due to the following: ${ }^{20}$

- lack of skills and capacities;

- lack of personnel and financial resources; and

- LGUs having different priorities.

In effect, the transition from state control to community-based forestry has not been operationalised at the ground level. In fact, the national forestry department still maintains its strong control through various ways, such as by adjusting its relations with other key stakeholders, revising its rhetoric, or requiring excessive technical requirements from local governments. ${ }^{21}$

In summary, lower-level government and non-government organisations and community associations have not been able to participate fully in the programme due to lack of resources, capabilities, and inadequate power. ${ }^{22}$ 


\section{Partnerships hardly exist...}

With the above problems, it is no surprise that partnerships among the DENR, LGUs, and the POs in the implementation of CBFM are rarely found. Furthermore, insufficient communication and information flow, and lack of institutional mechanisms have made it difficult for them to engage in partnerships. ${ }^{23}$ These have led to overlapping of functions and responsibilities and ineffective use of human resources.

To implement community forestry effectively, there is a need for forest agencies to shift from being centres of authority to centres of partnerships. ${ }^{24}$

\section{... and challenges continue}

CBFM implementation has also been facing other challenges. Among these are:

- There is a lack of sufficient incentives for the communities to take part actively. ${ }^{25}$ Incentives or benefits are in fact important conditions without which the communities cannot be encouraged to participate. ${ }^{26}$ Generally, there is an urgent need to provide a better system to ensure long-term tenure security and to develop income-generating activities for the communities, such as agriculture, handicraft making, furniture making, and timber utilisation. ${ }^{27}$

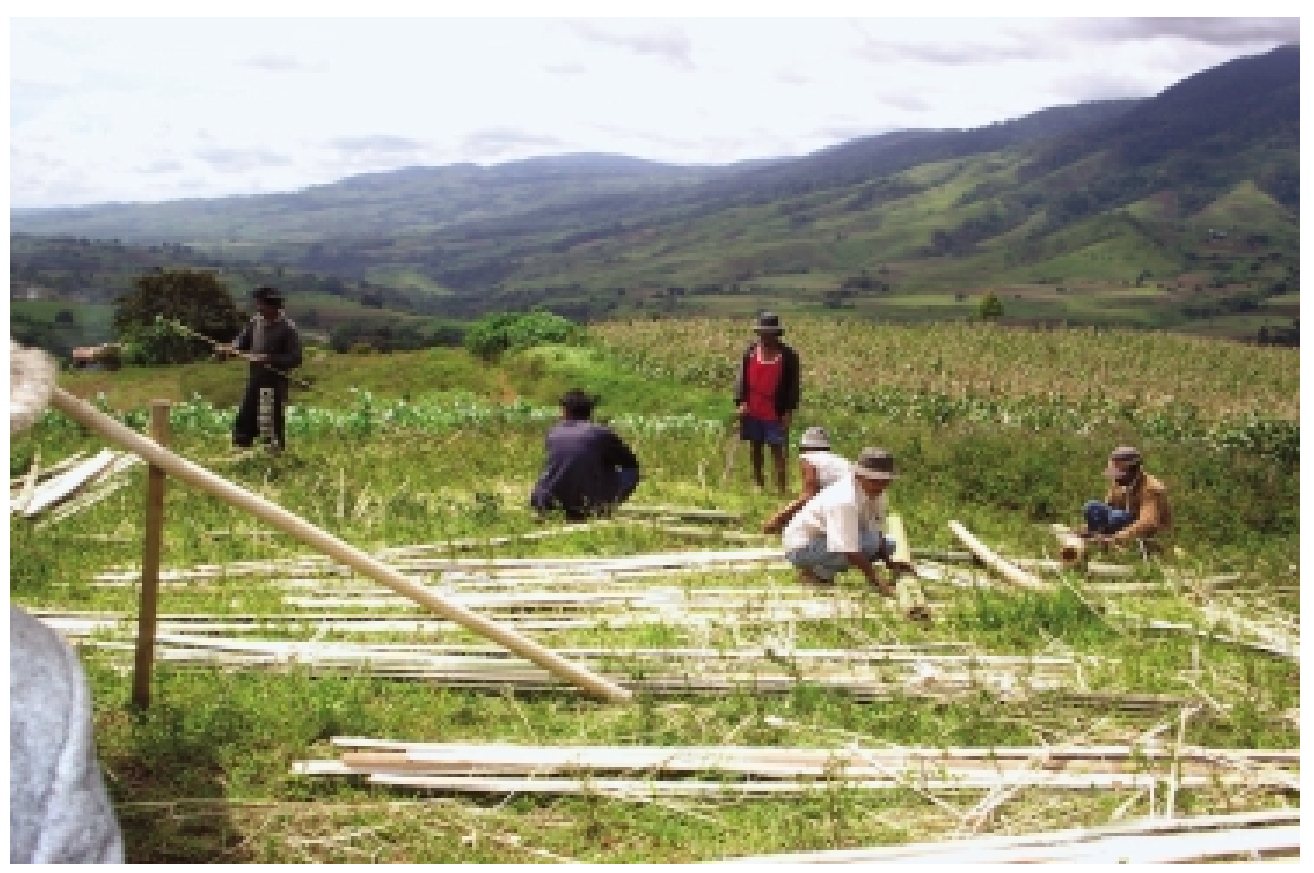

Income-generating activities such as furniture and handicraft making from abundant bamboo trees in the CBFM areas need to be provided. This is one of the many challenges that face CBFM implementation. 
- There are uncertainties, ambivalence, and contradictions among various laws and policies related to community forestry. Policy development processes often do not consider the realities, as pointed out by community members who say: 'Policies are complicated, there is no consultation with the communities in their development' and 'Policies that are being brought in are not applicable to communities, as policy makers have no idea of the realities at the community level. ${ }^{, 28}$

- Many POs are not fully capable of meeting the DENR requirements. Availability of funds from foreign agencies to assist the DENR in implementing community forestry nation-wide has led to the proliferation of many NGOs who do not have the skills nor the genuine interests to prepare the POs with the proper skills, attitudes and awareness necessary to implement CBFM. ${ }^{29}$

- DENR does not have enough financial resources and personnel to support the POs in their management endeavours. A DENR site coordinator is often assigned to handle 3-5 CBFM sites and consequently lacks focus. ${ }^{30}$

- There is a lack of regular monitoring to assess the impact of management practices and no immediate feedback system exists. Despite the existence of DENR's Environmental Performance Monitoring system, monitoring by POs and/or local stakeholders has hardly taken place. ${ }^{31}$

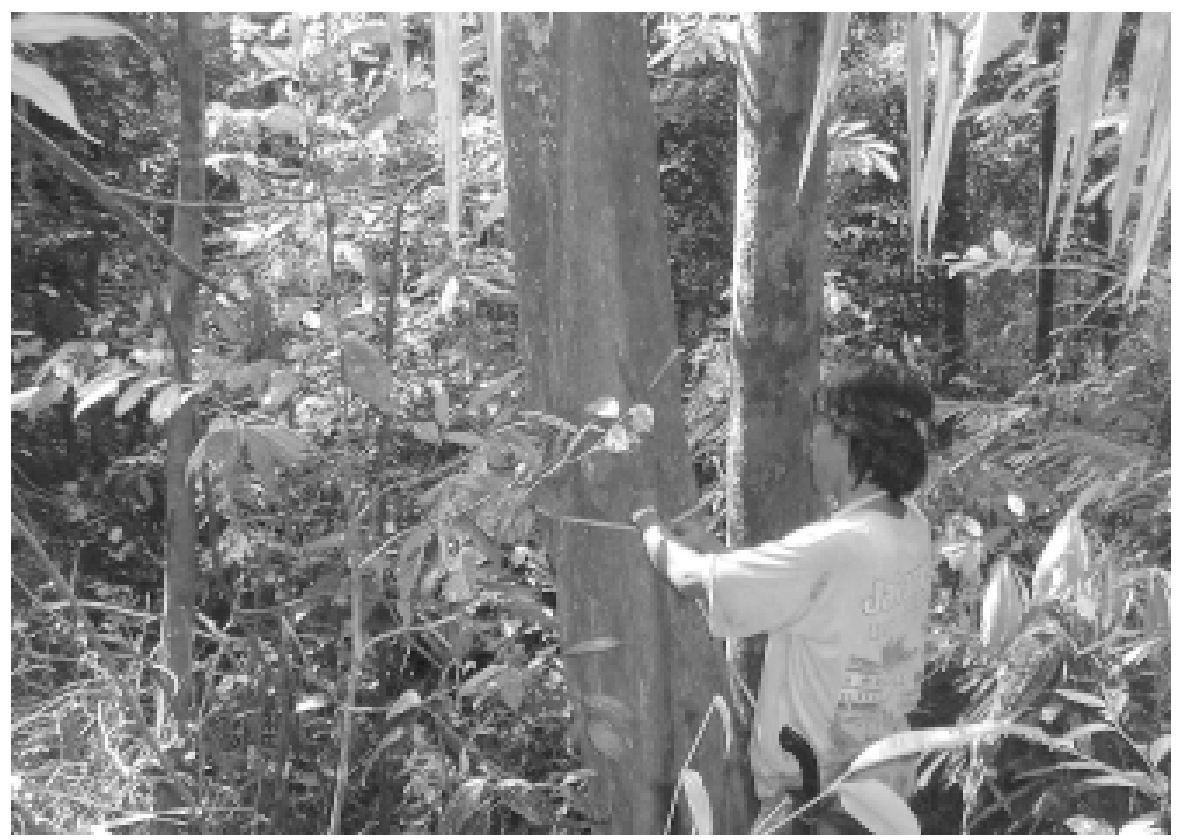

An important challenge facing CBFM implementors is the apparent lack of a monitoring and feedback system to assess impact of implementation that is significantly useful and relevant to the POs. 



\section{3}

\section{WHAT IS ACM?}

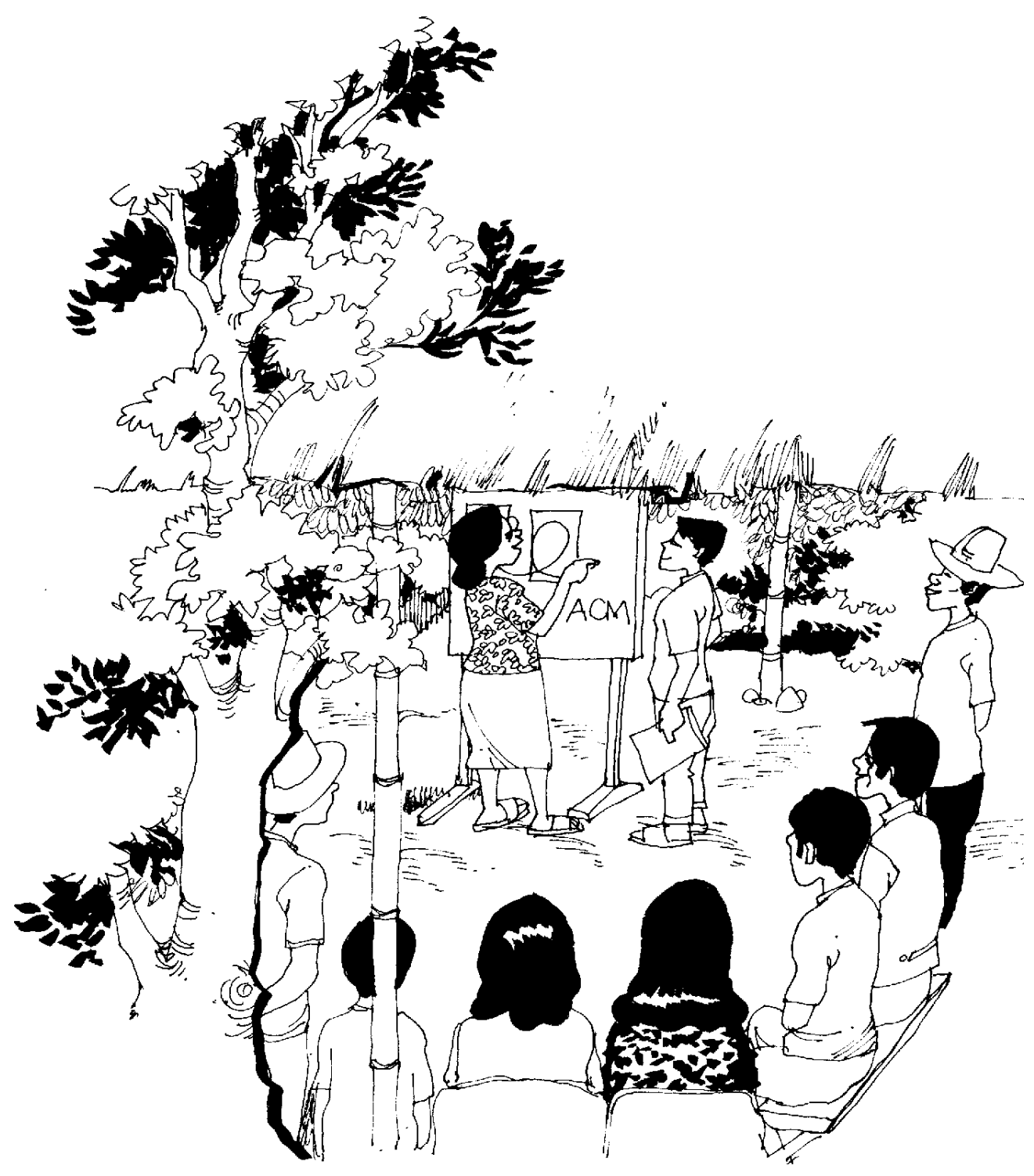




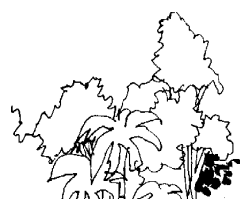

Governing large ecosystems is a matter of learning without teachers and experimenting without a laboratory.

(Kai Lee, 1993) 
Against the backdrop previously discussed, we feel that the adaptive collaborative management ( $A C M$ ) approach can improve and enhance CBFM implementation in the country. In this chapter, we describe the ACM approach, the rationale for developing this approach, and its key elements. We will also explain why we think ACM would strengthen CBFM implementation.

\section{ACM origins}

We cannot describe the adaptive collaborative management approach, its key processes and elements without describing other concepts that significantly influenced the development of the ACM concept.

One of the concepts is collaborative management. Collaborative forest management approaches are characterised by a combination of three elements:

- recognition of the legitimacy of values favouring development and conservation;

- the view that development and conservation goals are not necessarily antagonistic; and

- commitment to engage local people in management.

Different initiatives that have these three elements took the names of social forestry, community forestry, joint forest management, participatory natural resource management, integrated conservation development projects, etc. ${ }^{32}$

While the concept of collaborative management emerged in tropical countries, the term adaptive management was proposed in 1978 by an interdisciplinary group of scientists led by Canadian ecologist Clarence Holling. ${ }^{33}$ This concept was formulated for the management of large and complex ecosystems such as the Florida Everglades, the Columbia River, and the Baltic Sea.

The concept recognises that management of these complex ecosystems will have to take into account human dimensions and their interactions with natural systems. Furthermore, despite the lack of complete knowledge and information, decisions should be made on how to best manage the systems. The best approach, consequently, would be to prepare ourselves to live and deal with surprises and uncertainties by treating each management strategy as an experiment and an opportunity to learn. ${ }^{34}$ Monitoring and learning are, therefore, key elements of adaptive management. ${ }^{35}$ 
ACM integrates the elements of collaborative management and adaptive management. ACM places collaboration, coupled with learning and adaptation, at the centre of its approach. It not only tries to enhance collaboration or learning/ adaptation on their own, but emphasises the combination of the two.

\section{ACM IN THEORY}

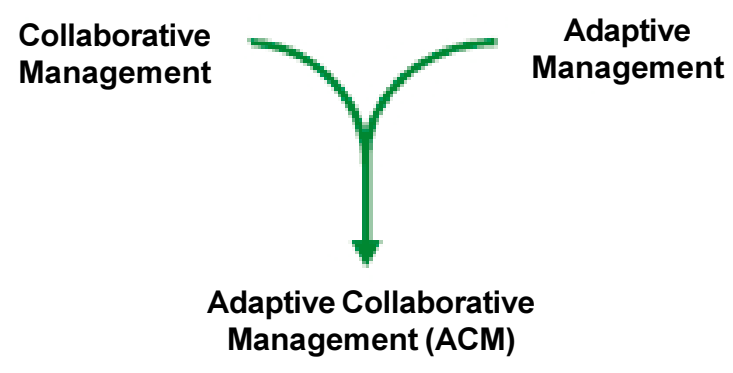

We at CIFOR define adaptive collaborative management as a process in which groups of people who use, control or have interests in a forest agree, on the basis of shared information, to act together when they draw up plans for the forests. They then implement their plans, aware that they may not fulfil their stated objectives. It is, therefore, important to observe and learn from the implementation in order to improve the plans or seek alternatives. ${ }^{36}$

\section{OXFORD ENGLISH DICTIONARY (1989) ONLINE:}

ADAPTIVE: from 'adaptation', the process of modification to suit new conditions; in biology, the process of organic modification by which an organism or species becomes adapted to its environment.

COLLABORATIVE: from 'collaboration', united labour, co-operation.

MANAGEMENT: the application of skill or care in the manipulation, use, treatment, or control (of things or persons), or in the conduct (of an enterprise, operation, etc.).

\section{ACM GROUP, 2001:37}

ADAPTIVENESS: the capacity of something or someone to actively respond positively to external or internal factors. 
ACM processes are characterised by stakeholders who are:

- consciously communicating;

- collaborating; and

- seeking out opportunities to learn as a group in order to continuously improve the benefits they are receiving from the forest. ${ }^{38}$

ACM is also defined as 'a long-term management structure that permits stakeholders to share management responsibility within a specific system of natural resources, and to learn from their actions. Participants are conscious of the fact that they are operating within a complex system and that they can learn, adapt, and modify the rules of their participation. ${ }^{39}$

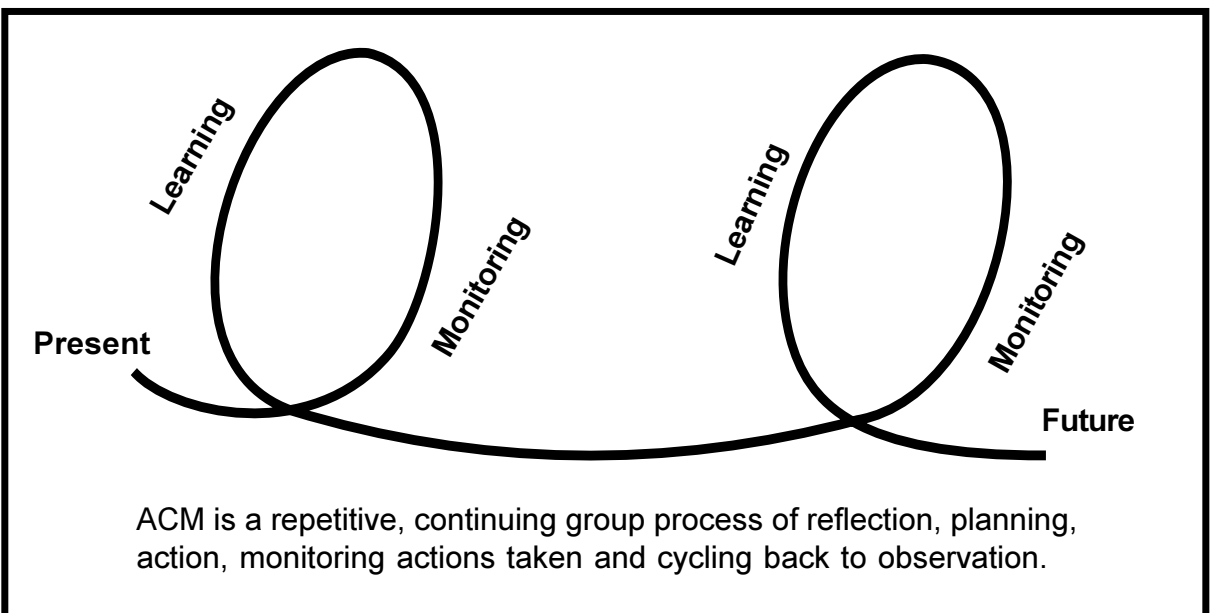

\section{Main elements of ACM}

In summary, adaptive collaborative management is characterised by 10 main elements:

1. Communication within the members of the same group or between different groups to share information.

2. Collective planning and decision making.

3. Effective decision making for complex and uncertain situations.

4. Collective action to carry out collectively agreed plans.

5. Intentional learning and experimentation.

6. Collaborative monitoring.

7. Social learning.

8. Incorporation of lessons learnt to refine management practices.

9. Presence of mechanisms to deal with conflicts.

10. Linkages and feedbacks between local communities and policy makers. 


\section{Social learning in ACM}

We mentioned earlier that learning is an important element of ACM. We highly emphasise social learning, the kind of learning that takes place within a group of people, rather than learning undergone by each individual separately.

One of the challenges in engaging different people in learning together as a group is when the members are situated in different positions of power. For example, in a CBFM project meeting, the group may consist of PO members, DENR and local government representatives, etc. As the meeting progresses, the members of the $\mathrm{PO}$ may tend to keep quiet and representatives from government institutions may dominate the discussion. In a situation like this, social learning cannot take place effectively.

Processes for social learning, therefore, need to be facilitated. This should be done by someone who knows about relationships among the group members and strong sensibilities about their learning style and preferences. ${ }^{40}$ Good facilitation is very important as it allows knowledge sharing and subsequent action to take place. Further details about facilitation in ACM can be found in Annex 2.

To enable us to undertake research on ACM, we applied a research methodology called participatory action research (PAR). This methodology was proposed as early as 1946 by Kurt Lewin in the context of experimental community projects in the USA.

\section{SOCIAL LEARNING DEFINED:}

- an intersection between collaboration and learning. ${ }^{41}$

- a combination of learning and action that takes place within a group of people. The concept captures both knowledge generation and the application of this knowledge in action. ${ }^{42}$

- knowledge sharing among group members is an important dimension of social learning. Members recognise and accept that each member has different values, capacities, perspectives, experience, etc. that make his/her contributions valuable in enriching the group's knowledge. ${ }^{43}$ 
We believe PAR would be the most suitable methodology as many studies have proven that PAR allows local people to participate and to be in full control over all stages of the research. ${ }^{44}$ This methodology has been proven to be useful and effective in empowering local people and local stakeholders in addressing their own problems. ${ }^{45}$ Participatory action research has the following characteristics: ${ }^{46}$

1. It combines action and research;

2. It involves a group of people around a specific issue or concern; and

3. The group consciously and systematically moves through repeated cycles of reflection, planning, action, observation or monitoring, and back to reflection again.

\section{In community development work, PAR is defined as:}

'A process through which members of a group or community identify a problem, collect and analyse information, and act upon the problem in order to find solutions and promote social and political transformation.' 47
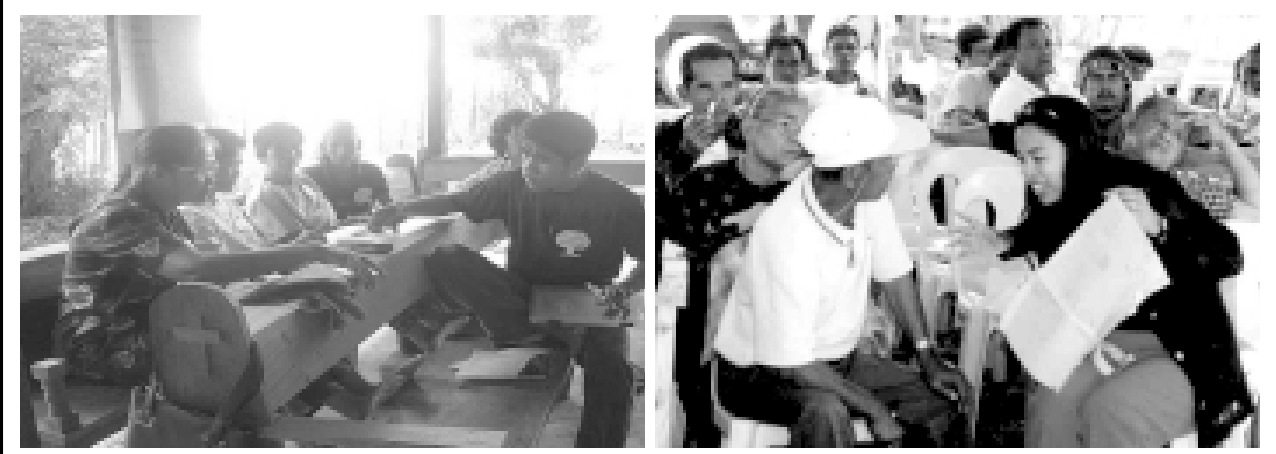

\section{What can ACM do for CBFM?}

In the previous section, we raised some of the challenges of CBFM implementation in the Philippines. Our experience shows that ACM can help POs, the DENR, and other concerned stakeholders in facing those challenges. ACM approaches and processes complement the implementation of the CBFM programme in six ways:

(1) ACM enhances and fosters genuine partnerships through proper stakeholder identification and deliberate conscious efforts of engagement among these different stakeholders based on trust, common interests and objectives. 
(2) ACM provides a platform to bring different stakeholders together to negotiate, resolve conflicts, and learn jointly from experience. The participatory action research methodology applied in ACM research puts local actors squarely in the focus of all innovation.

3 ACM facilitates and enhances social development of the communities. This subsequently enhances their capabilities in protecting and managing forest resources.

4 ACM helps communities in solving their own problems. If CBFM is empowerment from the outside, ACM is empowerment from the inside. Learning together as a group, discussing and analysing their problems, and experimenting, rather than waiting for outsiders to provide the solutions, improves the self-confidence of the local people.

5 ACM builds in mechanisms for checks and balances, feedback, and learning in CBFM implementation by all concerned stakeholders. ACM stresses collaborative monitoring of actions and outcomes as a means to enhance social learning. This closes the feedback loop effectively and consciously so that local actors can learn more effectively from their own actions. Furthermore, they can adjust their next actions accordingly.

6 ACM has a more holistic approach in addressing forest resource management and pays attention to other sectors and issues, such as livelihoods, education, health, etc. that may influence the success of CBFM implementation.

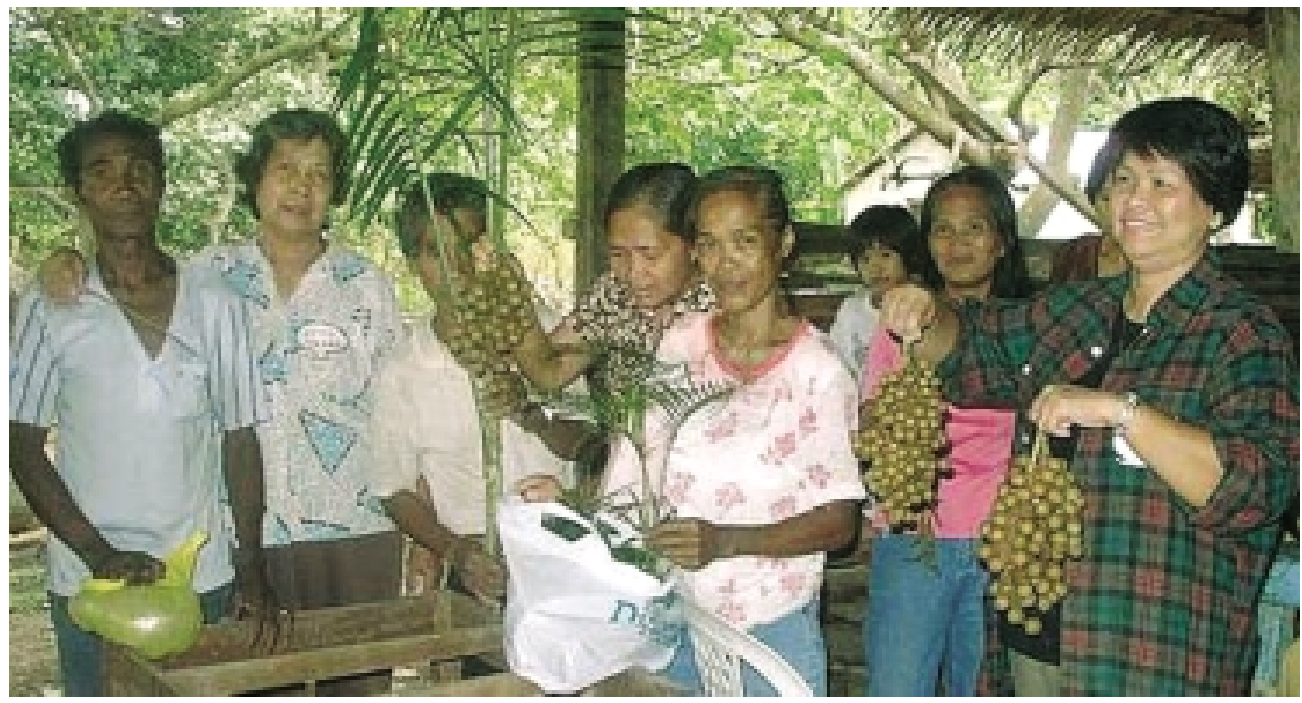




\section{4}

\section{THE ACM SITES}

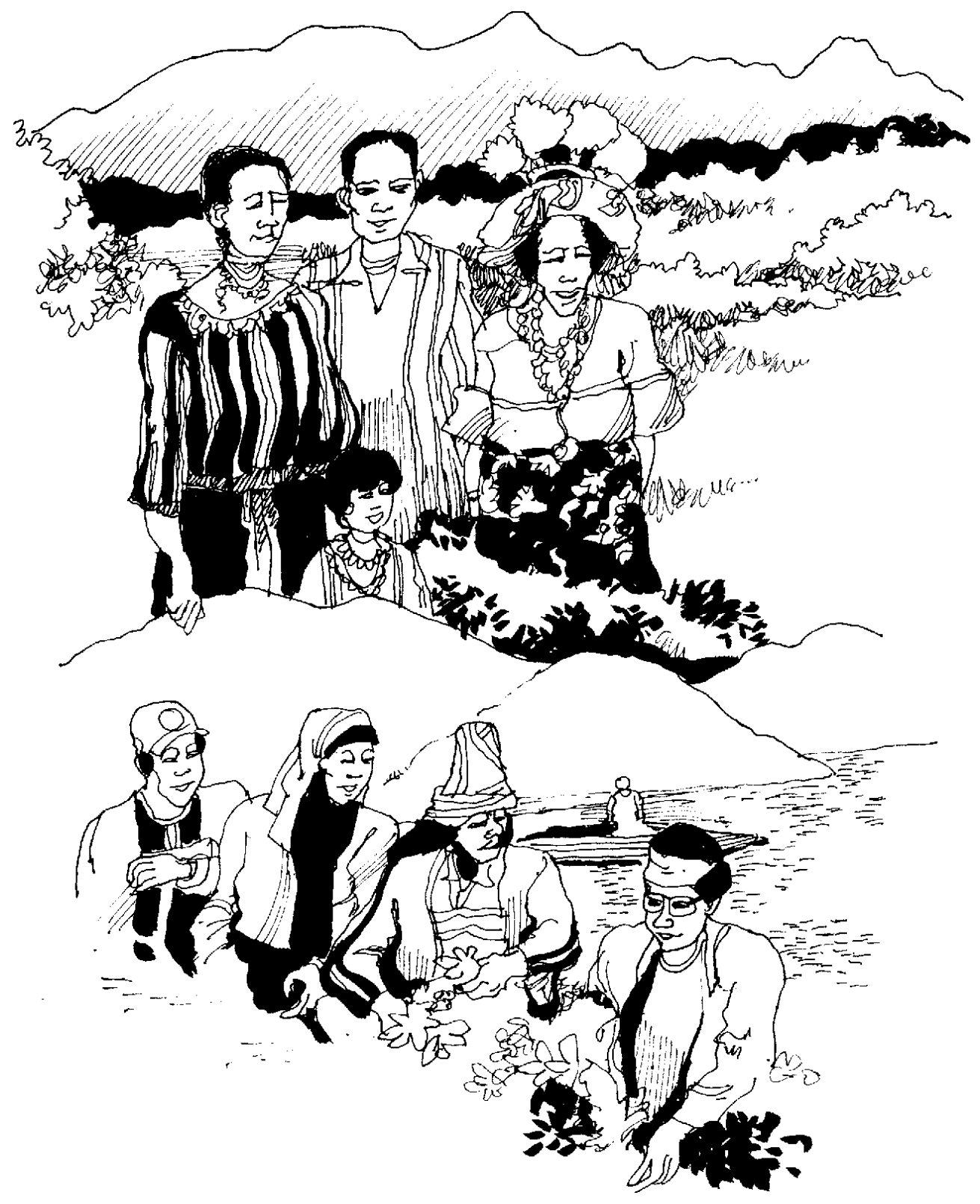




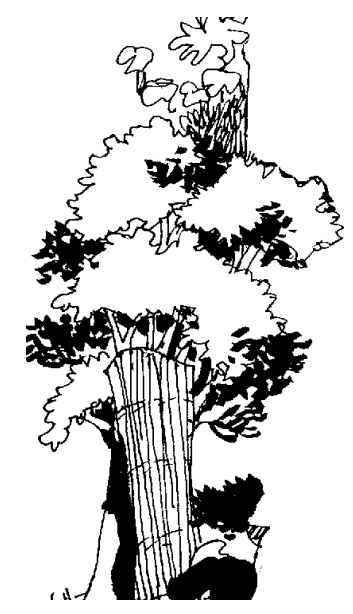

Your living is determined not so much by what life brings to you as by the attitude you bring to life; not so much by what happens to you as by the way your mind looks at what happens. Circumstances and situations do colour life but you have been given the mind to choose what the colour shall be.

(John Homer Miller) 
This chapter describes the geographic location of our ACM research sites, their biophysical conditions, and our stakeholders in these sites. It unravels the complexities in institutional interactions and management systems in the two sites. It is in the midst of these complexities that the ACM approach was applied.

We implemented our ACM research in two CBFM sites in the Philippines, one located in the island province of Palawan and the other in Bukidnon province. These two sites were selected as their characteristics complement the characteristics of other ACM sites in different parts of the world. This would allow us to undertake comparative analyses on the research findings and draw conclusions.

\section{San Rafael, Tanabag, and Concepcion villages: the Palawan site}

Our research site in Palawan is composed of three adjoining barangays (villages) namely San Rafael, Tanabag, and Concepcion of Puerto Princesa City, about 67 kilometres away from the city itself. The site is a CBFM area that has been put under the management of the People's Organisation of San Rafael, Tanabag and Concepcion Multi-Purpose Cooperative, Inc. (STCMPC), so named after the three villages. This area is one of nine pilot sites established all over the Philippines by the Natural Resource Management Program of DENR.

The CBFM area has 5,006 hectares. The area covers a series of watersheds behind the three villages, which includes a strip of disturbed forestlands that need rehabilitation and/or development. The western portion of the CBFM area consists of a running stream parallel to Sumurod River. The northern and eastern portions of the area are in direct contact with a closed canopy forest that has been threatened by continuous in-migration of people, many engaged in illegal activities. Logging operations by concessionaires and slash-and-burn agriculture have degraded the forests and other natural resources. These activities have also increased the flow of migrants into the area.

The CBFM area has been exposed to various technical assistance projects since the 1970s. These include:

- Community Forestry Program on forestry protection (1980 and 1989/90).

- Nursery establishment programme of the City Agriculturist (1980). 
- Natural Resource Management Programme (1996).

- Asian Development Bank-funded Comprehensive Site Development project on reforestation (1999).

These projects contributed to the improvement of forest cover of over 500 hectares and provided temporary employment for the people. Despite these efforts, the programmes contributed little in providing alternative livelihoods to the community and enabling the community to continue the work beyond the project lifetime.

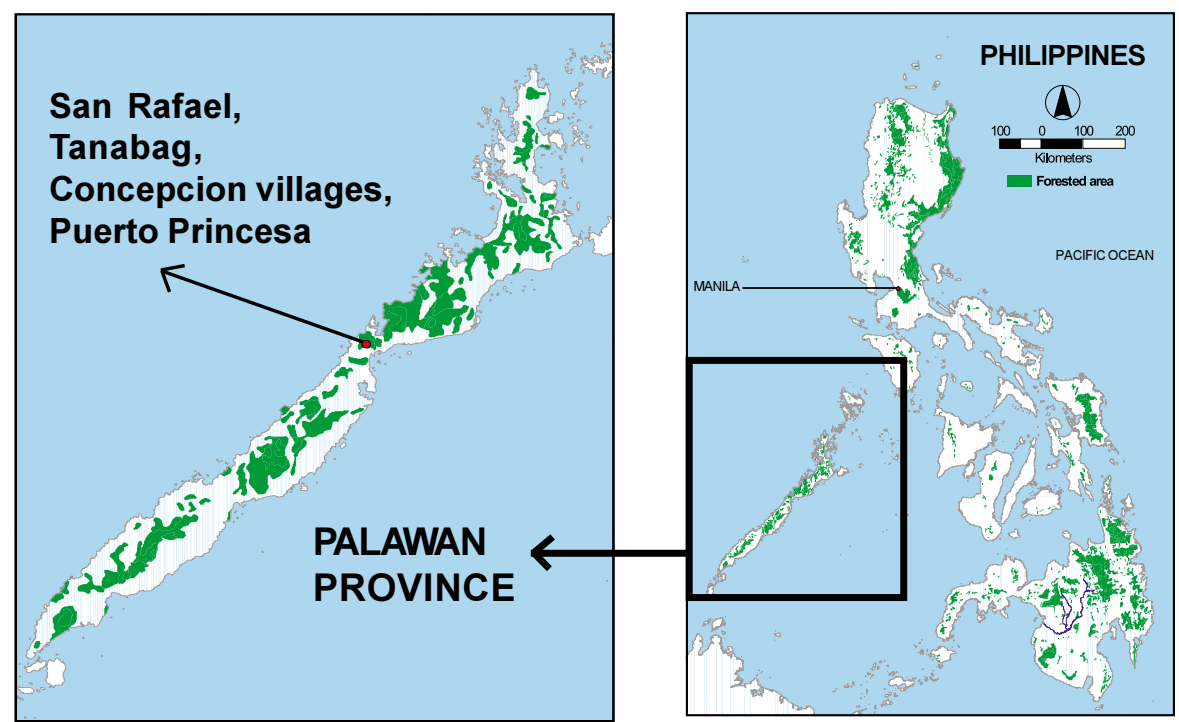

The ACM research site in Palawan province (above). A view of the site from the coast (below).

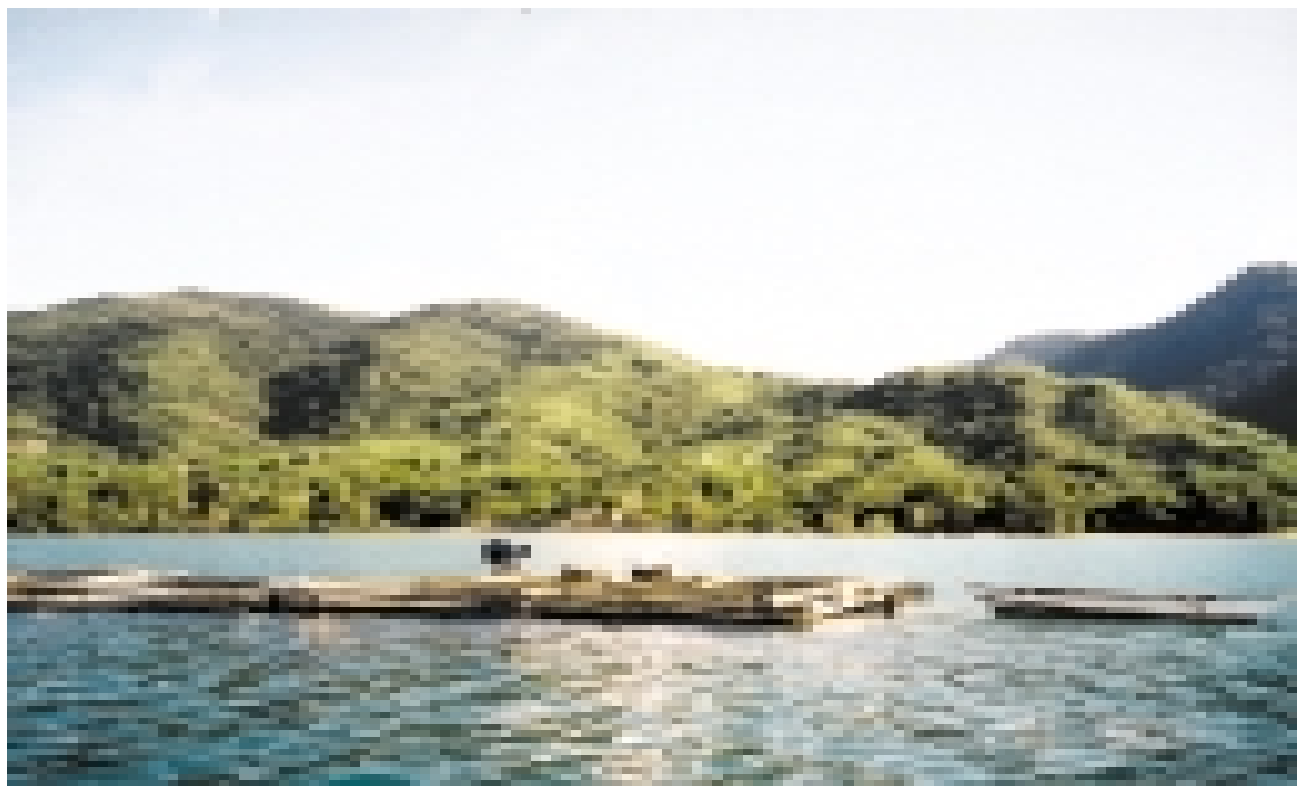


Based on the June 1999 census by the village government, the total population in the three villages was 3,597. San Rafael and Concepcion had the largest number of people (1,575 and 1,565 respectively) while Tanabag had 457.

The majority of the people in the villages are migrants and the rest are indigenous people, the Tagbanua and Batak. Migrants are composed of the Cuyonon who come from the Cuyo island of Palawan and other regional groups like the Tagalogs, Ilocanos, Bikolanos, and Visayans. They are mostly engaged in farming, fishing, logging, charcoal making, trading, and the collection of honey and almaciga (Agathis damarra) resin. Most are Christians.

The Bataks are native to Palawan. They occupy an area in Tanabag village where 36 families reside. They have a chieftain who represents them in meetings called by the local government units. An NGO called Haribon has assisted the Bataks in obtaining a CBFM area of around 900 hectares.

Of the total population, 1,993 (55\%) are women. They are engaged in farming, fishing, and collecting non-timber forest products. Women participate in the PO meetings but the migrant women tend to be more vocal compared to indigenous ones. Nevertheless, one Tagbanua woman sits on the PO Board of Directors (BoD).

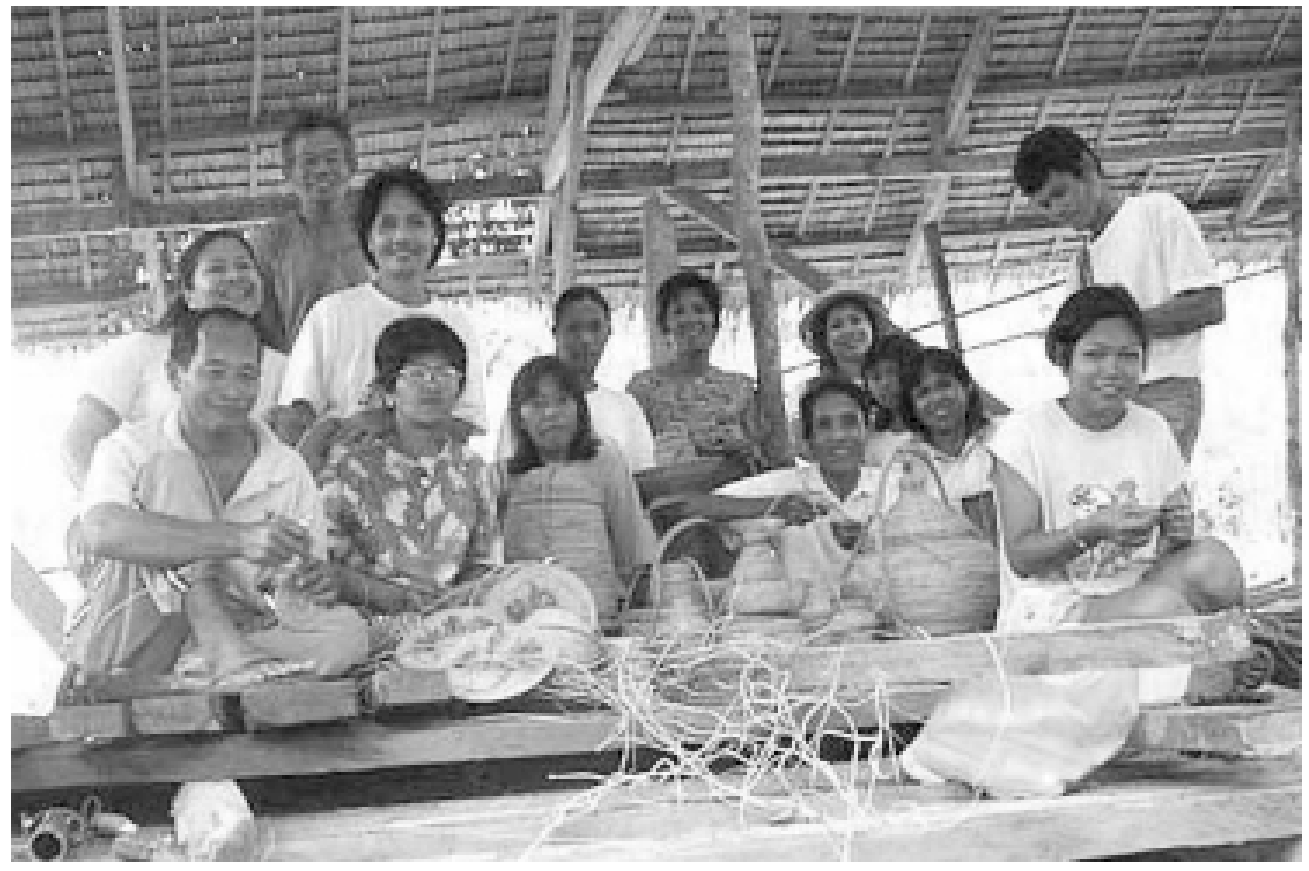

The population in the Palawan CBFM site is a mixed group of the indigenous Bataks, Tagbanuas, and migrants from other regions of the Philippines. These migrants are mainly composed of Tagalogs, Bikolanos, llocanos, and Visayans. 


\section{Basac village: the Bukidnon site}

Our other ACM research site is located at Basac village in the municipality of Lantapan, Bukidnon province in north central Mindanao. It lies in the southwestern foothills of Mt. Kitanglad, the second highest peak in Mindanao. The Mount Kitanglad Range Natural Park was declared a protected area in the category of Natural Park, by virtue of Presidential Proclamation 896 in 1996. The total area covered by the protected area and its buffer zone is around 15,000 hectares. ${ }^{48}$ Mt. Kitanglad Natural Park is one of ten sites in the Philippines funded by the World Bank's Global Environment Facility through the Conservation of Priority Protected Areas Project.

Unlike the STCMPC in Palawan, the CBFM agreement at this site was just awarded by DENR in 1999 to the Basac Upland Farmers Association Inc. (BUFAI). The CBFM area covers 517 hectares of land in the buffer zone of Mount Kitanglad.

Barangay Basac has a total land area of 2,800 hectares. It is bounded by the municipality of Talakag on the southwestern fringe and by Barangay Kibangay on the eastern side. Two large rivers namely Manupali and Timago, traverse the southern section of the village. They are the sources of water for domestic and farm use. The newly opened national road, which connects the north-western coastal town and cities to the southern region of Mindanao, passes through Basac.

Basac is subdivided into six puroks (wards/districts). It has 750 households and a population of around 4,000 people dominated by the Talaandig (95\% of the village population), one of the indigenous ethnic groups in Bukidnon. The rest are migrant settlers, mostly from the nearby provinces of Cebu, Bohol, and Leyte.

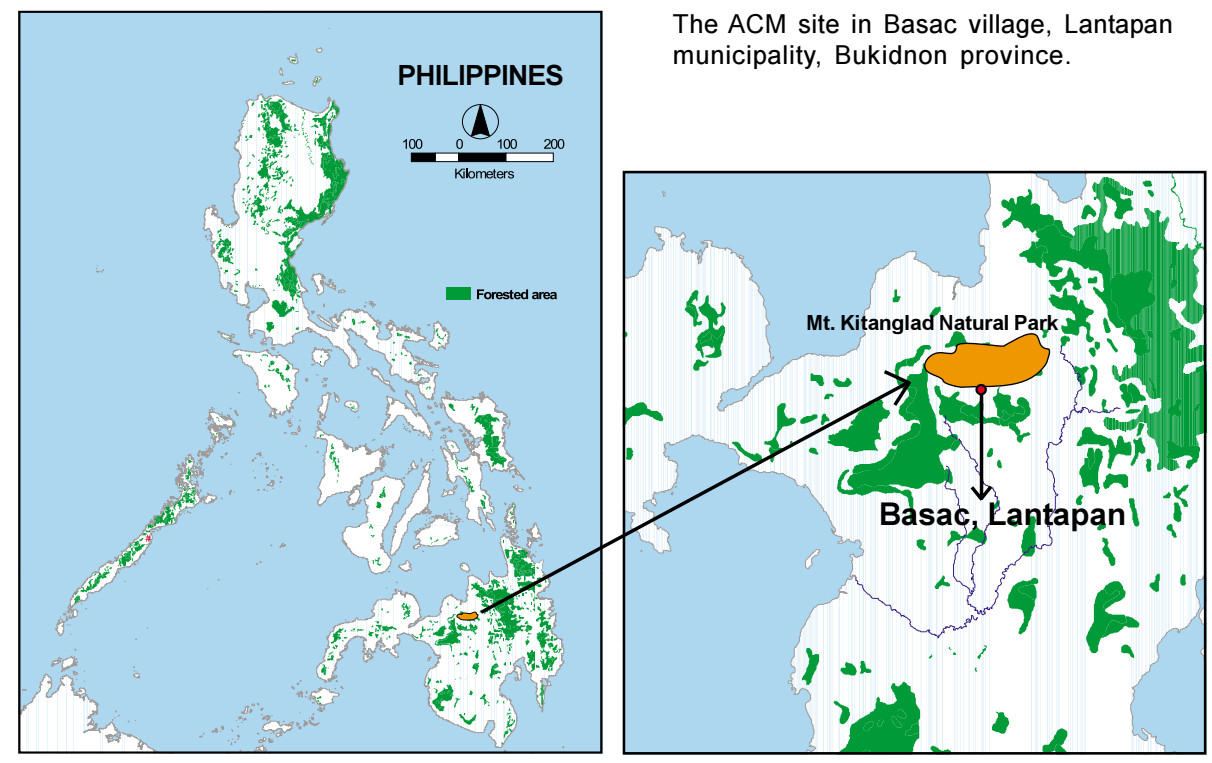


The village has a public elementary school and some Christian churches (both Catholic and Protestant). A great majority belong to the Roman Catholic religion (71\%).

The majority of the residents are lumad (indigenous) who have formed a Council of Elders composed of petty chiefs or datus from the other outlying settlements of Basac. The council serves as the repository of customary laws and rules as well as arbitrator during settlement of conflicts and disputes in the community. It also provides advice on spiritual matters such as the conduct of necessary rituals related to varied human activities.

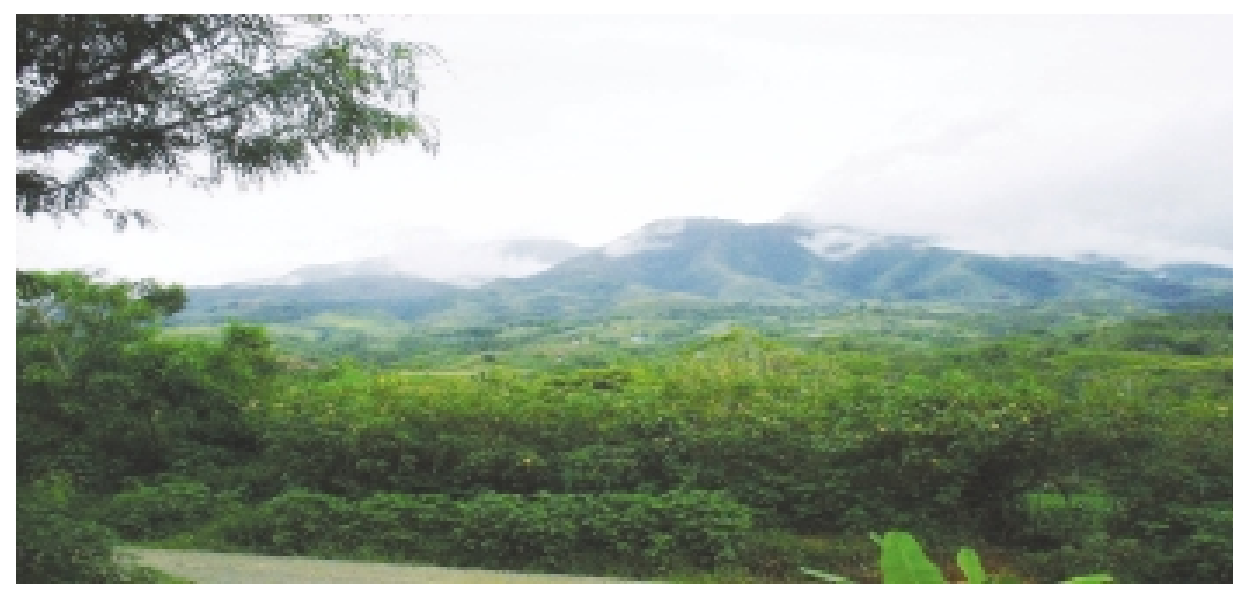

The ACM site in Basac village is located in the Mt. Kitanglad Range Natural Park (above). The local indigenous people are mostly composed of the Talaandig (below).

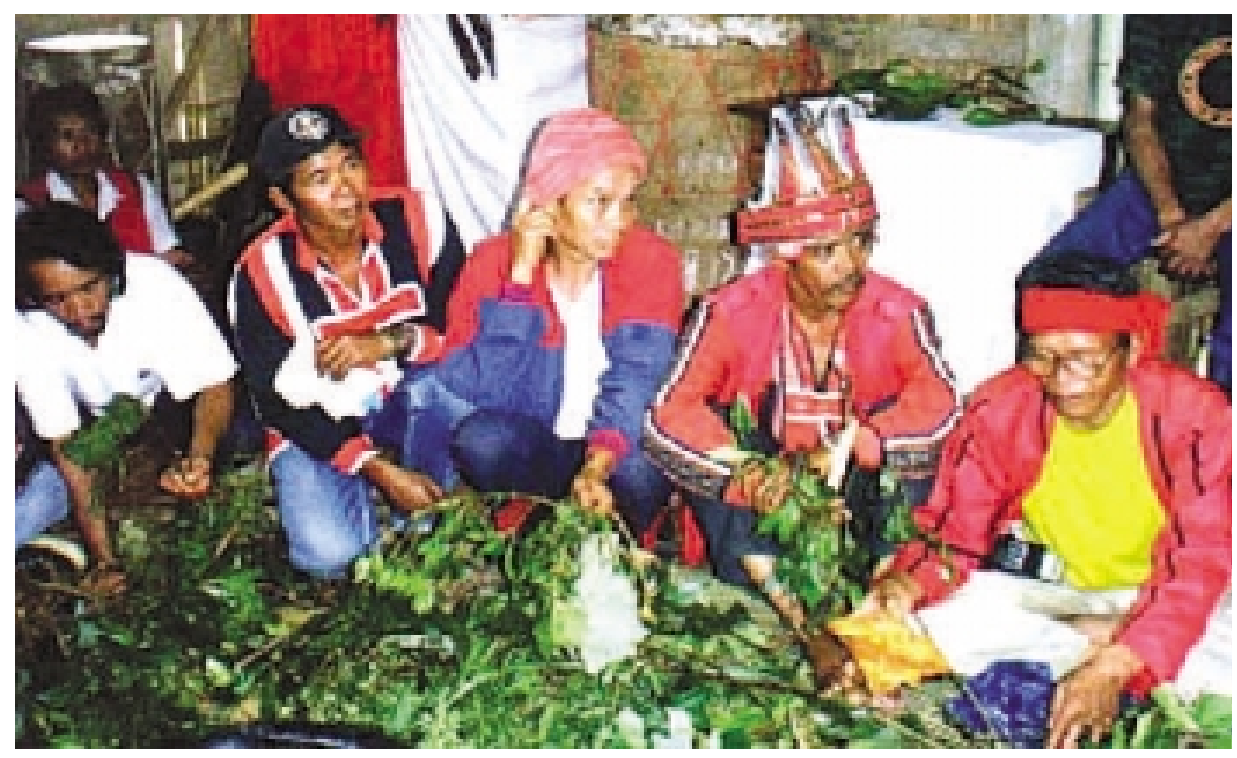


Like the Palawan site, Basac also received outside assistance, including from the World Agroforestry Centre (ICRAF), Heifer International, the Barangay Integrated Development Assistance for Nutrition Improvement, Adventist Development and Relief Agency, and Conservation of Priority Protected Areas Project.

Women in Basac are engaged in farming, pig-raising, poultry-raising, and in some small-scale economic activities such as vegetable selling and running sari-sari stores (sundry shops). Their involvement in BUFAI activities was very limited; only three women were active. There were several women's associations in the past but they were not sustained.

\section{The CBFM stakeholders}

There are many organisations and government institutions present in both areas. We identified the main stakeholders in forest management using the 'Who Counts Matrix' Analysis which is based on several criteria such as dependency on forests, pre-existing rights, proximity to forest, poverty, etc. ${ }^{49}$

\section{Stakeholder interactions}

Results of our analysis showed three main stakeholder groups composed of community groups (formal and informal organisations), government institutions and nongovernment organisations. The main stakeholders in forest management are described in Table 1. The results show that the stakeholders in both sites are numerous.
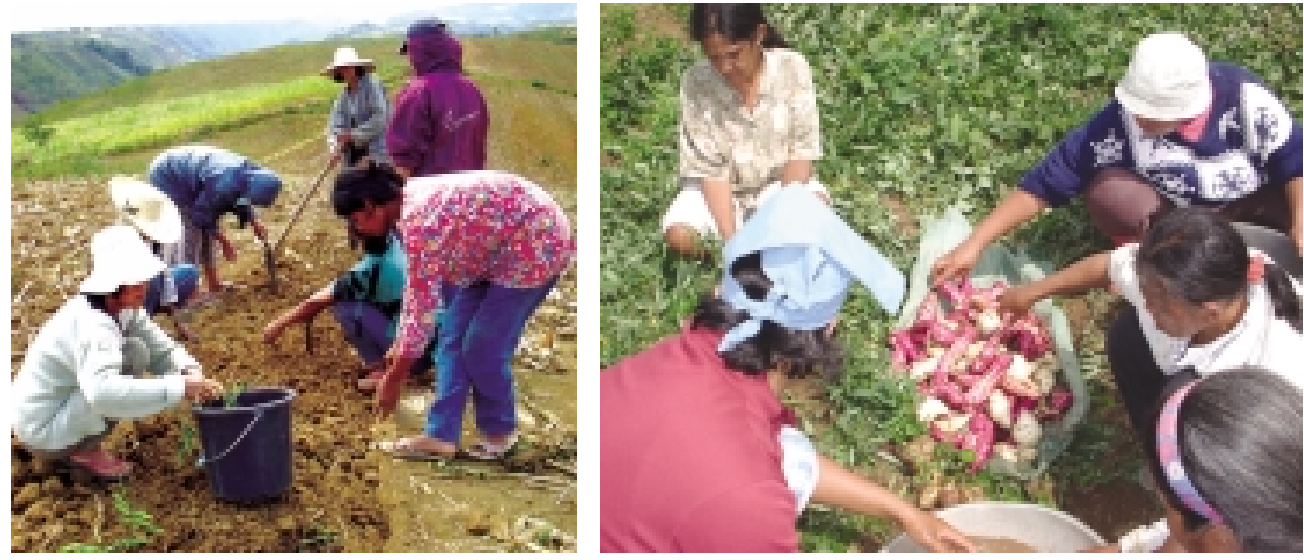

Basac women are mainly engaged in farming and other small-scale economic activities. Women's associations existed in the past but they were not sustained. 
Table 1. The main stakeholders in the ACM Palawan and Bukidnon sites

\begin{tabular}{|c|c|}
\hline PALAWAN & BUKIDNON \\
\hline \multicolumn{2}{|c|}{ COMMUNITY GROUPS } \\
\hline $\begin{array}{l}\text { 1. San Rafael, Tanabag, Concepcion } \\
\text { Multi-Purpose Cooperative, Inc. } \\
\text { 2. Fishermen's Association } \\
\text { 3. Women's Group }\end{array}$ & $\begin{array}{l}\text { 1. Basac Upland Farmer's Association, } \\
\text { Inc. } \\
\text { 2. Council of Elders } \\
\text { 3. Basac Tribal Farmers' Association } \\
\text { 4. BUFAI Women's Association }\end{array}$ \\
\hline \multicolumn{2}{|c|}{ GOVERNMENT INSTITUTIONS } \\
\hline $\begin{array}{l}\text { 1. DENR and its Provincial office } \\
\text { and Community-level office } \\
\text { 2. Local Government Units at the } \\
\text { barangay, city, and provincial levels } \\
\text { 3. Palawan Council for Sustainable } \\
\text { Development }\end{array}$ & $\begin{array}{l}\text { 1. DENR-Integrated Protected Areas } \\
\text { System } \\
\text { 2. Local Government Units at the } \\
\text { barangay and municipal levels } \\
\text { 3. Protected Area Management Board }\end{array}$ \\
\hline \multicolumn{2}{|c|}{ NON-GOVERNMENT INSTITUTIONS } \\
\hline $\begin{array}{l}\text { 1. Budyong Rural Development } \\
\text { Foundation, Inc. } \\
\text { 2. Enterprise Works Worldwide } \\
\text { 3. Environmental Legal Assistance } \\
\text { Centre } \\
\text { 4. Haribon Foundation }\end{array}$ & $\begin{array}{l}\text { 1. Kitanglad Integrated NGOS } \\
\text { 2. Barangay Integrated Development } \\
\text { Assistance for Nutrition Improvement } \\
\text { 3. World Agroforestry Centre } \\
\text { 4. Heifer International }\end{array}$ \\
\hline
\end{tabular}

Our research shows that the members of the PO (CBFM holders) were only a fraction of the community in the village. In Palawan, the members of the STCMPC number 433 people or around $12 \%$ of the whole village community. On the other hand, members of the Bukidnon BUFAI PO number only 180 people or around $4.5 \%$ of the whole village population.

Furthermore, at both sites, there were several other community groups with different interests from the POs holding the CBFM tenure. These were notably the Fishermen's Association and the Women's Group in Palawan, and the Council of Elders, and Basac Tribal Farmer's Association, Inc. in Bukidnon. These other community groups also depend on the forests in one way or another.

In reality, however, these groups were not included in the planning and implementation of CBFM programmes. This situation is common to other parts of the Philippines and it stems from a failure to recognise the diversity within the community, especially if their different ethnicities, occupations, and political interests are considered. 
The slow government devolution and decentralisation in the Philippines has led to a complex and confusing situation. With authorities, rights and responsibilities being exercised by various government agencies and communities, a greater number of 'groups' with different and sometimes conflicting policies, objectives and values have emerged, as in the case of Palawan province. ${ }^{50}$

Policy makers have been giving special attention to Palawan, as the last frontier in the Philippines, to ensure that its environment and natural resources are properly managed and protected. In 1992, the Strategic Environmental Plan Law for Palawan transferred to the Palawan Council for Sustainable Development, the authority to protect and manage natural resources in Palawan. ${ }^{51}$ In particular, the law states that the Council should function both as a planning, policy-making and coordinating body, as well as an implementing body in the management of natural resources.

With the establishment of Palawan Council for Sustainable Development, the current institutional arrangements became more complex. This was because the functions and powers of the Council and DENR overlapped. Eight out of ten respondents, in our interviews, identified the major sources of conflict between the two institutions to be related to the unclear authority to issue permits and licenses (e.g., extraction of timber and non-timber products, environmental clearances). ${ }^{52}$

There have been several attempts to establish a multi-stakeholder forum in the past several years, such as the Technical Working Group for Resource Management and other provincial technical working groups. This can be seen as an indication of the rising awareness of the need for concerned stakeholders to collaborate among themselves. However, these forums, though established with good and genuine intentions, have not been successful in facilitating collaboration and joint learning.

The situation in Bukidnon is a bit different from Palawan as the site is located within the protected area of Mt. Kitanglad. The National Integrated Protected Areas System Law in 1992 created the DENR-Integrated Protected Area System in 1994. The office is led by a Protected Area Superintendent who oversees the whole protected area. The Park Superintendent is also directly responsible for managing the implementation of CBFM projects within the protected area and its buffer zone.

Furthermore, a functional multi-stakeholder body called the Protected Area Management Board (PAMB) also exists in Lantapan. Established in 1993, PAMB is in-charge of the preparations of the management plans, project/programme implementation, monitoring and supervision of activities in the protected area. It is composed of representatives from the DENR (Regional Executive Director), the Park Superintendent, Local Government Units (8 mayors of the eight municipalities around Mt. Kitanglad, 28 barangay captains, 5 municipal chieftains), representatives of the indigenous people (3 leaders), local NGOs, and the POs. 
As things now stand, PAMB is still dominated by 'government' representatives. In the past, the mayors sitting on the board did not favour the indigenous communities. This changed when new mayors, who have more respect for local culture, became PAMB members. The dynamics within the PAMB itself have also gradually changed with the representatives of the indigenous people being able to express their concerns openly.

\section{Biophysical conditions}

In most areas of the Philippines, a continuous decline in forest cover has been noted. Within a span of eight years, forest cover was reduced from 21 million hectares in 1990 (amounting to 70\% of total land area covered by forests) to 6.6 million hectares in $1998 .^{53}$

It is interesting to note that the decline of forest cover in Palawan started in 1960, much later than in other parts of the Philippines, and the improvement started to take place around 1987. Even then, Palawan was the only island with a 56\% forest cover. $^{54}$

The 1992 satellite imageries showed that the majority of the total 18,110 hectares of the three villages in the ACM site was still covered by primary forests (67\%). The rest were secondary forests, brush land, and cultivated/crop land. ${ }^{55}$

Our key informant interviews with elders, barangay captain, Batak chieftain, etc. revealed that the area was fully covered with big almaciga, narra (Pterocarpus indicus),

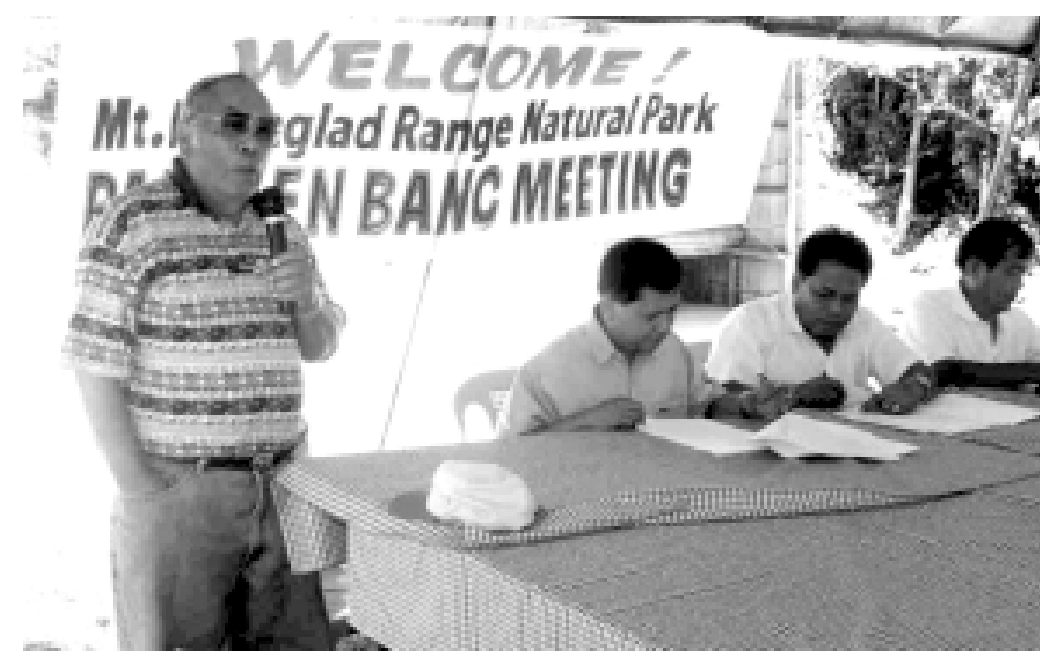

The Protected Area Management Board (PAMB) is a multi-stakeholder body that sets policies and directions in the CBFM implementation in the Mt. Kitanglad Range Natural Park. 
and ipil (Instia bijuga) trees in the 1950s up to 1960s. In the 1970s and 1980s, forest cover started to decline due to the logging operations of a timber concessionaire in the area. It was also during this period when kaingin (shifting cultivation) practised by migrants was rampant in the area. ${ }^{56}$

Logging was completely banned in Palawan in 1992 and at the same time, the then mayor of Puerto Princesa launched a massive drive against the practice of kaingin. These developments resulted in a sudden reversal of the trend in forest cover. Forest cover started to increase in 1992 and the same trend is observable until now.

Our study also showed that the most abundant tree species found in the old growth forest was Shorea guiso (local name is guijo), followed by Vatica manggachapui (narig), and Dipterocarpus sp. ${ }^{57}$ The almaciga forest was dominated by Agathis damarra. Since the almaciga forest is located at a high altitude and is farthest from the village, it has been less disturbed compared to other areas and consequently has relatively high species richness, just like the old growth forest.

Residual forest was the most dominant forest type in the CFBM area. The tree species most commonly found included Pterocymbium tinctorium (taluto), Symplocos ahernii (agosip), Ahernia glandulosa (sanglai), Litchi chinensis (alupag), Colona serratifolia (anilau), and Canarium asperum (pagsahingin).

Hunting is prohibited in Palawan for all but the indigenous tribes. Presidential Proclamation No. 219 of 1967 declared Palawan as a game refuge and bird sanctuary, and the smaller islands of the province have been designated as national reserves. ${ }^{58}$ However, there were indications that some small-scale hunting were taking place in the area as the meat of wild pigs and birds was sold in local eateries.

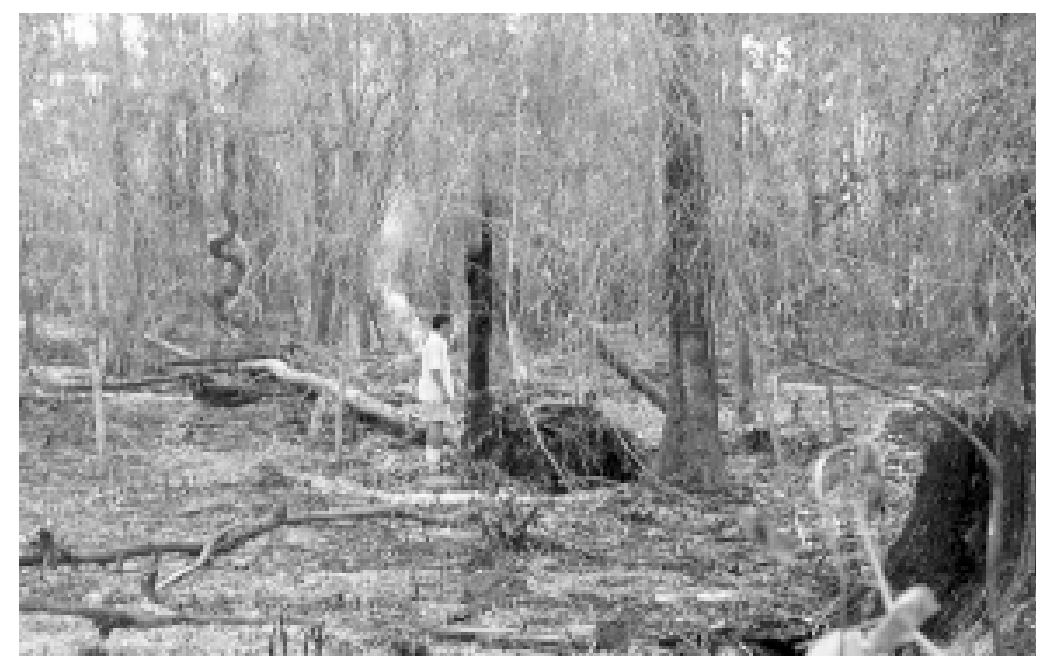

In 1970 to 1980 , Palawan forests were degraded by logging and slash-and-burn agriculture. Logging was completely banned in the province in 1992 . 
The forest condition in the ACM site in Bukidnon is quite different from the condition in the Palawan CBFM. The 517-hectare CBFM area in Bukidnon is much smaller than that of the STCMPC area in Palawan. Around 60\% of the CBFM area in Bukidnon was cultivated land, which was planted with food crops. Around 15\% of the CBFM area was grassland, $15 \%$ was open canopy forests, and only around $10 \%$ was closed canopy forests.

In pre-colonial times, the Talaandig people in the area depended on the forest and forest resources for almost the entirety of their existence. As the population grew, they adapted to a semi-settled system - gathering forest resources while cultivating the land through shifting cultivation.

This practice was sustainable for a number of generations. Talaandig forest use was characterised by a profound reverence for the environment and this respect was reflected in their use of the land. One interesting practice was their normal fallow period of 15 years after each planting season of rice and maize, allowing good regeneration of the area. They also planted perennials like abaca (Musa textilis) and root crops in a minimal quantity for consumption while waiting for harvest in new areas.

This Talaandig practice, however, was not sustained, with Spanish and American colonisation greatly contributed to the decline. New systems of forest and forest resource use were introduced. Permanent settlement and the introduction of new religions also changed the forestland use system. There was a significant change in the roles of people and the forest so that traditional taboos and systems of extraction were no longer respected.

It is important to note that immediately after World War II, the community was more concerned about food production and increasing harvests due to their experience of the war. Forest protection was never a concern then. Migrants introduced conventional farming, characterised by intensive chemical inputs. Monocropping almost completely wiped out the traditional way of cultivation. Today, the community realises that their crops will not yield well without fertilisers, unlike in the past.

Timber resources in the ACM site in Bukidnon dwindled in volume due to the continuous encroachment of the populace into the forest and also because of fires coming from other villages in Kitanglad during the 1983 El Niño. The fire destroyed most of the primary as well as the regenerating forests. Rattan, vines, medicinal plants, honey, and other non-timber resources also became scarce and inaccessible. Water, as a major resource and an indicator of the environmental condition, declined in quality. Flooding and drying up of springs occurred from time to time indicating environmental degradation. 
Unlike agricultural activities, there has been no significant commercial logging activity in the past. The only logging activity took place for a short period of six months, extracting very little timber from the forest.

Our participatory assessment conducted with various community groups showed that certain resources have significantly declined over time. These include rattan, abaca, coffee, herbs, wild animals, and forest trees. Some of the tree species that used to be utilised by the communities were ulayan (Lithocarpus llanosii), lagbuti, kulasi (Lumnitzera racemosa), boga (Ityeadaphne philippinensis), mangium (Acacia mangium), and uway (Calamus sp.). They were used as firewood, housing materials, rope materials, etc.

\section{Forest management systems}

Based on the CBFM Agreement, the POs are required to write their plans for managing their areas in two documents: a 25-year management plan called the Community Resource Management Framework (CRMF) and annual work plans (AWP). Only after these management plans are approved by the DENR can the POs carry out the activities specified in the documents.

The approval of the CRMF and AWP in Palawan involves a long and tedious process. The Palawan Council for Sustainable Development requires that before the CRMF and AWP are approved by the community-level DENR and endorsed by the Council, they also have to be endorsed by local government units (municipal and barangay levels) to ensure the social acceptability of the plans (see Figure 2 for details). In other parts of the country, endorsement from the local government units is not required. The whole process of getting their CRMF and Interim Resource Use Plan approved was really tedious in the case of STCMPC; it took them around four years. ${ }^{59}$ This delay was also partly contributed by the lack of support from the barangay captains who were reluctant to give their endorsements.

In the past, STCMPC tried to involve other stakeholders in the preparation of their management plans. A small core group of $\mathrm{PO}$ members usually developed the management plans, with major support from the assisting NGO. The management plans were then presented to a larger $\mathrm{PO}$ group and at the $\mathrm{PO}$ 's general assembly. The plans were also presented to groups of other stakeholders through a series of consultations. Feedback and additional inputs were incorporated, then presented again to a still larger group of stakeholders for validation and recommendations. Before finalisation, hard copies were distributed for feedback and comments. 
Figure 2. The approval process of CBFM work plan documents

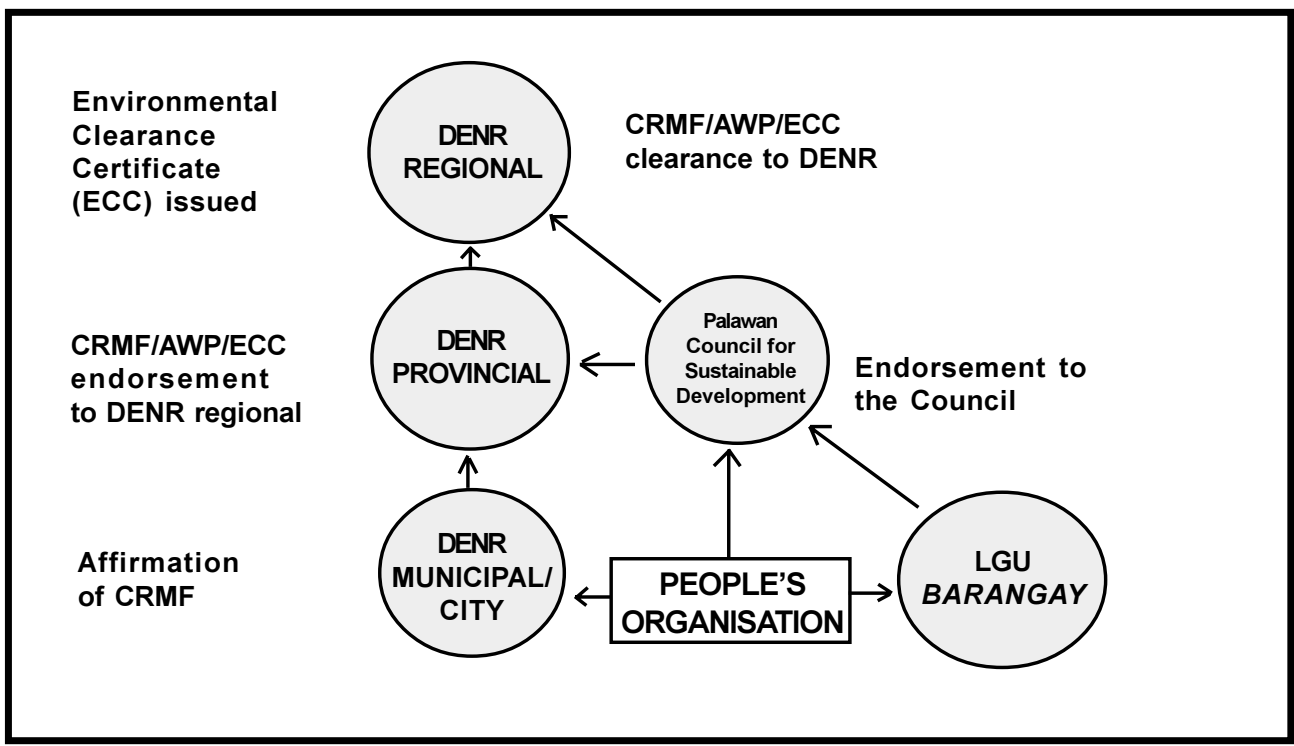

The quality of participation of different stakeholders in these consultations was found to be unsatisfactory by the PO. They did not receive much written inputs to the management plans that they distributed. At the same time, several stakeholders felt that they had been excluded in the earlier process although they noted improvements.

Collaboration between the members of the PO itself, however, was limited. The $\mathrm{PO}$ committees for forest protection, forest rehabilitation, livelihood, education, etc. were not functional. At the beginning of our ACM project, the only functional committee was the PO's Enterprise Development Unit that managed the felled logs operation. Most PO activities were handled by 2-3 key personnel as the PO members had received few benefits from CBFM and were therefore not motivated.

Before ACM, The STCMPC's forest management activity was mainly extraction of fallen trees or salvaged logs. The STCMPC got the permit to extract these fallen trees as part of their Interim Resource Use Plan to build capital for their CBFM activities. Started in late 1999, this operation provided temporary employment to some of the members. They have been allowed to continue this timber extraction until the present, and from 2001 they started utilising other products such as honey, rattan, and almaciga. ${ }^{60}$

One of the problems faced by the PO in their lumber operation is the relatively high forest charges. DENR Administrative Order No. 98-42 regulates productionsharing agreements for harvesting of forest resources between the $\mathrm{PO}$ and the 
government. ${ }^{61}$ In the past, STCMPC was required to pay US $\$ 0.24$ per board foot for premium species such as narra, ipil, and apitong (Dipterocarpus grandiflorus). ${ }^{62}$ At this rate, the business was barely profitable.

The PO had a dialogue with the community-level DENR and was advised to file a resolution with the Regional DENR office petitioning for lower forest charges. This resolution was endorsed by the community-level DENR. As a result, the basis for forest charge computation was revised and the new agreed forest charge was US\$0.14/ board foot. ${ }^{63}$

Compared to the PO in Palawan, The BUFAI PO in Bukidnon is relatively young. It was established in 1999 and consequently, has less experience. Most of the indigenous people opted for the CBFM tenurial instrument since it was the only available instrument at that time and because they wanted to get security over their land. This form of tenure would allow them to continue farming in their farms located within the CBFM area.

Another reason why the community adopted CBFM was to avail themselves of livelihood funds provided under the Conservation of Priority Protected Area Project. When the protected area law was applied in the area, the implementers realised that protection of Mt. Kitanglad would not be effective if the people who depend on the forests did not have alternative sources of livelihood. The Park Superintendent addressed this problem by extending financial assistance from the conservation project. This was the time when many POs were established to gain access to funds. The funds can be used for non-destructive livelihood options, and many people used them to plant trees, abaca, coffee, sweet potatoes, and other crops.

With regard to this fund, BUFAI received around 140 cows, 20,000 abaca suckers, 23,000 seedlings of Eucaplytus, some plows, and chicken dung. The latter was given for free. Under the financial assistance agreement, BUFAI will pay for the cows in five years, abaca costs will be repaid in 4 years, and trees in 10 years.

In their 25-year and annual management plans, BUFAI proposed several activities that they would like to carry out. Some of them had been initiated earlier. These activities were in livelihoods (animal care), forest protection and use (planting of abaca, Eucalyptus, and other tree species; the establishment of a plant nursery; soil and water conservation on the farms), monitoring, and organisational strengthening.

Similar to the situation at the Palawan site, less than $17 \%$ of their members were actively involved in CBFM planning and implementation. 


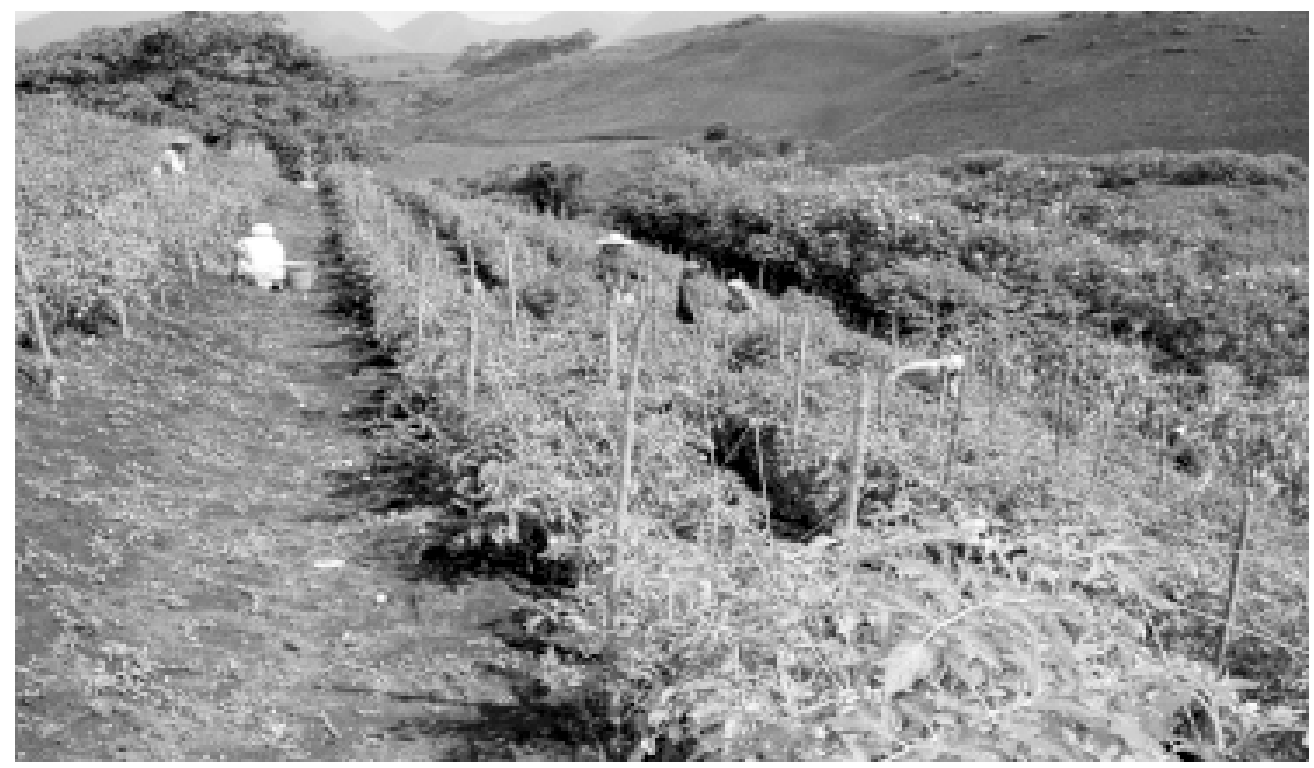

The BUFAI PO availed of the livelihood funds from a World Bank-financed project. The DENR Park Superintendent facilitated this assistance programme and encouraged people to engage in non-destructive livelihood activities.

\section{Collaboration and adaptiveness}

In Palawan, the level of collaboration among the POs, community groups, and other local stakeholders before the entry of our ACM research project was relatively low.

Firstly, there was a history of conflict between the PO and the neighbouring almaciga resin concessionaire who had political support from the barangay captains. This conflict contributed to a lack of support for the CBFM implementation from the barangay captains of Tanabag and Concepcion.

Secondly, the interactions of STCMPC with other stakeholders, e.g. provincial and community-level DENR, Palawan Council for Sustainable Development, and LGUs, at the beginning of the ACM work had been limited to occasional consultations.

It was also evident that there was limited effort on the part of the $\mathrm{PO}$ in consciously learning and adapting their strategies to the ever-changing socio-economic and political situations in Palawan throughout the implementation of CBFM. Reflections on past experiences were limited to discussions at meetings and lessons learnt were rarely incorporated into their subsequent actions. Furthermore, reflection processes were limited to the Board of Directors and a few members, and did not include other stakeholders. The learning processes and their links to adaptation were not obvious; PO members claimed that adaptation also took place, although unconsciously. 
A similar situation existed in the ACM site in Bukidnon. Collaboration among stakeholders in learning and in action in general was limited. BUFAI could establish networks with other stakeholders but this capability was limited to certain key officials. There was also a need for BUFAI to improve their collaboration with other POs in the barangay, such as the Council of Elders and Basac Tribal Farmers' Association. The level of trust between community members and barangay officials was also so low that community members tended to hold back their opinions at meetings. Information sharing was also limited to key people because the barangay leaders did not always share the information widely with other community members.

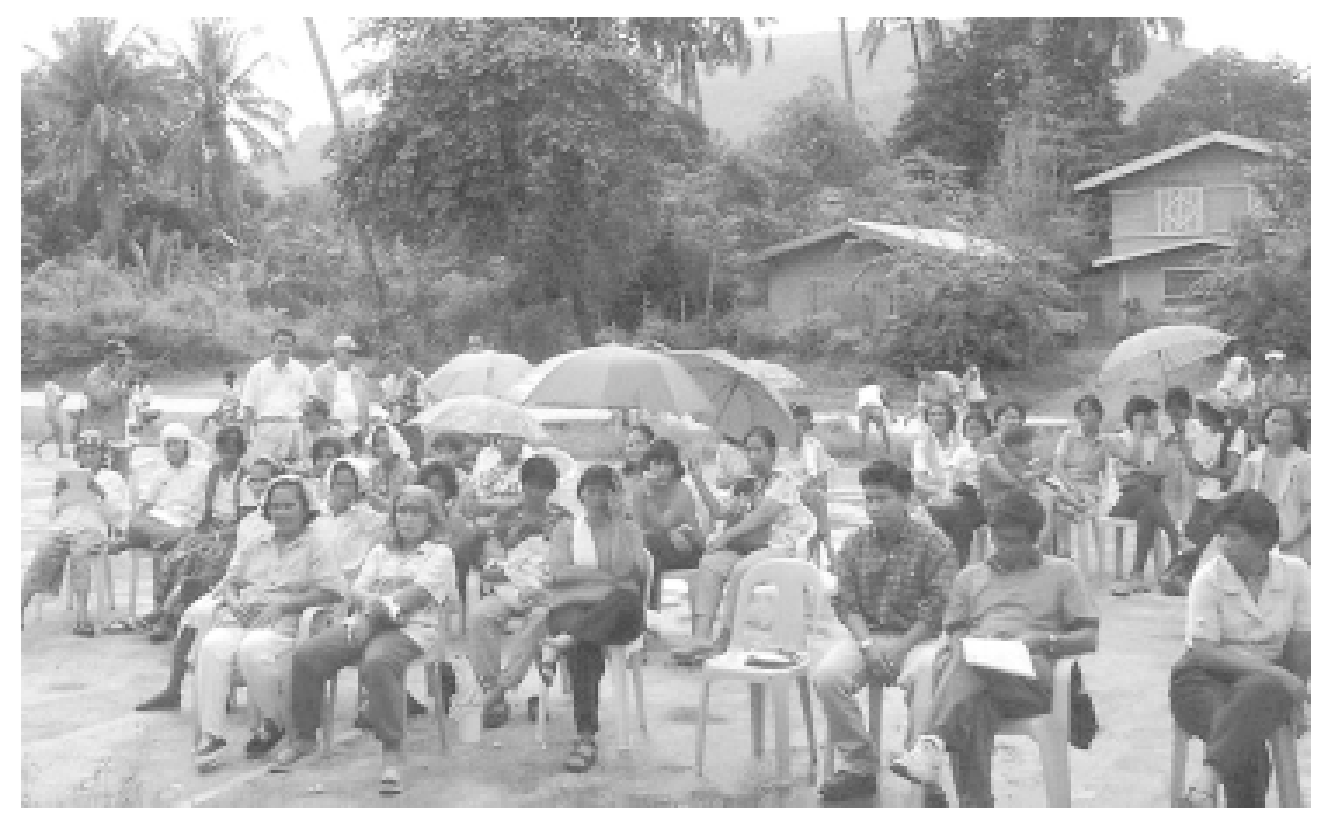

Community assemblies are often called by the PO Board of Directors to get feedback on their CBFM management plans.

At a higher level, there was a history of conflict between tribal leaders and the BUFAI. In 1997, the Mt. Kitanglad Council of Elders applied to DENR for a Certificate of Ancestral Domain Claim (CADC) covering a total of 15,000 hectares under eight different municipalities. This unified claim was presented to the Protected Area Management Board (PAMB) for Mt. Kitanglad.

The claim was not approved as the mayors and their indigenous constituents instead opted for a CADC for each municipality. Notwithstanding the rejection of the CADC application by the PAMB, the tribal council submitted its application to the National Commission on Indigenous People. Later on, in 1997, the Indigenous People's Rights Act was suspended when its constitutionality was questioned before the Philippines Supreme Court. This led to a stopping of the issuance of all CADCs by the National Commission on Indigenous People all over the Philippines. 
In the meantime, while waiting for the Supreme Court to resolve the issue, several communities applied for the CBFM programme, which was also introduced into the buffer zones of the protected area. Their applications were approved by DENR. In total, there are 13 CBFM areas being established within Mt. Kitanglad. This situation created conflicts in which DENR and the POs receiving CBFM tenure were accused of not supporting the unified CADC claim and of contributing to the disintegration of the communities.

As to adaptiveness, reflecting on experience to extract lessons was limited and not done intentionally. There was a prevailing tendency to rely on external assistance, seek a quick-fix solution, and concern oneself only with the 'here and now' among the community members. These attitudes may have resulted from the way much assistance in the past was provided to the community.

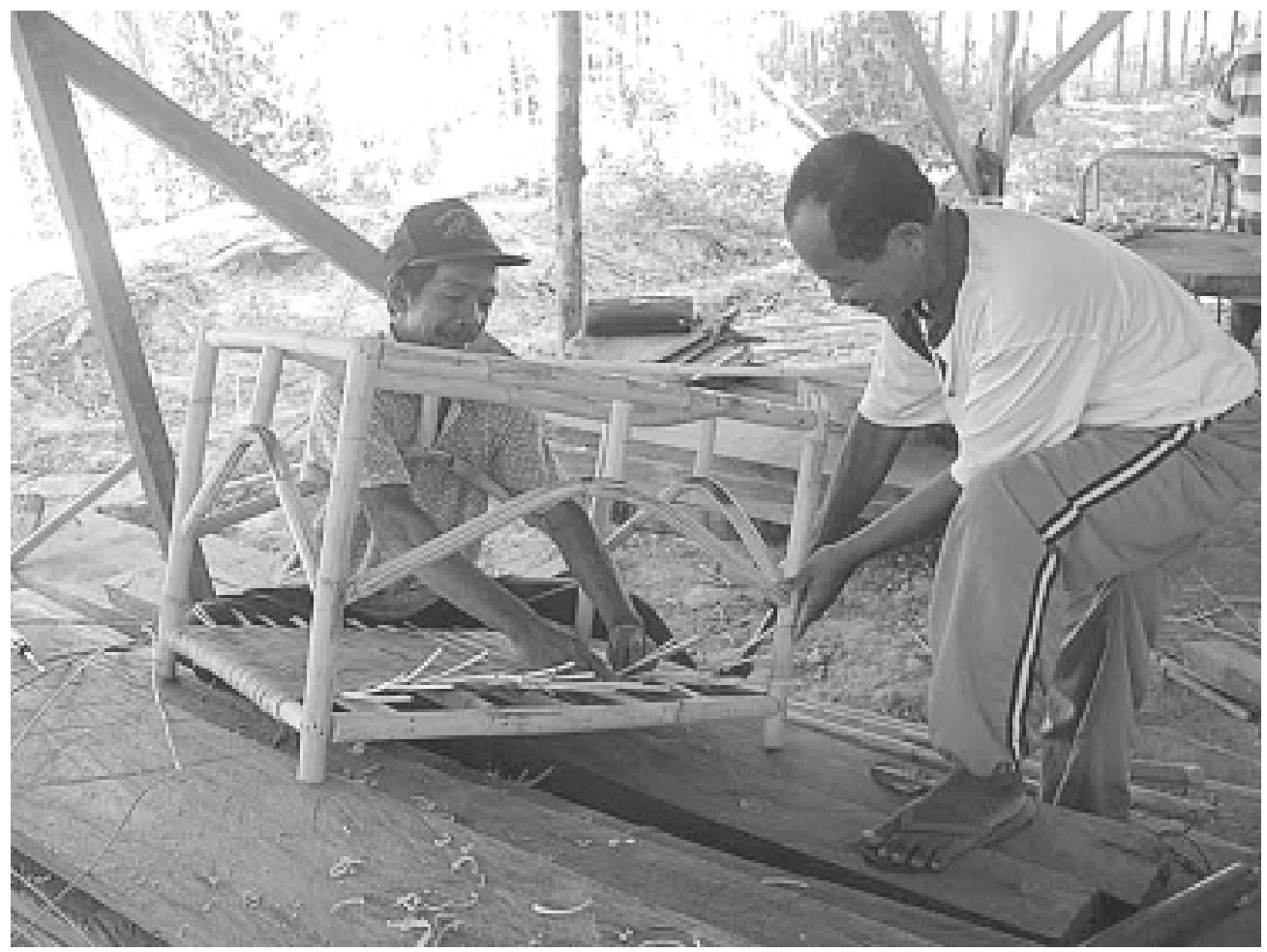





\section{ACM PRACTICE: HOW WE DID IT}

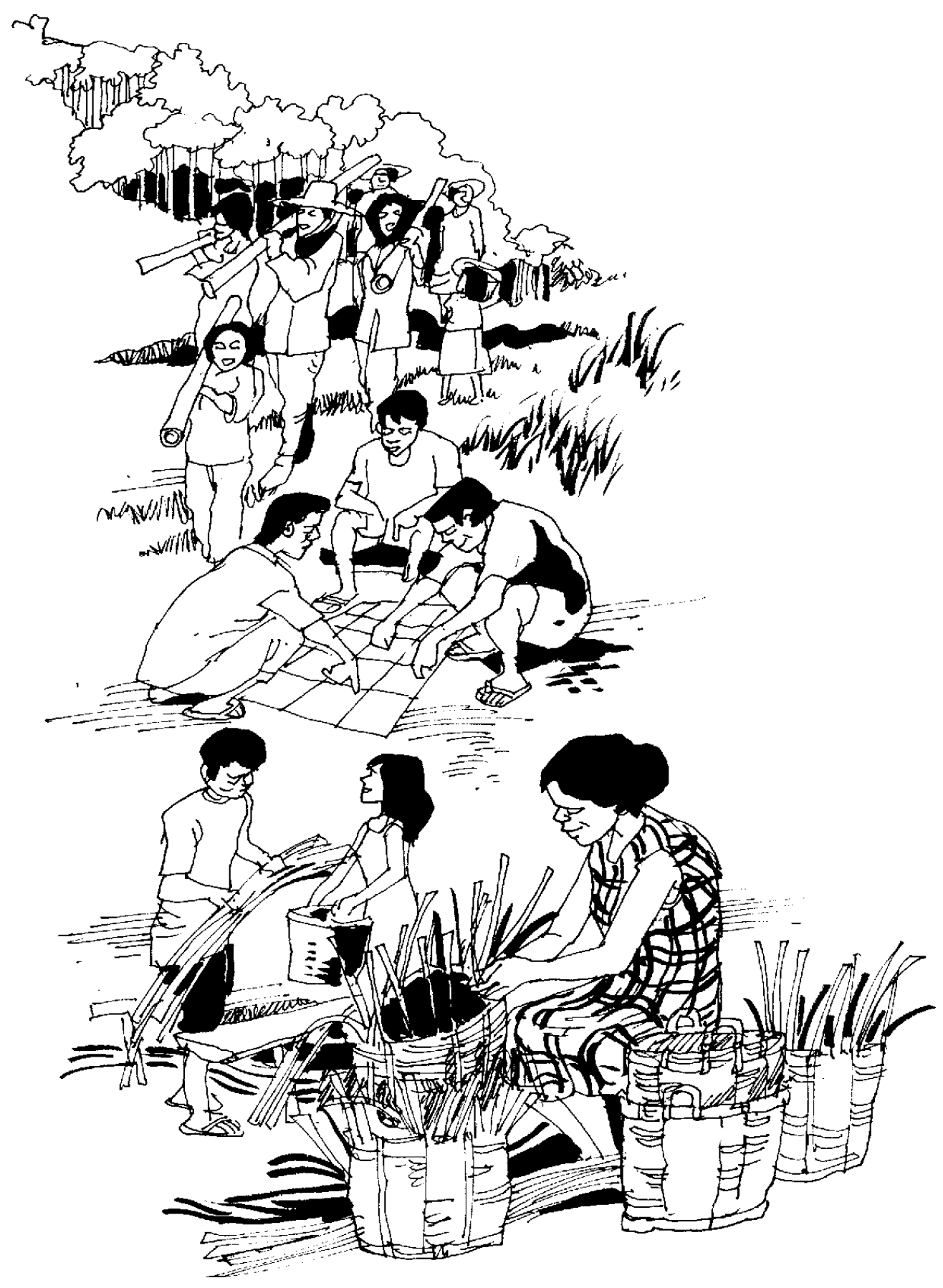




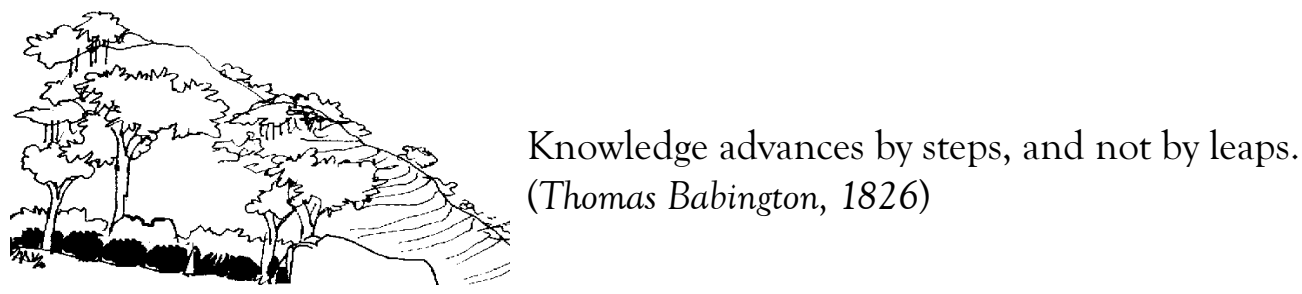


This chapter describes how the local people and the stakeholders were facilitated to use the ACM approach. We depict the local issues identified, the processes, and the tools used by the local people in handling the issues. We also highlight the outcomes of their efforts and the elements of ACM that were activated in the process.

In the first six months of ACM in the Palawan and Bukidnon sites, we familiarised ourselves with local conditions. We immersed ourselves in the villages, and built trust with local communities and other stakeholders.

We collected initial information about our key stakeholders and their interactions. In addition, we also collected information related to the biophysical and socioeconomic conditions of the area, level of collaboration and adaptiveness, and other relevant information. We applied both traditional and participatory data collection methods. The latter was used as much as possible so the necessary rapport between our researchers and local people could be built.

After the community immersion period, we initiated a participatory process to engage the PO, community members, and other local stakeholders in identifying and prioritising key issues that they would like to address in a collaborative and adaptive manner.

In a series of workshops and small group discussions, we brought together the POs and key stakeholders to identify their concerns with regard to CBFM and subsequently, to strategise their actions to address those concerns in a collaborative and adaptive way. This participatory methodology allowed members of the POs and representatives of local stakeholders to engage actively in:

- Identifying their problems;

- Planning together on how to address problems;

- Implementing the agreed strategies collectively;

- Monitoring their actions and learning from them; and

- Adjusting their management strategies accordingly.

\section{Prioritisation and focusing on key local issues}

As the first step in the planning process, we used the vision-type scenario building technique. Visioning is used to assist people to anticipate the future by stimulating them to think creatively and break away from their usual ways of thinking, or their 
mental models of how things work, so that they can deal better with complexity and uncertainties. ${ }^{64}$ In the workshop, we assigned the participants into several groups. We asked each group to produce a shared vision of the ideal future by drawing an illustration of this vision on a large sheet of paper. Once the visions were drawn, we held a discussion session to identify and discuss commonalities and differences among those visions, and in particular to find out whether there were indeed different visions among different groups.

The group's vision can be regarded as the goal or the direction in which the group members would like to move towards. Nevertheless, the vision needs to be further broken down into more specific components or conditions that would allow the participants to assess how far they are in achieving their goal. To help organise the participants' ideas on their future ideal conditions, we then introduced a tool called 'Criteria and Indicator (C\&I) framework for Sustainable Forest Management'. This framework can be used to describe, conceptualise, organise, and interpret information. The C\&I framework is usually composed of a hierarchy of Principles, Criteria, Indicators, and Verifiers. ${ }^{65}$

The participants were subsequently asked to identify components of their earlier drawn visions. Similar components were grouped together and a heading or theme was assigned for each group. In Palawan, the participants (consisting of $\mathrm{PO}$ members, community groups, and representatives from DENR, City ENRO, and local NGOs) identified the following themes: education, organisation, livelihood, forest and forest management, coastal resource management, infrastructure (including irrigation and electricity), health, and policy.

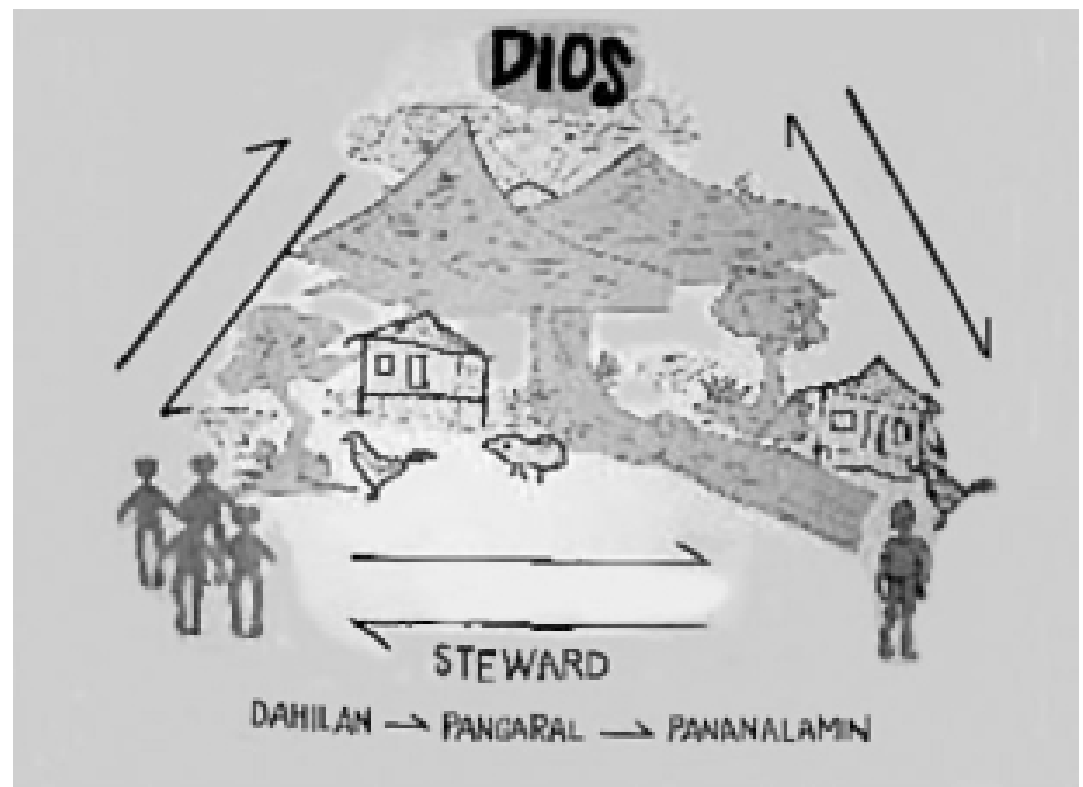

CBFM stakeholders envisioned themselves as a community that maintains good interactions among themselves and with God, and that they could take care of the environment. 


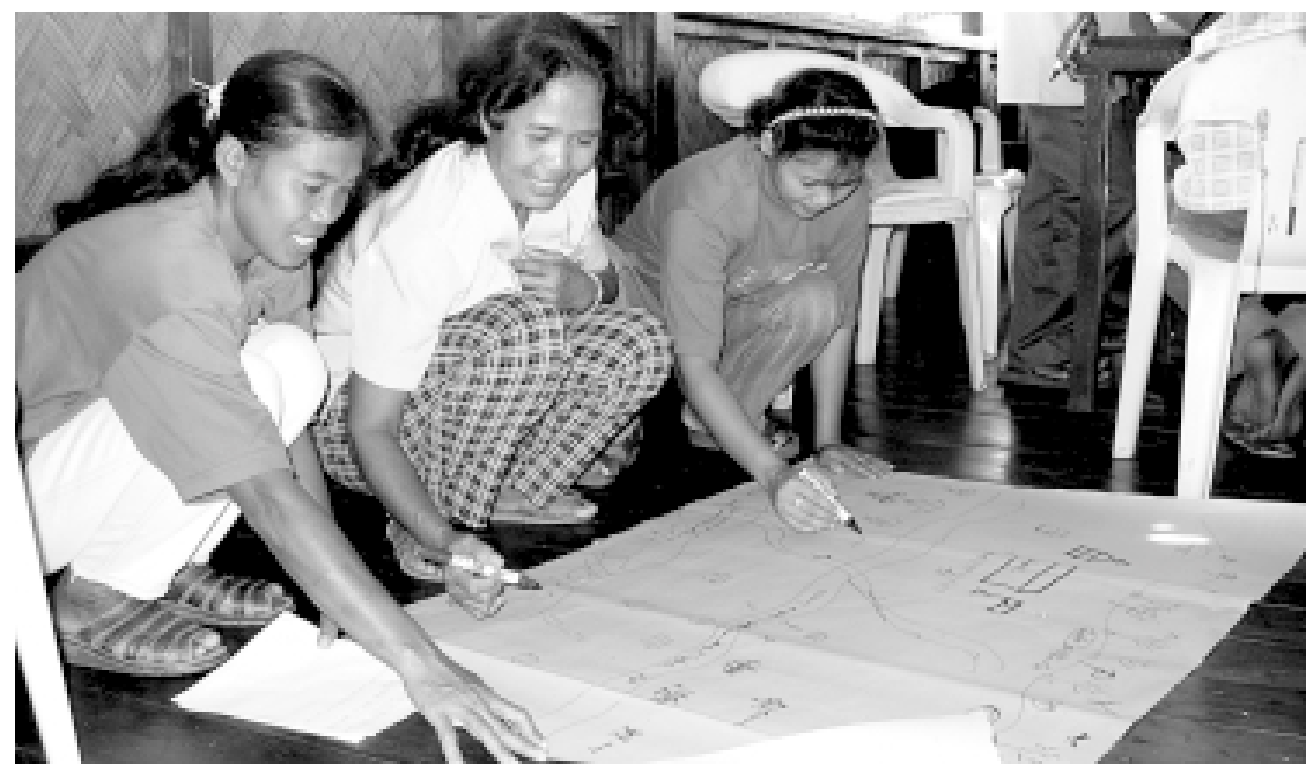

Participants in the Palawan C\&I workshop assess their current conditions against ideal aspirations in identifying local priority issues.

Once those themes were identified, the participants worked in groups to to further identify the specific conditions that would describe the ideal conditions of the corresponding theme. These specific conditions were later further broken down into smaller units which could be measured or observed in reality. These processes produced a three-level Criteria and Indicator (C\&I) framework, with themes as the criteria.

An analogy with a tree structure was used by ACM facilitators to explain the structure of $C \& I$ framework and to help the participants in understanding how the high levels of the C\&I (for example, 'Criteria') relate to the lower levels (for example, 'Indicators'). The trunk was used to describe criteria, branches described indicators, and leaves described verifiers. An exercise was also conducted in which the participants were grouped and asked to build a house that is 'big', 'strong', and 'beautiful' using plastic straws. They were then requested to select one house among other houses that met the three criteria. This exercise provided an opportunity not only for establishing team work among participants but also for creating a lively discussion on the indicators for the three criteria, the meaning of indicators and criteria, and how they relate to one another.

After this, the participants subjected the C\&I framework earlier produced to an assessment of their current conditions as against ideal conditions. We used a descriptive scoring system using an egg, a chick, and a chicken as symbols. The existing conditions that scored low (i.e., egg) were those that needed improvement. As the 'weak' conditions were still numerous and therefore could not be addressed all at the same 
time, the PO prioritised them using the following criteria: those that respond directly to the needs of the people, those that the PO can address with its current skills and resources, and those that can help the PO comply with DENR CBFM requirements.

While Palawan used a descriptive approach in prioritising local issues, Bukidnon used a more structured approach. The ones that were scored low were further assessed based on their importance and urgency. Those that were important but not urgent, urgent but not important, or neither important nor urgent were put aside for the time being. The workshops to identify and prioritise local issues were also conducted three times to capture the interests of different POs in the community.

\section{Key local priority issues}

Using the above described processes, the $\mathrm{PO}$ in Palawan identified six local priority issues while the $\mathrm{PO}$ in Bukidnon prioritised four issues as follows:

\section{Palawan}

1. Conflict on boundary delineation of CBFM area with the neighbouring Batak CBFM area

2. Lack of support from barangay leaders for CBFM

3. Low participation by the $P O$ and community members in CBFM implementation

4. Some government policies hindering CBFM implementation

5. Lack of a collaborative monitoring system

6. Lack of alternative livelihood options

\section{Bukidnon}

1. Lack of alternative livelihood options

2. Lack of medicines at the barangay health centre

3. Weak CBFM implementation

4. Poor local governance

\section{Who took part in addressing the local priority issues?}

In Palawan, the PO Board of Directors (a total of nine people) decided that they would be the main group who would address the local priority issues on the part of the local communities. They were the main group who engaged in every step of the ACM process. Other community groups and local stakeholders were invited to take part in the process. Several venues were also held to share the progress of the $\mathrm{PO} B \mathrm{BD}$ in handling the local issues with the wider communities and local stakeholders.

In Bukidnon, we proposed to the $\mathrm{PO}$ to create groups composed of the $\mathrm{PO} \mathrm{BoD}$, the women's group and other barangay residents to address the four issues identified. 
We believed that this way, more people could participate in the process. Each group was then assigned to be in charge of an issue dealing with a specific concern.

Membership in the groups was open to everyone who was interested in participating. Each group consisted of around 15 people. Relevant local stakeholders, such as DENR Integrated Protected Area System, municipal government, etc., were invited to take part in the whole process. Just like in Palawan, some of them did take part although not throughout the process. Several venues to share the progress with a wider audience were also arranged.

\section{How ACM processes were activated and facilitated}

Once local priority issues were identified and the groups who would handle the specific issue were formed, ACM researchers explained about the learning processes that the groups would go through in addressing the local priority issues. The learning loop was presented and explained. To assist the $\mathrm{PO}$ in handling the local issues, the researchers then facilitatated a series of small group discussions to reflect on the causes of the problem, past experience in handling the issue, and why previous attempts had failed. At this stage, we used methods such as Problem Tree Analysis, causal diagram (webbing technique), or Delphi technique (using coloured papers/cards) to facilitate the discussion in a more structured and participatory way.

After the causes of the problems were identified, the group then strategised their next actions. They were encouraged to identify several possible strategies (taking into account their past experience and the current conditions). Then they assessed the strength and weakness of each strategy. SWOT (strengths, weaknesses, opportunities, threats) analysis was introduced at this stage so that the group could decide the most suitable strategy to apply and understand that the strategy might produce the intended results under certain conditions.

The group then decided what actions should be carried out, by whom, and when. After the actions were carried out, they monitored the outcomes, and came together again as a group to reflect on the outcomes and decide their next action. By doing so, they gradually made changes and adjusted their strategies while learning and understanding throughout the process the consequences of their decisions and actions.

To illustrate the above general processes, we describe in the following sections how the PO and local stakeholders in Palawan and Bukidnon addressed some of their local issues. We have purposely presented the issues that have gone through several learning cycles so the readers can see how the strategies evolved over time. 


\section{Managing a CBFM area boundary conflict}

In the ACM Palawan site, DENR has awarded CBFM agreements to two neighbouring POs: the STCMPC and the Batak indigenous people. The STCMPC CBFM area covered 1000 hectares in the three villages of San Rafael, Tanabag and Concepcion. The CBFM Agreement was later expanded to a total area of 5,006 hectares. The Batak CBFM area is some 900 hectares and is adjacent to the CBFM area of the STCMPC.

When the area tenured to STCMPC was expanded in February 1997, no survey was conducted and there was no map made to indicate the boundaries of the new area. Only the original 1000 hectares had a complete survey. Later in 2000, Haribon (a local NGO assisting the Bataks) claimed that the Bataks were deprived of their rights over almaciga extraction and indicated that the areas of the two CBFMs overlapped. At that time, the Bataks were not allowed to extract resins as they still had to sort out the technical complications of the renewal of their extraction permit with the DENR. On the other hand, STCMPC then was able to renew their extraction permit. Furthermore, the Bataks reckoned that the area where they had been collecting almaciga in the past and their village were included in the expanded STCMPC CBFM area.

\section{Solving the delineation problem}

To solve this boundary delineation issue, we facilitated the $\mathrm{PO} B \mathrm{BD}$ to reflect on the causes of the problem and strategise how to handle it. They thought that the problem would be solved if they could show the Bataks the map showing that their CBFM areas did not overlap. Assuming that DENR may have the appropriate maps showing the location of the two CBFM areas, they decided to request DENR to check on the existing map to see whether or not the boundaries of the two CBFM areas overlapped.

Their first action showed that there was no such map in DENR. Learning about this fact, they decided to seek assistance from the Palawan Tropical Forest Protection Project to obtain complete global positioning system (GPS) coordinates of their CBFM area boundaries. In response to this request, a survey of the CBFM boundaries was done collaboratively by STCMPC, DENR, and Palawan Tropical Forest Protection Project in March 2001. This resulted in a clear delineation of the STCMPC CBFM area, which was marked on the ground (using natural features, such as rivers, caves, etc.) and on the map. It should be noted, however, that representatives from the Batak PO and LGU were not able to respond to the PO's invitations to participate in the survey.

When the map of STCMPC CBFM area became available, several representatives from the $\mathrm{PO} \mathrm{BoD}$ conducted a dialogue with the Bataks and presented the result of 


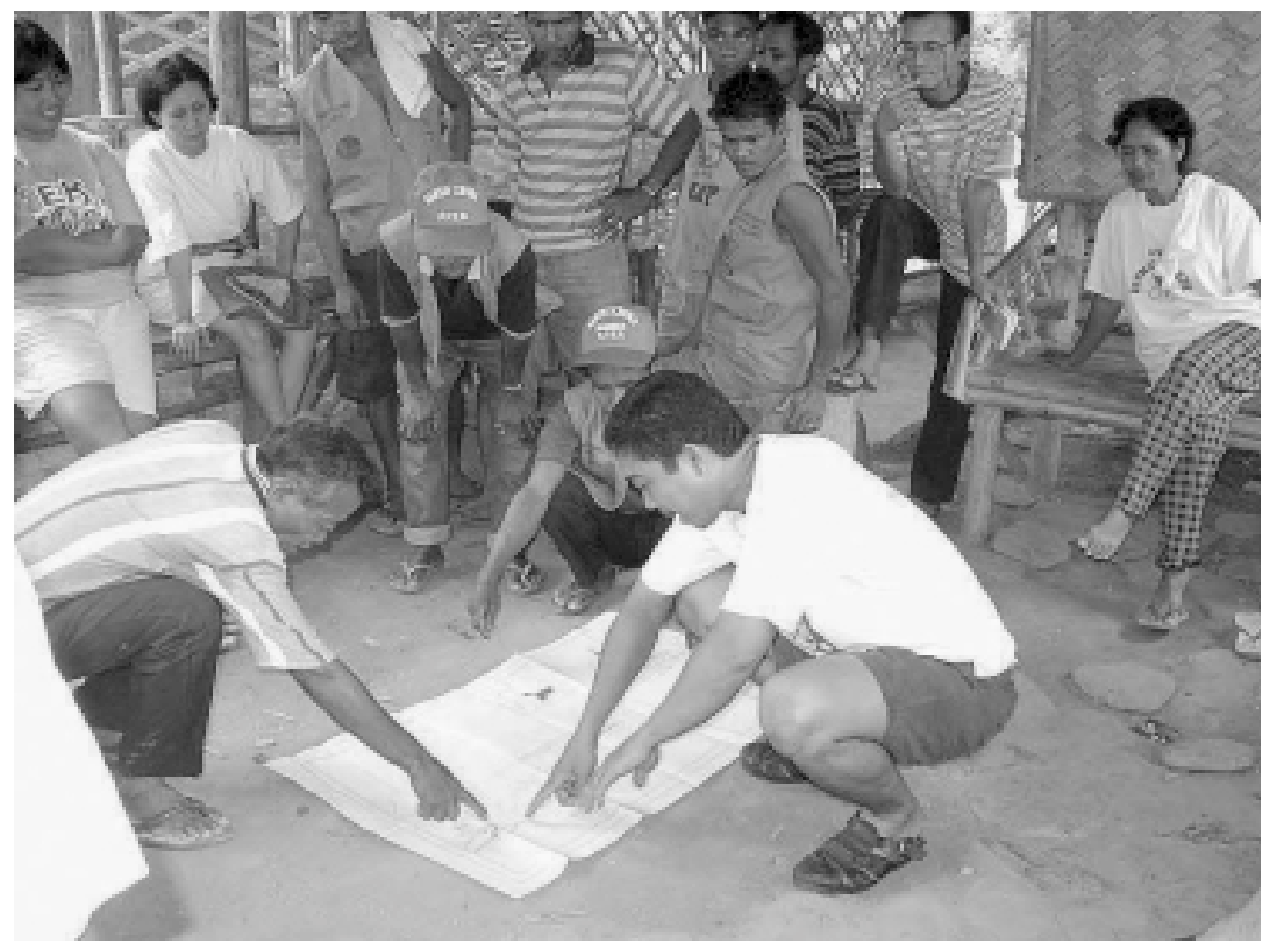

The STCMPC and the Batak PO resolved their boundary conflict. DENR CENRO and a local NGO participated in the dialogue.

the survey to them. The dialogue was facilitated by the DENR Site Coordinator. From the ensuing dialogue, it appeared that the map was not useful or effective in explaining to the Bataks where the two CBFM areas were located as the Bataks had a different concept of land boundaries. Furthermore, they learned that the conflict linked with the Bataks' problem in almaciga collection. The PO BoD decided that a map showing the boundaries of both the Batak CBFM area and the STCMPC area was still needed for future use, and they requested such a map from DENR. Nevertheless, they reckoned that they can solve the conflict by assisting the Bataks in dealing with their livelihood problem.

The group then negotiated an arrangement whereby the Bataks could extract almaciga resins in the STCMPC area as long as they sold resins to STCMPC, and the latter would purchase the resins at a competitive price. STCMPC provided a price margin per kilogramme of at least one half to one Philippine peso higher than the price offered by the local traders. STCMPC's assistance to the Bataks in terms of establishing a cash transaction was perceived to be a better arrangement. Previously, the Bataks bartered their almaciga resin for rice, coffee, or tobacco. In this arrangement, the Batak almaciga resin was valued at a very low level. The two POs further agreed that they would be partners in forest protection activities and would collaborate in other livelihood efforts. 
In anticipation of other possible conflicts in relation to the almaciga trading in the area, the group later conducted a dialogue with almaciga traders. The group explained to them the legal aspects of collection, selling, and buying of almaciga resin. They also discussed their CBFM activities and the permit they received from DENR to utilise forest resources. As a result of this dialogue, some of the traders agreed to coordinate and offered a royalty to STCMPC for extraction of resins from the CBFM area. Others, however, continued with their illegal activities.

The STCMPC also coordinated with the barangay council and the DENR field monitoring checkpoint on this matter. The PO's committee on almaciga business used their monitoring data to report incidents of illegal activities to DENR. The members wrote an article in their local newsletter exposing such activities that prompted DENR to conduct an investigation. As a result of these efforts, illegal transactions have been minimised within and adjacent to the STCMPC CBFM area (see Figure 3 for the whole $\mathrm{ACM}$ process that the $\mathrm{BoD}$ undergone in addressing this issue).

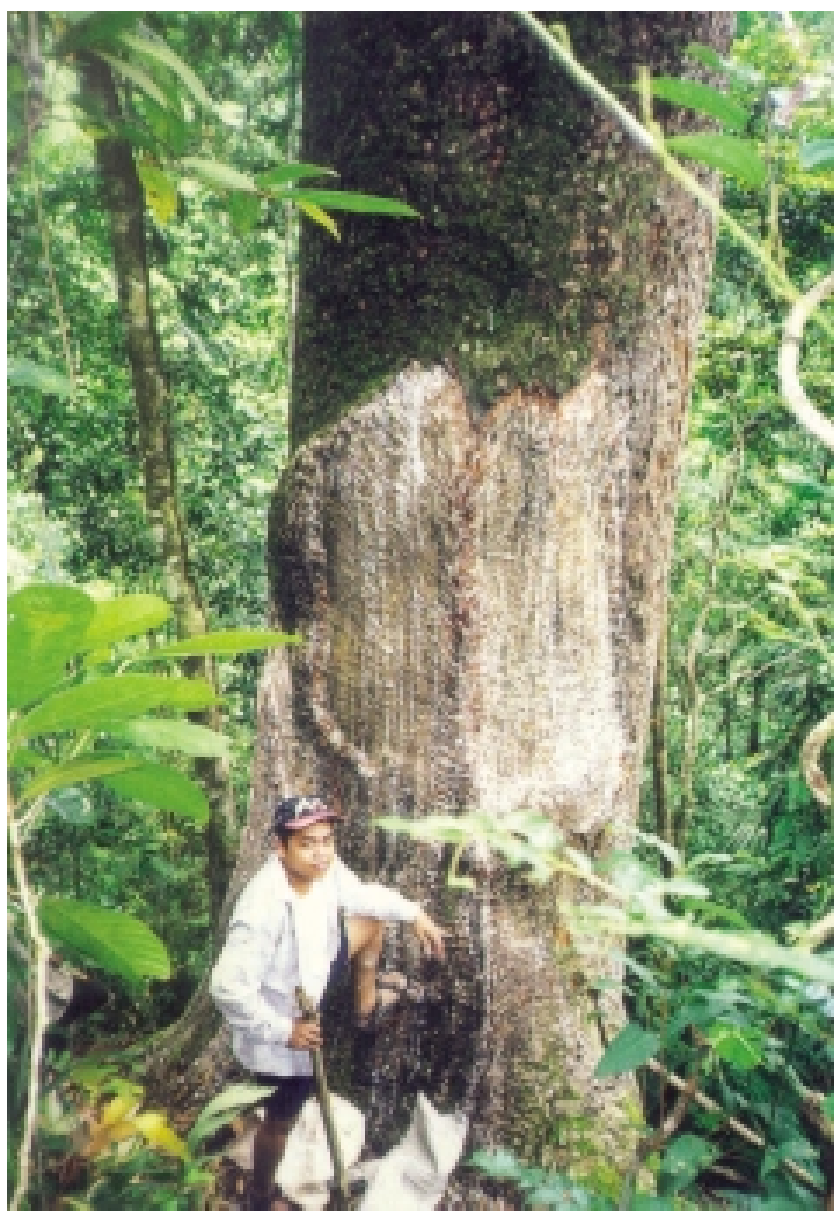

Resin from the almaciga tree is an important source of livelihood for many stakeholders. The Bataks have traditionally collected resin in the forest. They usually barter this for such necessities as rice, coffee, and other crops where they get very low value for their resin. STCMPC initiated a transaction arrangement that gave the Bataks a better price than that offered by local traders. 
Figure 3. The ACM process in addressing a CBFM area boundary conflict

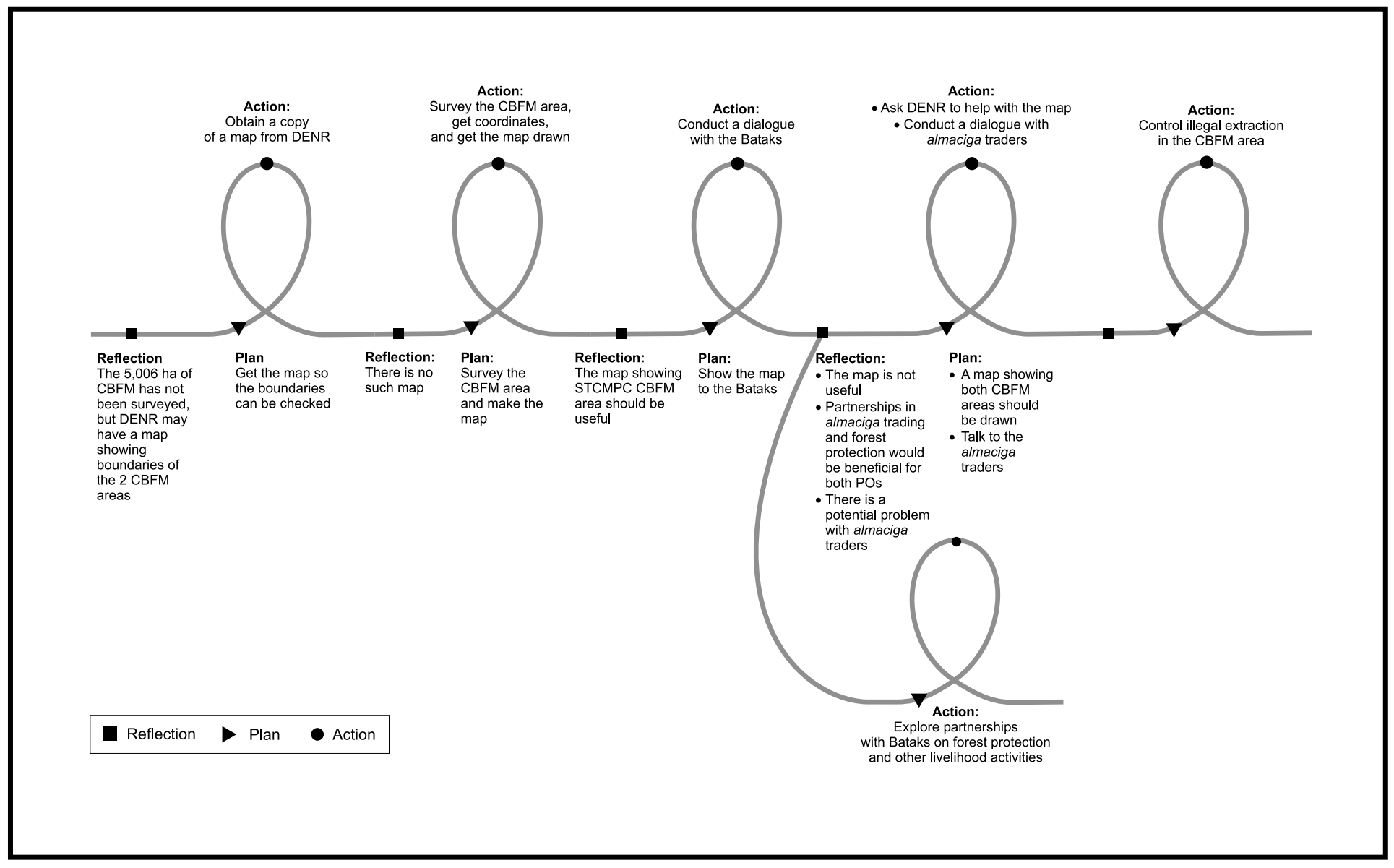




\section{Some encouraging results}

We have observed the following results of the STCMPC-Batak PO conflict resolution:

- STCMPC and Batak PO members have better sharing of information about indigenous knowledge, specifically on how to properly collect resin and on identification of herbs in the CBFM area.

- Batak PO members were invited by STCMPC to participate in livelihood training activities such as handicraft making and nursery establishment.

- There is better coordination between the two POs in terms of reporting illegal activities, such as cutting of fresh trees, and illegal almaciga collection and trading.

From the ACM perspective, these results were apparently brought about by increased collective action within STCMPC and across stakeholders to solve the boundary issue. Six PO members, representatives from Palawan Tropical Forest Protection Project, and DENR did the boundary delineation jointly. The dialogue between STCMPC and the Bataks was also attended by DENR and Enterprise Works Worldwide. Initially, only STCMPC, the Bataks, and Haribon addressed the issue, as there was no attempt to involve other stakeholders.

The issue was solved successfully because there was a sufficient level of trust between the STCMPC and the Bataks, despite the conflict, that allowed them to discuss the problem openly. Furthermore, around 33 Bataks were also members of the STCMPC and some of them were employed by STCMPC in their lumber operations before.

\section{Activation of ACM elements}

In addressing the issue of boundary conflict, several ACM elements were activated as shown in the box below. In particular, the processes activated mechanisms to deal effectively with conflicts. As described earlier, STCMPC tried different mechanisms to solve the conflict with the Bataks. The critical aspect was when they creatively addressed the problem by coming up with a new working arrangement with regards to resin extraction and trading that seemed to be beneficial for both parties.

\section{ACM ELEMENTS ACTIVATED}

- Communication between the members of the same group or between different groups to share information.

- Collective planning and decision making.

- Collective action to carry out collectively agreed plans.

- Social learning.

- Incorporation of lessons learnt to refine management practices.

- Presence of mechanisms to deal with conflicts. 


\section{Strengthening communication through newsletters}

In Palawan, one of the problems the $\mathrm{PO} \mathrm{BoD}$ identified was that only a few $\mathrm{PO}$ members were actively participating in CBFM activities. During reflection, the group attributed this low participation to:

- People's expectation for economic benefits from CBFM which had not been met by the $\mathrm{PO}$ due to the difficulties they encountered;

- Lack of clear orientation on CBFM; and

- Lack of regular updated information about the on-going CBFM activities in the area.

As their first strategy, the group decided to produce a newsletter. The first issue of the newsletter called Balangaw (rainbow) was produced by the general manager, the chairman of the $\mathrm{BoD}$, and the forester. It was then distributed to other $\mathrm{BoD}$ members and other STCMPC members. The newsletter was well received. PO members and the LGU said that it was a good way of providing them with CBFM updates. As observed in the first issue of the newsletter, it provided a clearer concept about the vision, mission and objectives, and the importance of CBFM in the community. It became a useful tool in reaching out to more $\mathrm{PO}$ members.

In the reflection session that followed, the group felt the need to organise an editorial team to handle the newsletter writing and production. Subsequently, the editorial team, consisting of 7 people ( 3 women and 4 men) was formed. Further discussions and planning recommended that a training on writing editorials and other articles for the newsletter be held to equip the team with appropriate skills. Furthermore, it was expected that the training could enable the team to apply a more popular and interesting format for the newsletter. This was based on observations that the newsletter readers do not prefer to read text, some could not read, and others just wanted to look at pictures.

To act on the above needs, a hands-on-training programme on news and editorial writing was conducted by ACM researchers for $13 \mathrm{PO}$ members ( 9 men, 4 women). This training was conducted as part of the agenda of the $\mathrm{PO}$ meeting to assess the progress of their operations.

After the training, the second issue of the newsletter was published, containing all the information written by officers and other community members who attended the progress assessment and the training. More pictures were included in this issue and in the succeeding ones. At present, 50 copies are produced and distributed to other local stakeholders like DENR, the city government, barangay councils, NGOs, and others. 
Reflection after the third issue of the newsletter revealed to the BoD the need for more formal training in newsletter production focusing on layout. The majority of the editorial team, however, believed that by making do with what they had and by actually doing the production themselves, they could learn and improve their skills in the process.

Nevertheless, two women and a male PO member were coached by ACM researchers in typing the articles with a computer and doing the layout in response to their previous request. This was done so that the editorial team could handle the newsletter preparation and production themselves with less assistance from the ACM researchers. Early in the process, ACM researchers assisted in the collecting and typing the articles, printing and photocopying the newsletters. Later, more and more tasks were handled by the $\mathrm{PO}$ members themselves. In the subsequent fourth to sixth issues of the newsletter, we assisted the $\mathrm{PO}$ editorial team in doing the newsletter layout only.

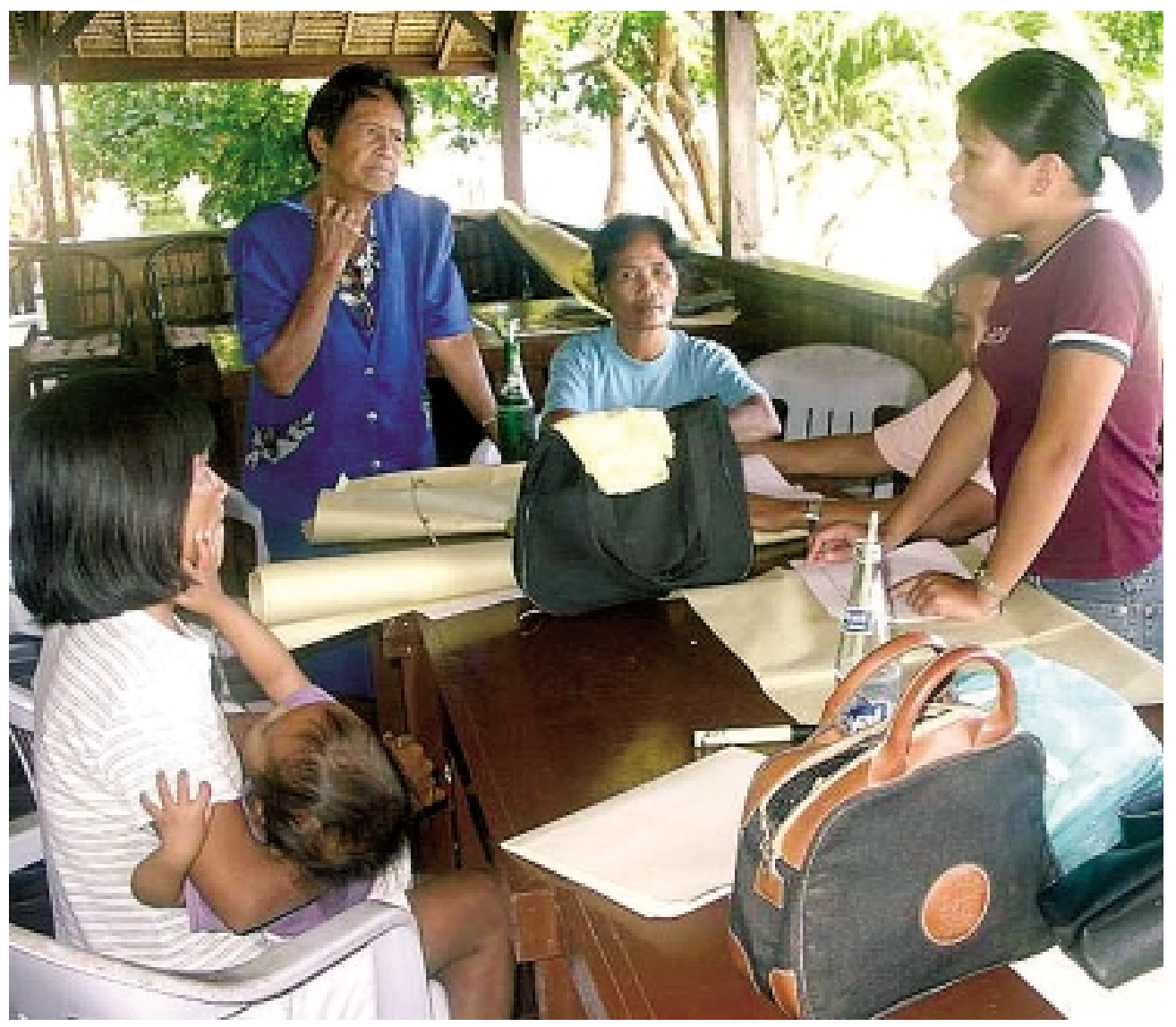

The editorial team believed that by actually doing the production themselves, they could learn and improve their writing skills in the process. 
Figure 4. The ACM process in strengthening communication to enhance participation by the PO and community members in CBFM implementation

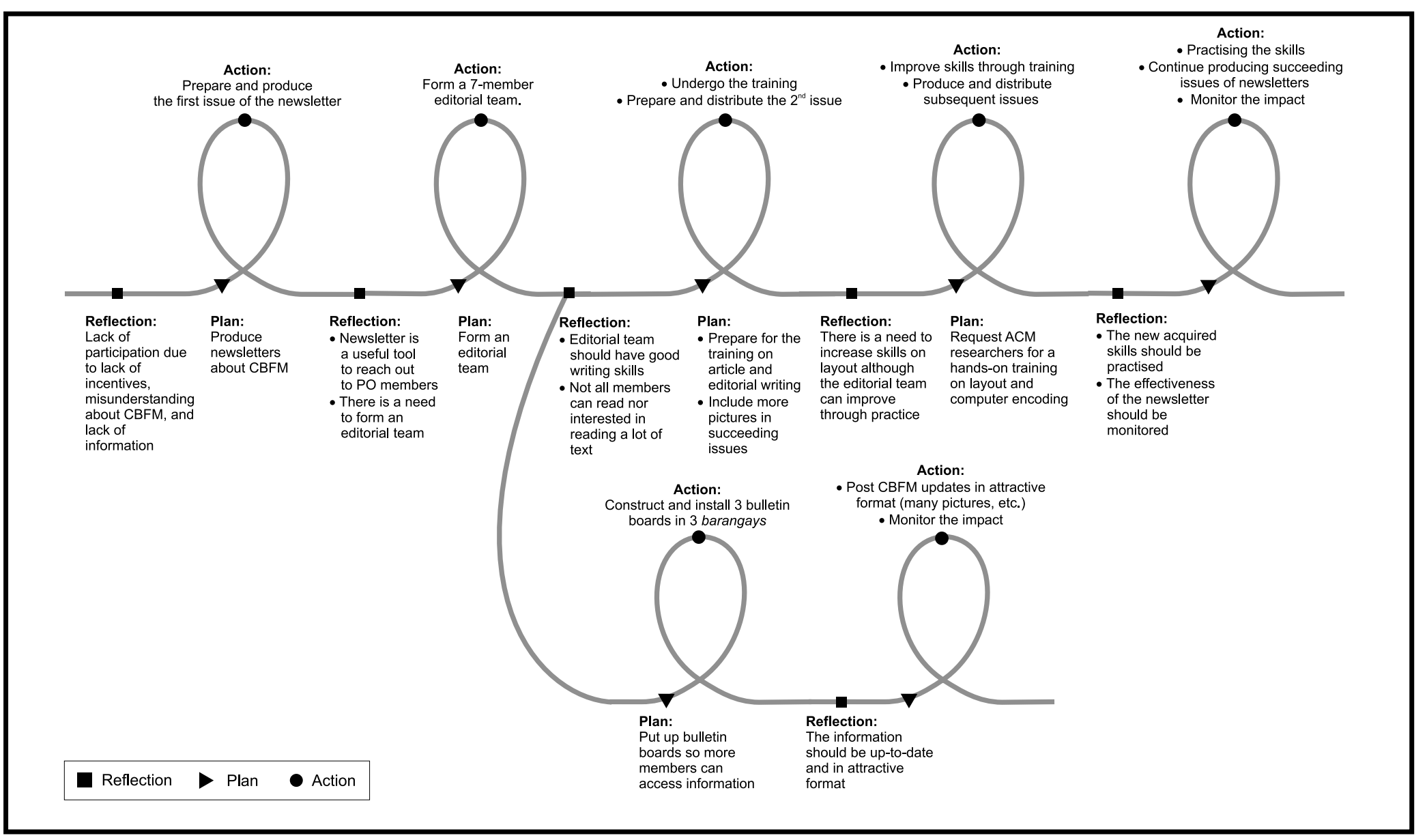


Another initiative that the $\mathrm{PO} \mathrm{BoD}$ undertook was the construction of bulletin boards. This was done as they realised, based on their observations, that not all members are literate and some preferred just to look at pictures rather than text. The group acted on these observations by putting up three bulletin boards, one in each barangay, at strategic places such as sari-sari stores in Concepcion and Tanabag, and in areas near the waiting shed in San Rafael. Just like the newsletter, the bulletin boards contained information on CBFM, photographs of activities undertaken, data on forest products being extracted, etc.

In the latter part of 2002, the PO made use of the bulletin board to post the observations about the seed germination experiment. They also posted the name of the person responsible for day-to-day maintenance of the nursery, such as watering the seedlings, noting down observations, etc. Figure 4 shows the whole process that the $\mathrm{PO} \mathrm{BoD}$ undergone in enhancing information sharing.

\section{Some encouraging results}

Newsletter writing provided a good opportunity for $\mathrm{PO}$ members to write and voice their opinions, share dreams, and even build up confidence in public speaking. The $\mathrm{PO}$ members told us that they were more confident of what they were saying as the newsletter provided the documentation that supports what they said.

Six issues of Balangaw were produced up to August 2002. Around 13 PO members are capable of maintaining the newsletter production and updating the bulletin boards. The $\mathrm{PO}$ has planned to involve teachers and out-of-school youth and establish linkages with local government units in this effort. Furthermore, they also planned to request air time on a local radio program (Radyo ng Bayan) for them and DENR to explain and provide updates about CBFM activities.

As more information and update about CBFM were disseminated more widely through the newsletter and bulletin boards, the PO BoD observed, as time went by, that more people stopped by the bulletin boards and visited the STCMPC office. Community members asked for some clarification and requested that information on training and other activities be posted on the bulletin boards so they would know when and how to participate in future training or other activities. It was expected that with increased interest and understanding of CBFM and the $\mathrm{PO}$ activities, more members would be encouraged to take part actively in CBFM implementation.

\section{Activation of ACM elements}

In addressing this issue, several ACM elements were activated. The one that was activated the most was communication and information sharing. Through newsletters and bulletin boards, the $\mathrm{PO}$ BoD communicated with their members in particular, 
and with other community members and local stakeholders, such as DENR, LGUs, etc., in general. The $\mathrm{PO}$ not only used communication mechanisms more effectively but they also used different mechanisms to reach out to different audiences.

\section{ACM ELEMENTS ACTIVATED}

- Communication between the members of the same group or between different groups to share information.

- Collective planning and decision making.

- Collective action to carry out collectively agreed plans.

- Social learning.

- Incorporation of lessons learnt to refine management practices.

\section{Creating better livelihood opportunities}

Many members of the CBFM community at our Palawan site had expected that the lumber operation of the STCMPC would serve as an economic pump priming activity. They had hoped that the profits generated from the lumber operation would be invested in other livelihood options for members, and the community in general. However, this did not work as expected. The STCMPC did not produce enough capital from its lumber operation because their product could not compete with the cheaper lumber (extracted illegally) in the market.

The majority of the PO BoD members decided, based on their reflection and feedback from other members, that they would explore other livelihood possibilities (see Figure 5 and 6 for the overall process). Two BoD women then led seven PO members in exploring available options. They realised that they had to explore other forest resources that could generate income. They decided as their first strategy to learn from other POs who had been successful in generating incomes.

In July 2001, we assisted the group in visiting two CBFM areas in Nueva Vizcaya province in Luzon. These are located in the municipalities of Sta. Fe, Bayombong and Solano. Sash contractors and multi-purpose cooperatives in these CBFM sites are assisted by the USAID-funded CASCADE project and the Department of Trade and Industry. Twelve $\mathrm{PO}$ officers and members, and one representative from the community-level DENR participated in this activity. The cross-visit proved useful as the participants were able to exchange ideas with the host CBFM implementers and learn from their experience. The group became aware of the importance of properly managing and protecting the forests to ensure sustainability of the resources. Upon their return to Palawan, they planted 160 Gmelina seedlings within the CBFM area. They planned to continue planting more trees at a later stage. 
On subsequent reflection, the group realised that they would need a local partner with financial resources to help them start a woodwork business. This was one of their earlier plans which was not implemented due to a lack of financial capital.

The Budyong Rural Development Foundation Inc., a local NGO, later approached them to set up a partnership in woodwork production. The foundation then presented to the $\mathrm{PO}$ a draft Memorandum of Agreement (MOA) to formalise their partnership. Reviewing the draft MOA, the group realised that the provision on profit sharing was not fair for them. Furthermore, there was no provision on transfer of skills that would allow them to do the business on their own at a later stage. Through a series of negotiations, they reached a new agreement and the partnership began. The PO would supply 500 board feet of lumber every month, while the NGO would provide the necessary equipment and a mentor who would train the PO members in woodworking. The business operation started in August 2002.

\section{The women pitch in}

Encouraged by what they learned in the cross visit, a small group of twelve women started analysing their past livelihood efforts. They first reflected on why their attempts failed in such activities as weaving of pina cloth (made from pineapple leaf fibers) and raising pigs and poultry. Based on this reflection, they decided to look at different options that best suited their interests. They decided that the options should utilise abundant resources in the area, and be initiated at a small scale without major financial investments.

At the same time, one member of the group knew of a PO member who could share her skills in weaving nito (Lygodium circinatum) into products such as flower vases, wall decorations, pack bags, jars, and utility cases. The group then decided to conduct a training programme. They approached the Department of Agriculture who later sponsored a trainer, identified by the $\mathrm{PO}$, to assist the group.

The first training with nine female participants was done in December 2001. The training not only aimed to improve their skills, but also to improve the quality of the products, explore new designs, and conduct trial marketing. The training on nito weaving continued every other month until April 2002. The women also collaborated with the Bataks to learn about their indigenous knowledge in making bags and winnows.

To ensure that their products would be marketable, the next step for the women was to explore the market in Puerto Princesa City. They observed what products were being sold, at what price, and the designs of the products. This was to complement their reflections in every training session. They realised that their products should be affordable, of good quality, and appealing in the eyes of the customers. To set the 
Figure 5. The ACM process in creating better livelihood options

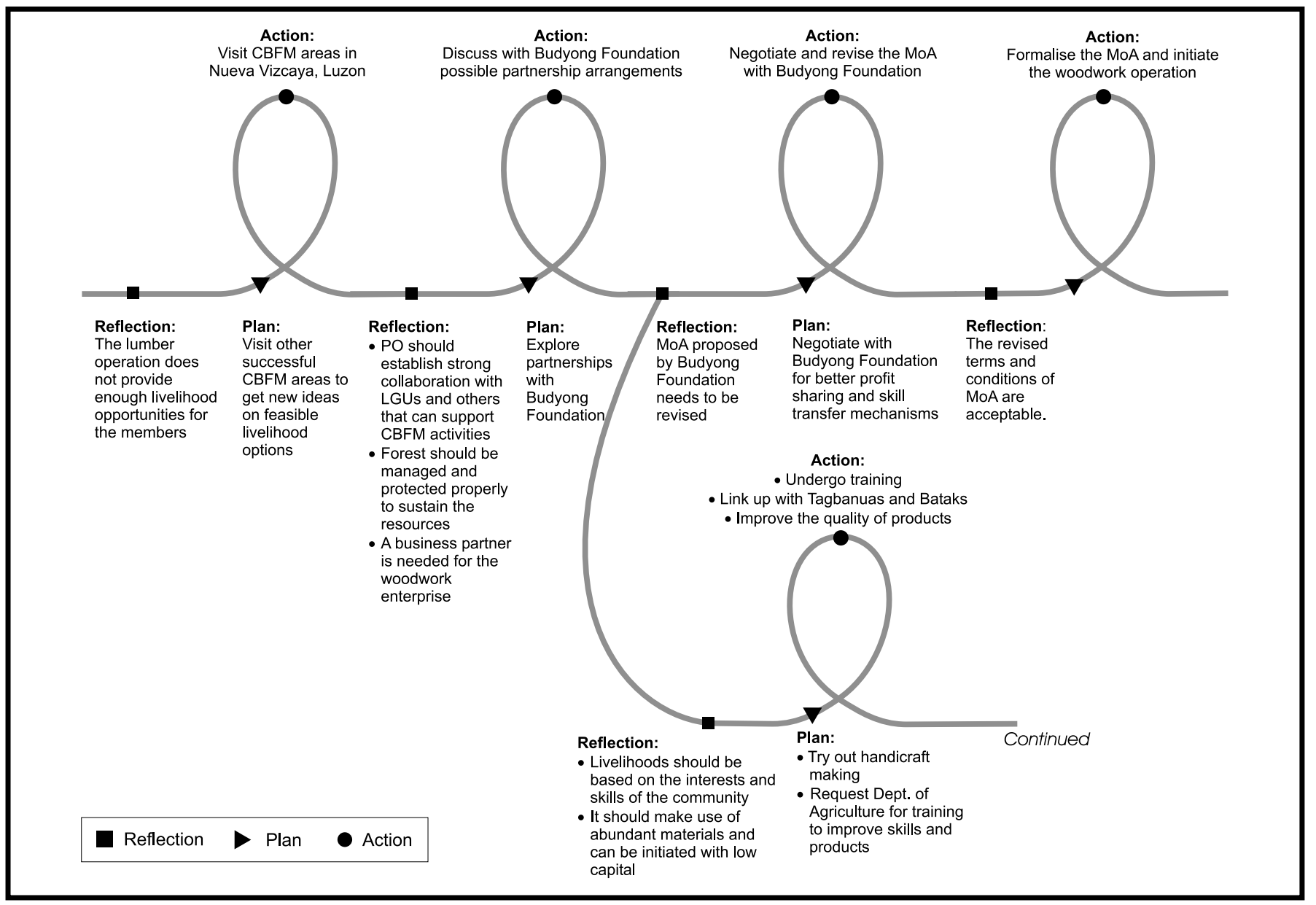




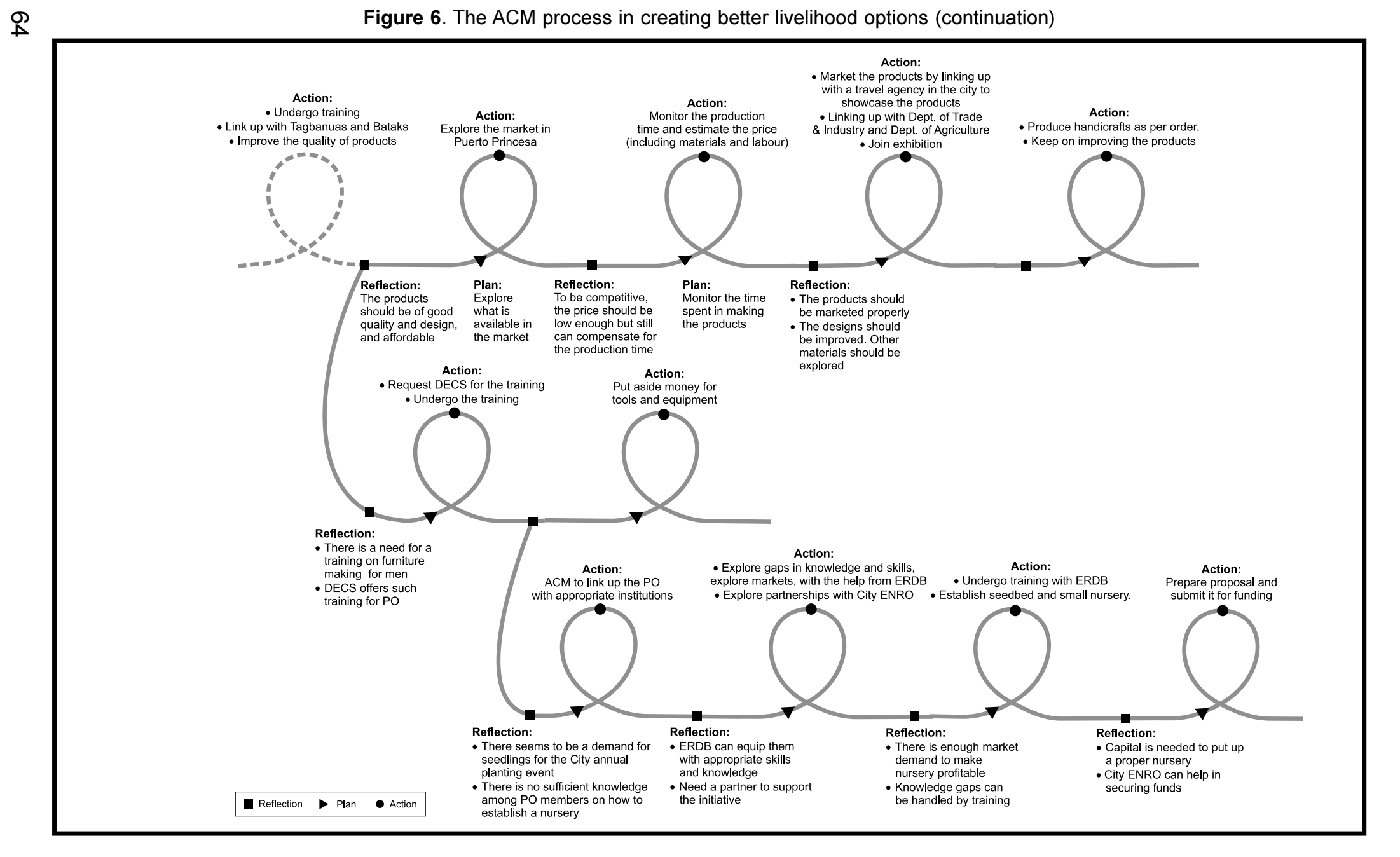




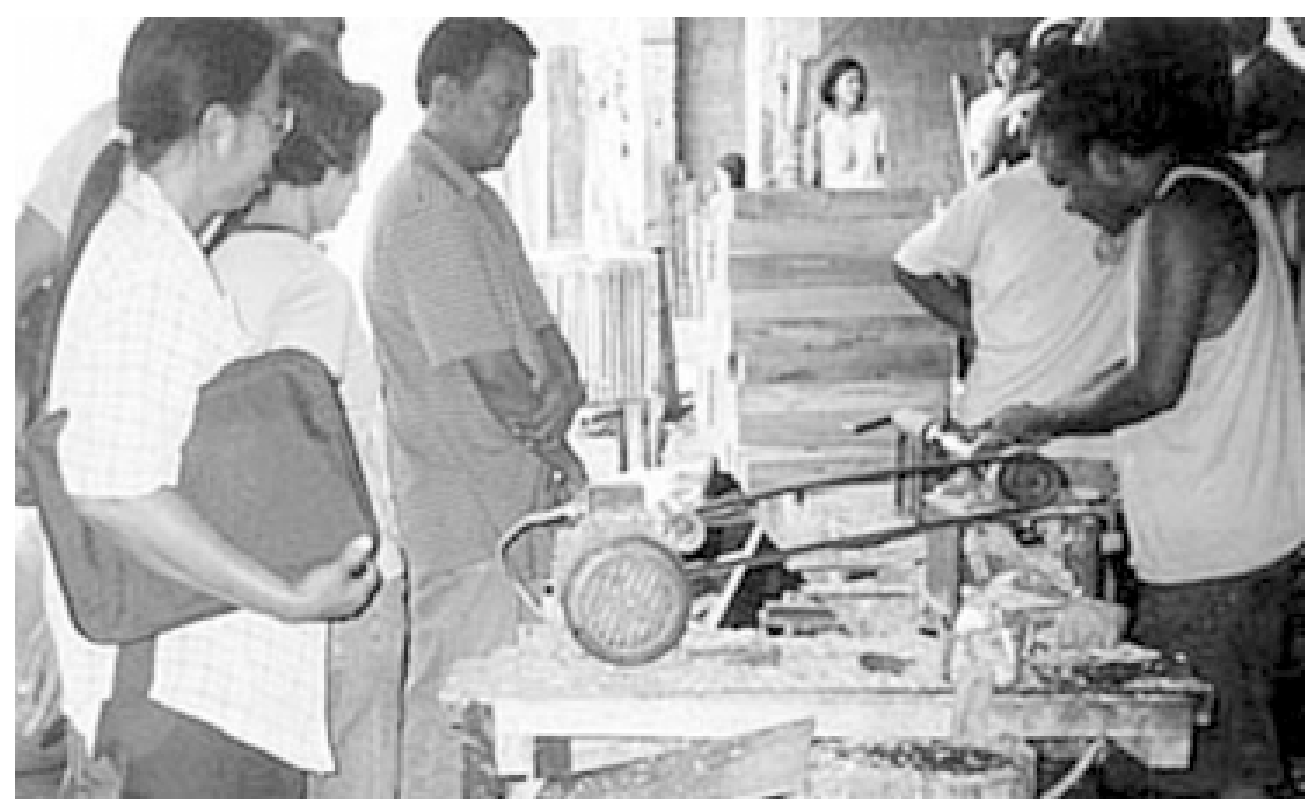

The STCMPC cross-visit to learn about the activities of another CBFM PO in Northern Luzon provided insights on other alternative livelihood projects that the $P O$ is exploring for its members.

price, they started to record the time needed to finish one product to find out if the price could compensate for their time while keeping it low enough to be competitive.

\section{Men are inspired}

In the first two series of weaving training, three men also joined the training. After each training, they shared what they learned and expressed that a similar training programme on bamboo or rattan furniture processing should also be conducted for the men.

Rattan furniture making was planned long ago but for one reason or another, it never happened even though rattan is abundant within their CBFM area. The group also realised that processing rattan into furniture would be more profitable than just selling raw materials.

In a short while, the acting general manager of the PO found out that the Department of Education, Culture, and Sports (DECS) was extending help to PO members by supporting livelihood training. The PO then requested this support from the DECS.

In February 2002, training for rattan furniture processing was held with nine men attending. Currently the PO is putting aside some money to buy necessary tools and equipment before they can start the production. They are also exploring linkages 
with several agencies that can help them in the marketing of their products.

\section{Trying out a new scheme: establishing a seedling nursery}

The women's initiatives in handicraft making continued to encourage members to explore other income-generating activities. Another possible income-generating option that the PO has been exploring is a seedling nursery. There is a market demand, as thousands of seedlings have been supplied and transported from Los Baños, Laguna province, for the annual planting event of the City Government.

Realising that they had little knowledge on how to establish a nursery and how to properly germinate seeds of certain species, they requested that we link them with institutions that could help them. As the first step, we approached the Los Bañosbased DENR's Ecosystems Research and Development Bureau (ERDB). ERDB has been undertaking research on seed germination and conducting training for many upland communities in the Philippines. Two ERDB staff visited the PO in early March 2002 to assess their training needs and to make a joint assessment with them on whether or not there would be sufficient local demand for seedlings to make the nursery profitable.

After this visit, the group further explored the marketability of seedlings in Palawan and seek support from the City ENRO. They learned that there are POs in Palawan who need seedlings to rehabilitate their CBFM areas and they also received a positive indication from the City ENRO. Based on these positive observations, the PO decided to push forward with the training programme. The training was held by ERDB (with the support of the ACM project) in September 2002 for 34 PO members (28 women and 6 men) and 7 non-PO members.

Realising that they could better develop their nursery if financial capital were available, the $\mathrm{PO}$, with assistance from the ACM researcher, developed a project proposal for funding. The City ENRO further improved the proposal and submitted it to the Fisheries Resource Management Program, a special programme of the city government. The proposal has been approved and the PO is just waiting for the funds to be released.

While waiting for this support, the PO started building a nursery right after the training with what resources it had and with its newly gained skills and knowledge. The PO put up the seedbed and the accompanying nursery and has started some experimentation on seed germination treatment for mangium (Acacia mangium), rattan and narra seeds. Currently, the plan is to collect some seeds for germination and sample seedlings of endemic species such as ipil, different species of rattan, narra, amugis (Anacardium edule) and others within the CBFM area for exhibition and identification. This effort is being coordinated with the Bataks and Tagbanuas who 

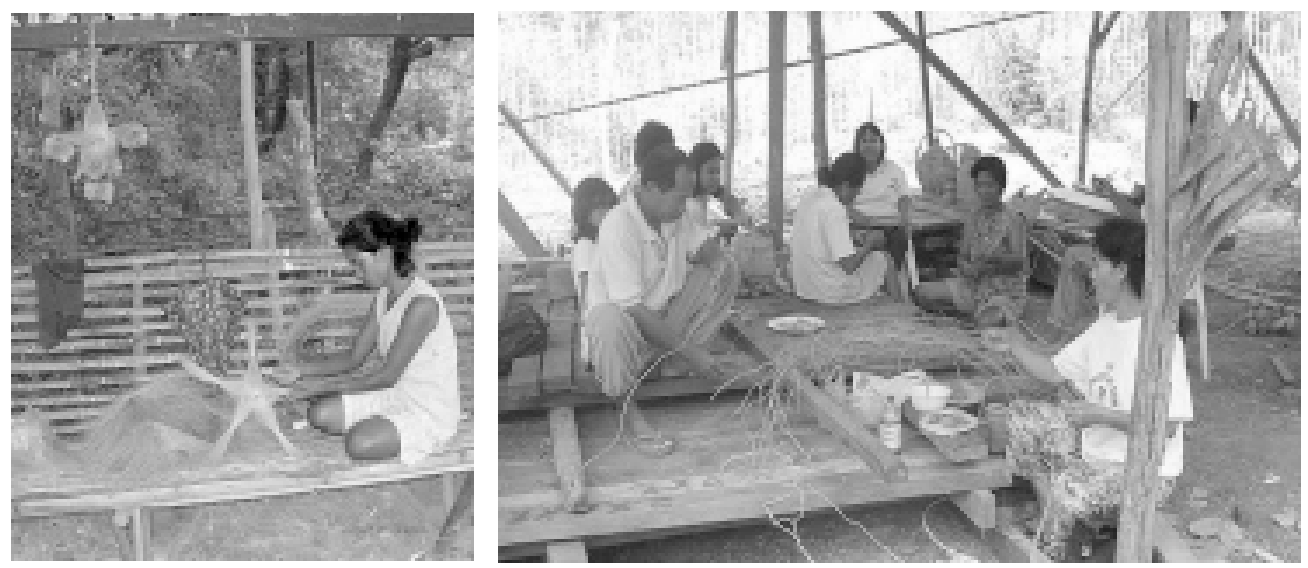

Realising that their lumber operation could not provide enough livelihood opportunites for the STCMPC members, the women initiated a nito handicraft venture that gave them a new source of income. While many of the men explored furniture making, some of the men also joined the training on nito weaving.

can share with the community their indigenous knowledge about these different tree species.

\section{Some promising results}

The women have generated around US\$160 from handicraft sales over a period of four months. Since their handicraft making is more at the household level at the moment, they planned to link up with STCMPC operations to help them in marketing the products. In June 2002, the group joined the Baragatan exhibit, a yearly celebration of the foundation of Palawan province. On this occasion, they made use of the booth provided by the DENR for displaying their products.

The group is also establishing linkages with relevant government institutions, such as the Department of Trade and Industry and the Department of Agriculture, for more innovative designs and finishing, and to explore other forest resources such as buho (Schizostachyum brachycladium) to make products like sleeping mats, place mats, bags, and slippers. From just depending on lumber operations, the group has diversified its options to include other under-utilised forest resources.

In addressing this issue, the group was also able to engage more members in exploring livelihood options and learning new skills. Most importantly, they brought together different community groups, in particular the Tagbanuas and Bataks.

Present challenges confronting them include benefit sharing among themselves and the PO and maintaining the sustainability of raw materials. 


\section{Activation of ACM elements}

In the above described processes, several ACM elements were activated. In particular, we would like to highlight the monitoring efforts of the women to determine the price and the marketability of their products.

In addition, diversification of the livelihood options was a clear example of how the group dealt with uncertainties with the markets. The group also dealt effectively with the gaps in their knowledge by experimenting with different germination techniques.

\section{ACM ELEMENTS ACTIVATED}

- Collective planning and decision making.

- Collective action to carry out collectively agreed plans.

- Effective decision making for complex and uncertain situations.

- Intentional learning and experimentation.

- Collaborative monitoring.

- Social learning.

- Incorporation of lessons learnt to refine management practices.

\section{Harnessing indigenous knowledge: The case for herbal medicine}

While the indigenous knowledge of Palawan's Bataks and Tagbanuas on local tree species can be harnessed as discussed in the preceding section, a very significant situation occurred in our Bukidnon site. This time, it was the indigenous knowledge of traditional medicine of the Talaandigs that propelled the success of a local herb garden that is now being used by the community.

As we have previously mentioned, four groups were created in the ACM Bukidnon site to address the four priority issues they had identified at the start of the ACM project. One of these groups was the health group composed of nine members of the all-women BUFAI Women's Association (BWA), the village health workers, and several mothers.

The health issue appeared since Basac has a high occurrence of illness and diseases. It has the second highest number of malnourished children in the municipality. Furthermore, the health centre was able to cater to certain health services only, such as prenatal examination, weighing babies, determining the incidence of malnourished children, and family planning (i.e., distributing 'modern' contraceptives). 
Tasked to address the health issue, the group initially looked at the health conditions in Basac. In a focus group discussion (using the Delphi technique), the group identified several problems. The most pressing one was the unavailability of both traditional and modern medicines in Basac.

In the past, the municipal health officer of the local government established a botica sa barangay, a store that sold modern medicine. At the start, the store went well; but later on it folded. What factors brought about the failure of the enterprise? The health workers who managed the store said that it did not work because of unpaid debts by the residents. With more probing, however, they came up with several reasons:

- No clear arrangements on how the store was to be managed.

- Lack of skill to manage the business.

- No clear monitoring mechanism for the enterprise.

The ACM facilitators identified another possible reason for the failure, i.e., that the proposed solution to the lack of medicine came from people outside of the community. It was never an idea of the residents.

Given the lessons learned from the past, how else could the problem be addressed considering that the government has no budget for the health workers to put up another botica? The women also asked: What good would a nice health center building and energetic health volunteer workers be if the patients coming in to the health center then go back home unattended due to the unavailability of medicines needed? Why not build our own medicine stock from our local plants?

\section{The herb garden is the solution}

After a series of discussions and reflection, the health group decided that for them, traditional herbal medicine is more effective than modern medicine. They took note of the fact that traditional herbal healing has always been a part of their community's history and culture. Despite modernisation, traditional medicine prevailed because the community felt that herbs have proven medicinal values. Furthermore, these plants were easier to obtain as these were readily available.

The group then decided that establishing a local herb garden was the appropriate option (see Figure 7 for details). They recalled that their past efforts to establish an herb garden had failed for two reasons: 1) the drought brought about by the El Niño phenomenon in 1997-1998, and 2) there was no land tenure security for the area that was used for the herb garden as the land was private property and the owner later wanted to use the land. Nevertheless, the group thought that the community would consider the herb garden a good option. 

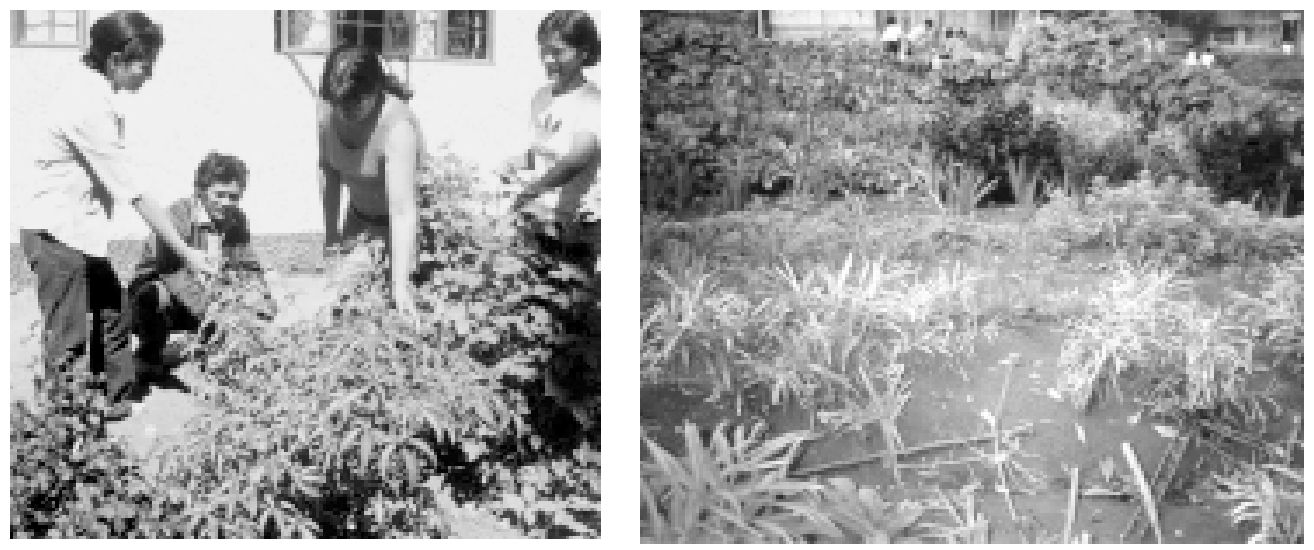

The BWA health group's herb garden beside the village health centre provides the residents with needed herbal medicine to treat common ailments.

Learning from their past experience and to ensure the land security of their future herb garden, the group requested permission from the barangay captain to make use of the vacant lot beside the health centre. The captain approved this request and the group can now make use of an area of 400 square metres.

In the subsequent sessions, it was decided that the group should start with plant propagation. We facilitated their discussions to decide what herbs to grow. A simple tabular format was prepared in which the group listed all the herbs that are available in the community, those that are frequently and commonly used, and those that are in demand and have been found effective.

Initially, the group came up with 24 varieties of plants. The common herbs identified were lagundi (Vites negundo), hilbas (Artemesia vulgaris), and angelica (Angelica archangelica). The sources of these plants were listed as follows: from their own plots at home, from immediate neighbours, from adjacent villages, or from the forest. Once the list was ready, the group noted that many plants could be obtained from Basac only and few were available in adjacent villages. This is because Basac residents planted herbs but the varieties were limited. A few plants could also be obtained from the forest but only a few people knew their uses and specific locations.

After reviewing the above information, the group assigned members to perform specific tasks. The assigned individuals were to gather the plants and obtain additional information on the plants that could be taken only from the forest. They agreed to record, for monitoring purposes, all plants that would be brought in on an agreed date. 


\section{Some observations on the propagation activity}

The observations that followed the plant propagation activity were noted by the group members:

- Most of the plants were brought in by a village health worker, an influential member of the community who had more indigenous knowledge, about the plants and the location of their sources, than others.

- Nobody collected herbs from the forest because their environmental conditions were different from those in the health centre.

- Not all the herbs listed in their monitoring form could be obtained. The group had to look for other plants.

- One member appeared to be the only source for lagundi. She was encouraged to plant this herb by the Project Heal of the Adventist Development and Relief Agency.

The group then collectively gathered the remaining herbs and planted them in their herb garden. Their husbands helped in putting up bamboo fences around the plot and children helped in watering the plants. They then planted additional food crops like beans, pechay (Brassica chinensis), patola (Luffa acutangula), gourd, and some cut flowers.

Based on their assessment, the group felt the need to expand the area by utilising a portion of the BUFAI CBFM area. This was because some residents lived far from the health centre. They requested permission from the BUFAI President to set up a herb garden within the CBFM area. The request was approved and a 1000-square metre herb garden was set up. They also noted the need to plant root crops like sweet potato, cassava, and taro in the new area so that those who participated in the community's pahina or collective community efforts could partake of the fruits of their labour.

As these activities prospered, many people took notice of the group's efforts. Other community members and visitors began to flock to the new garden but were sometimes disappointed because they expected to see a larger number of herbs rather than food crops. This was recognised by the group, and learning from this observation, they propagated more herbs, especially those that were often used and asked for by residents. 
Figure 7. The ACM process in addressing lack of medicines at the barangay health centre

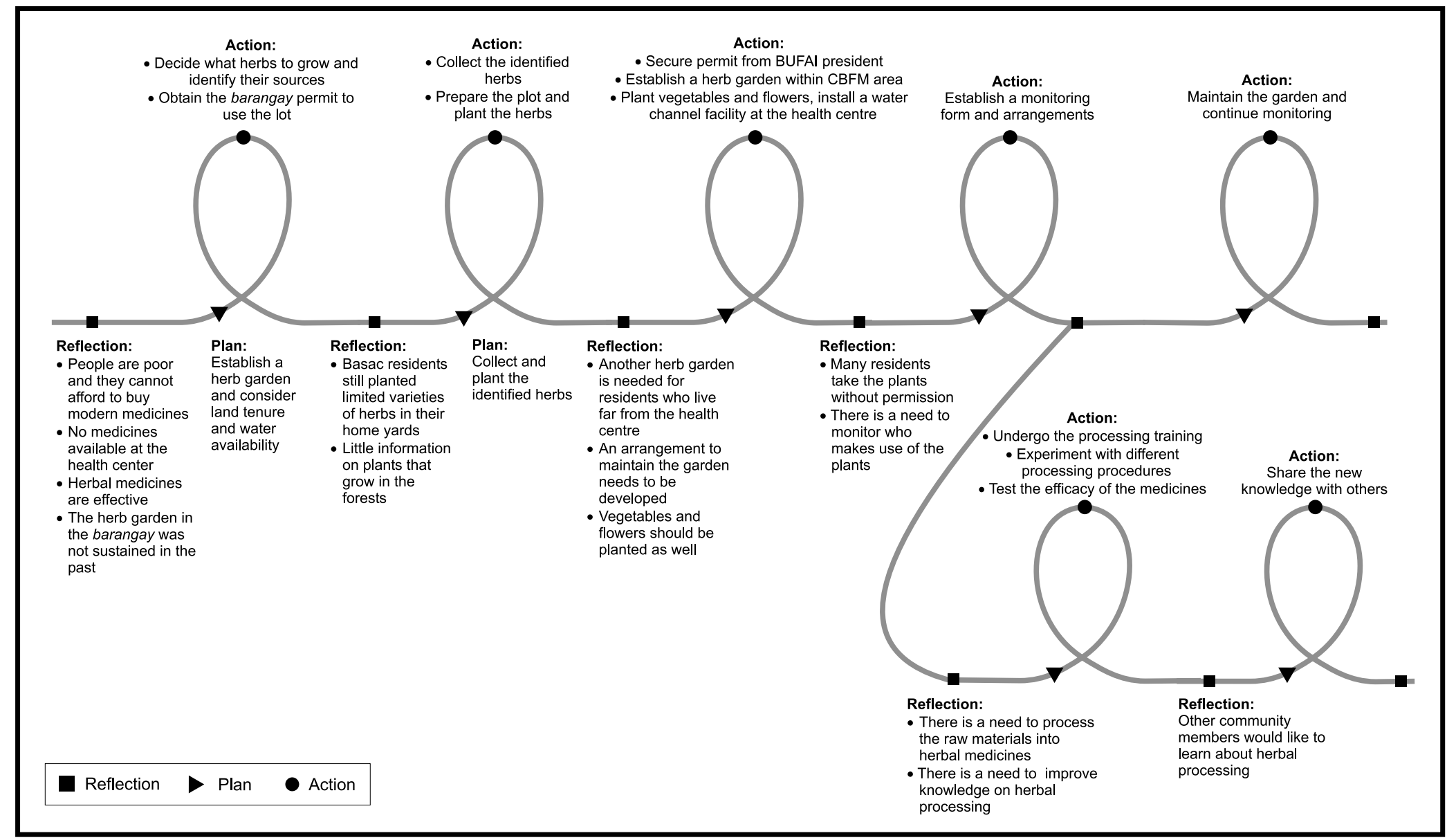




\section{Making the herb garden useful for the community}

The group's herbal plant propagation project and organic vegetable garden establishment were progressing very well. Many residents took some herbs to plant in their own lots and others partook of the vegetables for home cooking. Some took the plants without permission. With the increasing demand and to determine who actually made use of the plants, the group decided to monitor the use of the garden. ACM researchers facilitated a discussion to come up with a monitoring form as shown in Table 2.

Table 2. Monitoring form for herb garden

\begin{tabular}{llll}
\multicolumn{2}{c}{ Beneficiary } & Herbs & \multicolumn{1}{c}{ Use } \\
1. & Consorcia Zulita & Atay-atay & For propagation \\
2. Pelinia Coliling & Angelica & Treatment of fever \\
3. Bads & Bawing, herba buena & For propagation \\
4. Consorcia Zulita & Bawing & For propagation \\
5. Juanita Luna & Lagundi & For propagation \\
6. Merlyn Carpe & Lagundi & For propagation \\
7. Rosita Wacdas & Lagundi & Cough treatment \\
8. Teresa Tinio, Juanita Luna, & & \\
& Perlita Abando, Merlinda Sinhayan & Petsay & For cooking \\
9. Glenda Zulita & Lagundi & Cough, fever treatment \\
10. Diana Sihagay & Angelica & Treatment for swelling \\
11. Narcisa Sanghid & Kalabo & Cough, fever treatment \\
12. Bong Gonzalez & Kalabo, herba buena, comfrey & Cough, fever treatment \\
& & &
\end{tabular}

When the plants grew and propagated naturally, we felt that linking them up with a group advocating sustainable medicine production would be the next step to make full use of the herbs. We proposed this idea to the health group who thought that it would be a good next step. We then invited the Katilingbanay Foundation, an organisation that advocates traditional medicine, to conduct a training programme for the community and share new information on traditional healing. We expected that this training would provide an opportunity for the group to transform the herbs into medicines that could be made available at the village health centre and subsequently, to be used by the community members.

The training was held for two days in July 2002 for 5 BUFAI members (men), 13 BWA members, and 2 non-PO members. The training was primarily on herbal processing and experimentation. Fundamental issues or the 'why aspects' of things were emphasised. It employed methods of reflection, integration and learning from experimentation as the group was led to reflect and understand cultural and integrative medicinal concepts. 
As a start, participants were encouraged to examine closely the roots, stems, leaves, and flowers of different herbs, and describe each part of the plants including its form, color, and smell. This exercise enabled the participants to know the plant and be sensitive to what it is in relation to human healing, nature, sickness, and health.

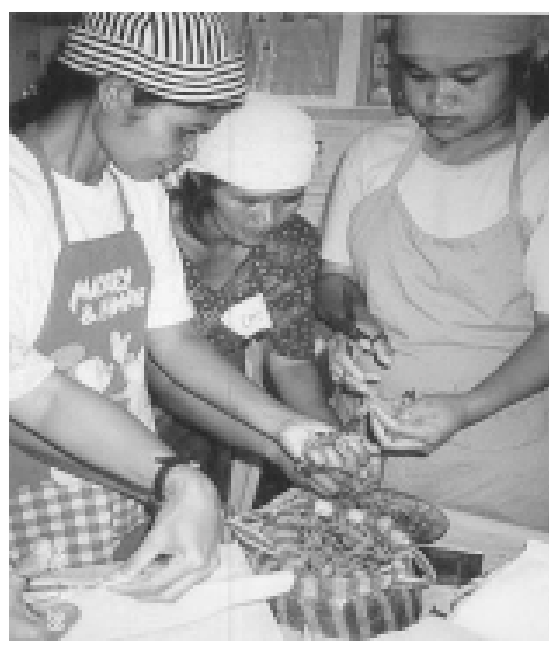

Basac women learn about the characteristics of herbs and getting a hands-on experience in making herbal medicines for treatment of common illnesses and disorders.

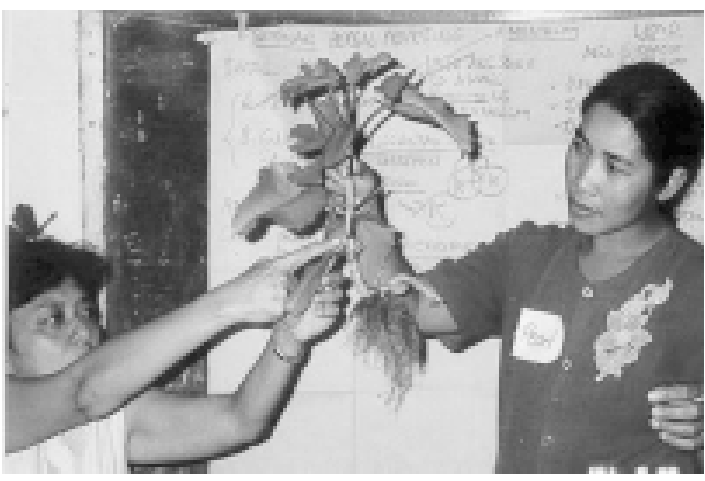

With the basic principles of sustainable medicine, the participants then learned the procedures in making herbal home remedies such as cough syrups, liniment ointment, oil, teas, medicinal soaps, and moxa rolls (a cone or cylinder of cotton wool or other combustible material, placed on the skin and ignited in order to produce counterirritation). Using an intensive small group practicum, the Katilingbanay team of community-based trained mothers taught the group about practical diagnostic and herbal processing procedures. In the process, the procedures taught became integrated with the participants' own experiences. There was an exchange between trainers and participants on the processes in both traditional and modern diagnostic and preparation procedures. As a result of the training, the group learned to process lagundi into cough syrup, ginger to massage oil, sambong (Blumea balsamifera) to tea, and acapulco (Cassia alata) into medicinal soap.

After the training, the participants took home and tested their products and distributed about 183 different medicinal concoctions to the community.

\section{Some promising results}

The efforts of the group in addressing the health problem in the village had positive impacts in the community: 
- Other mothers and even men were attracted to join in the next training programme.

- Several mothers were inspired to plant herbs in their own gardens; others to expand their gardens.

- Other participants experimented with and processed other plant varieties and taught the process to other members of their families.

- A BWA officer, who joined the training, shared knowledge and trained other BWA members who were not able to join the first training programme.

- Staff from Agriventures, a banana plantation firm in a nearby village, visited the community and offered an exchange of planting stocks of medicinal herbs.

The activity also drew the attention of the health workers of the municipal and provincial governments. The municipal health workers invited the BWA health group to train others in the municipality. The group declined, saying that they have not gone far enough yet in terms of training people within their own barangay. However, the municipal health office promised the group that it would provide a budget for them to conduct another training programme for different participants.

Meanwhile, the efforts of the women were recognised and appreciated. The barangay council of Basac explicitly expressed its appreciation in one of their meetings. The women's contribution in addressing the local problem was therefore acknowledged.

Furthermore, there were several comments made by the community members attesting to the efficacy of the herbs as shown on the following page.

\section{Activation of ACM elements}

\section{ACM ELEMENTS ACTIVATED}

- Collective planning and decision making.

- Collective action to carry out collectively agreed plans.

- Intentional learning and experimentation.

- Collaborative monitoring.

- Social learning.

An important ACM element activated in the herb garden activity was the powerful monitoring form that the women used. As we mentioned earlier, we assisted the group in developing a checklist. The checklist provided information on how many varieties of plants were already collected, which plants still need to be collected, which plants are abundant, which are diminishing in supply, which ones are frequently used, etc. 


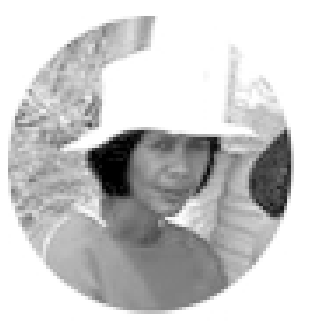

Bibeth Abundo,

Basac Health

Worker, sitio

Kinusuhan

'Sa ako, kami ra sa akong mga anak ug bana ang nag gamit sa atong mga herbals nga nahimo kay ting ubo baya to. Ako ato gi-ubo. Sa siging haplas sa ginger oil ug pag inom sa Lagundi syrup nawala ang akong ubo. Kada gabii ang ginger oil ako pong gaihaplas sa akong mga ugat nga nang gawas tungod sa pasmo. Karon nawala wala ang mga pasmo sa akong mga ugat.' (For me, only my family consumed the herbal medicines we processed. I had a cough at that time. Constant application of ginger oil and taking lagundi cough syrup relieved my cough. Every night I also applied ginger oil to my legs and arms with pronounced varicose veins. Now the varicose veins have receded.)

'Wala na ko naggamit ug mga paracetamol, gisigihan lang nako ug haplas ang likod sa akong mga anak kung mag init init.' (I don't use paracetamol anymore, I just constantly apply ginger oil all over my children's body when they get hot due to fever.) Inday Maning, Basac sari-sari

\section{store owner}

'Ang buyo ointment naka-ayo gayud sa luway nga dugay na giantos sa akong bata.' (Ointment made from betel leaf is effective in treating the lip infection of my child from which he has suffered for a long time already.) Rosana Pinsahan, BWA member

'Interesado ko moapil sunod ninyo himo sa herbal nga tambal ilabi na atong acapulco ointment kay ang nuka sa dalunggan sa kong anak naulian gyud. Human nako waswasan sa bayabas ako dayong gihaplasan ug acapulco nawala na ang nuka dali ra, na ba to diha tanom sa center kay mangayo unya ko akong itanom.' (I'm interested in joining the next herbal processing training. I want to learn especially how to process acapulco ointment. It cured the skin infections around the ears of my daughter. After washing the infection with water from boiled guava leaves, I applied acapulco ointment and in a very short time the infection was cured. Do we have that plant at the health centre? I'd like to ask for some to plant in my backyard.) Judith Sanghid, resident, upper Basac

'Gapaliton nila ang akong gibagging nga lagundi ug dos pison per bag kay nasinati gyud nila anga kaepektibo sa tambal.' (Some of the women wanted to buy my processed lagundi at $\mathrm{PhP} 2.00$ per bag. They have experienced efficacy of the herbal medicines.) Teresa Tenio, Basac Health Worker, sitio Mampalanay

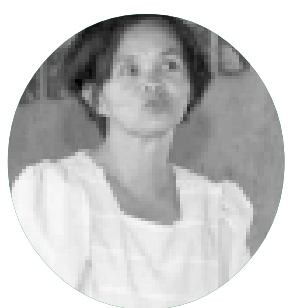

Nang Conching

Zulita, Basac Health

Worker, sitio

Kibugtong
'Tinood epektibo gayud ang mga tambal. Naa gani mi silingan ga pahimo gi ingnan nako pagpalit lang ug gamay nga mantika kay tudloan ta ka sa paghimo.' (It is true that the herbal medicines are effective. We have a neighbour who requested me to process the herbs into medicines. I told her to buy some oil that I could use in the preparation, which was quite easy, and I just taught her how to do it.) 
As the group conducted its weekly activities in the herb garden, the simple practice of going back to the checklist became a part of a formal monitoring system. The system evolved very naturally, developing as its function or use also evolved. This monitoring system also became a tool for sharing information. Some of the women came to know about herbs that grow only in the forest. Also, the monitoring form became a tool for women to access information from men who were usually more informed about herbs. Finally, this simple monitoring system, first used for information in establishing the herb garden, evolved into a tool for social learning among the group members.

\section{Learning to improve organisational governance}

Poor governance has been a constant problem faced by many barangay organisations. This was typically true of the BUFAI PO in our Bukidnon site.

In the prioritisation of key issues in the village, BUFAI highlighted weak organisational governance as one of the four priority issues. To address this issue, a group of people came together to tackle the poor governance problem. This group is composed of BUFAI, barangay officials, and leaders.

Several sessions were held by the governance group to reflect on the problems. Our ACM facilitator found it quite a challenge to facilitate the discussions in this group. First of all, the group consisted of mostly men who were busy with their farms and work. Furthermore, the issues related to governance were numerous and the group ended up with a long list of problems in the first few reflection sessions.

Realising the complexities of the issues and their interconnection, the ACM facilitator decided to apply a causal diagramming technique. This technique appeared to be effective for the group to see how complex and connected were the identified problems, and allowed them to prioritise the most important ones. The group finally came up with four specific issues that they would like to address. These were:

- lack of information on the CBFM activities in the area;

- lack of leadership skills;

- $\quad$ poor implementation of barangay ordinances; and

- lack of transparency in barangay financial reports.

\section{Lack of information dissemination mechanisms on CBFM}

The group realised that a lot of information was not being disseminated properly to the communities because of the lack of information sharing mechanisms. They said 
that the lack of knowledge and information resulted in the lack of action or slow response to address the problem.

The group also noticed that the old bulletin board was not relevant to their information needs as it only contained pictures of local entertainment events such as the Lantapan pageant and fiestas. In addition, the bulletin board was inside the barangay office which was closed most of the time because the assigned officer of the day was frequently absent.

To address this issue, the group decided to put up a new bulletin board (see Figure 8 for the whole process). They then agreed that the bulletin board should be installed at the door of the barangay office and that relevant information should be posted. This way, more residents could have better access to information.

Billboards were used in another situation to meet the need for providing appropriate information for people residing outside Basac. During one of the governance group meetings, the group shared their observations that there were outsiders who came to the CBFM area during holidays, such as Holy Thursday and Good Friday. As no outsiders are allowed in the CBFM area, they thought that putting up the billboards with the appropriate information would discourage such unlawful entry.

The barangay leaders and BUFAI officials who made up the governance group of our ACM research put up a new bulletin board to inform their constituents about their governance and CBFM activities. The bulletin board was deliberately placed at the door of the barangay office so that more people could have access to relevant information.

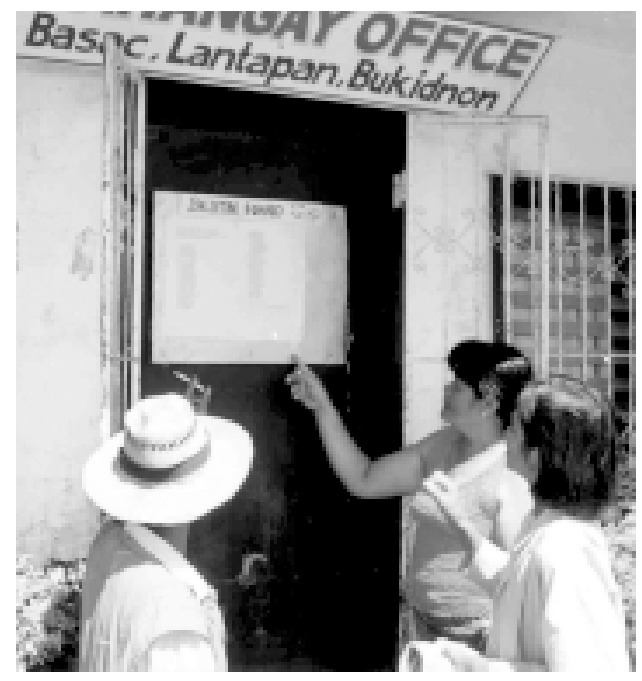

In a subsequent meeting, they agreed to put up billboards in other nearby nonCBFM areas to inform outsiders that their entry into the CBFM area is not allowed. They also thought that these billboards would be an effective communication mechanism to inform other non-PO members, who are residing in the CBFM area, about the do's and don'ts inside the CBFM area, such as restrictions on animal grazing, illegal methods of fishing, and disposing of garbage in rivers and streams. This is important as the CBFM is located within the buffer zone of a protected area. 
Figure 8. The ACM process in improving local governance by addressing lack of information dissemination mechanisms

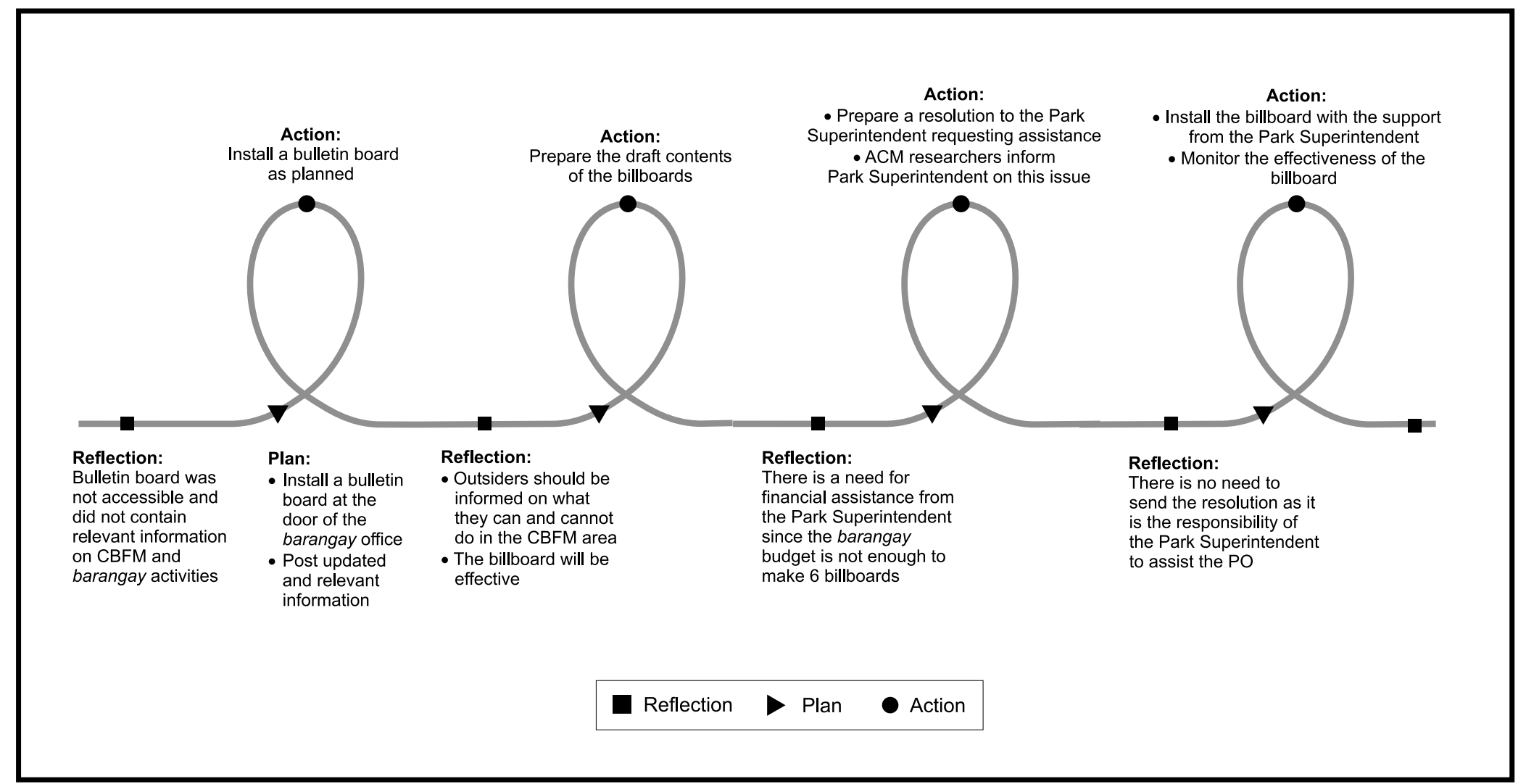

ชै 
Realising that they need some financial assistance in the making and installation of billboards, they decided to ask DENR's Park Superintendent for assistance. With our facilitation, the group initially made a resolution requesting the Park Superintendent's assistance.

The group then asked for the help of our ACM researcher to inform the Park Superintendent about the meeting that took place and the billboard plan, and also present the content outline made by the group for posting on the billboard. The Park Superintendent responded by informing the ACM researcher that there was no need for the resolution since it was part of their mandate to assist the $\mathrm{PO}$ in such an undertaking. He then promised to extend his institution's help in making the billboards. After two months, the Park Superintendent office constructed the billboards.

An example of the information posted on the billboard that was put up in the CBFM area reads as follows:

'Let it be known that outsiders are not allowed to enter the CBFM area unless permitted by either of the following: Park Superintendent, barangay council, CBFM holder, and Kitanglad Guard Volunteers.

No burning is allowed inside the CBFM area unless you ask permission or inform your neighbouring lot to avoid the destruction of the plantation and other crops. Animal grazing is not allowed here either.

No one is allowed to cut trees especially for commercial purposes. Trees can only be cut for housing purposes and only Basac residents are permitted to do so.'

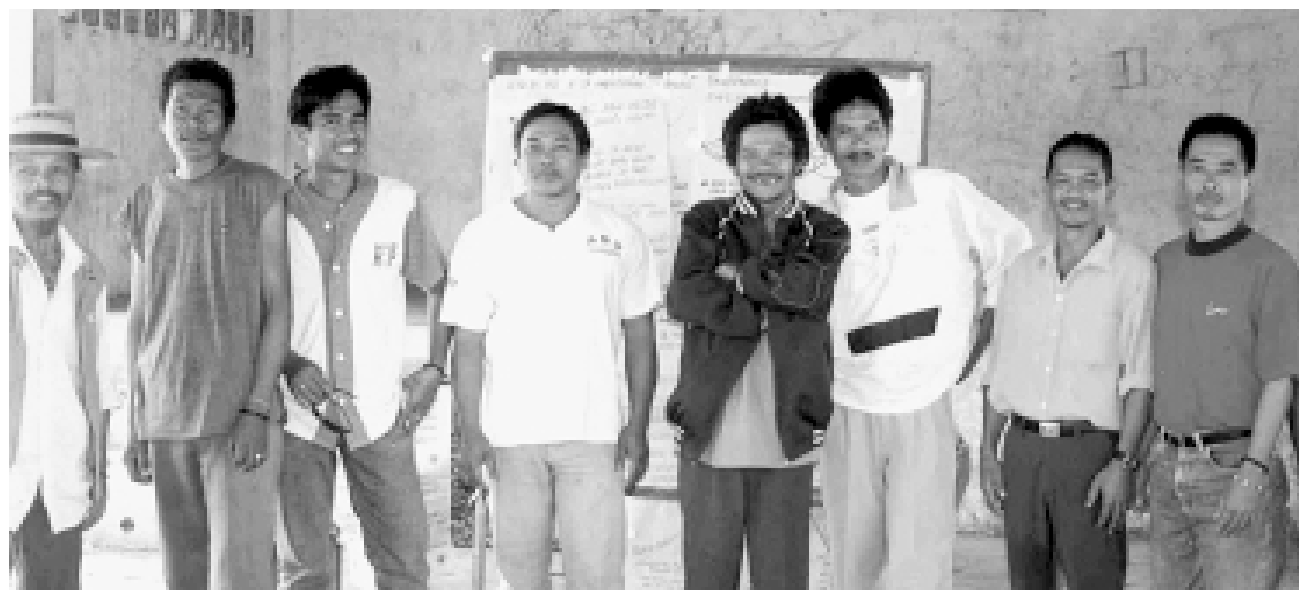

The members of the governance group were mostly officers of BUFAI and the barangay council of Basac. They led the community in identifying priority local governance issues and addressing these problems. 


\section{Lack of leadership and organisational skills}

Another issue that the governance group addressed was their lack of skills in the area of organisation and leadership (see Figure 9). This lack of skills has prevented them from effectively establishing good governance at the barangay level. The group felt that there was a need for capacity building and requested the ACM researcher to facilitate such training.

Responding to this request, a training programme was held for 3 days in August 2002 for 12 participants ( 5 men and 7 women). We linked up with a local NGO (Balay Mindanaw Foundation, Inc.) that had wide experience in organising similar training programmes in the past. In this training, the group learned about basic facilitation skills, local government-related rules and policies, roles and responsibilities of the barangay, etc. After the training, the group reflected on their experiences. They found the training rewarding and said that they learned many things. They immediately applied the new knowledge that they gained from the training programme.

Figure 9. The ACM process in improving local governance by addressing lack of leadership and organisational skills

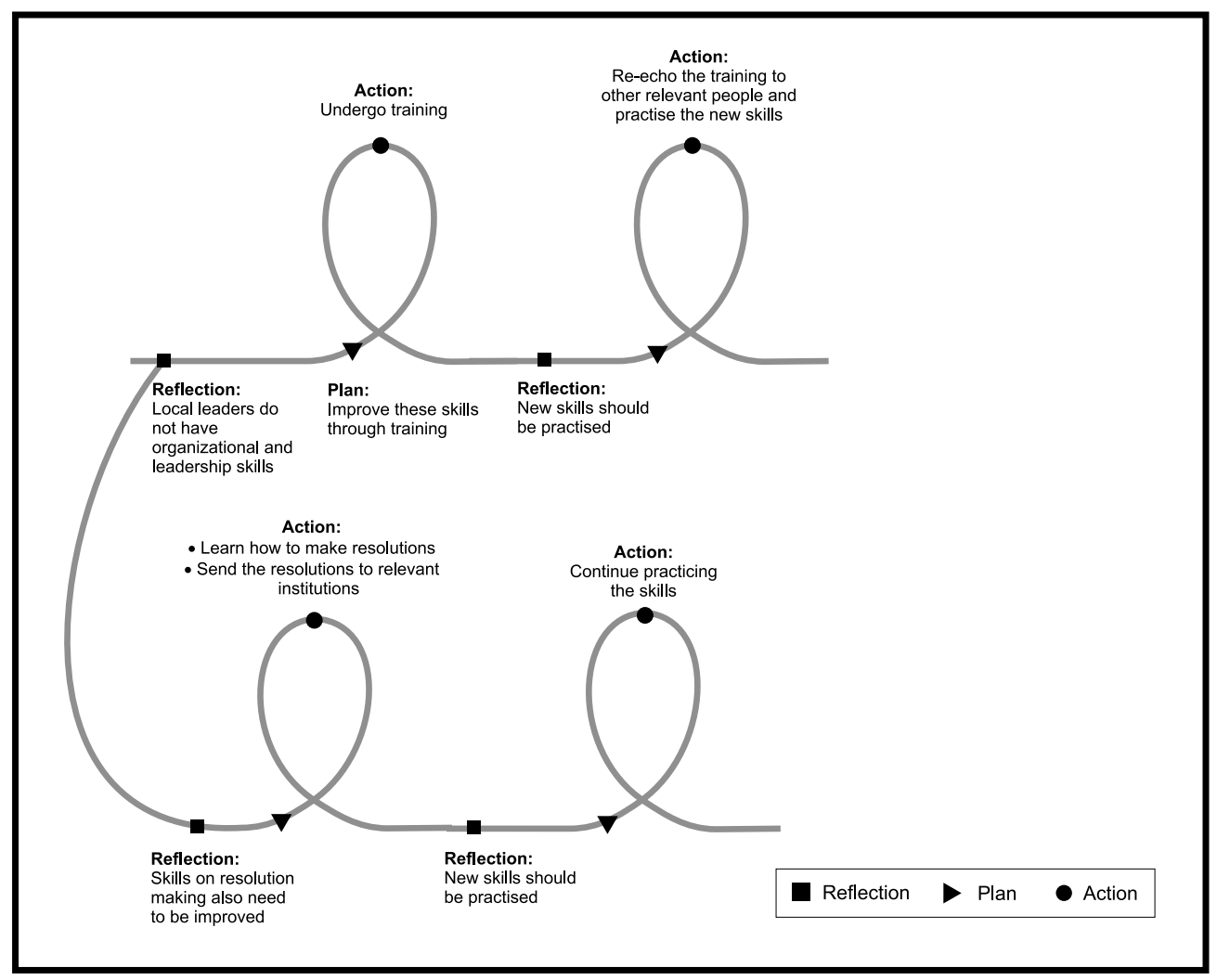


Furthermore, the barangay and PO leaders who attended the training immediately conducted a similar programme in one of their regular meetings in which they acted as resource speakers. This activity achieved two purposes: they shared with their comembers the new knowledge on effective facilitation they had acquired from the training, and they practised their newly acquired facilitation skills. Their co-members fed back to these new facilitators their assessment of their performance.

While they practised and applied their new skills in their work, the group identified the need to enhance their skills in making official resolutions. They recognised that resolutions are the normal forms of communication and transactions with formal organisations and offices and they were not skilled at doing this.

With facilitation from ACM researchers, the group underwent several sessions and practical exercises on making resolutions, from conceptualisation to writing the draft and the final copy. As a result, the group has drafted and finalised several resolutions that they intend to submit to different institutions. An example was a resolution addressed to Heifer International formally requesting assistance for training on cattle management. Another was addressed to DENR requesting replacement of the seedlings of abaca, Eucalyptus, and other tree species that they earlier received and that did not grow well on their farms.

\section{Weak implementation of ordinances}

In the past, the barangay council had passed many ordinances but these were not implemented efficiently. The governance group then decided to examine and make

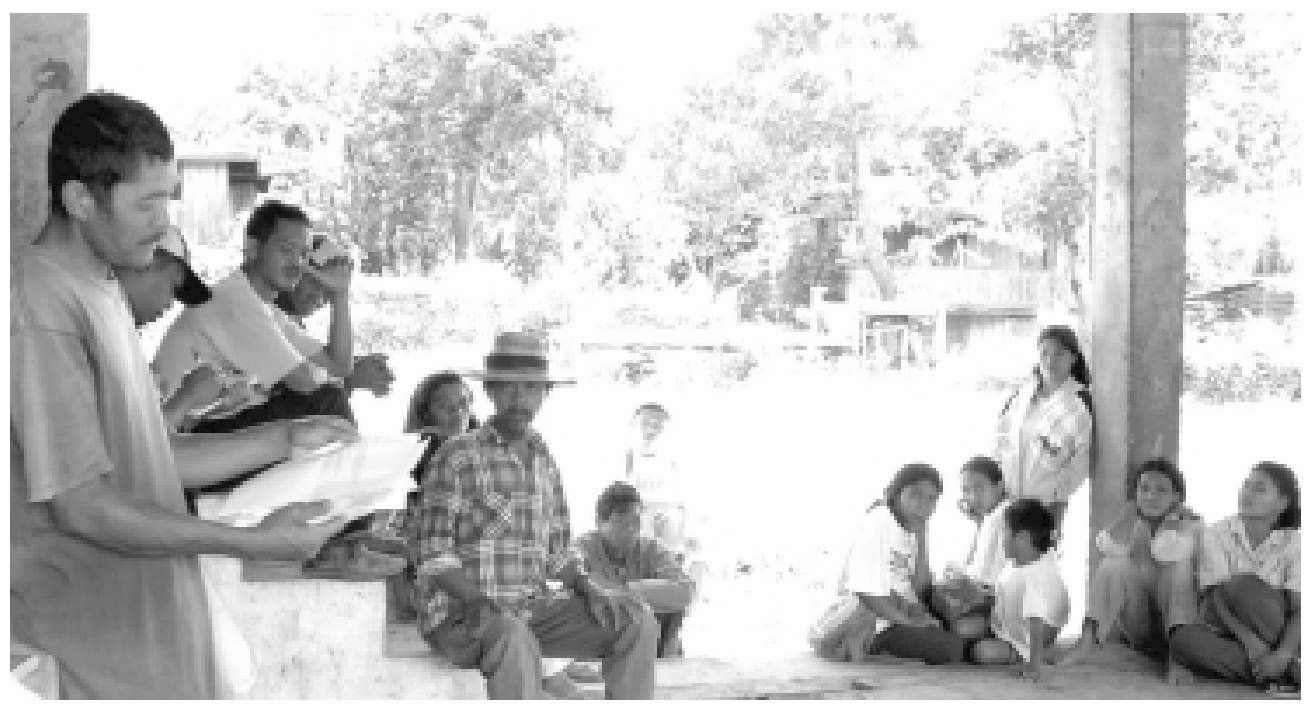

The new facilitators: The leadership seminars have produced leaders who eagerly practise what they have learned. They improve their skills by serving as facilitators in their regular PO meetings. 
an inventory of these ordinances. The group reviewed all the existing ordinances and evaluated which ones were implemented and which ones were not implemented effectively, and why. The results of the analysis were then used as their basis to plan their actions to more effectively implement their policies.

In their analysis of the ordinances, the group discovered that in 1995, many ordinances were formulated. Also, a year had passed since the new barangay officers had taken office but no regular meeting had been held. An officer of the day who was assigned to be in the office had not been active over the past year. They then decided that a penalty should be imposed on this officer for his absence, as well as other sanctions for absences of other officers. Furthermore, the group decided to re-activate the position of officer of the day in the barangay office. All these decisions were implemented (see Figure 10 for details).

Figure 10. The ACM process in improving local governance by addressing weak implementation of ordinances

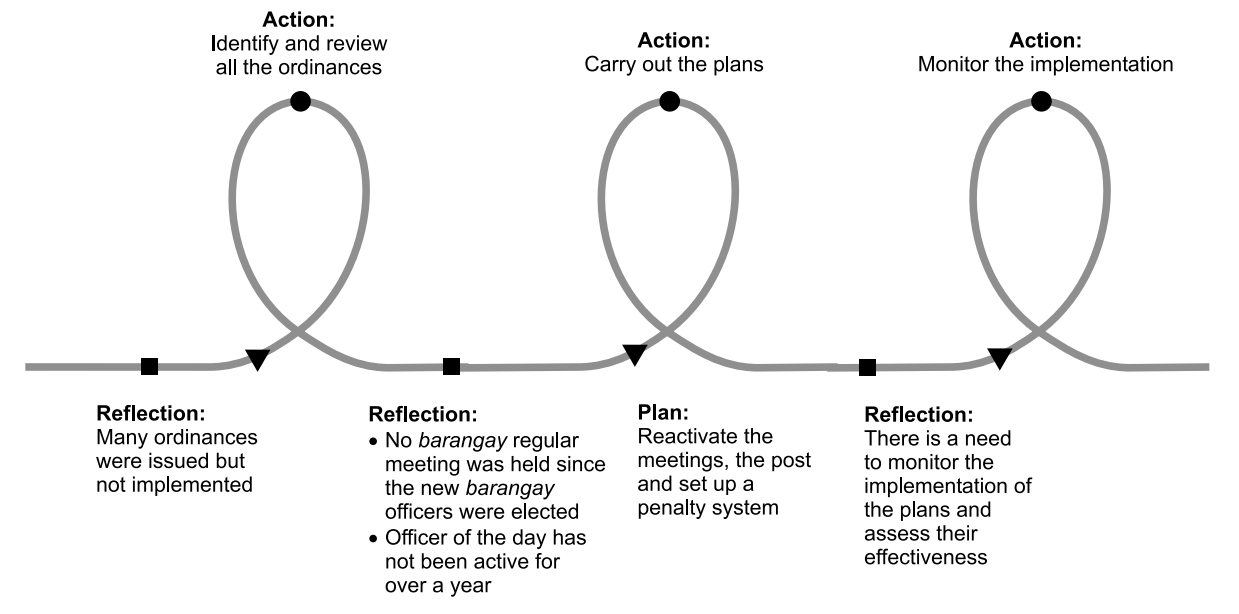

\section{Lack of transparency in financial reporting}

The group also observed that there had been no report from the barangay treasurer. To ensure transparency in the management of the barangay financial system, the group agreed that the concerned barangay officer should report on the financial status during the regular barangay meeting. A time slot was allocated for this purpose. They also concurred that the different barangay committees should submit regular reports. They then proposed a penalty system for those officers who failed to do so. Figure 11 describes the process. 
Figure 11. The ACM process in improving local governance by addressing lack of transparency in financial reporting system

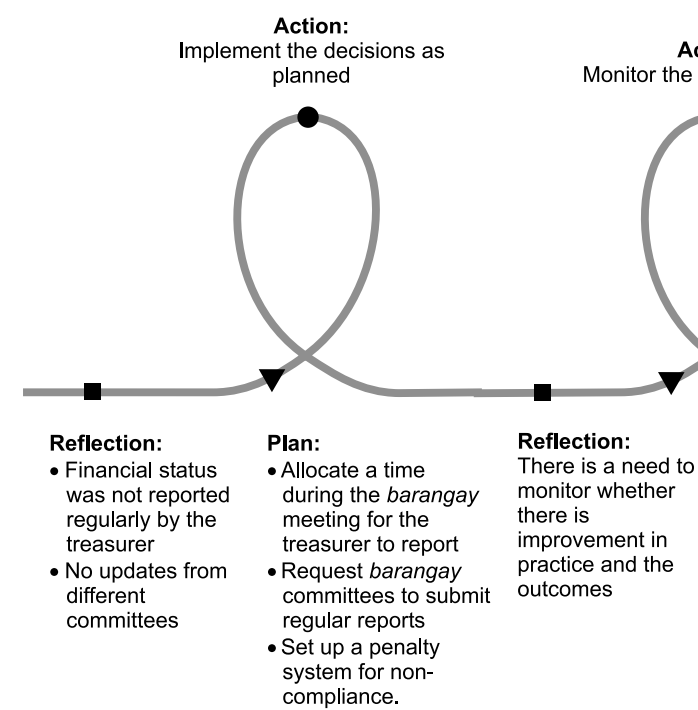

Action:

the implementation

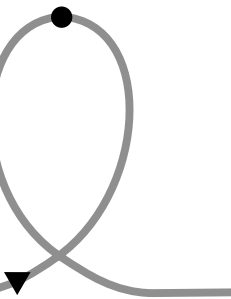

Reflection:

was not reported

during the baran

improvem is

No updates from

committees to submit

system for non-

Reflection

Plan

Action

\section{Some promising results}

As a result of the efforts of the governance group, the barangay government has looked closely at how they have been operating so far and identified some of the old problems that should have been solved earlier.

The group has started to address some of those problems. However, newly acquired skills and the introduction of new systems to increase transparency and accountability should be consistently practised and enforced before good governance is achieved. The learning cycles in the four governance issues were relatively shorter compared to other issues. These were not solely because of the short timeframe itself but also because the subsequent cycles would naturally need constant practice and monitoring.

\section{ACM ELEMENTS ACTIVATED}

- Communication betwen the members of the same group or between different groups to share information.

- Collective planning and decision making.

- Collective action to carry out collectively agreed plans.

- Social learning. 


\section{ACM Outcomes in Palawan and Bukidnon Sites}

We describe briefly the outcomes of ACM processes in the two sites that are directly linked with the local priority issues. We group these outcomes into those that are related to human and social capital and those that relate to natural, physical, and financial capital (see Table 3 and Table 4).

We noticed the improvements in human and social capital of the POs in both sites. We observed increased skills and capacities in communication, networking, proposal making, monitoring and record keeping, managing small interprises, reflecting and learning from their experience, etc.

Other improvements include higher level of trust among and between PO officers, PO members, and other stakeholders, increased awareness on the importance of engaging their members and other stakeholders, and the actual inclusion of community members and stakeholders who were excluded in their previous CBFM planning and implementation activities.

The changes in natural, physical, and financial capital were, however, not as impressive as those observed in human and social capital. There are several reasons for these.

Firstly, the ACM project did not make financial investments to directly improve the natural or physical conditions of the ACM site, for example, by rehabilitating certain portions of the community forests or setting up a nursery for the communities. What we did was to facilitate the process so that the PO could identify areas that need improvement, and assisted them in securing external financial resources if needed. In many cases, the POs initiated their efforts on a small-scale using their own resources, for example in setting up small-scale nurseries for cut flowers in Lantapan and timber tree species in Palawan, planting trees in their CBFM areas and their farms, etc.

Secondly, while the improvements in human and social capital should eventually affect their natural and physical systems, we stress that these changes may only be observable beyond the time frame of the project. Despite the modest improvements, it is worth pointing out that there was no decline in natural and physical capital observed during the ACM project that could offset the outcome. 
Table 3. Outcomes of ACM in Palawan site

\begin{tabular}{|c|c|c|}
\hline $\begin{array}{l}\text { Local Priority } \\
\text { Issue }\end{array}$ & $\begin{array}{c}\text { Human and Social } \\
\text { Capital }\end{array}$ & $\begin{array}{c}\text { Natural, Physical, } \\
\text { and Financial } \\
\text { Capital }\end{array}$ \\
\hline $\begin{array}{l}\text { 1. Conflict on } \\
\text { boundary } \\
\text { delineation of } \\
\text { CBFM area with the } \\
\text { neighbouring Batak } \\
\text { CBFM area }\end{array}$ & $\begin{array}{l}\text { 1. Increased skills of the PO BoD } \\
\text { to negotiate and explain } \\
\text { issues. } \\
\text { 2. Increased awareness of the } \\
\text { importance of collective } \\
\text { actions, and inviting other } \\
\text { stakeholders to be involved in } \\
\text { dialogue. } \\
\text { 3. Increased joint action across } \\
\text { different stakeholders, i.e., } \\
\text { Palawan Tropical Forest } \\
\text { Protection Project, DENR, } \\
\text { and PO, in resurveying the } \\
\text { boundaries. } \\
\text { 4. Increased trust between PO } \\
\text { and the Batak that led to } \\
\text { partnerships in almaciga } \\
\text { trading, forest protection, and } \\
\text { handicraft making. } \\
\text { 5. Increased skills ( } 3 \text { PO } \\
\text { members) to use compass and } \\
\text { GPS properly. }\end{array}$ & $\begin{array}{l}\text { Reduced illegal } \\
\text { almaciga collection and } \\
\text { trading. }\end{array}$ \\
\hline $\begin{array}{l}\text { 2. Lack of support } \\
\text { from barangay } \\
\text { leaders for CBFM }\end{array}$ & $\begin{array}{l}\text { 1. Increased awareness of the PO } \\
\text { BoD to update not only PO } \\
\text { members but also barangay } \\
\text { council on CBFM activities. } \\
\text { 2. Increased group effort within } \\
\text { the PO to clarify } \\
\text { misunderstandings of CBFM } \\
\text { that prevailed among the PO } \\
\text { members and barangay } \\
\text { councils. } \\
\text { 3. Increased awareness of the PO } \\
\text { BoD and barangay councils } \\
\text { that forest protection and } \\
\text { watershed rehabilitation } \\
\text { should be done in a } \\
\text { collaborative manner. }\end{array}$ & $\begin{array}{l}\text { Re-opening of the } \\
\text { access road to } \\
\text { CBFM in barangay } \\
\text { Tanabag, that was } \\
\text { previously blocked } \\
\text { by the barangay council, } \\
\text { that improved the } \\
\text { accessibility for PO } \\
\text { operations. }\end{array}$ \\
\hline
\end{tabular}




\begin{tabular}{|c|c|c|}
\hline $\begin{array}{l}\text { Local Priority } \\
\text { Issue }\end{array}$ & $\begin{array}{c}\text { Human and Social } \\
\text { Capital }\end{array}$ & $\begin{array}{c}\text { Natural, Physical, } \\
\text { and Financial } \\
\text { Capital }\end{array}$ \\
\hline $\begin{array}{l}\text { 3. Low participation by } \\
\text { the PO and } \\
\text { community members } \\
\text { in CBFM } \\
\text { implementation }\end{array}$ & $\begin{array}{l}\text { 1. Improved capacity to share } \\
\text { ideas both in writing and } \\
\text { discussion ( } 9 \mathrm{BoD}, 5 \text { other } \\
\text { PO members). } \\
\text { 2. Better information sharing } \\
\text { with other stakeholders (LGU, } \\
\text { DENR, City ENRO, local } \\
\text { NGOs) in terms of CBFM } \\
\text { activity updates. } \\
\text { 3. More PO members became } \\
\text { aware of CBFM and its } \\
\text { activities (around } 50 \\
\text { members). } \\
\text { 4. Increased awareness of forest } \\
\text { protection and rehabilitation. } \\
\text { 5. Illegal activities were properly } \\
\text { reported (4 cases reported in } \\
3 \text { months). }\end{array}$ & $\begin{array}{l}\text { 1. } 3 \text { bulletin boards } \\
\text { being put up in } 3 \\
\text { barangays. The } \mathrm{PO} \\
\text { invested around } \mathrm{PhP} \\
900 \text {. } \\
\text { 2. Six issues of the } \\
\text { newsletters have been } \\
\text { published. Around } \\
\text { PhP } 1000 \text { has been } \\
\text { invested by the } \mathrm{PO} \text { in } \\
\text { the publication of the } \\
\text { newsletter. }\end{array}$ \\
\hline $\begin{array}{l}\text { 4. Some government } \\
\text { policies hindering } \\
\text { CBFM } \\
\text { implementation }\end{array}$ & $\begin{array}{l}\text { 1. Increased collaboration } \\
\text { between STCMPC and the } \\
\text { CBFM PO Federation. } \\
\text { 2. Support from DENR, } \\
\text { Palawan Council for } \\
\text { Sustainable Development, } \\
\text { City ENRO, and Enterprise } \\
\text { Works Worldwide for the PO } \\
\text { to get a lower forest charge. }\end{array}$ & \\
\hline $\begin{array}{l}\text { 5. Lack of a } \\
\text { collaborative } \\
\text { monitoring system }\end{array}$ & $\begin{array}{l}\text { 1. Increased skills in data and } \\
\text { information collection of all } \\
\text { PO BoD members ( } 2 \text { women, } \\
7 \text { men) and other PO } \\
\text { members ( } 12 \text { women, } 4 \text { men). } \\
\text { 2. Increased analytical skills to } \\
\text { make sense of the data and } \\
\text { generate sensible conclusions. } \\
\text { 3. Increased awareness of the } \\
\text { importance of monitoring. } \\
\text { 4. More active members engaged } \\
\text { in monitoring ( } 16 \text { women, } 10 \\
\text { men). }\end{array}$ & \\
\hline
\end{tabular}




\begin{tabular}{|c|c|c|}
\hline $\begin{array}{l}\text { Local Priority } \\
\text { Issue }\end{array}$ & $\begin{array}{l}\text { Human and Social } \\
\text { Capital }\end{array}$ & $\begin{array}{c}\text { Natural, Physical, } \\
\text { and Financial } \\
\text { Capital }\end{array}$ \\
\hline $\begin{array}{l}\text { 6. Lack of alternative } \\
\text { livelihood options }\end{array}$ & $\begin{array}{l}\text { 1. Increased knowledge about } \\
\text { different livelihood options } \\
\text { that led the PO to diversify its } \\
\text { options: from lumber only to } \\
\text { include almaciga resin, nito, } \\
\text { rattan, etc. } \\
\text { 2. Increased awareness of the } \\
\text { importance of sustaining } \\
\text { production by sustaining the } \\
\text { resources. } \\
\text { 3. Around } 12 \text { women were } \\
\text { skillful weavers and actively } \\
\text { participated in livelihood } \\
\text { activities. } \\
\text { 4. Improved skills in record } \\
\text { keeping and monitoring (4 } \\
\text { BoD, } 5 \text { women). } \\
\text { 5. Increased awareness of the } \\
\text { importance of partnerships } \\
\text { with other stakeholders: } \\
\text { Budyong Rural Development } \\
\text { Foundation, Inc. on } \\
\text { woodwork, DECS on rattan } \\
\text { training, ERDB, and City } \\
\text { ENRO on nursery } \\
\text { establishment. } \\
\text { 6. PO BoD involved other } \\
\text { community groups, such as } \\
\text { Bataks, Tagbanuas, and other } \\
\text { non-PO in training. } \\
\text { 7. Increased appreciation of } \\
\text { women's contribution to } \\
\text { additional household income. } \\
\text { 8. Men were inspired to improve } \\
\text { their skills in rattan furniture } \\
\text { making; } 9 \text { men learned the } \\
\text { skills. }\end{array}$ & $\begin{array}{l}\text { 1. One (1) rattan divider } \\
\text { for displaying } \\
\text { handicraft products } \\
\text { was put up in the local } \\
\text { travel agent's office. } \\
\text { 2. Income was generated: } \\
\text { - lumber : PhP } \\
700,000 \text { (in } 1 \text { year } \\
\text { period); } \\
\text { - nito : PhP } 8,000 \text { (in } \\
4 \text { month period); } \\
\text { - rattan : Php } 3,000 \\
\text { (in } 1 \text { month period); } \\
\text { - almaciga resin : PhP } \\
18,000 \text { (in } 6 \text { month } \\
\text { period). } \\
\text { 3. Planting of } 180 \\
\text { Gmelina seedlings. } \\
\text { 4. A semi-permanent } \\
\text { nursery and a } 4 \times 8 \mathrm{~m}^{2} \\
\text { seedbed. } \\
\text { 5. Funding of PhP } \\
\text { 150,000 was received } \\
\text { from the City } \\
\text { Government. }\end{array}$ \\
\hline
\end{tabular}


Table 4. Outcomes of ACM in Bukidnon site

\begin{tabular}{|c|c|c|}
\hline $\begin{array}{l}\text { Local Priority } \\
\text { Issue }\end{array}$ & $\begin{array}{c}\text { Human and Social } \\
\text { Capital }\end{array}$ & $\begin{array}{c}\text { Natural, Physical, } \\
\text { and Financial } \\
\text { Capital }\end{array}$ \\
\hline $\begin{array}{l}\text { 1. Lack of alternative } \\
\text { livelihood options }\end{array}$ & $\begin{array}{l}\text { 1. Increased documentation skills. } \\
\text { 2. Increased proposal making skills } \\
\text { (12 proposals were made and } \\
\text { submitted to funding agencies). } \\
\text { 3. Increased facilitation skills ( } 3-5 \\
\text { people). } \\
\text { 4. Potential leaders emerged (4 } \\
\text { people). } \\
\text { 5. Increased creativity to come up } \\
\text { with creative designs for } \\
\text { handicraft making. } \\
\text { 6. Increased level of trust among the } \\
\text { participants and increased } \\
\text { commitment to the shared goals. } \\
\text { 7. Increased level of participation in } \\
\text { meetings (15 people). }\end{array}$ & $\begin{array}{l}\text { 1. A 100-square metre of } \\
\text { cut flower nursery was } \\
\text { established and fenced. } \\
\text { It was planted with four } \\
\text { kinds of cut flower } \\
\text { plants. } \\
\text { 2. A signboard was put up } \\
\text { in front of the nursery } \\
\text { and a 14-metre net } \\
\text { cover was installed to } \\
\text { protect the plants. } \\
\text { 3. The group invested } \\
\text { around PhP } 20,000 \text {. }\end{array}$ \\
\hline $\begin{array}{l}\text { 2. Lack of medicine at } \\
\text { the barangay health } \\
\text { centre }\end{array}$ & $\begin{array}{l}\text { 1. Increased knowledge on herbal } \\
\text { concoctions and soap making } \\
\text { (20 people). } \\
\text { 2. Skills to document and monitor } \\
\text { the planting and utilisation of } \\
\text { the herbs from the gardens. } \\
\text { 3. Skills to share information with } \\
\text { other community members ( } 20 \\
\text { people). } \\
\text { 4. New leaders emerged ( } 3 \text { people). } \\
\text { 5. Recognition of the group } \\
\text { efforts from the barangay } \\
\text { officers and other community } \\
\text { members. } \\
\text { 6. Established collaboration with } \\
\text { other stakeholders, e.g., ICRAF, } \\
\text { Katilingbanay Foundation, and } \\
\text { DENR. }\end{array}$ & $\begin{array}{l}\text { 1. } 400 \text { square metres } \\
\text { planted with } 24 \text { herbs, } \\
\text { varieties of vegetables } \\
\text { and cut flowers at the } \\
\text { health centre. This } \\
\text { garden is fenced, with a } \\
\text { gate and a garbage } \\
\text { disposal facility } \\
\text { constructed. An } \\
\text { information board was } \\
\text { put up. } \\
\text { 2. Around } 1000 \text { square } \\
\text { metres have been } \\
\text { planted with herbs and } \\
\text { vegetables in the CBFM } \\
\text { area. } \\
\text { 3. The group's investment } \\
\text { was around PhP } 6500 \\
\text { 4. Sharing of herbs and } \\
\text { herbal medicines with } \\
\text { others. }\end{array}$ \\
\hline
\end{tabular}




\begin{tabular}{|c|c|c|}
\hline $\begin{array}{l}\text { Local Priority } \\
\text { Issue }\end{array}$ & $\begin{array}{l}\text { Human and Social } \\
\text { Capital }\end{array}$ & $\begin{array}{c}\text { Natural, Physical, } \\
\text { and Financial } \\
\text { Capital }\end{array}$ \\
\hline $\begin{array}{l}\text { 3. Weak CBFM } \\
\text { implementation }\end{array}$ & $\begin{array}{l}\text { 1. Enhanced skill for proposal } \\
\text { writing (4 women, } 3 \text { men). } \\
\text { Two proposals for livelihood } \\
\text { activities were completed. } \\
\text { 2. Increased analytical thinking } \\
\text { of the group (15 people) in } \\
\text { discussion (considering } \\
\text { strengths and weaknesses), } \\
\text { extracting lessons learnt and } \\
\text { providing recommendations. } \\
\text { 3. Increased collaboration with } \\
\text { others, such as ICRAF, Heifer } \\
\text { International, Barangay } \\
\text { Integrated Development } \\
\text { Assistance for Nutrition } \\
\text { Improvement, and DENR. } \\
\text { 4. Exchange of knowledge } \\
\text { (farmer-to-farmer) in soil and } \\
\text { water conservation training } \\
\text { (11 farmers). }\end{array}$ & $\begin{array}{l}\text { 1. Planting of: } \\
\text { - } 2 \text { black wattle and } \\
\text { Eucalyptus ( } 2 \text { boxes } \\
\text { of seeds); } \\
\text { - } 18 \text { seedlings of } \\
\text { durian; } \\
\text { - } 18 \text { seedlings of } \\
\text { citrus trees; } \\
\text { - } 2 \text { loads of napier } \\
\text { grass planted for } \\
\text { hedgerows. } \\
\text { 2. Two farm plots were } \\
\text { contoured. }\end{array}$ \\
\hline $\begin{array}{l}\text { 4. Poor local } \\
\text { governance }\end{array}$ & $\begin{array}{l}\text { 1. Increased writing skills ( } 4 \\
\text { people), } 2 \text { resolutions were } \\
\text { drafted. } \\
\text { 2. Potential leaders emerged ( } 4 \\
\text { people). } \\
\text { 3. Increased participation in } \\
\text { meetings. } \\
\text { 4. Increased knowledge on local } \\
\text { government rules and } \\
\text { policies, roles and } \\
\text { responsibilities ( } 9 \text { barangay } \\
\text { officers). }\end{array}$ & $\begin{array}{l}\text { Billboard and bulletin } \\
\text { board were installed. } \\
\text { The barangay invested } \\
\text { around PhP } 12,000 \text {. }\end{array}$ \\
\hline
\end{tabular}




\section{Spin-offs of ACM}

We described in the earlier section how we applied ACM processes in addressing specific issues at the site level. Now we know that these issues - such as raising herbs or monitoring harvesting - are connected in many ways to the larger political, social, or ecological systems that people are trying to manage for their own benefit. In handicraft making for instance, sale affects incomes, availability of the resource, time commitments of the people concerned, and the way they organise themselves, plan, and carry-out the next inititiaves. Success leads to self-confidence and new initiatives.

Generally, the issues we looked at were only a small part of a larger web of interactions. So it is important not only to understand the immediate impacts of ACM while addressing such issues. It is as important, or possibly more important, to understand how changes in this small part of the system affect the larger web.

In Palawan, where we had more time to observe and understand the multiple connections, we have been able to trace the impacts of some of these issues on the larger web of the social and ecological systems. We can see how processes and outcomes of certain site-specific efforts interacted and contributed to higher-level outcomes. We need to emphasise however that by their nature, these 'emergent' outcomes were not the results of ACM alone, as several other non-related ACM processes also contributed to the outcomes.

In Bukidnon, such 'emergent' outcomes were not observable since the local-level processes took place for over a year only. We describe two such outcomes that we observed in Palawan below.

\section{Controlling illegal activities}

One example is the improved mechanism to monitor and control illegal extraction of forest resources in the CBFM area, in particular the almaciga resin extraction. This was brought about by the two issues that ACM directly facilitated, i.e., resolution of the boundary conflict between the $\mathrm{PO}$ and the neighbouring Batak CBFM, and the collaborative local monitoring employed (see Figure 12).

As described earlier, the conflict on boundary delineation was resolved by an agreement between STCMPC and the Batak PO on almaciga extraction and trading, and controlling illegal activities. At the same time, the collaborative monitoring initiated by STCMPC took off. As a part of their monitoring efforts, the PO recorded the volume of the almaciga resins that they were able to extract. They learned that they were not able to collect as much resin as they expected. They suspected that this was due to the illegal extraction activities taking place in the area. They subsequently monitored and controlled these illegal activities in coordination with concerned 
agencies such as the DENR, LGU (both city and barangay levels), and with community groups such as the Bataks, Tagbanuas, and the fishermen's group.

Figure 12. Causal loop diagram showing the 'emergent' outcomes of ACM in reducing illegal resin extraction and trading in the Palawan site

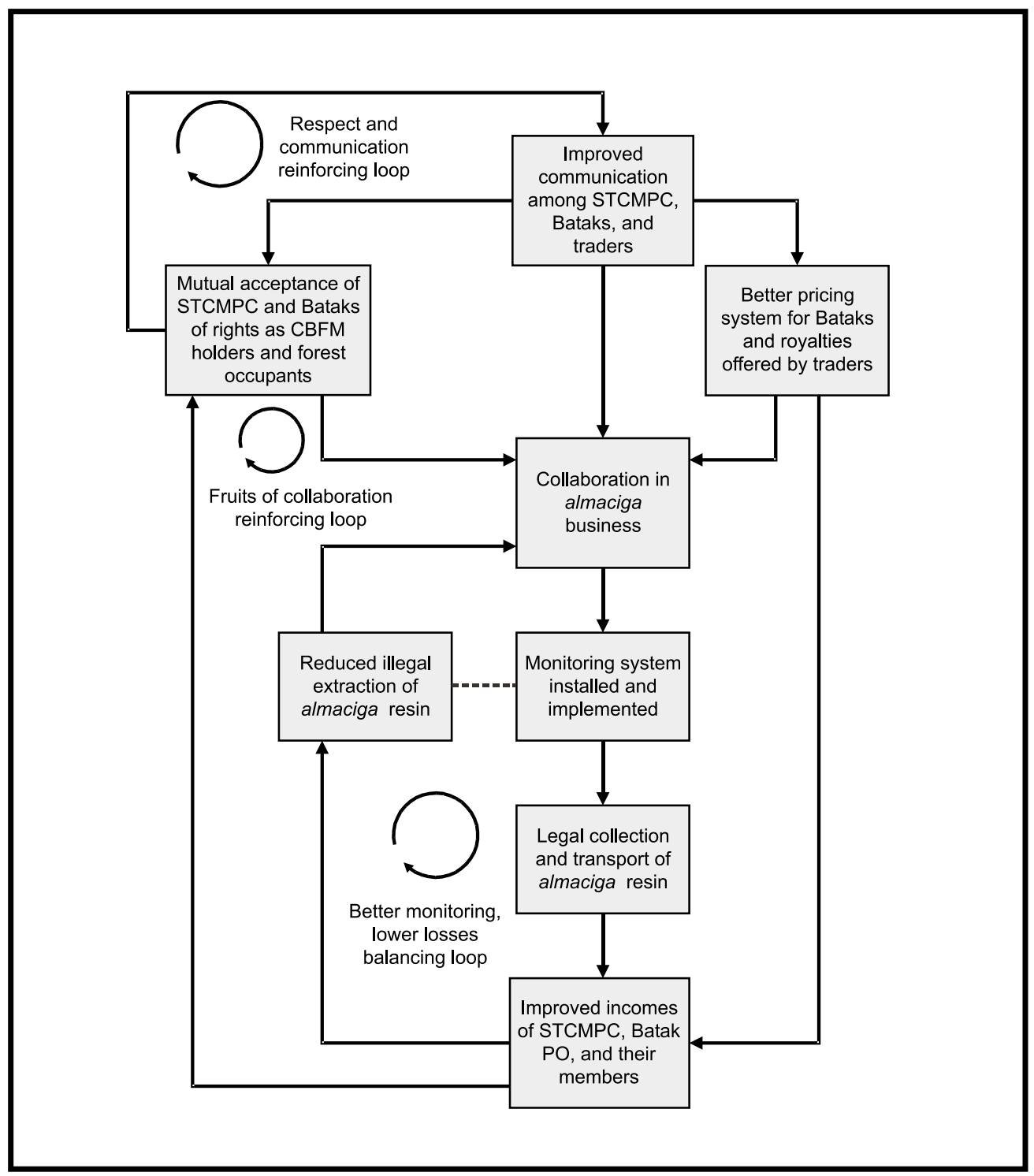




\section{A more democratic CBFM planning and decision making process}

Another spin-off effect of ACM was in the way the PO put together their annual work plan. The process was more participatory and involved different community groups. It was observed at the beginning of ACM that the management plan was put together by $2-3$ key persons in the $\mathrm{PO}$. The process did not involve wider participation from $\mathrm{PO}$ members and other community members.

With the increased awareness of the importance of involving other $\mathrm{PO}$ and community members in CBFM implementation and with better understanding of CBFM (as a result of better information sharing), the PO developed a rotation system in which a small group of PO members drafted the 2002 annual work plan and passed it on to other groups who improved the plan further.

Once they came up with the final draft of the plan, they invited community members and other stakeholders and presented the plan for their input and feedback. The comments were incorporated in the plan and the final management plan was then submitted to the DENR.

The approval process only took two months, in comparison with a previous plan which took them almost four years. This was also a result of the improved relationships and collaboration between the PO and the DENR (see Figure 13). 
Figure 13. Causal loop diagram showing the 'emergent' otcomes of ACM in making CBFM planning and decision making processes in the Palawan site more democratic

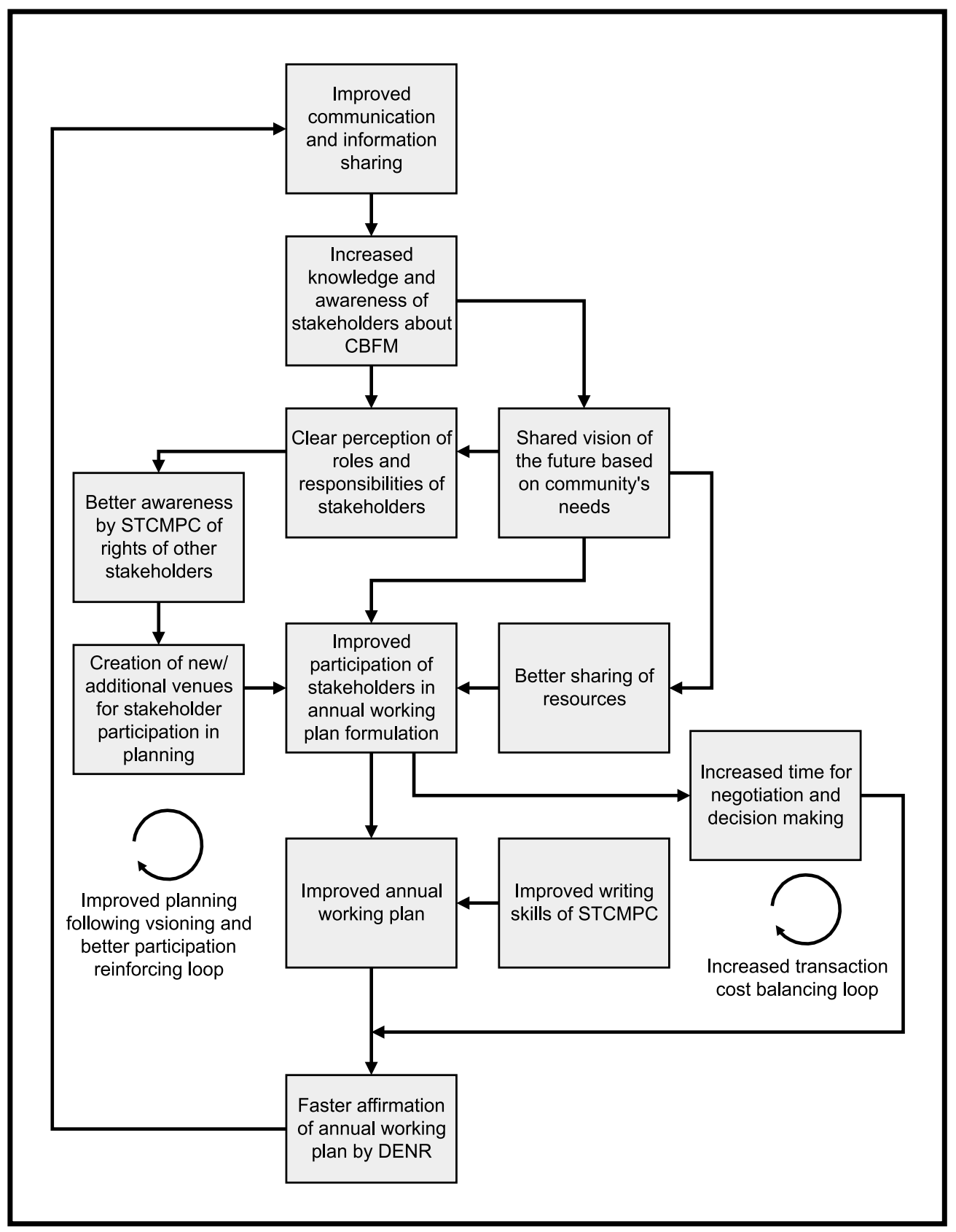




\section{6}

\section{CONSTRAINTS AND CHALLENGES}

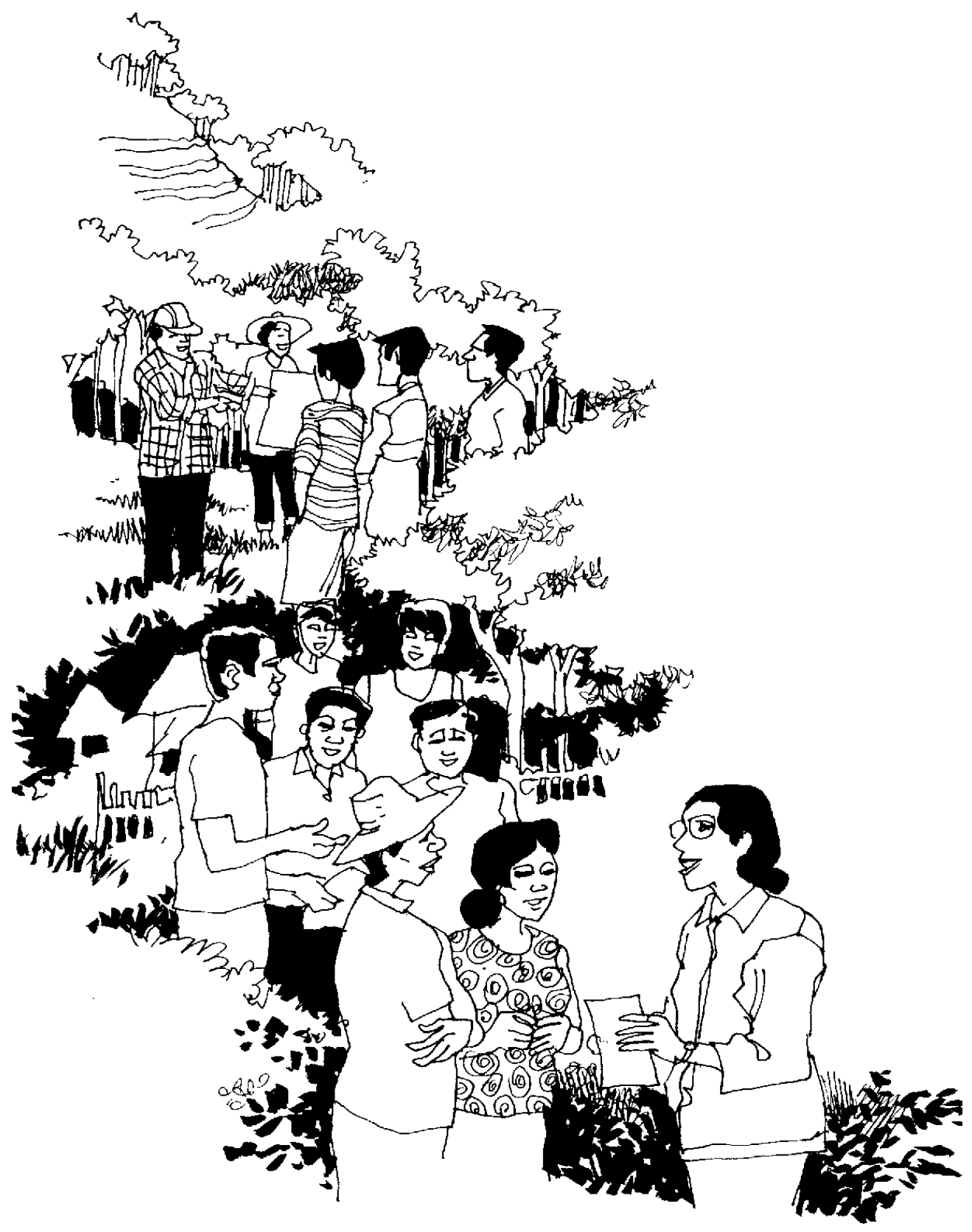




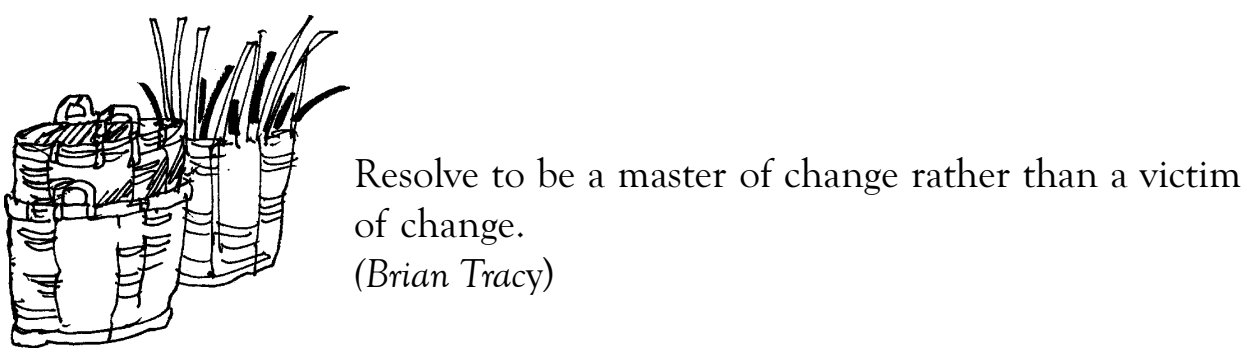


In this chapter, we present certain difficulties that we faced in using the ACM approach in CBFM activities. We also discuss the challenges that lie ahead for ACM practitioners.

We have described and shared our research findings on ACM in the two CBFM sites. The preliminary results showed that forest management, when implemented based on the ACM processes of collaboration, social leaning and adaptation, produced promising outcomes in less than two years.

ACM, however, is not the answer to all problems and it is not without limitation. Despite its unlimited application to various conditions, our research shows that ACM will be more effective in certain conditions:

- ACM has its values in complex conditions where various stakeholders with overlapping and conflicting interests exist. The situation in which there are only a few stakeholders with common views, interests, and goals for natural resources may not need the ACM approach.

- ACM is called for in a complex system where various systems interact with one another. In such cases, the complexity of the interactions and relationships among the elements make it impossible for certain problems, when they arise, to be solved with a single-fix solution. To solve problems in such situations, people have to try out or experiment, observe outcomes, and adapt. In situations where the solution is known, such as when a certain disease epidemic occurs in a village that can be handled with a certain tested medicine, or low harvest that can be handled with known silvicultural treatments, ACM will not be the most costeffective approach. Despite the fact that people can learn from experimentation, advances in science and technology offer many useful insights and ready solutions. In this case, there may be no need for the people to 're-invent the wheel'.

In implementing ACM, we found several challenges that determine the outcomes of ACM. These challenges are:

\section{Lack of willingness of certain stakeholders to collaborate}

As described in previous sections, each stakeholder group has its own interests. In situations with diverse stakeholders, diverse interests also abound. For instance, local people tend to be more interested in land tenure and better livelihoods. On the 
other hand, government agencies may be more interested in forest protection and rehabilitation, while businesses are more interested in profits. In this case, ACM can be applied only if there is willingness from relevant stakeholders to discuss, negotiate, and work together towards common goals.
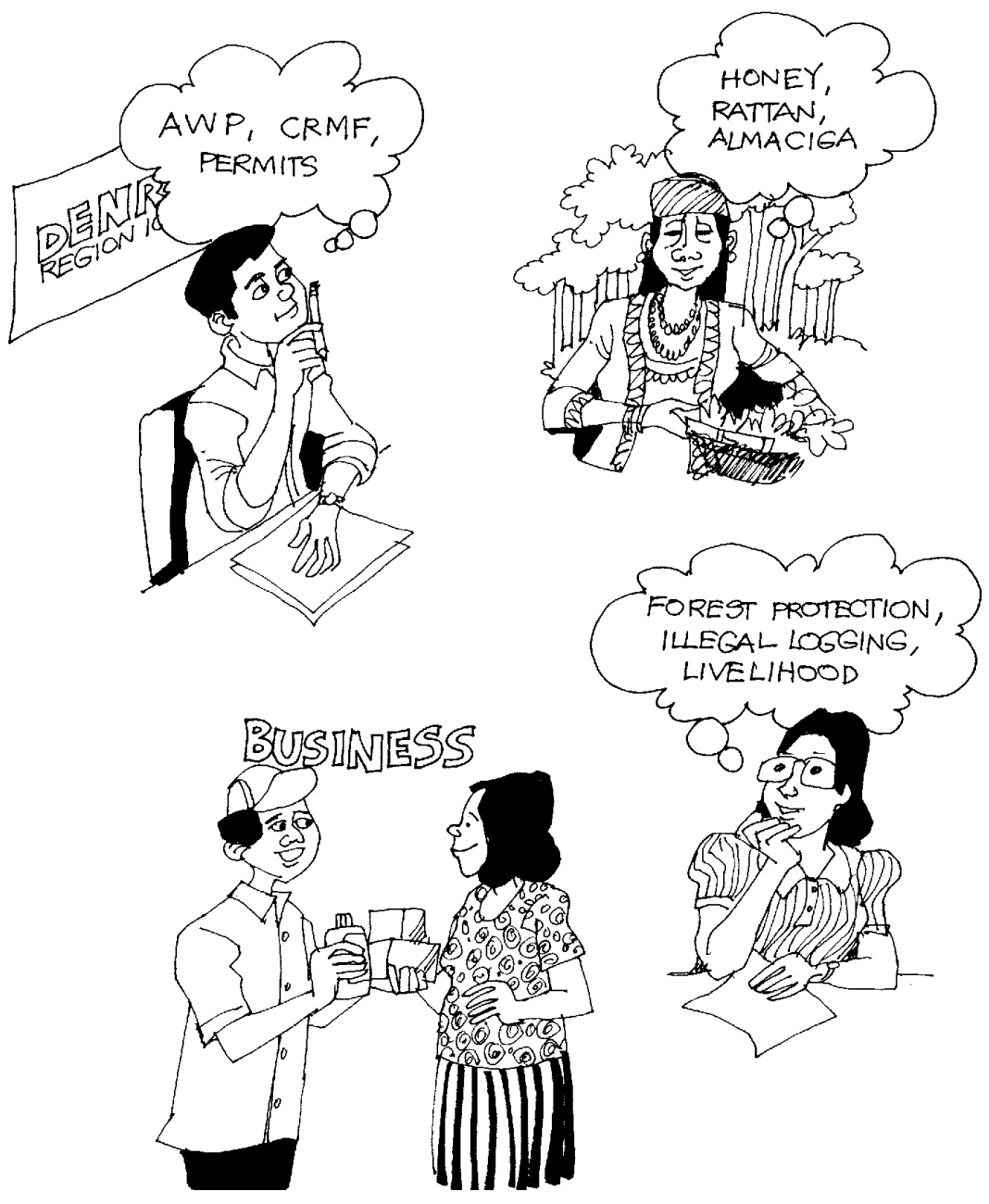

In some situations, there was a long history of conflicts between certain institutions or individuals. If conflicts are really high and unmanageable, a deadlock situation may occur in which the conflicting organisations or leaders refuse to accept their differences or to search for a common ground for collaboration. In a situation like this, our experience showed that ACM can not be applied and produce outcomes unless there is a change of attitude, behaviour, or awareness on the part of these organisations or leaders. It may be necessary to wait for a change of leadership in which the new leader is more willing to collaborate. When consensus is reached over the management goals and how to reach them, collaboration can take place. 


\section{The need for a 'neutral' facilitator}

ACM obviously requires a facilitator who is perceived to be relatively neutral and can gain the confidence of related stakeholders at different times on different issues to effectively facilitate the process. In the absence of ACM researchers, members of the PO or community, field officers of DENR, LGUs, NGOs, or a combination of them can play the role of facilitating ACM processes for different issues. The challenge will be for the staff of government institutions and organisations to put aside their institutional mandates and interests so that they can really facilitate the processes to meet the groups' goals.

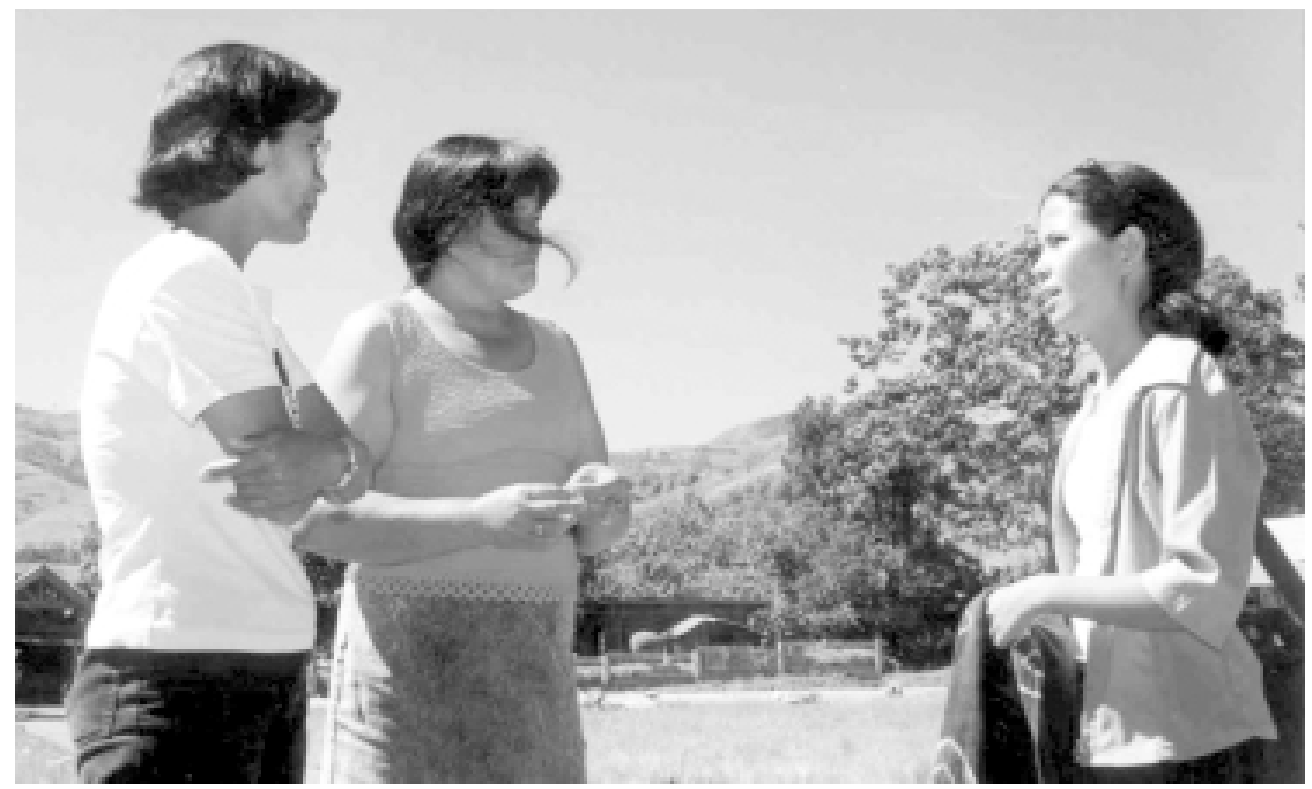

In facilitating ACM processes, what is obviously needed is a neutral facilitator who can set aside organisational affiliation and who can easily gain the trust of various CBFM stakeholders.

\section{Low self-confidence, self-reliance, skills and capacity of the local people}

ACM researchers have had to work hard to change the dependency and dole-out mentality common in their communities. Having been used to quick-fix solutions provided by other agencies in the past, e.g. animal dispersal, loans, infrastructure establishment, local people expected the ACM project to provide similar cash and assistance.

The feeling of inferiority, lack of confidence to negotiate, debate, and perhaps the long history of discrimination and marginalisation are several factors that prevent local people from reaching out and establishing linkages to services and appropriate institutions. 
In Basac, the attitude of ulaw (shame) makes it hard for them to do so. A simple letter to government agencies requesting services is difficult to produce because they are ashamed that their English or composition might not be good enough to get the attention of such offices.

This attitude needs to be changed to a more positive one. Our research shows that this can be achieved by facilitating the development of communication skills in the community and thus, also improving their confidence. This becomes crucial as provided by the following example. In late 2002, an outbreak of typhoid fever and diarrhea occurred in Basac community. The disease caused the death of little children, while a dozen were hospitalised and over 30 people were sick, as the disease was not diagnosed properly. The people felt helpless. A simple letter written by a barangay resident (a former NGO worker) requesting basic medical services and sent to the higher LGU, coupled with constant follow up by the barangay captain, prompted the Municipal Health Office to provide the needed service.

Furthermore, in indigenous communities such as the Talaandigs in Basac, language can become a barrier to articulating their distinct culture and interests. This has been a persistent problem that makes local people especially the indigenous people dihado (disadvantaged) in most situations where their well-being is at stake. The old dignity of their culture faded away with time and they became sulugo-on (servants of authority). For example, when government officers come to their villages and call a meeting, local people would go to extraordinary lengths to find a means to attend simply because the mayor or someone in authority had called for it. They also tend to be easily persuaded by people in authority even if it is against their culture or welfare.

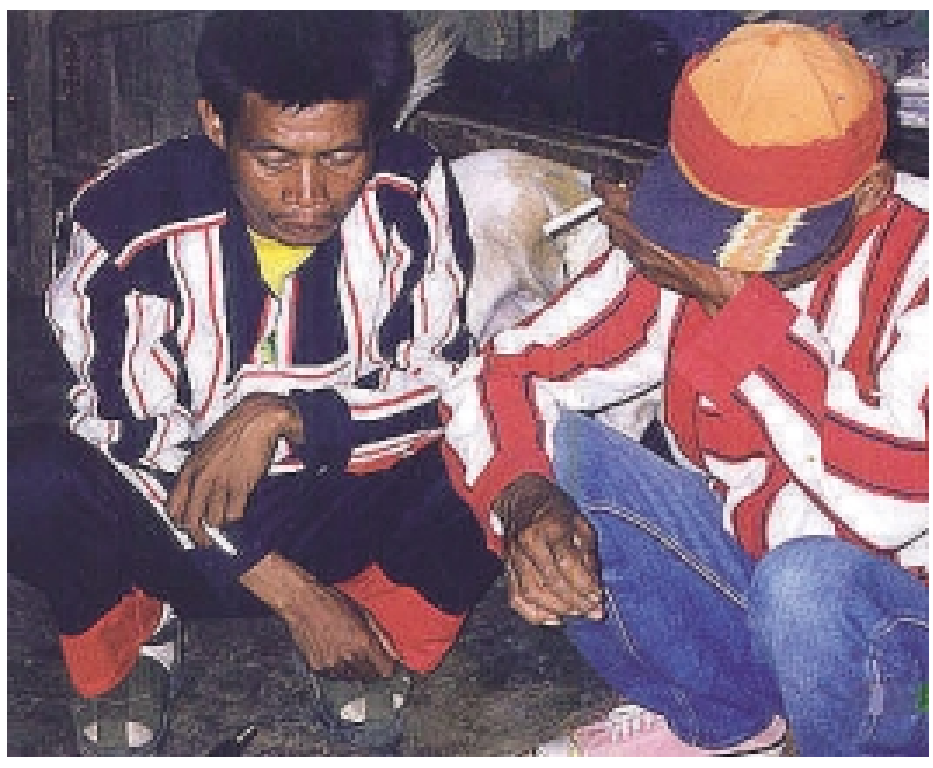

Indigenous people may not be as equipped with the necessary communication skills to articulate their aspirations and needs. This has led to certain difficulties in employing the ACM approach. 
ACM must deal with these attitude and behaviour, and at the same time try to enhance the capacity of the people in basic communication skills, such as expressing their views to other stakeholders, writing letters and proposals, documentation, etc. This must be done before action at the next level, such as strengthening their voice through representation, networking, and alliance building, can take place.

\section{Poverty}

ACM promotes collaboration, communication, experimentation, and adaptation that require resources on the part of the people. When financial and other resources are really scarce, ACM can be caught in the middle of the process of promoting selfreliance and encouraging people to depend on their own resources and capacities. Furthermore, the results of the process may not be immediate.

Direct economic benefits are most needed in places where the people are struggling with poverty. As one local person of Barangay Basac pointed out: 'Ayuwa un malugun sa kaghunhuna hu kaayuhan para sunud ha lalima ha tuig ku hura nud makaun asuma ku maanlaw, samut un kalugun hu paghunhuna para hu kaayuhan hu sunud ha kabukalagan ku hura nu gani ikapakaun hu kabataan nu iman (it is already difficult to think about longterm benefits coming to us in the next five years when today we are hungry and have nothing to eat for tomorrow; it is more difficult to think about the future generation when today you can hardly feed your children)'. Facing these realities, people unsurprisingly selected, for their local priority to be addressed in an adaptive and collaborative manner, things that would produce relatively immediate results and contribute directly to their livelihoods.

\section{Lack of enabling and conducive environment}

The ACM research project is likely to be only one of the many 'actors' working in the area. There will always be other NGOs and government agencies that bring development projects and programmes to the people. They can demand time and attention from the community. Furthermore, they might offer dole out and quick cash that induce the very dependencies that ACM is trying to eliminate. Having their own targets and goals, these organisations and agencies cannot readily change their schedules or the way they deliver their assistance to the communities.

Nevertheless, our experience showed that certain DENR, LGU officers, etc. could be very open-minded and receptive to new concepts and ideas. Many have faith in local people's capacity and willingness in managing forests. They also have respect for their values, culture, and norms. They are visionary leaders who usually do not heavily rely on the 'command and control' approach. They can create and open up space at 
the local level that can be conducive for learning, creativity and novelty to emerge. It is important to identify people with these characteristics, as they are really key facilitators and partners for ACM.

\section{Relatively short project timeframe to promote internalisation of ACM processes}

ACM facilitates social changes that take a longer time to achieve and internalise. Outcomes have been attained within the project timeframe but the process of learning and adaptation requires a longer time to be facilitated properly, especially in places where all the above-mentioned challenges exist, before they will be internalised by the people.

It is therefore important for the ACM concept and processes to be adopted and promoted by government agencies and LGUs so that they can take up the role of facilitators, incorporate the ACM concept into their own programmes, and support local people in managing forest resources in an adaptive and collaborative manner.
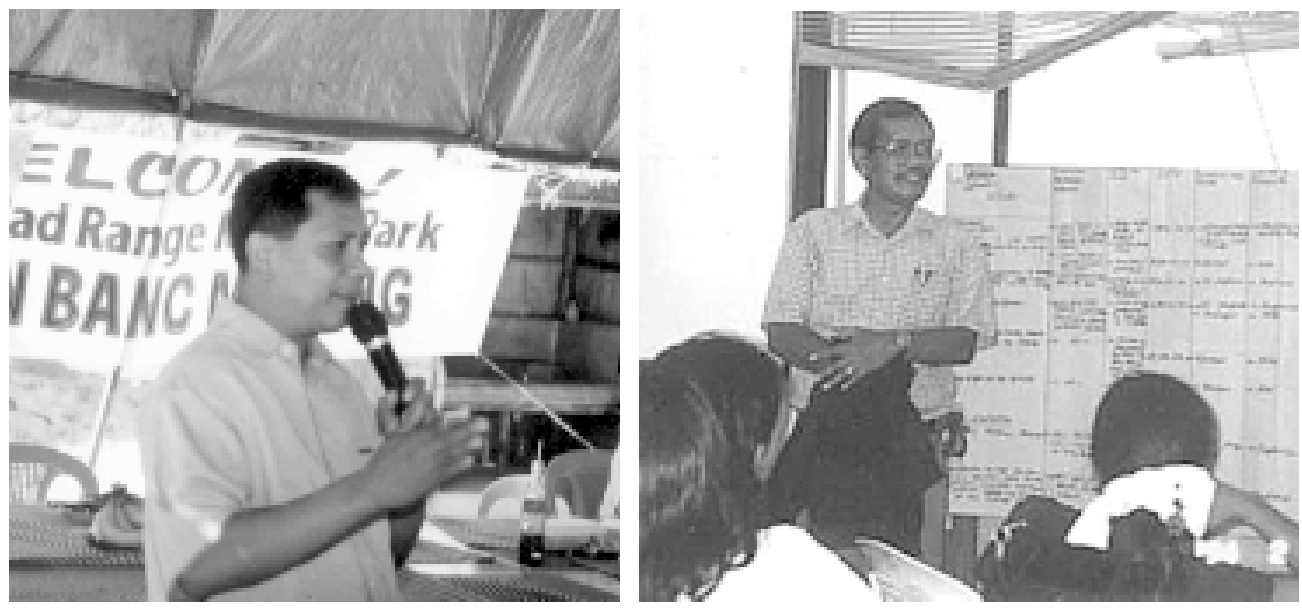

DENR, LGU officers, and other field workers can be very open-minded and receptive to new concepts and ideas. They can become key facilitators of the ACM process. 


\section{IMPLICATIONS OF ACM ON CBFM}

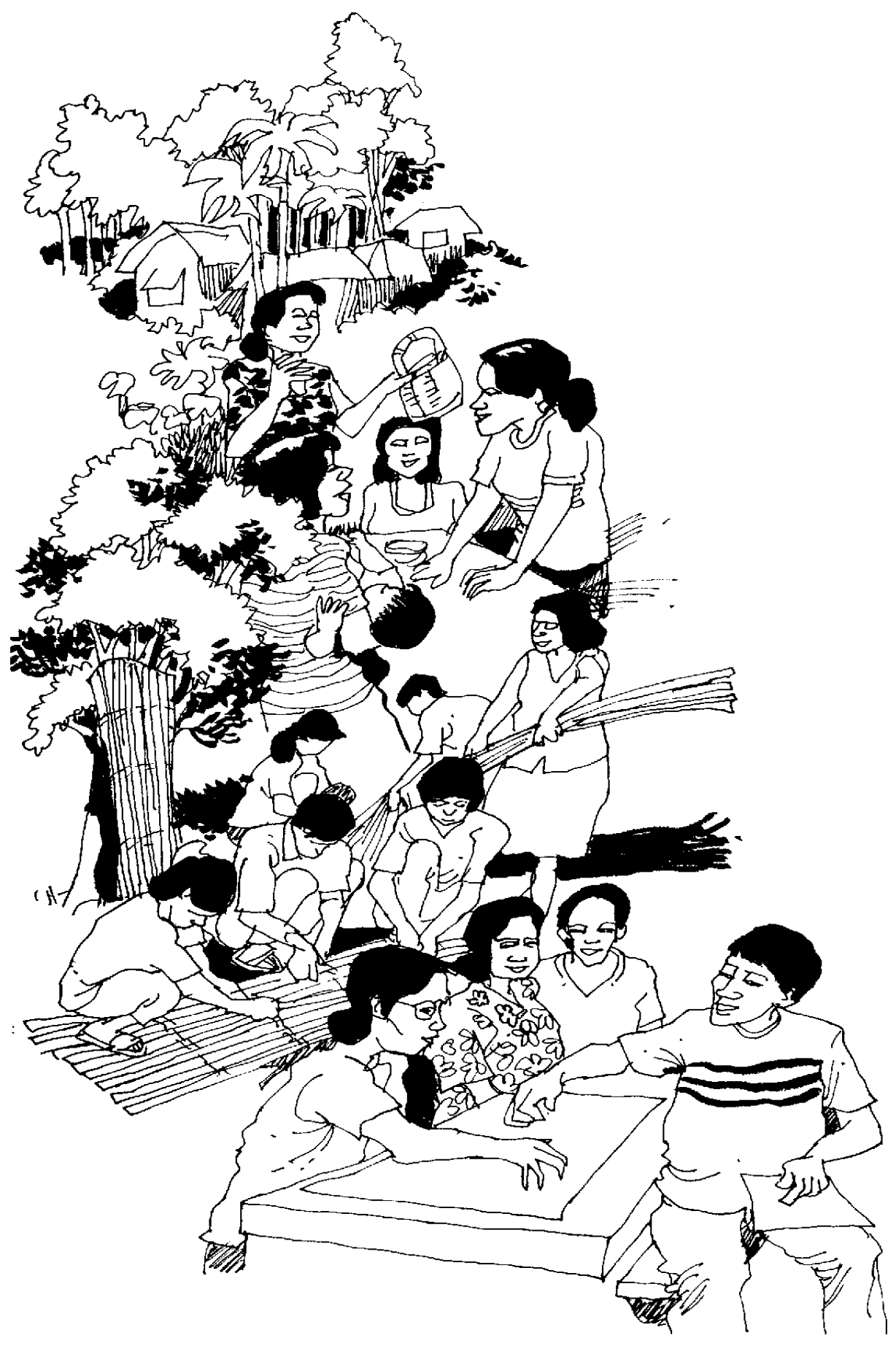




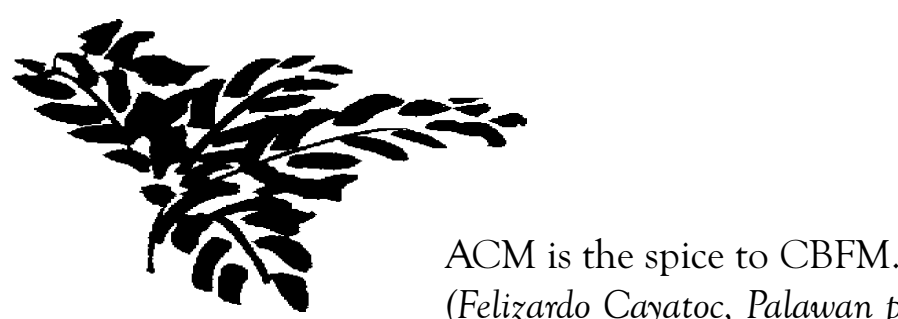

(Felizardo Cayatoc, Palawan provincial DENR, 2002) 
This chapter covers the important implications of the results of our ACM research. We feel that the future CBFM programme in the Philippines can be reoriented to accommodate these implications. We believe that doing so can greatly enhance the success of CBFM in the entire country.

The results of ACM research showed that for ACM to be effective, a conducive and enabling environment needs to be created. These have some implications for the way community forestry in the Philippines is implemented. Several important implications are as follows:

\section{Proper stakeholder analysis prior to tenure grant}

- Our research revealed that the rights to manage the forests under CBFM were granted not always based on proper analysis of who depends on the resources nor consideration of the histories of resource management. Once tenure is granted, planning and decision-making are also often centralistic and are dominated by several key $\mathrm{PO}$ members without full participation from other $\mathrm{PO}$ members, community groups and stakeholders. The formation of POs has often created divisions and conflicts within the communities and with other local stakeholders which later hinder effective management of the CBFM area.

Mechanisms and processes in granting tenure for POs should include proper identification of stakeholders, their interactions with natural resources, their interests and roles in forest management, etc. so that relevant community groups and stakeholders are not excluded and marginalised in CBFM implementation.

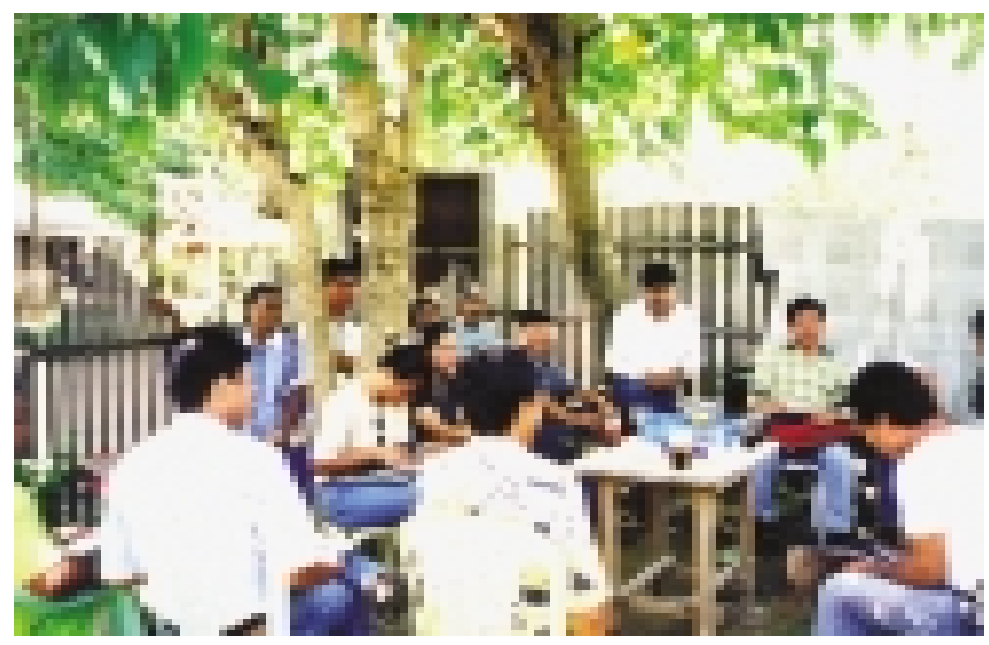




\section{Participation of other government agencies and NGOs}

- The complexity of the issues faced by the POs in managing a CBFM area is beyond the capacity of the DENR to handle on its own. This is especially relevant now when DENR's financial resources are limited. Different institutions and organisations may have different skills, knowledge, and resources that cannot be offered by DENR. More importantly, we observed that they were generally willing to assist the POs in their endeavour if it is within their capacities and mandates.

DENR, as the institution that oversees the overall implementation of CBFM in the Philippines, needs to create 'space' for other government institutions and NGOs to participate.

\section{Multi-stakeholder forums for CBFM}

- At the implementation level, a platform that brings relevant stakeholders together to share information, discuss the issues of concern, collectively plan and proactively implement such plans has proven to be effective. This is because this multistakeholder forum brings out into the open information that is kept separately by different stakeholders. Also, this forum brings together different perspectives, experience, and knowledge that are useful in solving problems creatively. Our research findings revealed that such a forum would be effective only if it has decision making power, and if the participating institutions and groups are committed, have the capabilities to address the issues, and most importantly have the right attitude and behaviour.

DENR should share its decision making power with other government institutions and facilitate the formation of multi-stakeholder forums in places where there are overlapping interests, and ensure that necessary conditions are provided for the effective functioning of such forums.

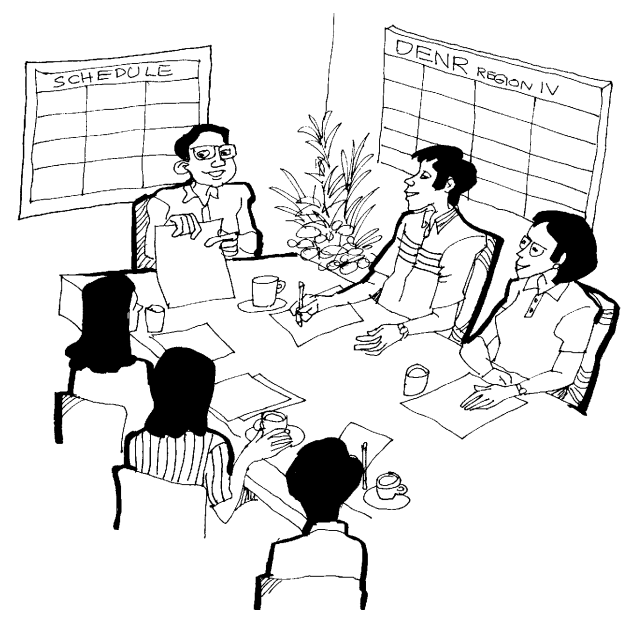




\section{Simplified CBFM policies}

- One of the challenges of the POs is to cope with the complexities of the DENR regulatory requirements. Policies and regulations are written in legal language and are not fully explained to local-level DENR officials. This has led to misinterpretations and unintended enforcement. Furthermore, complicated and detailed regulations hinder their wide applications in the very diverse situations found in CBFM sites. They also suppress the emergence of innovative solutions and initiatives.

DENR must simplify its regulatory requirements and move away from a blueprint approach. This implies that the locus of action planning and decisionmaking for CBFM should be transferred from the national level to the local level, with the national level maintaining responsibility for setting overarching policies and facilitating an 'enabling environment.'

\section{Adoption of deliberate learning processes}

- We observed that the CBFM planning and implementation at both ACM sites in the past were quite mechanistic and linear. There was no tight feedback loop based on reflections on the implementation processes and outcomes that could have strengthened subsequent planning.

The cycle of reflection-planning-action-reflection should be done intentionally and self-consciously practised as an integral part of CBFM planning and implementation.

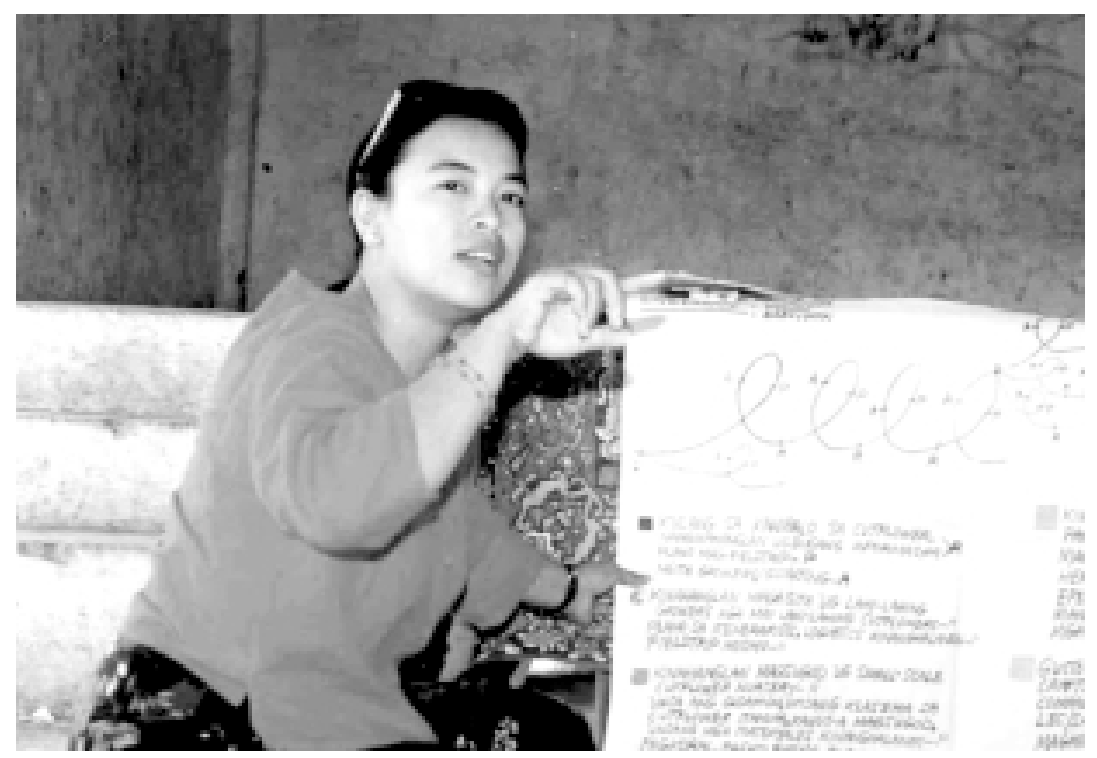




\section{Effective facilitation}

- We learned that the processes of making learning conscious and deliberate have to be facilitated properly. At the same time, as the POs mature and acquire the necessary technical skills, they will be less dependent on the technical assistance from DENR. Naturally, the role of DENR in the future should be more facilitative.

DENR, as well as the other relevant government institutions and NGOs, have to equip their field staff with sufficient facilitation skills, and the staff should in turn, possess the necessary behaviour and attitude.

\section{Monitoring for learning and adaptation}

- DENR has made tremendous efforts to establish a monitoring system that could be modified and adopted by the POs on a voluntary basis. Our experience showed that there is still a need to build the POs' documentation skills and capability to analyse and interpret monitoring results. We also learned that the POs would monitor only if the results are meaningful and useful to them. Consequently, introducing a monitoring system more for the purpose of reporting to DENR is not likely to produce the intended results, i.e., adoption by the PO.

There is a need to re-orient the purpose of monitoring - from monitoring for reporting and accountability to monitoring for the purpose of learning and adaptation.

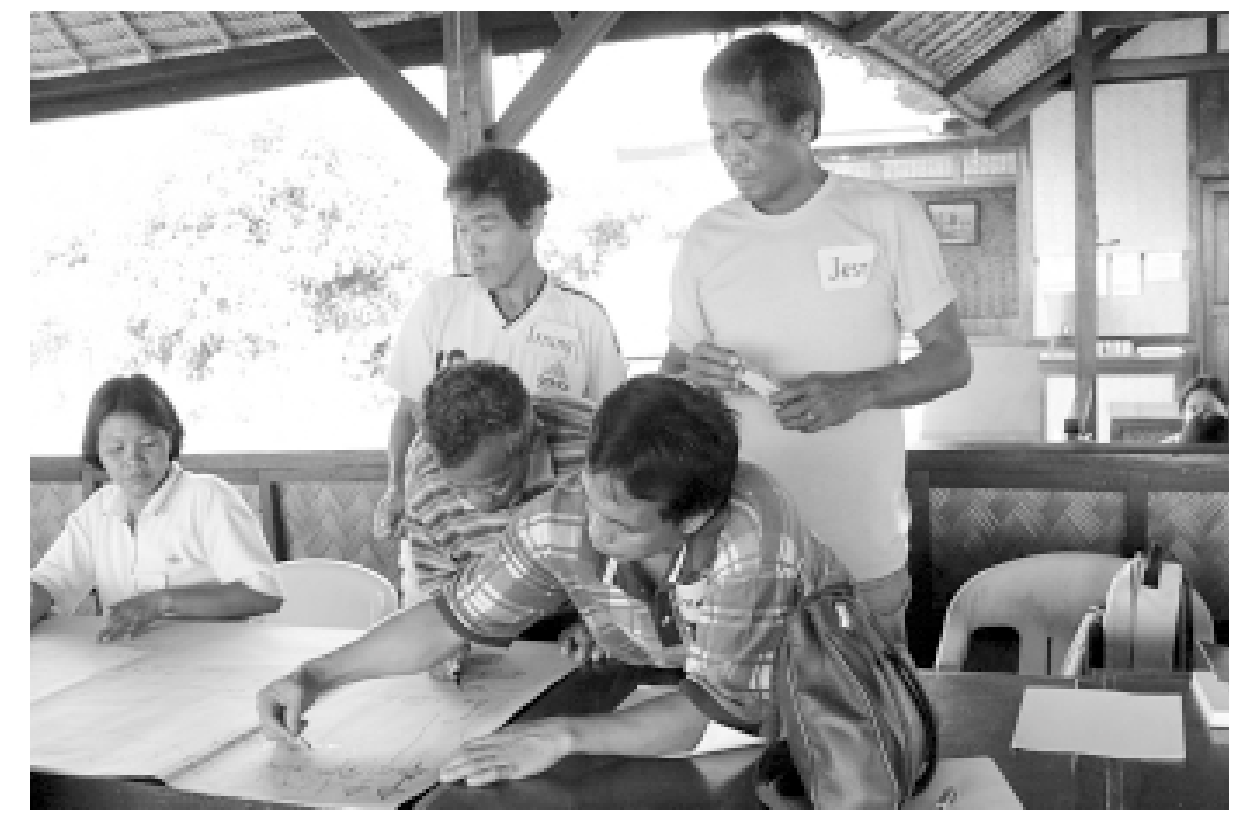




\section{Holistic development of CBFM areas}

- There has been a lot of attention given to the technical and productivity aspects of CBFM management. Less attention was given to the social, economic and institutional aspects, as shown for example in the lack of livelihood options and low capabilities of the POs in effectively managing their CBFM areas in our ACM sites, that may have more significant effects on CBFM implementation.

Holistic approach should be applied in CBFM planning and implementation. Different aspects should be considered to meet the long-term goal of forest conditions improvement while enhancing the capabilities of the people in forest management and meeting their immediate livelihood needs.

\section{Considering the learning pace of the POs}

- We observed that the POs were sometimes slow in addressing issues and in implementing certain activities. This is especially true when they encountered new things and when they did not have sufficient capacity and skills. CBFM is a new initiative to most of them despite their past experience in managing forest resources. Quite clearly, there are limits to the extent to which processes of adoption and adaptation can be speeded up.

There is a need for CBFM to adjust its implementation pace to allow the POs to internalise what they are learning properly.

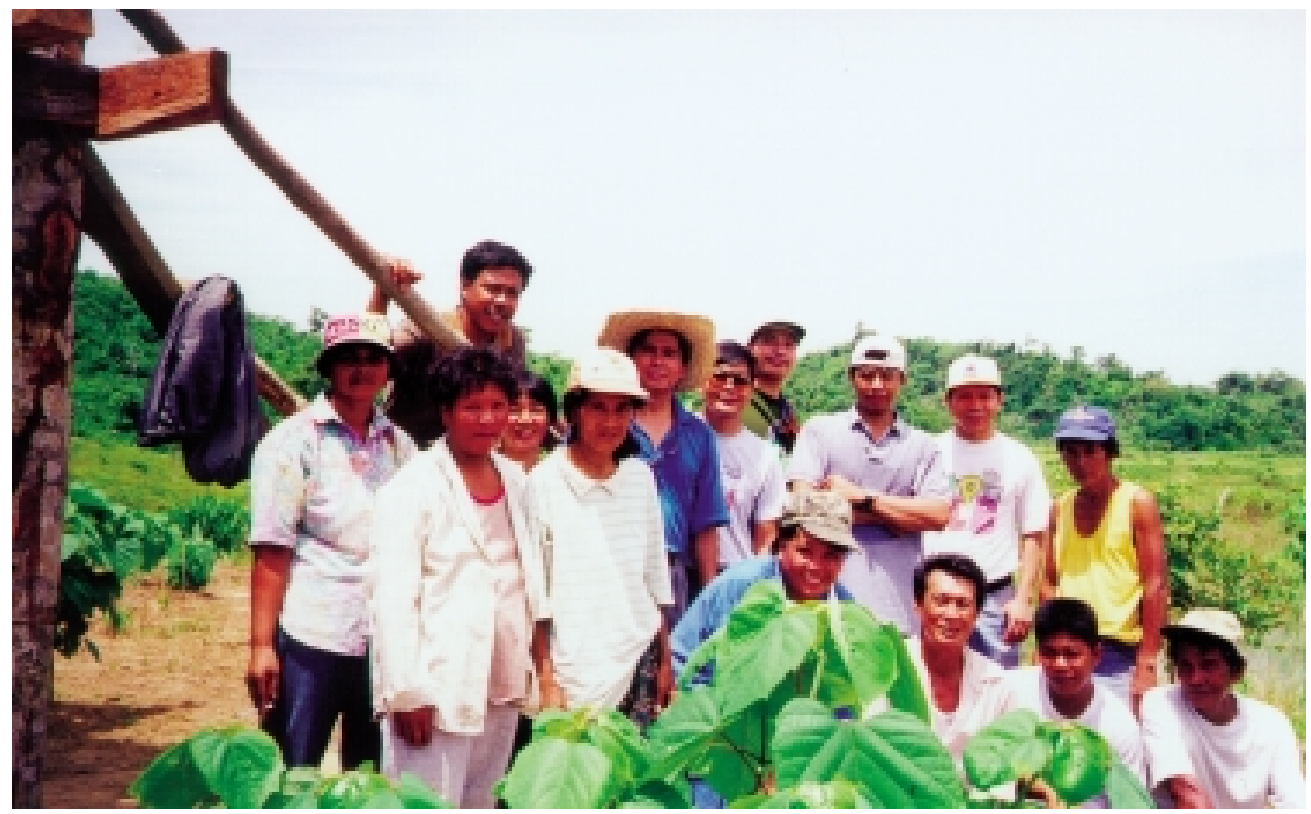





\section{8}

\section{CONCLUSION}

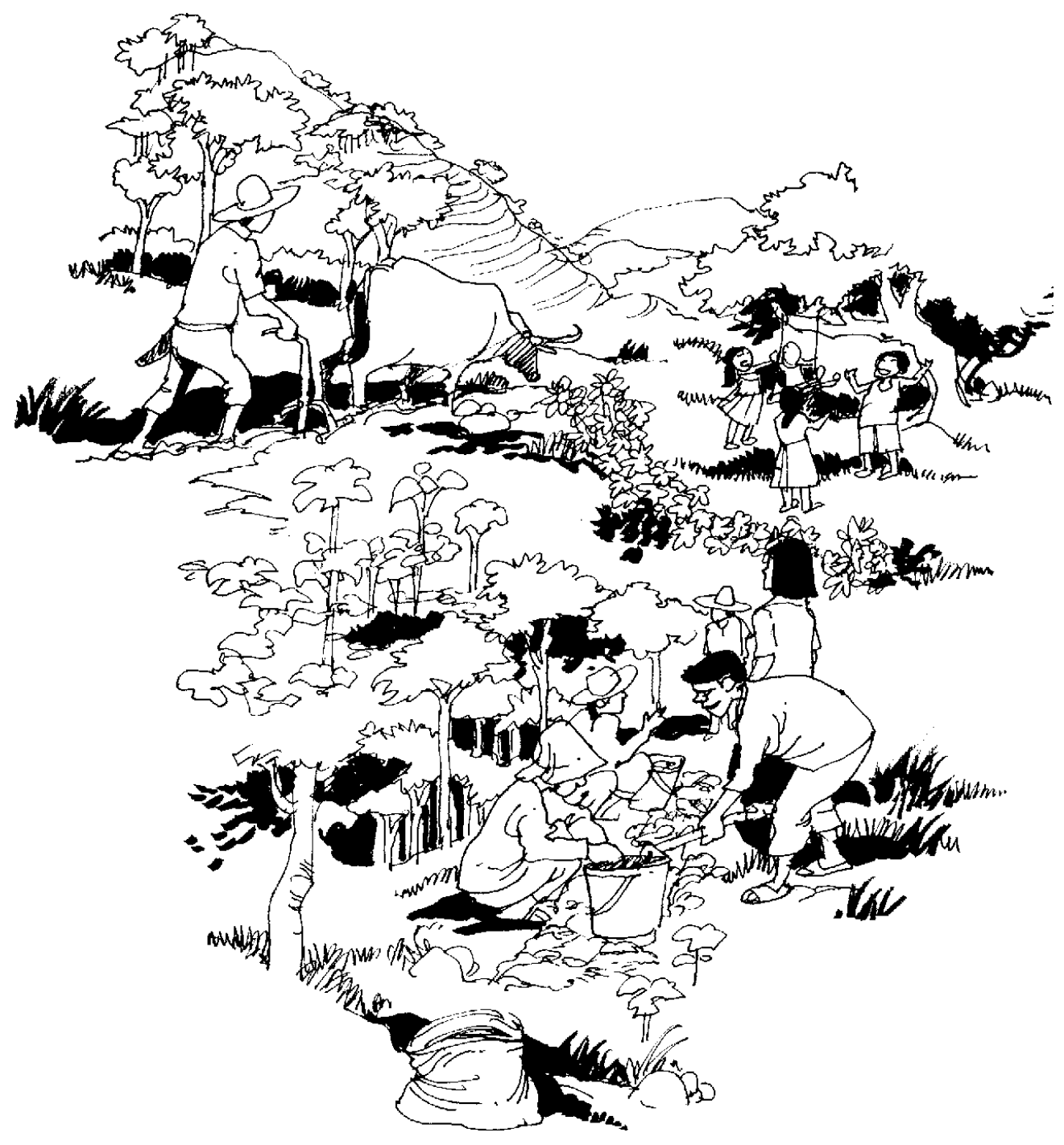




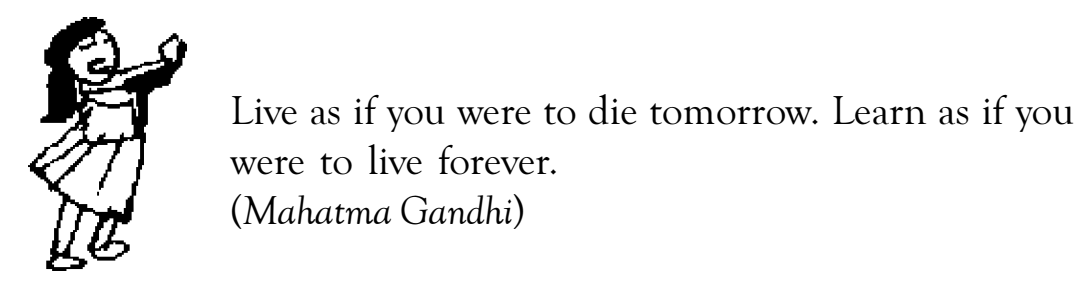


In this chapter, we summarise the processes and the results of our ACM research work. We conclude that indeed, ACM can add value to CBFM implementation in the Philippines.

Our research findings showed that the adaptive collaborative management approach adds value to CBFM planning and implementation by making the processes more participatory and focused. It engages relevant POs, community members, and local stakeholders who may have been previously excluded in such processes as planning, decision making, learning, and action.

Furthermore, the structured and intentional learning processes, i.e. the continual reflection-planning-action-reflection cycle, encouraged the POs to observe and monitor the outcomes of their decisions and adapt their subsequent actions. These also improved the capacity of the POs to better deal with the ever-changing situations and uncertainties in managing forest resources.

ACM is about making collaboration and learning intentional and deliberate throughout CBFM planning and implementation. It is an iterative process through which gradual and incremental improvements will occur.

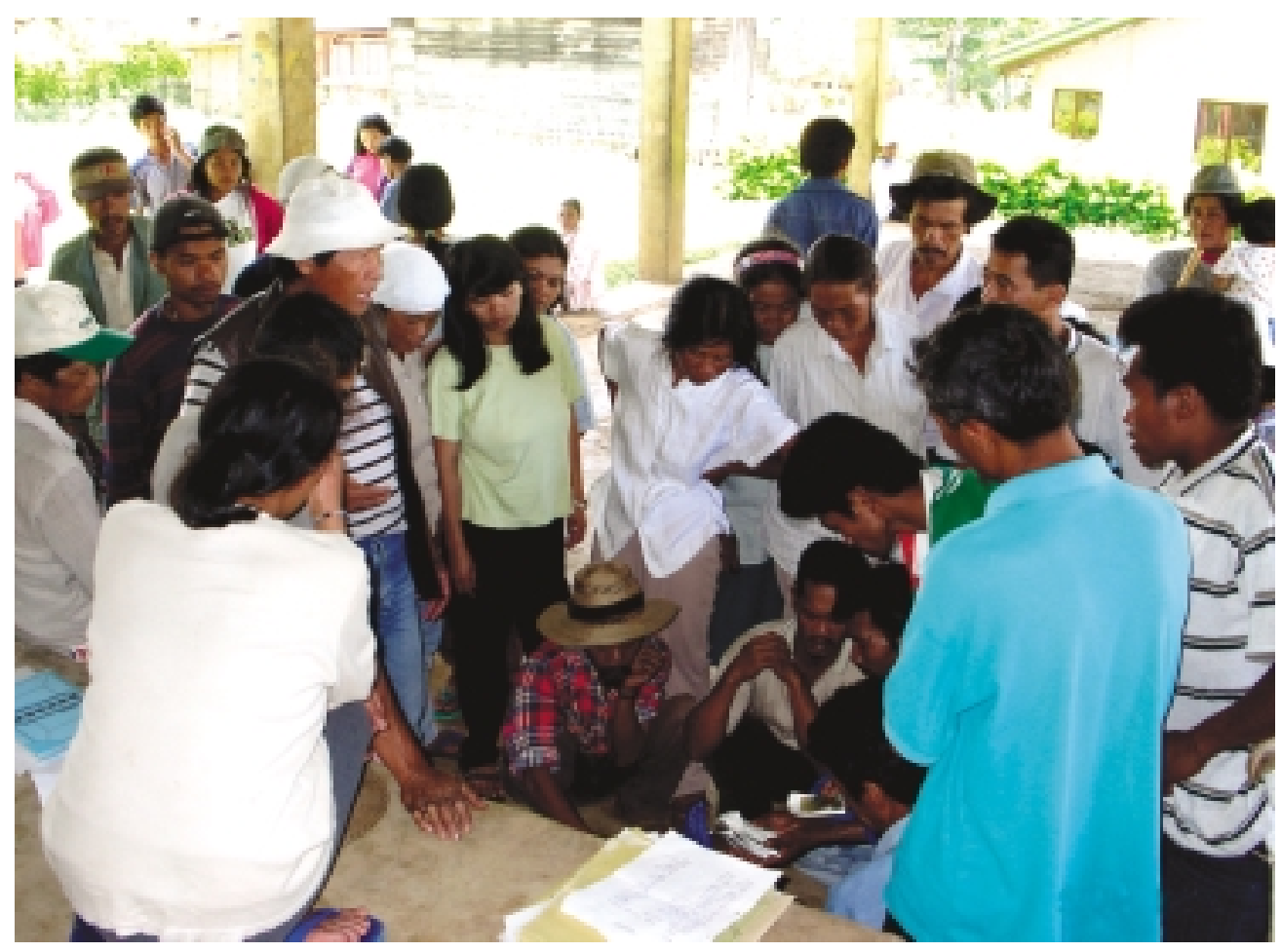




\section{ACM improves various skills}

The results of our work in the two sites showed that there were improvements in the skills and capacity of the POs and community members in:

- documentation;

- expressing and communicating their views and opinions;

- effectively using different mechanisms for information sharing (e.g. billboards, bulletin boards, newsletters, different forums);

- networking;

- proposal writing; and

- managing small enterprises.
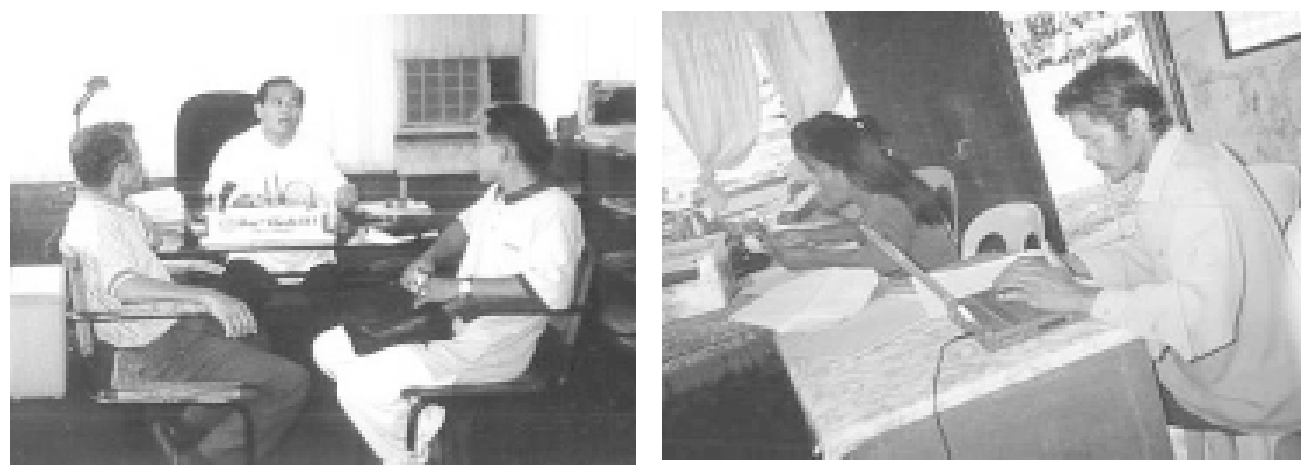

The ACM approach significantly contributed to the improvement of the PO's organisational and management skills. Photos above show the PO members in dialogue with the DENR (left) and employing new computer skills for the production of their newsletter (right).

Improvements were also observed in the level of trust, communication, and relationships within the POs and across stakeholders, which resulted in improved collaboration and participation in planning and action. In the end, the POs enjoyed stronger support from various government institutions and NGOs in implementing CBFM. The POs have also become more aware of why they have to reach out and engage other community members and stakeholders, and to manage, rather than, avoid conflicts.

We also observed increased self-confidence and self-reliance of the POs. They have were exercising a more democratic decision-making process and were employing an improved long-term planning process which resulted from their more forward-looking orientation. All of the above improvements should enable the POs to manage the forest resources and their CBFM areas in a sustainable manner, and share the benefits from CBFM equitably. 
Due to our relatively short project duration, no significant improvements in forest conditions and people's livelihood were observed. However, several income-generating activities were initiated from a wider range of forest resources (from lumber only to non-timber forest products) and finished products. Incomes were also generated from these activities.

\section{Conditions where ACM can be most effective}

The ACM approach is not without its limitation. However, we pointed out earlier that ACM would be an appropriate approach to deal with complexities and uncertainties. It has its values in conflicting multi-stakeholder situations, where people are willing to negotiate, resolve their conflicts, and work together.

ACM may not be the most effective approach in situations where:

- There are few stakeholders with common views and goals.

- Deadlock situations where the level of conflict is high and the conflicting stakeholders are not willing to manage the conflict.

- The problem is simple and the solution is readily available so that the long process of learning and iteration to find the 'best solution' is not needed.

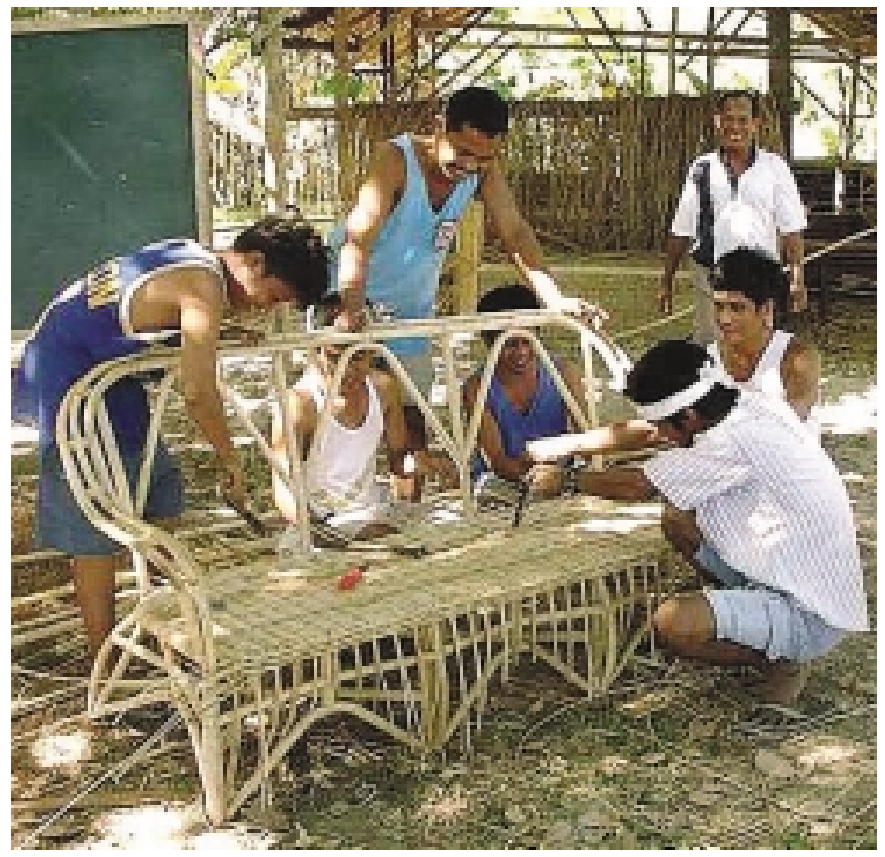

While the strong point of ACM was the strengthening of the PO's skills in organisational and management aspects, the ACM project nevertheless provided opportunities for the POs to engage in livelihoods like furniture and handicraft making.
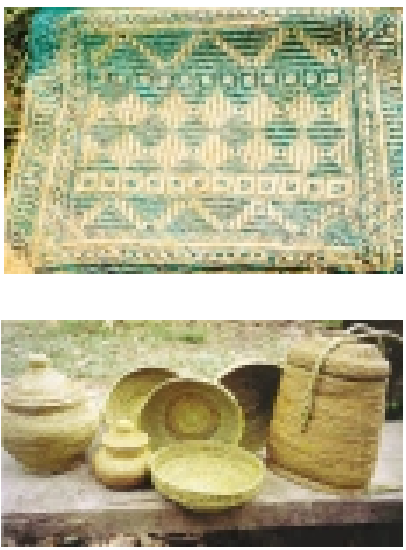
Generally, the ACM approach could be applied in various conditions and contexts in the Philippines. It is likely to produce immediate outcomes when:

- Level of conflict is manageable.

- There is effective facilitation.

- The PO is strong and has the capacities and resources to negotiate and deal with more 'powerful' institutions, establish linkages, learn and adapt.

- There is a conducive and enabling political environment.

Despite its difficulties and challenges, we found ACM can really help in empowering local people. This is because ACM recognises the inherent creativity of human beings and builds on it to create a more effective natural resource management and community development. We and our partners found the experience of applying ACM to be uplifting, and we hope you will too.

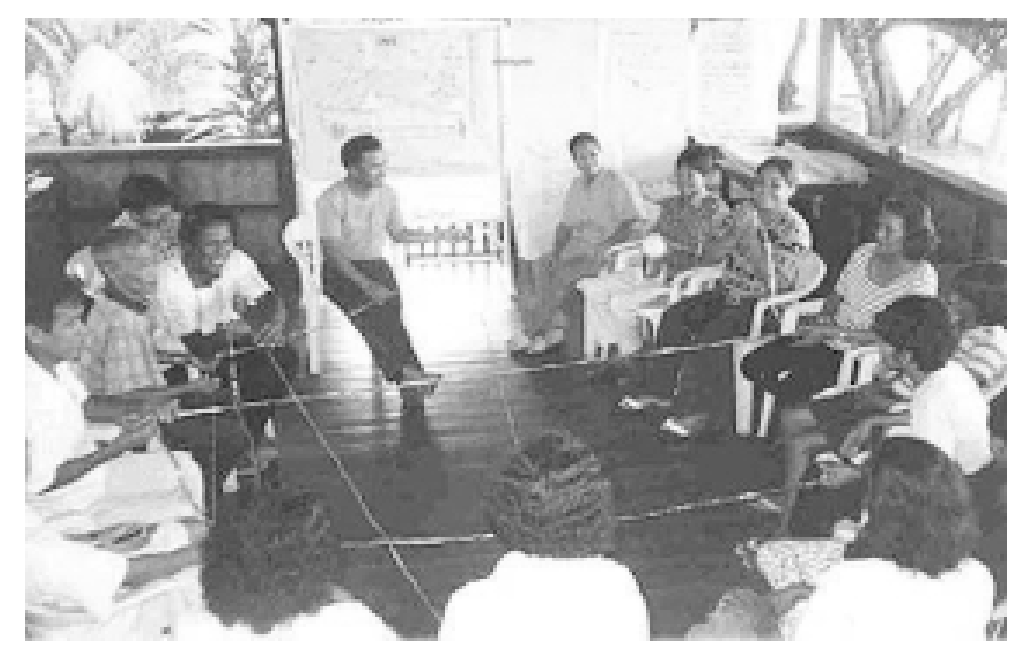

ACM can be an effective approach in situations where multi-stakeholder interests collide but willingness to negotiate and work together exists. 


\section{ANNEXES}

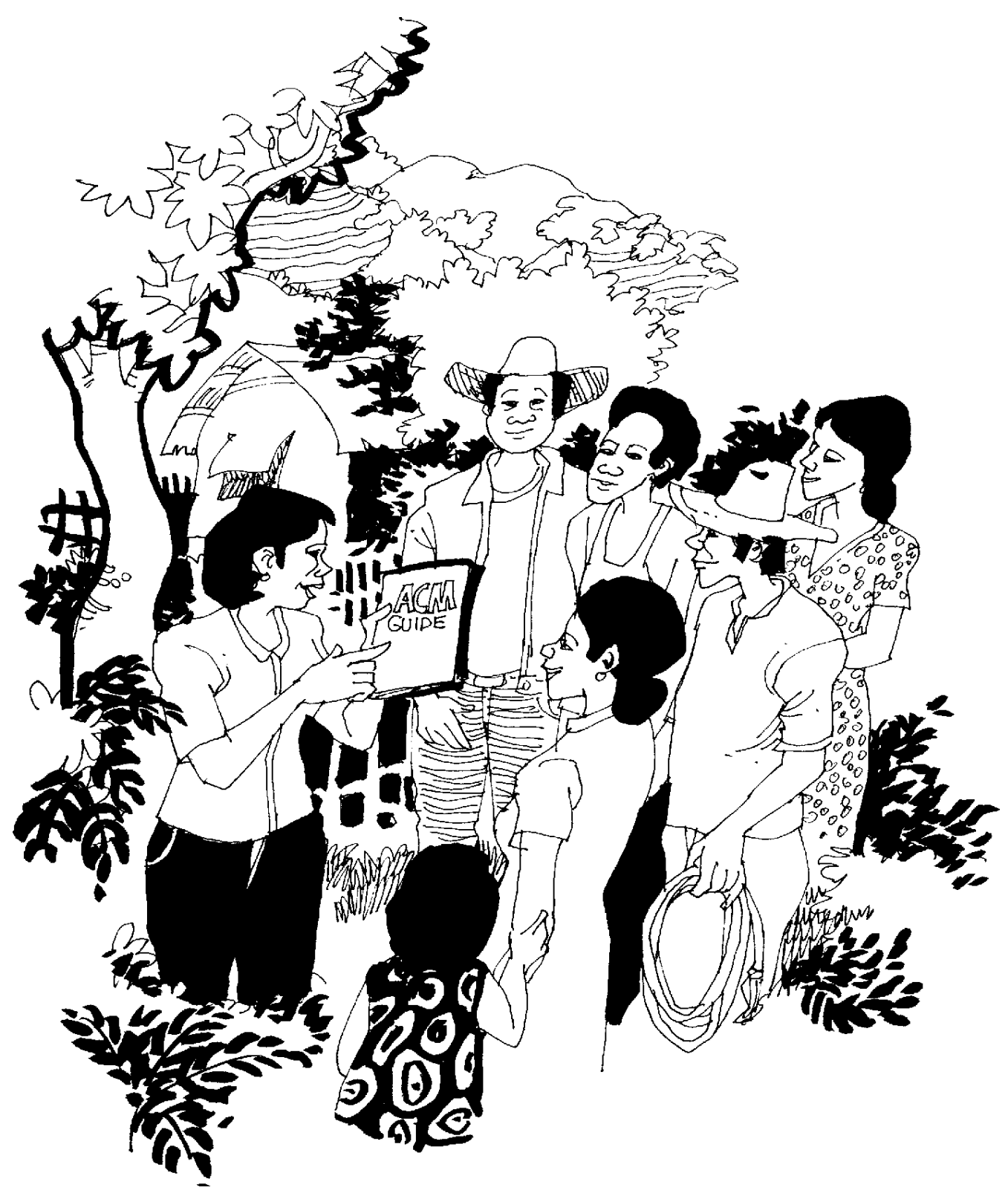




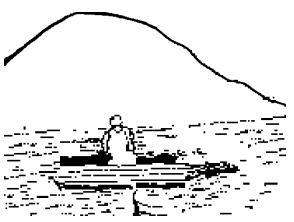

Give a man a fish and he will eat for a day; teach him how to fish and he will eat for a lifetime. (Chinese proverb) 


\section{ANNEX 1 \\ A GUIDE ON HOW TO IMPLEMENT ACM PROCESSES}

A very important element of the research process is that researchers should share the results of research with others so that the information is used and applied. In our case, we take great pleasure in sharing with you, our readers, some practical guidelines on how you can apply the ACM approach in your work.

We hesitate to break down the ACM approach into rigid sets of steps, as its application requires flexibility and creativity of the practitioners to identify different ways in which they can apply the ACM approach and processes. There is the danger those steps will be treated strictly like a recipe or a prescription so that important elements and principles are lost on the way. Despite this danger, we also realise the need to translate ACM into more operationalised and simple steps so that it can be better understood and applied more widely.

We present in this annex key phases and series of steps that you can follow in integrating ACM processes into your work in community forestry. It is important for you to keep in mind that this is only a guide rather than a how-to-manual. Therefore, you should feel free to modify certain processes to make them more suitable for your purpose and more appropriate for the local conditions.

There are four main phases described in this guide:

Phase I. Community Immersion and Understanding the Local Context

Phase II. Identifying Local Priority Issues

Phase III. Facilitating the ACM Processes

Phase IV. Monitoring and Impact Assessment

These four phases are interlinked in a continual process of learning and improvement. In an ideal situation, therefore, we can imagine these self-improvement processes taking place endlessly.

For those of you who are working in a Community-Based Forest Management (CBFM) area or other areas that have been formally devolved to the community (such as areas under Certificate of Ancestral Domain Claim or CADC), we make recommendations on how you could integrate each step into the CBFM implementation stages. We use the term 'CBFM' in general for simplification purposes. However, the recommendations are also applicable to other community forestry schemes. ACM processes can also be used in other areas that are managed by the communities, outside the formal government programmes. 
Depending on how long you have been working in the area, your understanding about the stakeholder interactions, the history in the area, and at what stage the People's Organisations or the community that you facilitate is in, you can select certain phases that are most applicable and useful to you. It does not matter whether you are just starting or you have already been working in a certain area for 10 years or more. It does not matter if the People's Organisations that you facilitate are still at an early stage or are already relatively advanced in their forest management. You still can use and integrate $\mathrm{ACM}$ processes. Remember, $\mathrm{ACM}$ can always add value and enhance the processes that you initiated already. It's never too late to start integrating ACM approaches and processes! 


\section{PHASE I. COMMUNITY IMMERSION AND UNDERSTANDING THE LOCAL CONTEXT}

Before you engage local people and stakeholders in ACM processes, you should familiarise yourself with the local conditions, and understand the different groups, institutions, their dynamics and interactions, their activities, the history of the area, and other basic important information. Most importantly, you should get to know the people and gain their trust. This would allow you to have a feel on who should be invited to take part in the ACM processes, the key issues that could be best addressed with the ACM approach, and possible modifications that you may need to do to make the ACM approach and processes more appropriate to the site where you are working in.
If you are a DENR field officer, an extension worker, an NGO facilitator, or someone else who has been working in a certain area for several years and are already familiar with the local conditions, you can skip Phase I and go directly to Phase II. However, we recommend that you go through the bullet points in each step and identify issues that you do not know. Then collect that information.

For those of you who are just starting to work in an area, you can start from Step 1. You can document the information and knowledge that you gain in your field notes.

\section{STEP}

DESCRIPTION

IN WHICH CBFM

IMPLEMENTATION STEP CAN IT BE APPLIED?

\section{Getting to know who} the key stakeholders are

Knowing and understanding the key and important stakeholders is crucial because their participation (or the lack of it) could affect forest management and forest sustainability.

You need to identify who among the different groups in the community (such as different $\mathrm{POs}$ or associations), government institutions at different levels (barangay, municipal, provincial), and NGOs are the key stakeholders involved in forest management

You need to be clear about these 5 major issues:

- What formal and informal groups (such as different POs, Fishermen's Association, Women's Group, Youth Club, etc.) exist in the community?
There are several tested research methods that can be used to identify key stakeholders. One of them is the "Who Counts Matrix' ${ }^{66}$

This method involves creating a tabular presentation. You can do this together with a mixed group of people from the community, different institutions or organisations. Ask the group to identify key community groups, government institutions, NGOs, etc. in the area, and write their answers across the top of the matrix.
Stakeholder analysis can be done at the early CBFM stage and periodically during CBFM implementation. The exercise is useful to review the relationships among different institutions and to identify other potential partners for CBFM implementation especially when there are new organisations working in the area. 
- Do divisions exist in the community that may affect the management of forests? For example, are there divisions between the migrants and indigenous communities, members and non-members of $\mathrm{POs}$, or divisions due to barangay administrative boundaries, etc? If divisions exist, how do these affect forest management?

- What are the activities of those stakeholders and in what ways do their activities affect forest resources in the area?

- What are the forest resources that are used by the communities, how much of the resources are extracted, in what way are they being used, i.e., for commercial or for household use?

- What are the roles and responsibilities, mandates of government institutions and NGOs, their interests, and priorities with regard to forest management?
To assess the relative importance of the identified stakeholders, ask the group to score them against the following criteria. Write down these criteria along the left hand side of the table/matrix:

1. Proximity or closeness to the forests.

2. Prior claims to the forests.

3. Dependency on the forests.

4. Level of poverty.

5. Level of local knowledge.

6. Culture/forest integration.

7. Lack of power over forests.

The scoring system of $1-3$ can be used ( $1=$ high, 2 = medium, $3=$ low). The scores of each column are then averaged (total score divided by 7). Stakeholders whose scores are below 2 can be considered as

important stakeholders who should be involved in ACM processes.

Another method that you can use is the Venn Diagram technique. ${ }^{67}$ You can do this exercise simultaneously with different homogenous groups. You might want to separate men from women, old from young, or different stakeholder groups, so that each group can express its opinion

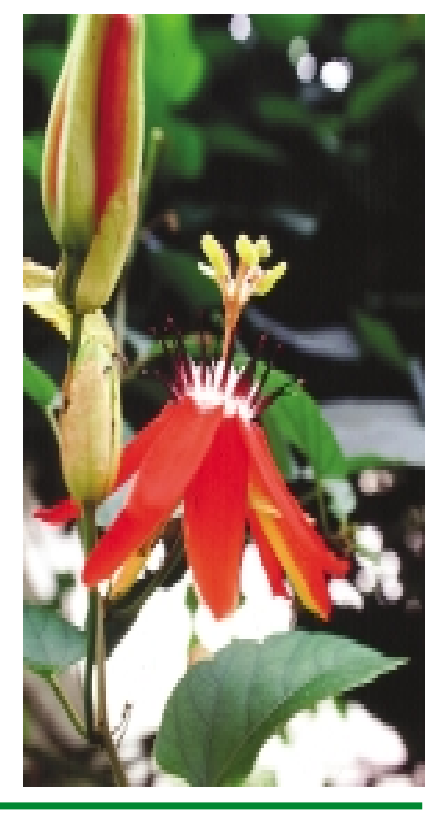




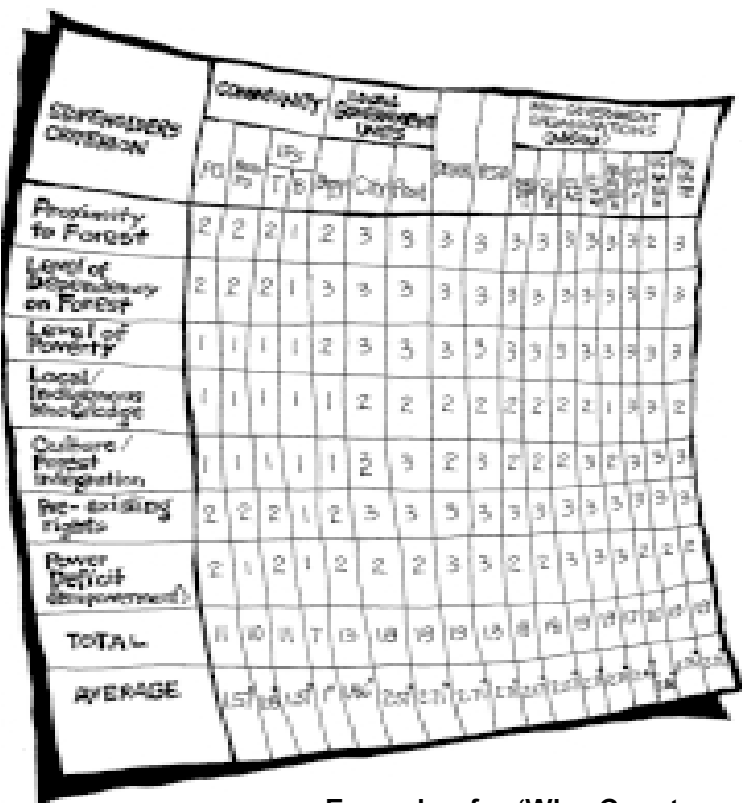

Example of a 'Who Counts Matrix' indicating the relative importance of stakeholders in the community. freely, and differences and similarities of different groups' perceptions can be identified.

The groups need to prepare several circles of different sizes cut-out from coloured card or plain paper. Each circle cut-out represents a certain stakeholder. The bigger the size of the circle, the more important is the stakeholder in forest management.

On another larger sheet of paper, each group draws another much bigger circle to indicate the barangay boundaries. The participants should then locate the different circle cutouts according to the degree of their relationships to one another. Those stakeholders whose roles and

responsibilities are similar, their circle cut-outs will overlap. Institutions located outside the barangay should be located outside the barangay circle.

The location and size of each circle should be discussed within the group. The results of the different groups' output should be presented. Subsequent discussions should highlight different and contrasting perceptions among the groups with regard to roles and responsibilities of different stakeholders. 


$\begin{array}{lll}\text { IN WHICH CBFM } & \text { WTE } \\ \text { STEP } & \text { DESCRIPTION } & \text { HOW TO DO IT? } \\ \text { CANIT BEAPPLIED? }\end{array}$

\section{Understanding} the policy context

Rules and regulations influence and shape stakeholder relationships, their activities, and therefore affect the welfare of the people and the conditions of the forest resources.

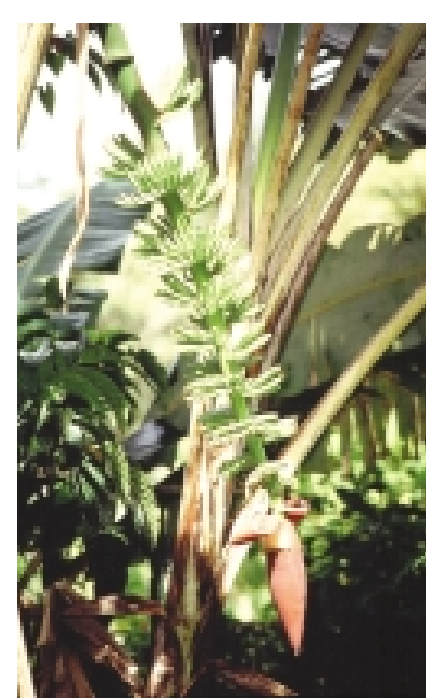

Key issues that need to be understood:

- What is the status of the forests: community-managed forests in the forms of CBFM, CADC, etc., community-managed forests without formal tenure from the DENR, CBFM located within the protected area, or others?

- What are the key rules and regulations related to CBFM?

- What are the implications of those rules and regulations for the way CBFM is being managed?

- Who oversees the implementation of those rules and regulations?

- Are there any non-forestry rules and regulations (such as agrarian, etc.) that may be conflicting with forestry regulations?
You can get the information by:

- Obtaining a copy of key policies from DENR or other relevant government institutions.

- Asking relevant government officers to explain about those key rules and regulations.

- Asking certain members of the POs who may be aware of those policies and their implications. 
3. Understanding the socio-economic conditions of the people

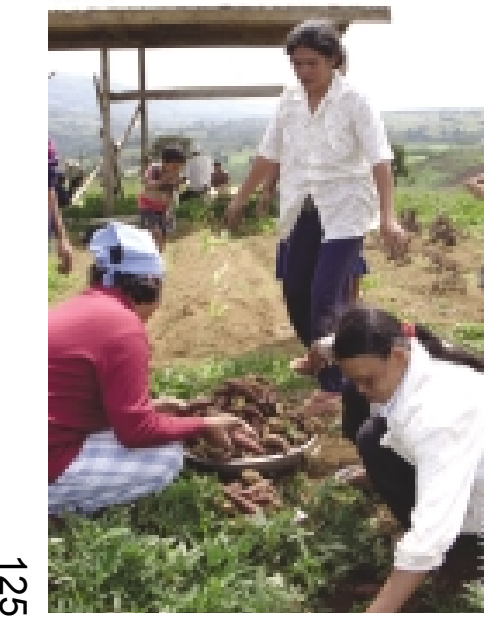

Important points that need to be taken This information can be obtained by: into account

- Who controls access to forest resources and in what way?

- Who utilise forest resources and do different community groups feel secure about their access to forest resources?

- How are the benefits from forest management shared, and do different community groups feel that benefits are equally distributed? Keep in mind that benefits are not only in the form of cash or income, but also employment and training opportunities, etc.

- How active are the $\mathrm{PO}$ members, community groups, and different stakeholders in forest management? For example, in attending planning meetings, annual assembly meetings, participating in different activities, etc.?
- Interviewing key people in the PO, community, government institutions, or NGOs.

- Holding discussion sessions with a group of people.

- Obtaining data from relevant stakeholders.

- Observing the situations directly. You may get important insights especially on sensitive issues that people are reluctant to share openly.

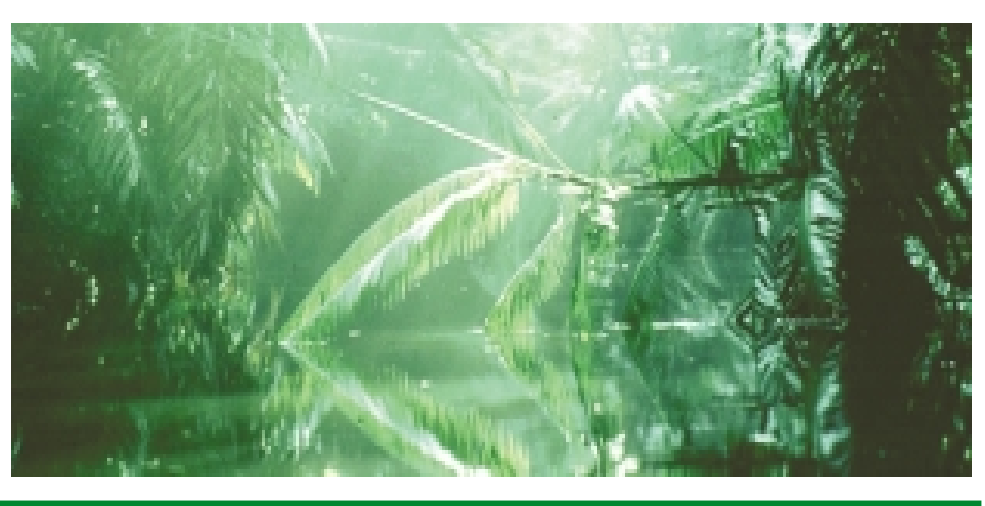




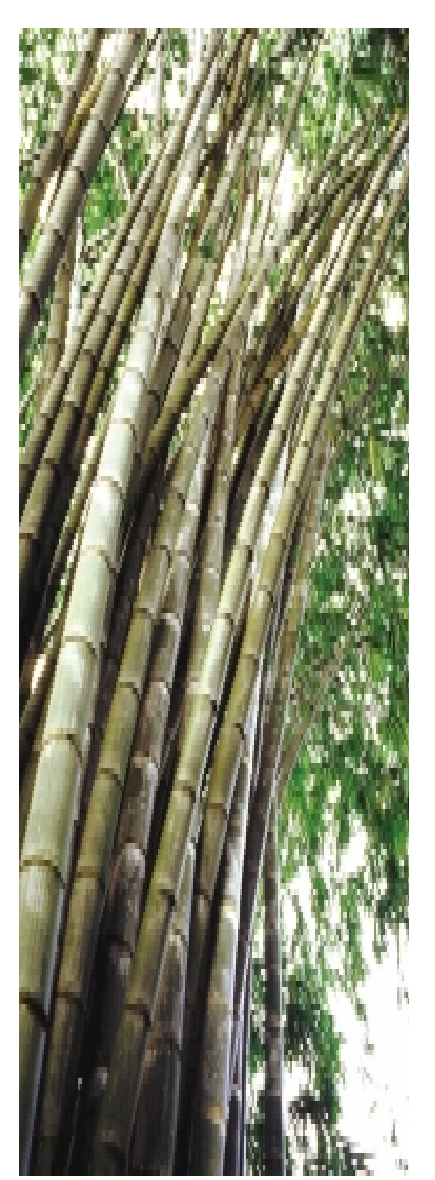

- Who are respected and perceived as leaders in the area, and how effective are their leadership?

- How effective is the implementation of the POs' internal policies and by-laws?

- Do conflict management mechanisms exist and are they effective in resolving conflicts?

- What is the main source of income in the area, what is the average income per household, and how do these compare to other neigbouring barangays?

- What is the level of education, literacy rates (for men and women), and level of awareness of forest and natural resource management?

- What are the roles of women in forest management?

- What are the factors that put pressure on the forest and its resources (such as high population, illegal logging and extraction, market demand, etc.)?

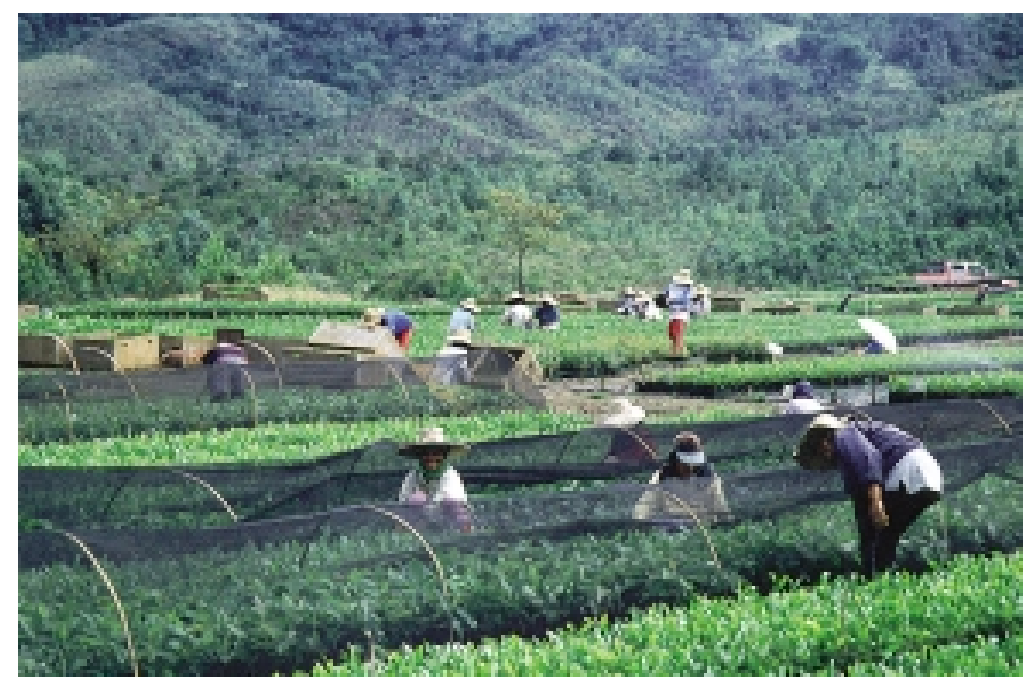




\section{Understanding the} biophysical and forest management context

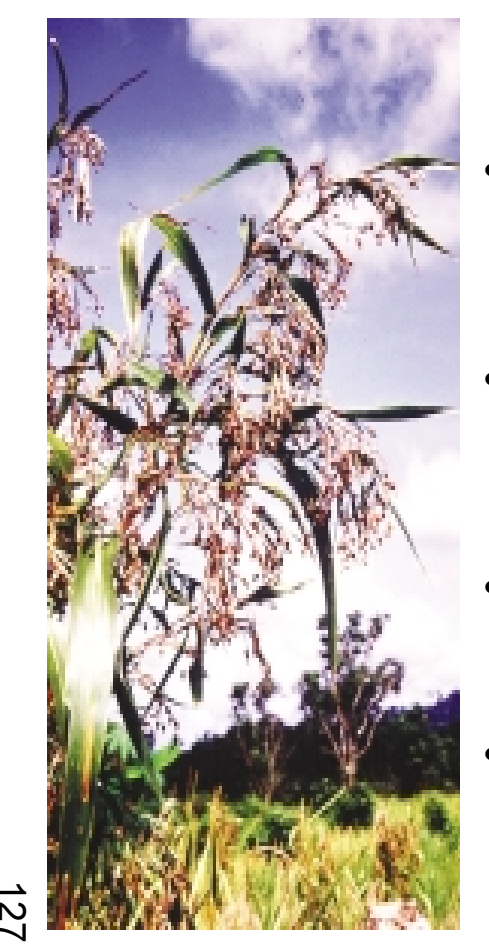

Key environmental data that need to be collected:

- How are the current forest conditions and resources (such as timber, rattan, resin, honey, etc.) compared to the past? Are they declining or improving?

- How do people extract these forest resources? What tools are being used, etc., and what are the likely impacts of these practices?

- Are there any signs of forest degradation, for example, soil erosion, increased open areas due to deforestation, slash and burn, etc?

- How often do natural disasters, such as floods, fire, and typhoons, occur and what are the trends over time?

- Has the PO developed a management plan? How effective is the implementation of this plan?
You can obtain this information using the same methods as above.

To assess the trends over time with regard to forest resource abundance, quality of the river water, etc., a participatory method called 'Pebble-sorting method' can be used ${ }^{6}$

This method involves drawing a tabular presentation on an area in the ground with the participants gathered around the area.

The table is divided into several columns. In the first column, different forest resources such as timber, rattan, honey, etc. are written. The rest of the columns represent different time periods.

You should invite a group (ideally including older members of the community). Ask the group to define the time periods for each column by using important events that affect the forests and environment as time references. Each period can cover a period of 10 years or more, e.g., 1951-1960, 1961 1970 , etc.

Once the forest resources and the periods are defined, ask the participants to distribute 100 pebbles for each forest resource according to abundance or

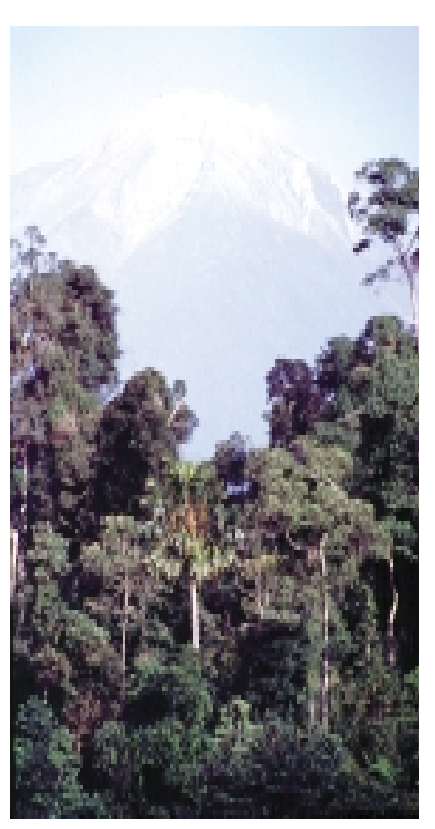


- What is the involvement of other stakeholders in developing and implementing the plan?

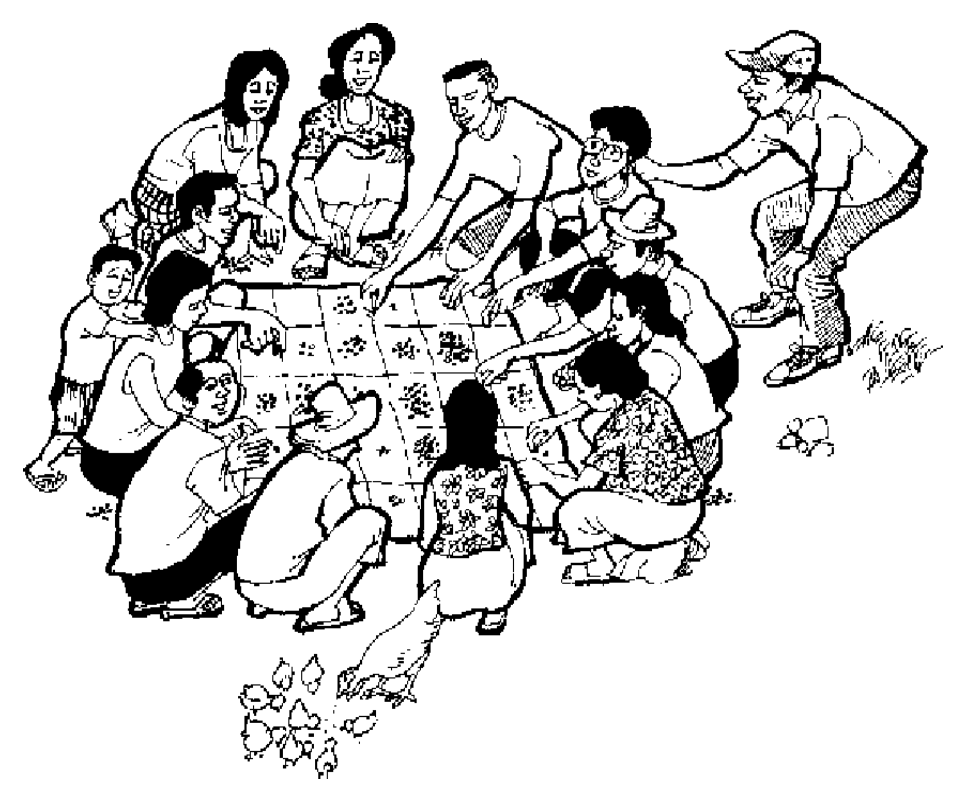

quality. The more pebbles allocated in a certain row, the more abundant or the higher quality the resources are. Get the participants to discuss and agree on how many pebbles should be allocated. Follow this up with a discussion on why those resources have declined or improved.

Besides pebbles, other easily available materials such as beans, shells, sticks, etc. can also be used.

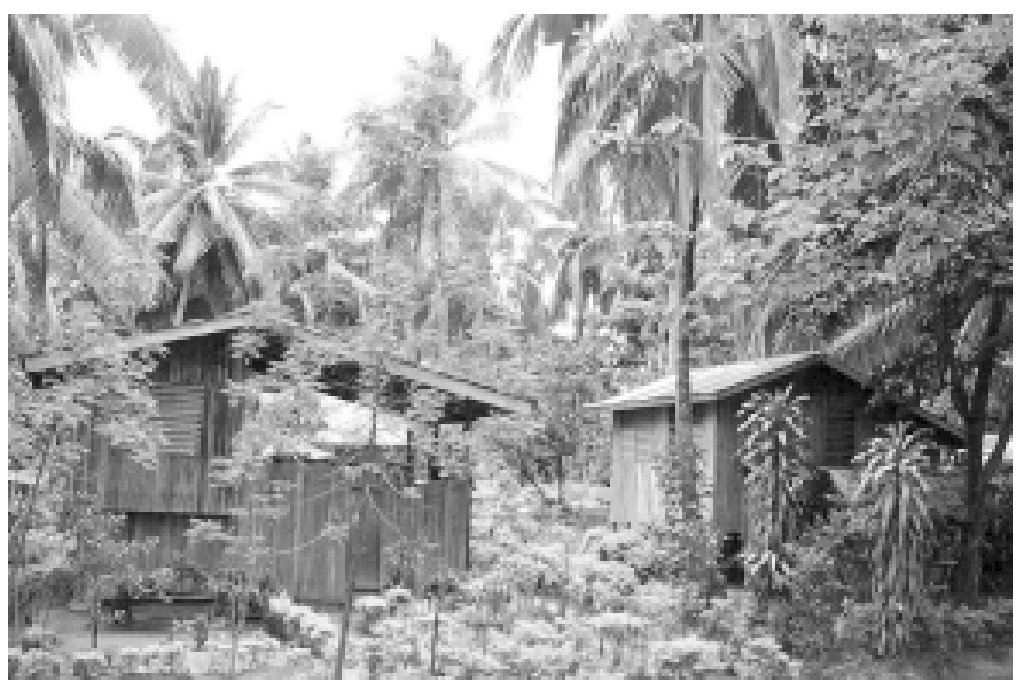




\section{Understanding stakeholders' collaboration in action and learning}

This step is important to assess the level of

collaboration among stakeholders in planning, decision making, and action. It is also useful in understanding to what degree major stakeholders intentionally look for opportunities to learn, and incorporate that learning to continually improve their management practices.
Understanding stakeholders' collaboration You can obtain the information using in action and learning can be generated the same methods described in Step 3. from the following indicators:

- Are there any forums (such as meetings, formal/informal discussions, barangay meetings) used by the $\mathrm{PO}$ or other stakeholders to bring together different groups to share information and make plans?

- In these forums, do the people express their views and opinions freely, and take part in the decision making process? If not, what are the factors that inhibit free discussions

(domination by certain people, lack of trust, high level of conflicts among different groups, etc.)?

- Are the agreed decisions implemented or acted upon after the meeting? If not, what are the factors that hinder the implementation?

- Do people seek opportunities for learning as a group, such as visiting

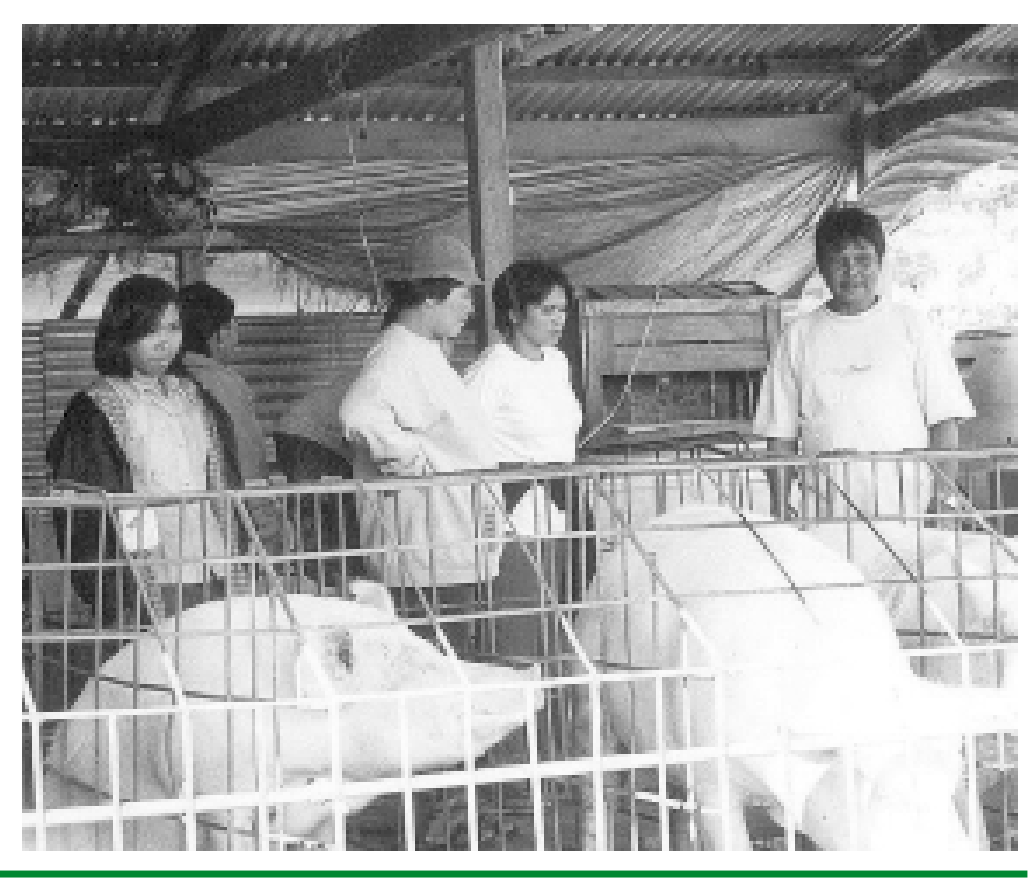




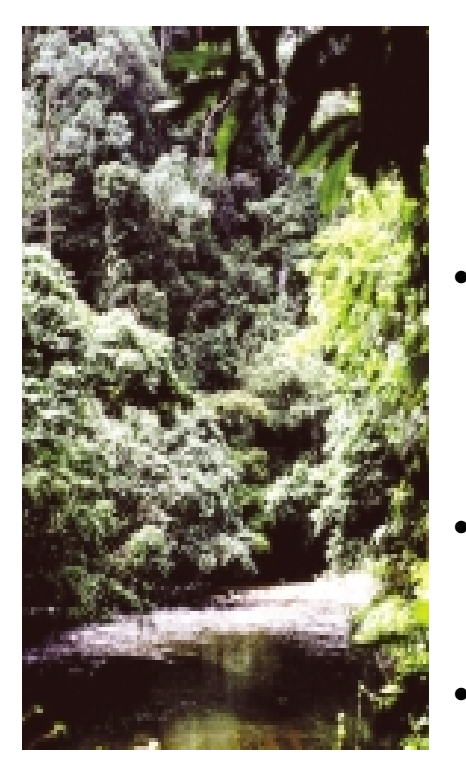

other communities to learn certain skills, experimenting with certain agriculture/agroforestry techniques, reflecting on their past experience, etc.?

- Do people monitor their management actions in a structured way, such as monitoring the volume of forest resources extracted, survival of the seedlings planted, etc?

- Do people reflect on the results of monitoring and learn from their experience?

- Do people improve or adapt their subsequent actions based on what they have learned?

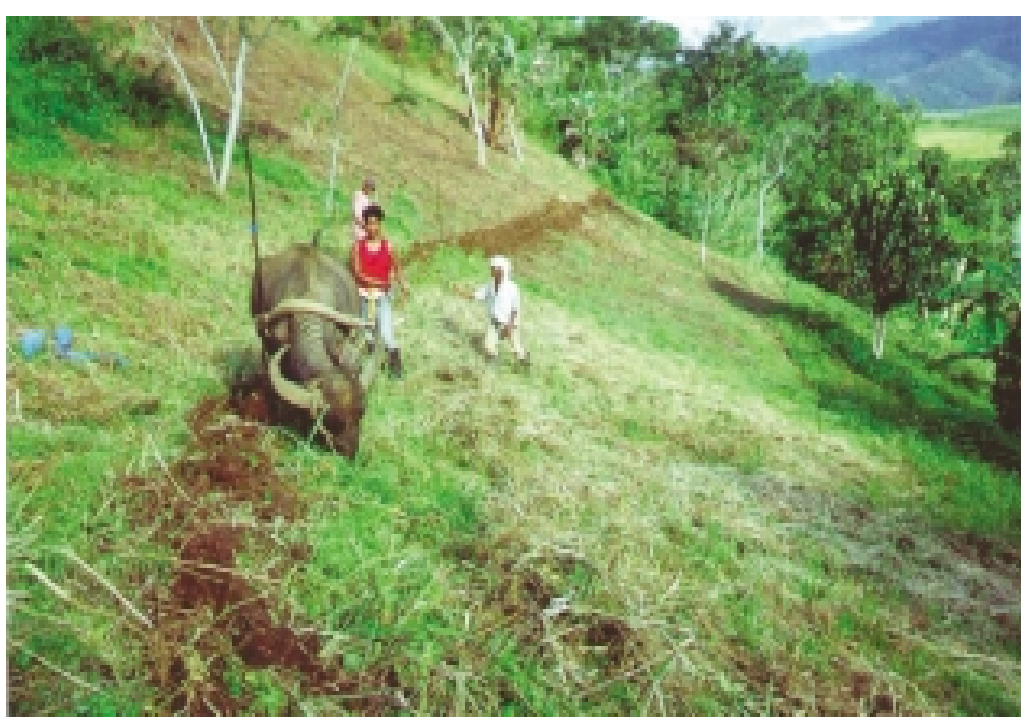




\section{PHASE II. IDENTIFYING LOCAL PRIORITY ISSUES}

The action research starts here. As the first stage, you need to assist the People's Organisation, communities, and other identified key stakeholders to identify key issues that they would like to address using the ACM approach and processes. This phase describes different steps that you can carry out to help them.

It is possible to undertake steps 6-9 in a 2-3 day workshop, depending on the number of participants. You should also ensure that the persons who participate in the whole process are more or less the same people. Alternatively, steps $6-9$ can be done in several separate discussions.

If specific problems have been already identified by the People's Organisation and other local stakeholders in any stage of their management plan implementation, you can skip this phase and go directly to Phase III.

\section{STEP}

DESCRIPTION

\section{HOW TO DO IT?}

Developing a shared vision is important for different stakeholders to work together. They should at least have:

- the same or complementary goals of sustainable forest management;

People with conflicting views on how best to utilise and manage certain natural resources in the short-term may have a common vision or long-term goal. This should be generated and agreed upon so that it can be later used as a basis to decide on how to achieve the goal.
- the same or complementary directions in which they will move together.
For this purpose, you can use vision-type scenario building techniques, such as Future Scenario. ${ }^{69}$

Invite representatives from the $\mathrm{POs}$, different community groups and stakeholders to participate in the exercise. They can form several groups, ideally according to their institutions, so that differences and similarities of the different groups' visions can be identified.

Ask them to visualise an ideal future, i.e., an ideal situation with regard to the community forests that they would like to see in $15-25$ years' time. Let them present
IN WHICH CBFM

IMPIEMENTATION STEP CAN IT BE APPLIED?

If you are working in a CBFM area that has not developed a 25-year management plan, you can apply Steps 6-7 to help the $\mathrm{PO}$ in setting its vision, goal, and other strategic long-term plans. The information generated from this exercise can be incorported directly into their 25-year management plan. 


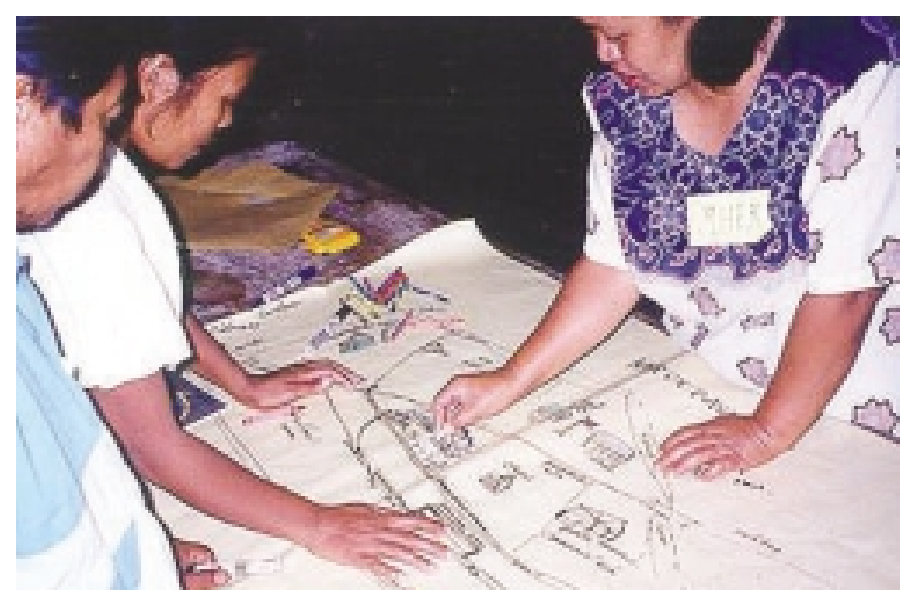

and share their drawings with other groups. Facilitate discussions to identify key areas of commonalities and differences among the visions drawn.

It is expected that the participants could come up with one common vision for the future. It is also possible to identify the main components or themes from different scenarios, such as:

- Healthy forests.

- Good infrastructure in the village.

- There are livelihood options and other income-generating activities for the communities.

- Strong and functional POs.

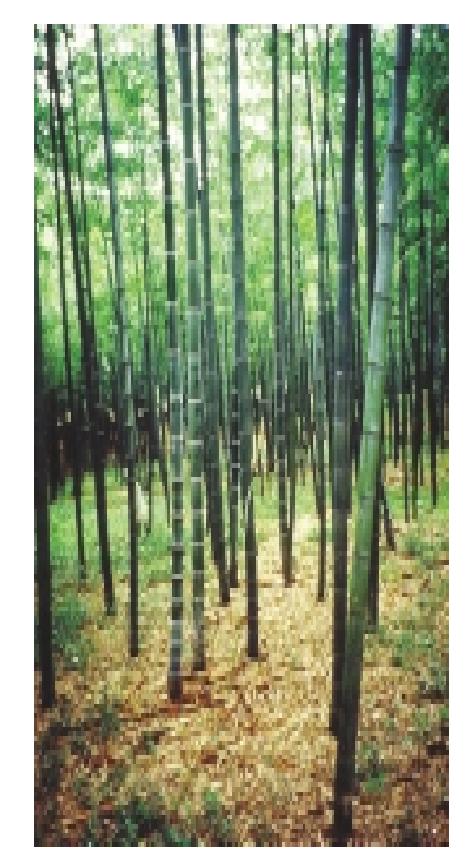




\section{Developing indicators of successful} community forestry

The themes generated in Step 6 are typically still too broad so they need to be specified further into measurable and observable conditions. These specific and observable conditions are called indicators. By monitoring the conditions of these specific conditions, the $\mathrm{PO}$, community members, and stakeholders can assess how close they are to achieving their goal of sustainable forest management.

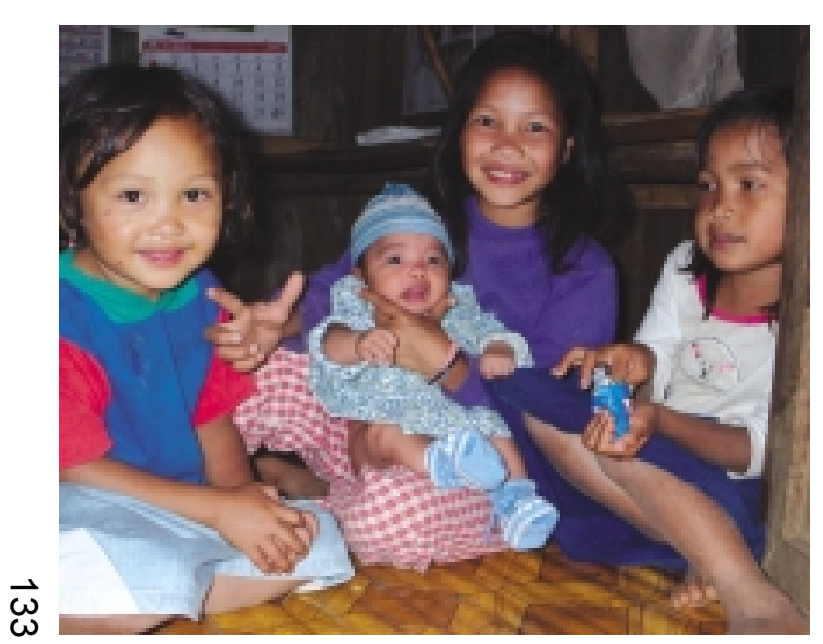

The framework that can be used to organise and conceptualise information relating to

sustainable forest management is the Criteria and Indicators (C\&I) framework.

Representatives from the $\mathrm{PO}$, different community groups and stakeholders can split into several groups and each group works on different themes. Ask them to further specify the specific conditions that would provide for the ideal of each theme. The conditions should be specific enough so that they can be measured or observed over time.

Example:

Theme: Existence of sources of income for the community

The specific measurable conditions might be:

- increased incomes;

- presence of livelihood alternatives;

- parents can pay for their children's

education;

- etc.

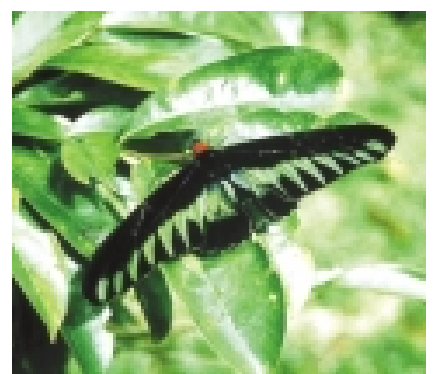




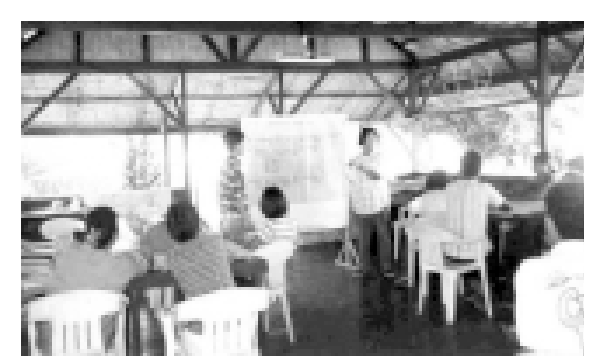

This exercise will produce a three-level C\&I framework, that consists of:

- Vision statement as defining Principle.

- Themes as Criteria.

- Specific conditions as Indicators.

8. Assessing current conditions against the ideal conditions

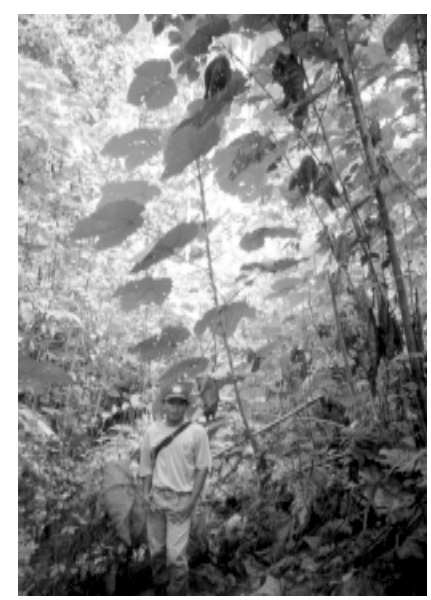

Representatives from different community groups and stakeholders should go through each indicator that they develop and qualitatively/quantitatively assess the present conditions in comparison with the ideal conditions (indicators).

By assessing the current conditions against the ideal conditions, the $\mathrm{PO}$, community members and stakeholders can identify 'weak' areas that need improvement.
Qualitative assessment could be done by using symbols, such as:

- $E g g=$ if present conditions are still very far from reaching the ideal conditions.

- Chick = if present conditions are half way towards the ideal conditions.

- Chicken $=$ if present conditions already meet the ideal conditions but still need to be sustained.

Different sets of symbols can also be used, such as: dark moon, half moon, full moon. ${ }^{70}$
Once the indicators are developed and assessed, the PO can repeat the assessment annually, using the same indicators. This could become their regular monitoring system. The results can indicate whether the conditions improve over time and how far the $\mathrm{PO}$ has gone in achieving its goals. For more details see Step 18.

If the PO decides to regularly monitor the above indicators, it should coordinate as well with the local DENR offices as 


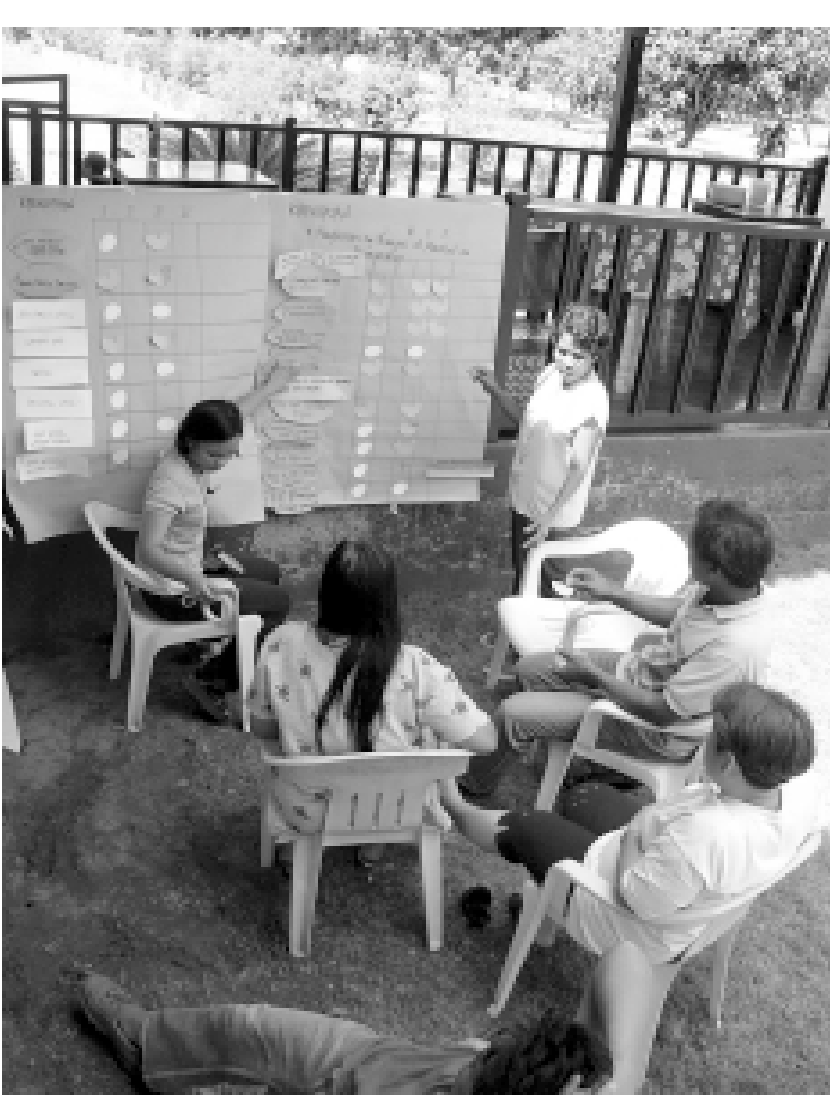

Quantitative assessment can be done by giving a score of $1-3$, such as:

- 1 = if present conditions are still very far from the ideal conditions;

- 2 = if present conditions are half way towards the ideal conditions;

- 3 = if present conditions already meet the ideal conditions.

Assessment scaling systems can be made a little bit finer by using 5 categories, such as egg, egg/chick, chick, chick/chicken, and chicken, or the scoring system of 1-5.

Any scaling or scoring system can be used as long as they are applied consistently and are understandable to the participants.
DENR has also developed a

monitoring system called

'Environmental Monitoring

Performance'. ${ }^{71}$

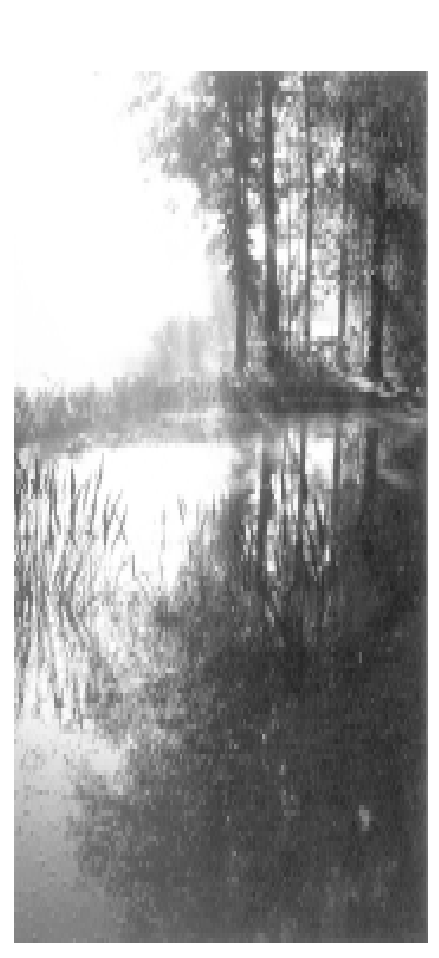

$\vec{\omega}$ 


\section{Identifying and} prioritising weak

areas

The prioritised weak areas for improvement are the local issues that will be addressed in an adaptive and collaborative manner.

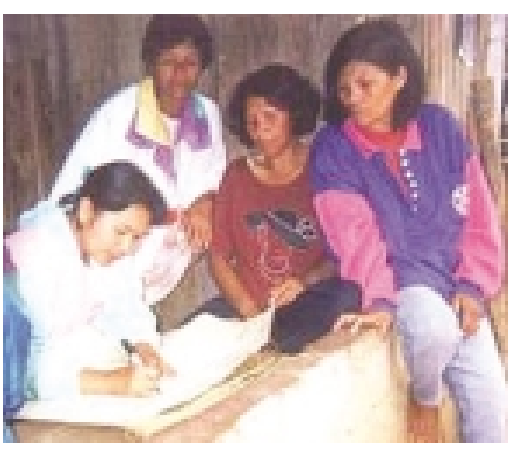

The PO and other local stakeholders may have various difficulties and problems in managing CBFM. Reality shows that they often have limited resources (time, funds, personnel) to deal with all those problems. Prioritisation helps them in focusing and utilising their limited resources on key, important issues first.

Those of lower priority are not excluded and forgotten, but rather put aside for the time being. Once some of the issues of higher priority are addressed sufficiently, resources can be devoted to address other areas of concern.
Once the assessment is completed for each indicator, average scores should be generated for the corresponding criteria. The criteria that are scored low could be extracted from the list. The participants should decide whether they just want to focus on the ones scored low (egg or 1), or they would also include those that scored medium (chick or 2).

If the number of weak areas produced from the above step is beyond the capacity of local people and stakeholders to handle, they could be further prioritised based on:

- level of urgency: whether or not it should be addressed immediately;

- level of importance: how significantly it affects forest management and people's livelihoods.

Other methods for prioritising, such as ranking, pair-wise comparisons, etc., can also be used.
This step can be applied in any medium-term planning process, probably in the annual planning process to develop an Annual Work Plan or in some other long-term development planning activities.

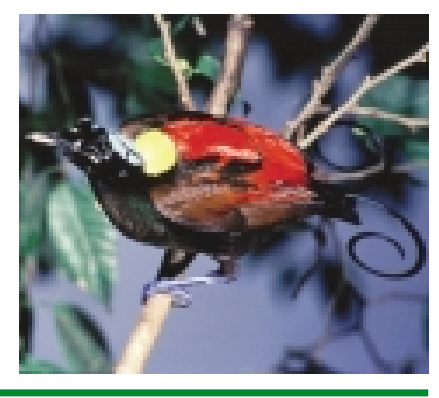




\section{PHASE III. FACILITATING THE ACM PROCESS}

This phase describes how you can facilitate the POs, communities, and local stakeholders in addressing their identified local priority issues. The steps in this phase include the formation of action/learning groups, and various stages of the learning cycle that the groups will go through in addressing their local issues.

Phase III can be initiated and implemented anytime during the implementation of the CBFM management plan.
If specific problems have already been identified by the $\mathrm{PO}$ or other local stakeholders in any stage of their management plan implementation, you can start directly with this phase.

Before you start facilitating the action/learning process, you should pay attention to the importance of acquiring the necessary skills, behaviour, and attitude that a good facilitator should have. You can refer to Annex 2 of this book for details.

\section{STEP}

DESCRIPTION

\section{HOW TO DO IT?}

To ensure that each local priority issue is addressed effectively, each issue could be handled by a group of people. The groups should be formed based on people's interests. These groups of people may exist already. Therefore, it is important for you to check what kinds of groups exist and whether they are interested in addressing the local priority issues. If they don't exist or are not appropriate, then you can facilitate the formation of new groups.

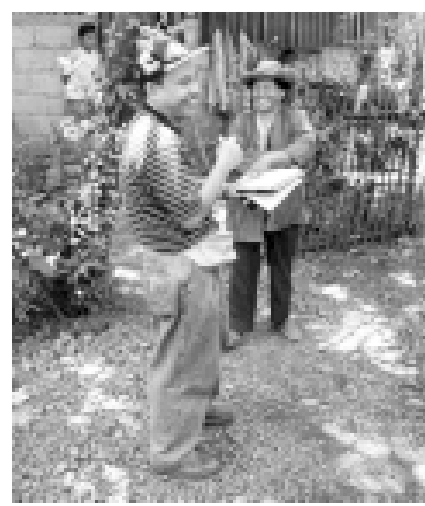

If you are working closely with the $\mathrm{PO}$, then you can ask them to identify and approach existing groups that would be interested to handle the issue. Alternatively, they might be able to identify some people who may be interested to handle the issue and establish a group.

The action/learning groups can consist of:

- The committees established by the PO as art of its organisational structure

- Members of the Board of Directors

- PO members

- Non-PO members.
IN WHICH CBFM IMPLEMENTATION STEP CAN IT BE APPLIED?

If you are a DENR field officer, you can facilitate the discussion sessions described in Steps 10-16 in one of your regular visits to the CBFM area. If you regularly attend the PO monthly meetings, the venue can also be used for this purpose. This would reduce the logistic arrangements, i.e., inviting the $\mathrm{PO}$ members, finding the appropriate venue, etc. 
Keep in mind that groups should be fluid and flexible enough that they could accommodate new members if new interests emerge. The action/ learning groups should not become exclusive or create unhealthy competition with the existing groups.

The groups can then be facilitated to decide on:

- how often does the group want to meet?

- where does the group want to meet?

- who will document the discussions?

- who should facilitate the discussions?

You may need to facilitate the first few sessions, then gradually step back so members of the group can try facilitating the discussions themselves.
The number of people within each group can vary from 7-10 people. It would be more difficult for you to facilitate larger groups. You should make sure that the groups capture, as much as possible, the diversity within the community and that they are not dominated by the members of the elite in the community.

In some instances, the groups can also include representatives of government institutions, and NGOs.

You may want to think strategically about who should be invited to participate in the action/learning groups. If there is a tendency for certain people, for example representatives from government institutions or other organisations, to dominate the discussions and decision making processes and thus hinder the group from learning together, then it may be better to invite them at a later stage when the capacity of the group members to communicate, express themselves, and their self-confidence is sufficiently high so that they are not intimidated by the dominant ones.

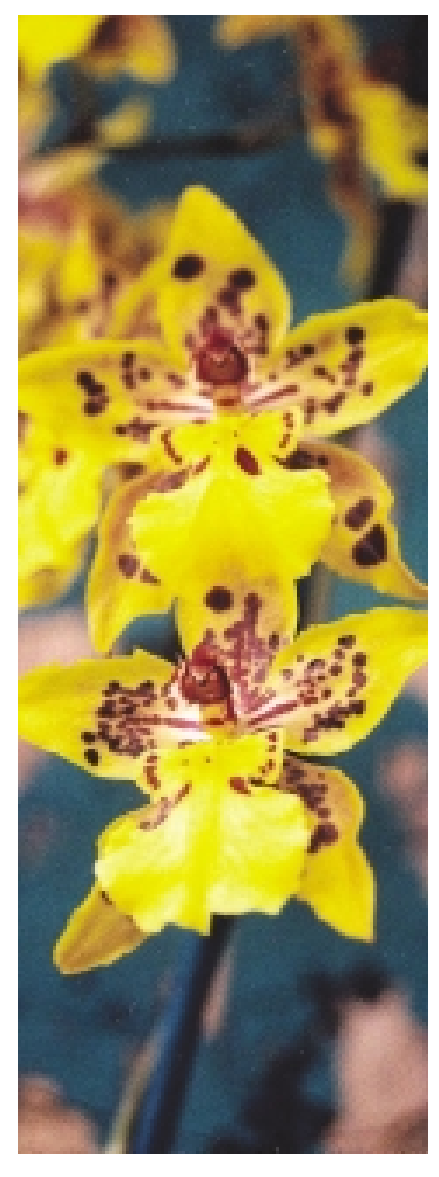




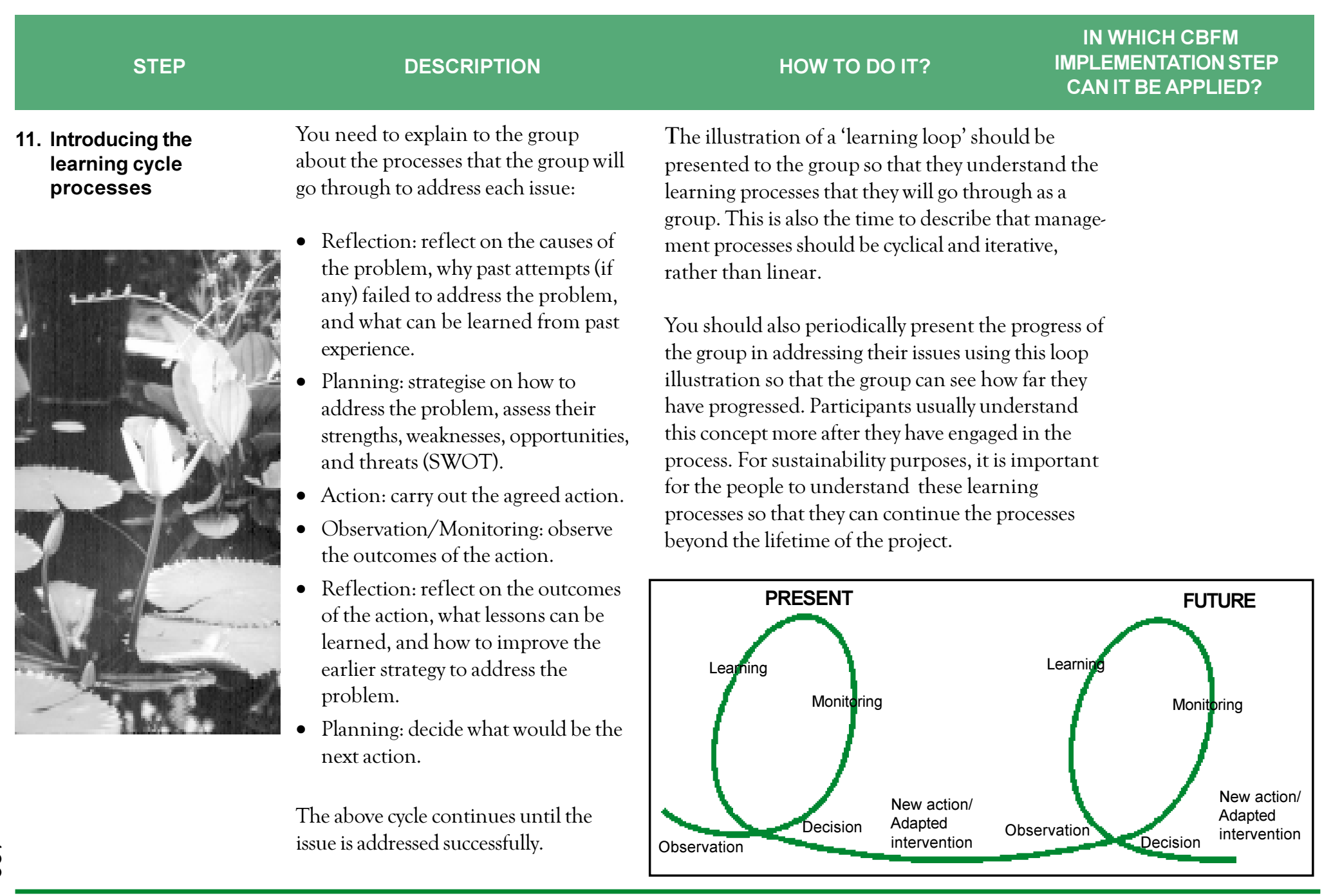


For each local priority issue ('problem') identified in Step 9, you facilitate the group to reflect on the causes and consequences of the problem.

If time permits, it is recommended that you facilitate Step 12 and Step 13 in one meeting or discussion session.

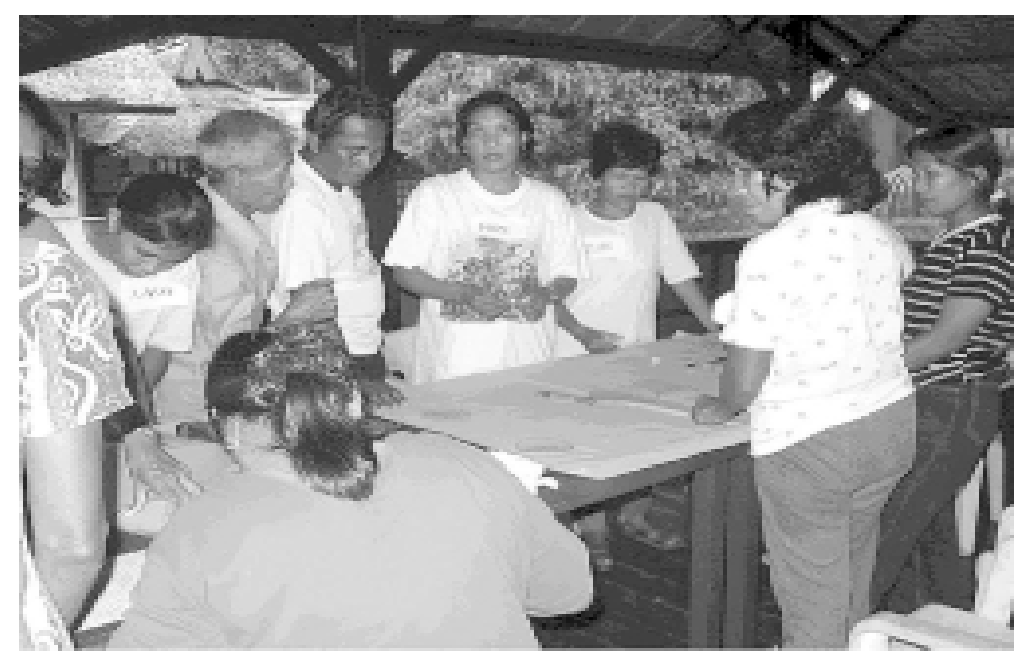

You can use the problem-causes-effects tree analysis in this step. ${ }^{.2}$

For each problem, you need to draw a big tree on a flipchart with its roots, trunk, and branches. The problem is written in a metacard and posted at the trunk of the tree. Explain that the roots represent the causes of the problem, and the branches represent the consequences of the problem.

Facilitate the session so that the group is able to identify the causes and consequences of the problem. Each cause and consequence should be written in coloured cards and posted at the roots or branches of the tree. It is quite likely that during the discussion the participants will change their views of the 'real' problem so that several cards will probably need to be moved around.

Based on the results of the exercise, facilitate the group so it can subsequently identify several strategies to address the problem. The group needs to decide whether they will address the roots of the

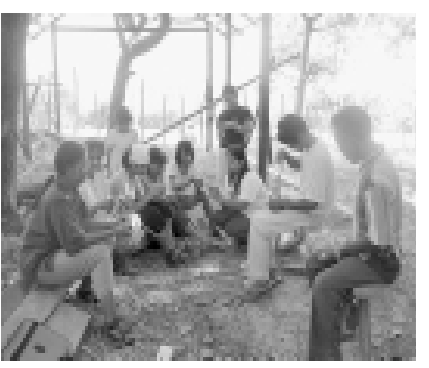




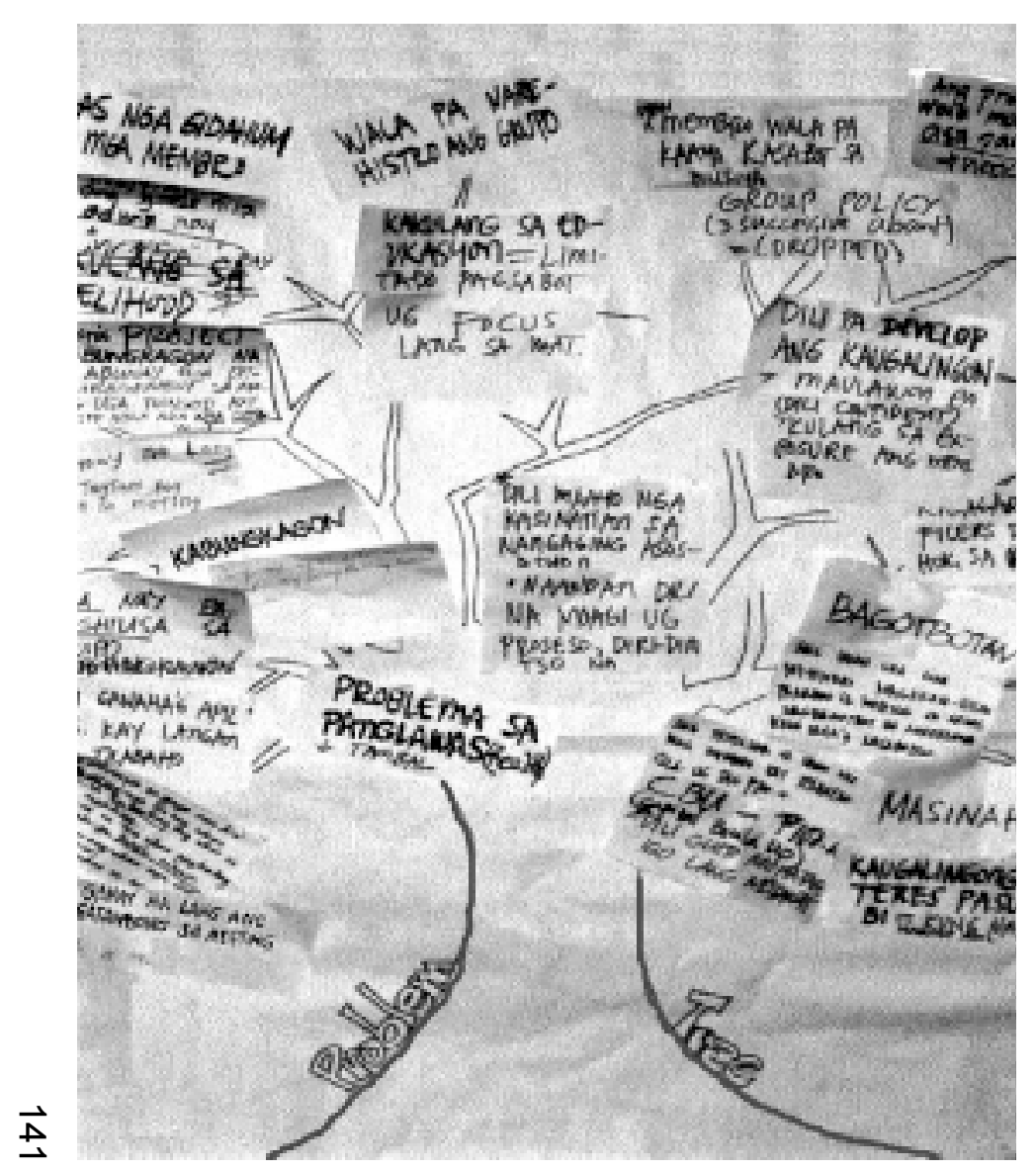

problem or its consequences. The

discussion should be directed so that the

participants will understand that there are different strategies that can be used, and that there will be a trade-off between addressing the roots of the problem (longterm results) and addressing the 'symptoms' (for producing more immediate results).

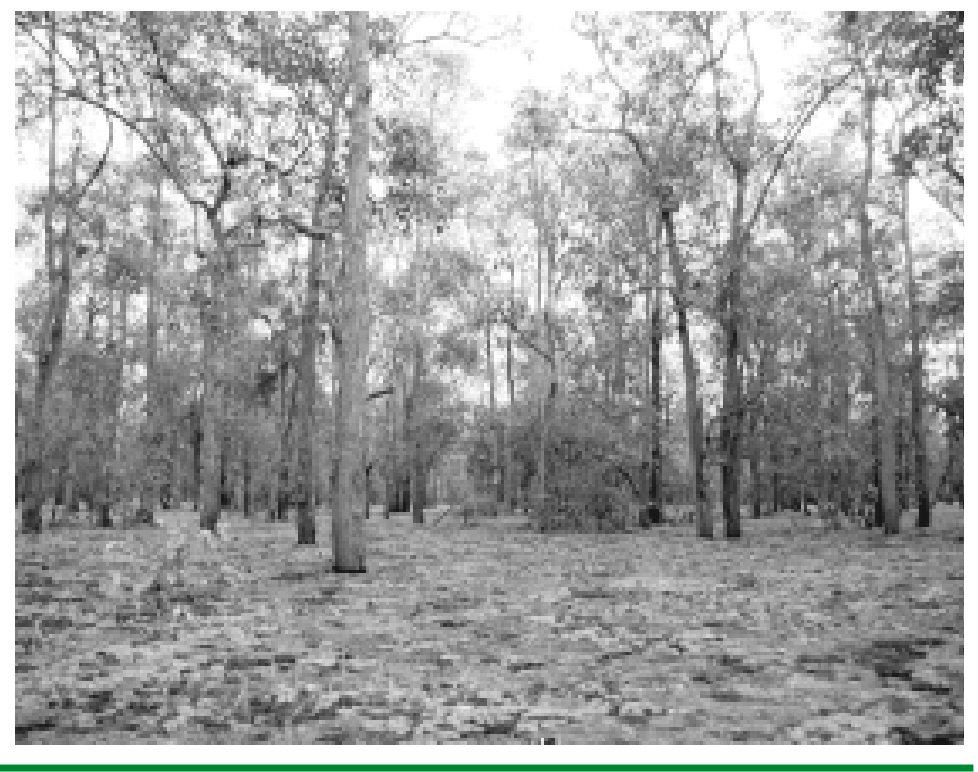




$\begin{array}{lll}\text { IN WHICH CBFM } & \text { IN } \\ \text { STEP } & \text { DESCRIPTION } & \text { HOW TO DO IT? } \\ \text { CANIT BEAPPLIED? }\end{array}$

13. Planning for action

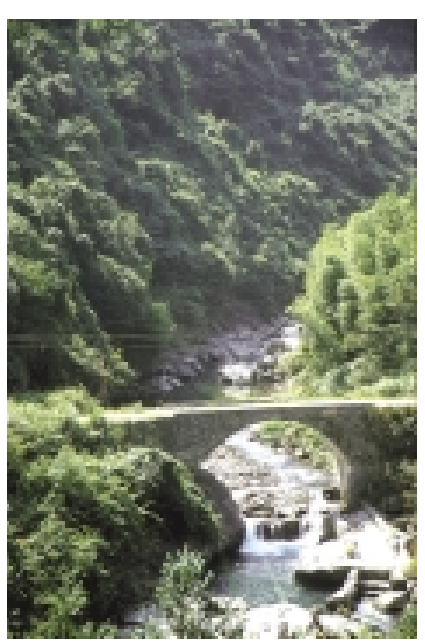

Based on several strategies identified in Step 12, the group is facilitated to assess which strategies are likely to be effective.

If similar action has been tried before in the past, but failed, the group should evaluate why their past attempts failed.

The group can then determine which strategy is likely to be effective by assessing the strengths and weaknesses of each strategy, the opportunities, and the factors that may hinder the achievement of its intended results. Based on the assessment, the group can make a decision on their actions, and develop an action plan with regard to:

- what actions or activities should be carried out?

- who, within the group, will carry out the action? Are there any representatives from government institutions and other stakeholders who should be involved?

- when will the actions be carried out?
SWOT Analysis can be used at this step. This is a good method for the group to assess each strategy and to anticipate uncertainties. This method also allows the group to anticipate unexpected outcomes if the identified hindering factors come into play at a later stage. The group can also identify new factors at play if their strategy produces unexpected results.

In this process, the group can draw up a table and list the possible strategies identified in the first column. The other columns are used to list the strengths, weaknesses, opportunities and threats for each strategy.

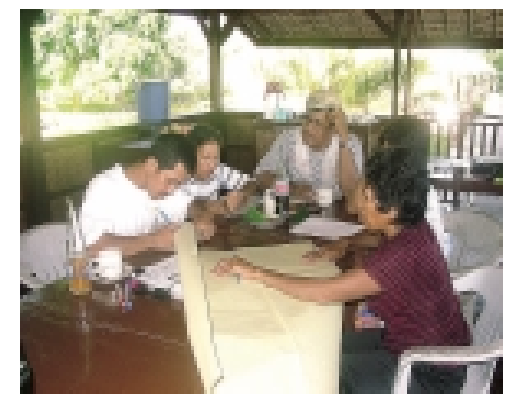

There is a tendency for certain people to come up with big plans that require significant amounts of resources. In most cases, the plans cannot be carried out as the resources are not sufficient or do not exist. The group may opt to put together a proposal for funding as their first step. Although this is a viable option, momentum could be lost as getting funding may take time.

A different strategy should be tried in which you encourage the group to come up with action plans that are realistic and within their capacity to

implement in the meantime. They should be encouraged to start small, on an experimental basis, so that they can learn from the experience. If their initial efforts are successful and they decide to expand, then they could be facilitated to access funding resources through proposal making, etc. 
- what are the expected outcomes?

- what are the indicators of success?

- when should the group meet again to evaluate the outcomes of the action?

\section{Collective action}

The group should carry out the action together according to the agreed action plan. If the plan is realistic and clear (on who should conduct the action, when, and how), it is very likely that the action will take place.

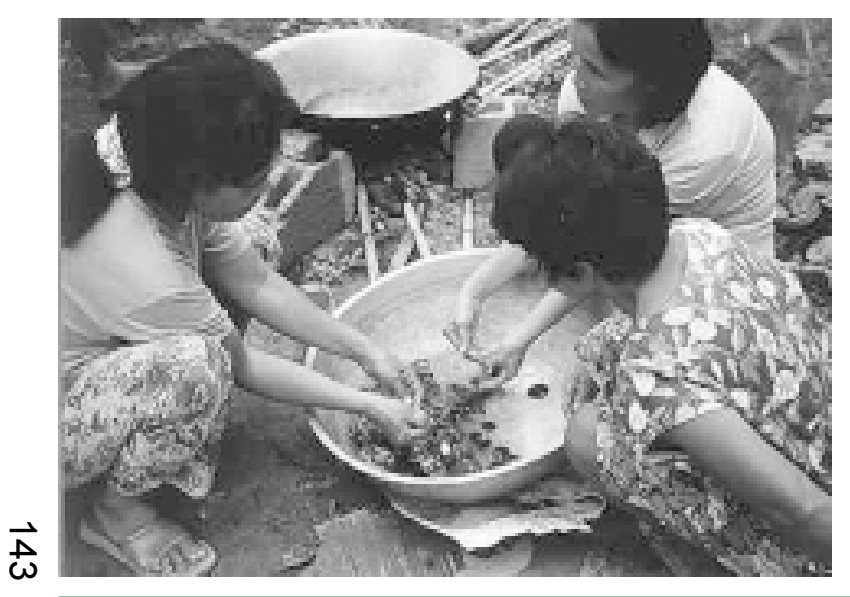

The collective action can be carried out by:

- 2-3 representatives of the group assigned by the group to implement a certain action, e.g., visiting a government office to request a map or legal document, or

- all the group members, for example, preparing a piece of land for a nursery, collecting seedlings from the nearby forests, etc., or

- a combination of several members of the group and representatives from the government institutions, for example, surveying the CBFM boundaries. 
15. Observing and monitoring the results of the action

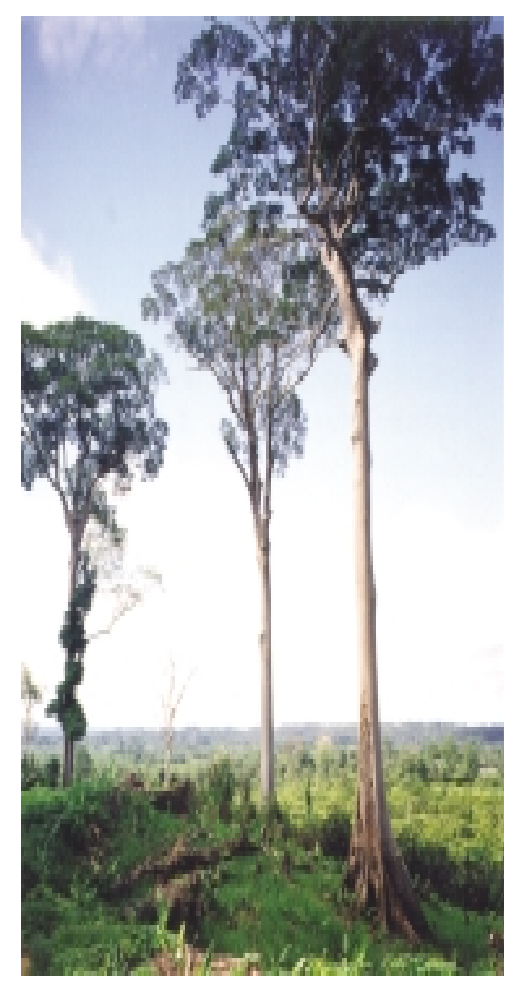

Once an action is being carried out, the group should also monitor the outcomes of that action. The outcomes of the action could be straightforward and observable, such as:

- certain documents from certain government institutions obtained

- a certain number of seedlings collected

- a certain area prepared and ready to be planted.

In other instances, the outcomes are not straightforward and may need to be observed over a longer period of time before the group can conclude whether the action produced the intended results. For example:

- the group decides to compare two agricultural treatments applied on two different plots to learn which one produces a better harvest. Once the treatment is given, the
In Step 13, the group should define the success indicators of their actions. At this step, you should facilitate a discussion on how to measure those indicators and for how long. A tabular form (or table) can be generated if much data need to be collected. In other instances, direct observation on a specific indicator can be done without any kind of forms.

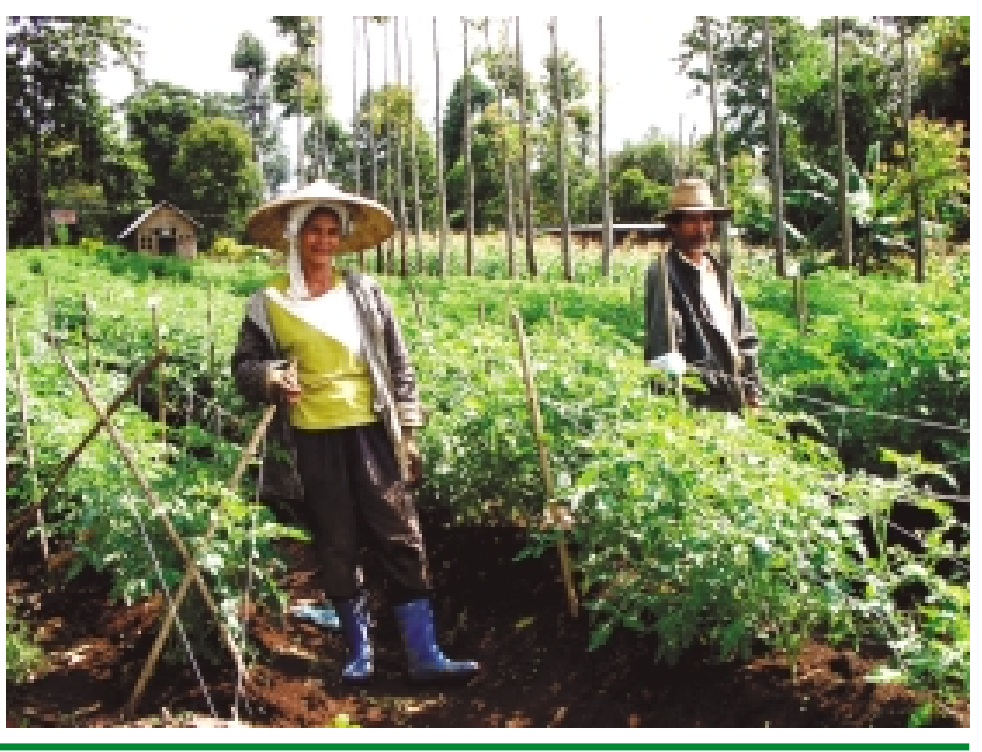




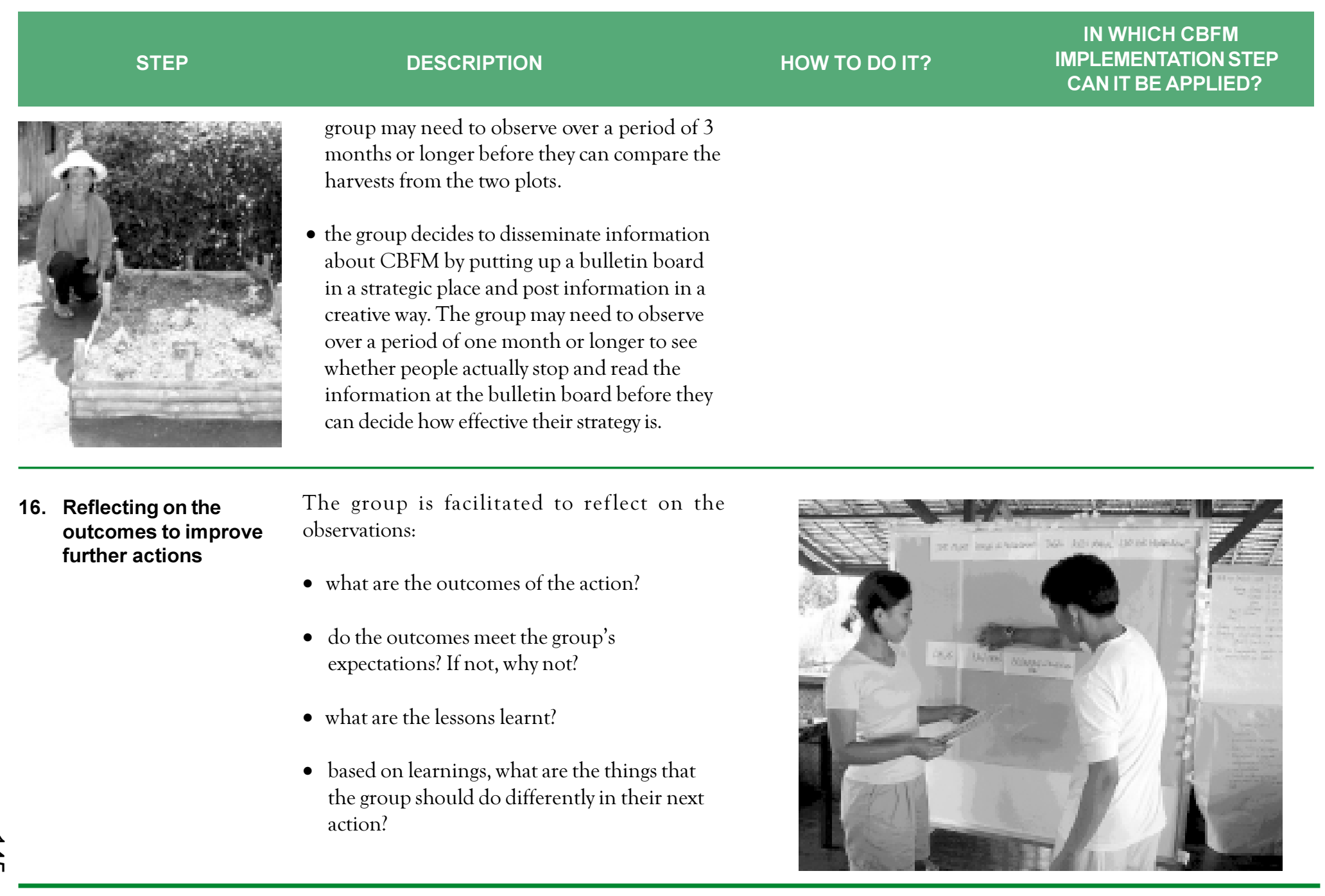




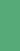

17. Continuously improving the Based on the lessons learnt from their management strategies through the cycle of reflection-planning-action reflection

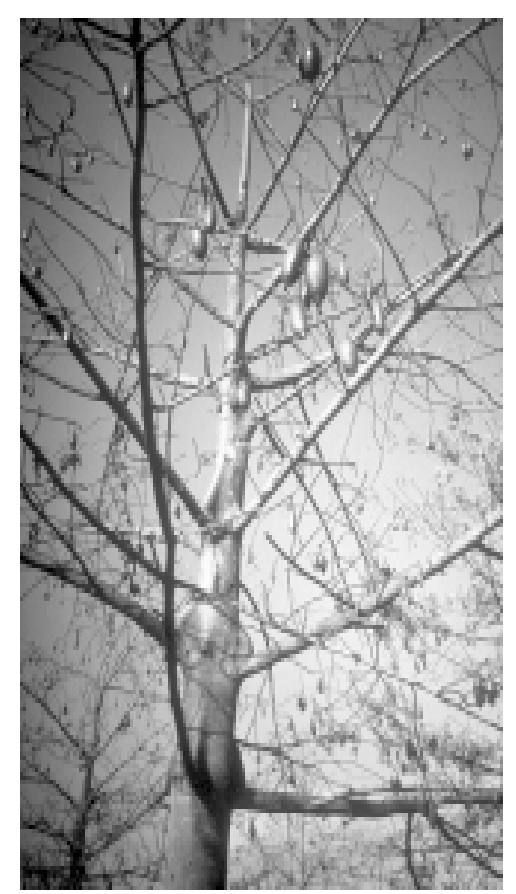
reflections, the group can decide their next action. The group may opt to:

- continue their previous strategy because the results are quite promising;

- apply a different strategy altogether if their previous action did not produce the intended results;

- apply a different strategy to complement their previous action. This means they are engaged in new action while maintaining their previous efforts. In this case the learning loops branch out and produce new loops.

Once their decision is implemented, the group should continue following the same cycle of observation, reflection, planning, action, etc. The cycle will continue until the goal is met. It is expected that through this cycle, there will be a gradual improvement in the management practices generated from within the group.

Once the resources needed to address the issue are reduced by their success, the group can decide to focus their attention on other issues while keeping an eye on this issue.

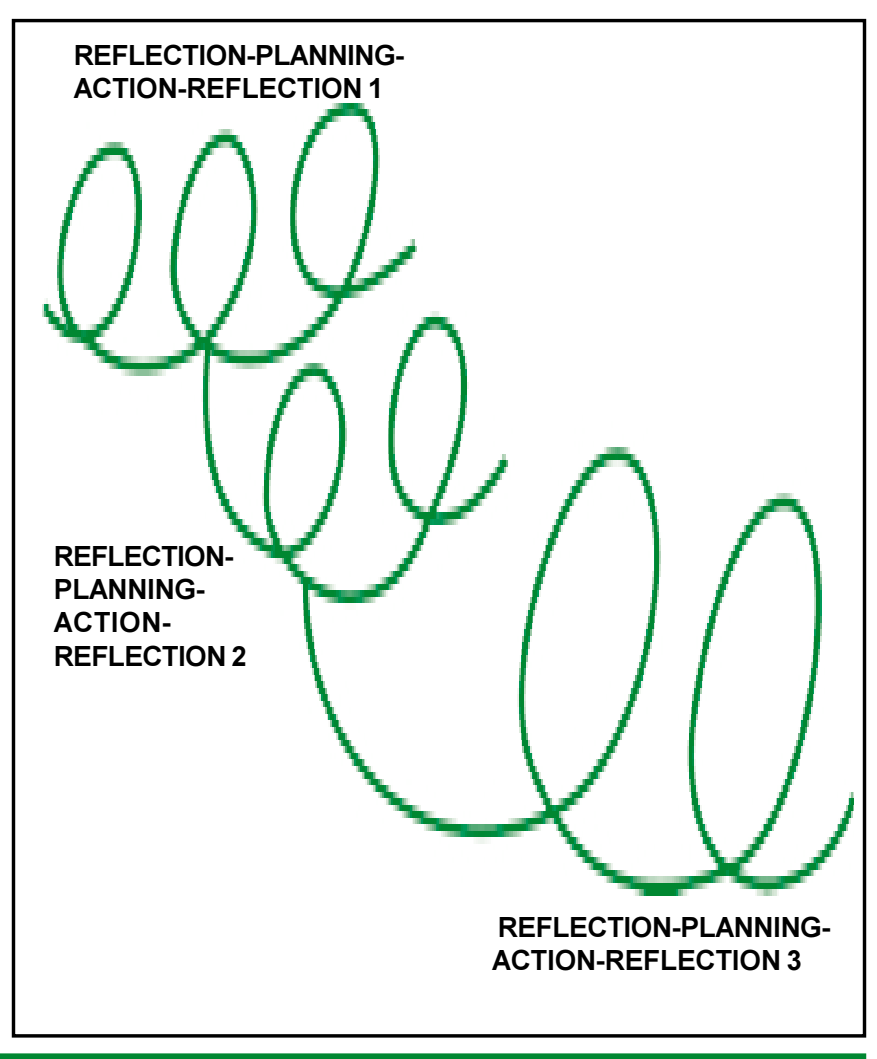




\section{PHASE IV. MONITORING AND IMPACT ASSESSMENT}

This phase describes how the important element of ACM, i.e. monitoring, can be carried out by the local people and stakeholders in a participatory way to assess their progress in achieving their goal. Furthermore, it also describes how you, as the facilitator, can assess the impact of your work in the community.

STEP DESCRIPTION

Besides monitoring and observing the direct outcomes of their actions, the $\mathrm{PO}$, community members, and other local stakeholders can also monitor the outcomes of all ACM processes at the community level.

The results of the initial assessment of the C\&I framework produced in Step 7 can be used as the 'baseline' against which progress can be measured. However, we recommend that the reassessment of all indicators in the C\&I framework be done annually so the results can indicate any improvement or lack thereof with regard to CBFM implementation.
Once the C\&I framework is developed (see Step 7), the PO, local community, and other local stakeholders can engage in monitoring each indicator.

The group should discuss:

- what information is already available and how can the data be tapped?

- if the information is not available, what methods or tools could be used to collect the information?

closely and systematically, and the results can be integrated directly into subsequent management plans. It can be timed in such a way so that it

follows the same management cycle of CBFM implementation.
- who should be responsible for collecting the information for each indicator?
IN WHICH CBFM IMPLEMENTATION STEP CAN IT BE APPLIED?

The re-assessment of the C\&I framework can be done towards the end of the management cycle (i.e., at the end of the annual management period). The information and the lessons learnt can be fed back directly into the planning processes of the subsequent Annual Management Plan.

The PO can undertake the reassessment together with their own PO members only. Alternatively, the reassessment can be done together with other community groups and stakeholders in the area. 


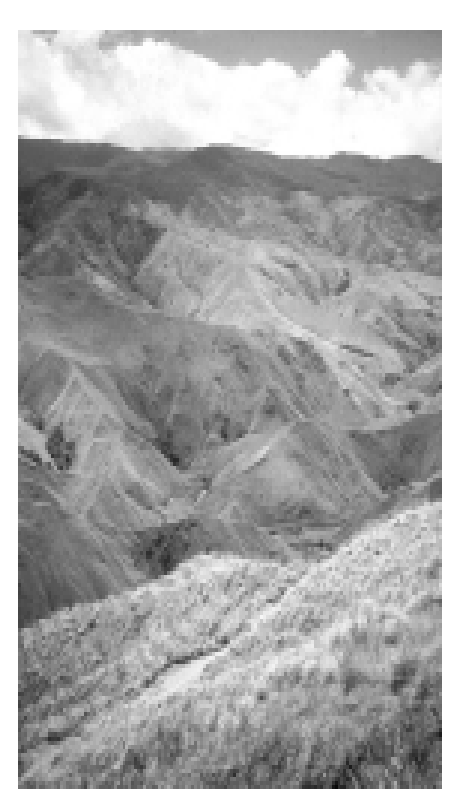

It is important to keep in mind that:

- the outcomes may not necessarily be contributed by ACM processes alone. There are many contributing factors that may influence the changes. It is crucial to identify these factors and assess in what way they could facilitate or hinder progress.

- some actions will not produce immediate outcomes. It may take more than one year before any outcomes are observed.
- how often should the information be collected?

- how long should the information be collected to be meaningful?

When information is being collected, it is crucial to facilitate discussion sessions regularly, e.g., on a sixmonthly basis, to look at the information, analyse it, and interpret it. Any lessons learnt can be integrated directly so that the $\mathrm{PO}$ can improve its management practices.

The PO may decide to monitor intensively a certain number of parameters only, for example the ones related directly to their CBFM activities such as extraction of forest resources, while monitoring other parameters much less frequently.
The latter can take place if there is a high level of trust among these different institutions and organisations so that they can openly and honestly assess improvements and identify factors that hinder improvements without blaming one another.

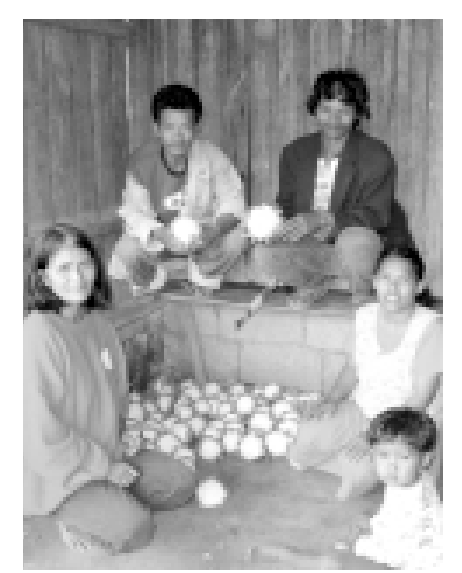




\section{Monitoring the impact} of ACM processes

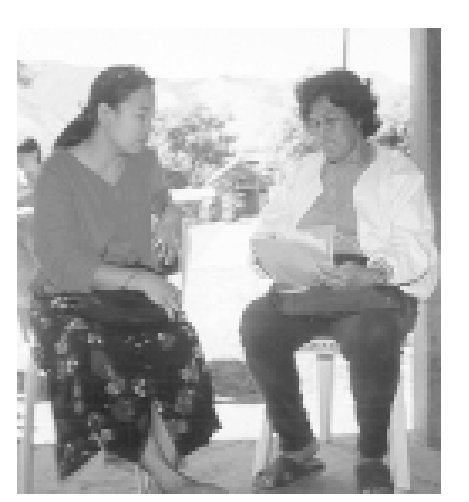

Over a longer period of time, i.e., 3-5 years, you may be interested to assess the impact of your work and the ACM processes that you facilitated on the following:

- socio-economic conditions of the people;

- the way different stakeholders interact with one another;

- improvements in forest conditions, etc.

Similarly, you may want to analyse the factors that contribute to the changes.
You can monitor the impact of your work and ACM processes by re-assessing the same information that you collected in Steps 1-5. By comparing the information with what you collected earlier, you will notice the changes.

Keep in mind that certain socio-economic and biophysical conditions take a long time before the changes are noticeable.

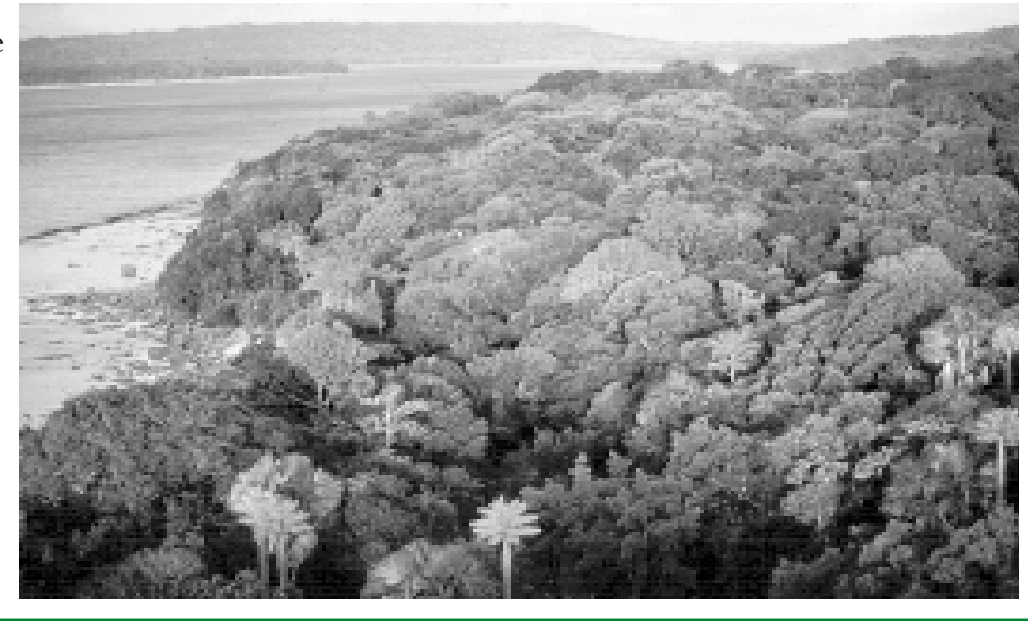





\section{ANNEX 2. EFFECTIVE ACM FACILITATION ${ }^{73}$}

\section{What does facilitation mean?}

Facilitation is different from teaching or mentoring. It is not a one-way activity in which someone (i.e., the facilitator) is at the giving end and the rest (the participants, learners, etc.) are at the receiving end. Being a facilitator means that you are a colearner in the process.

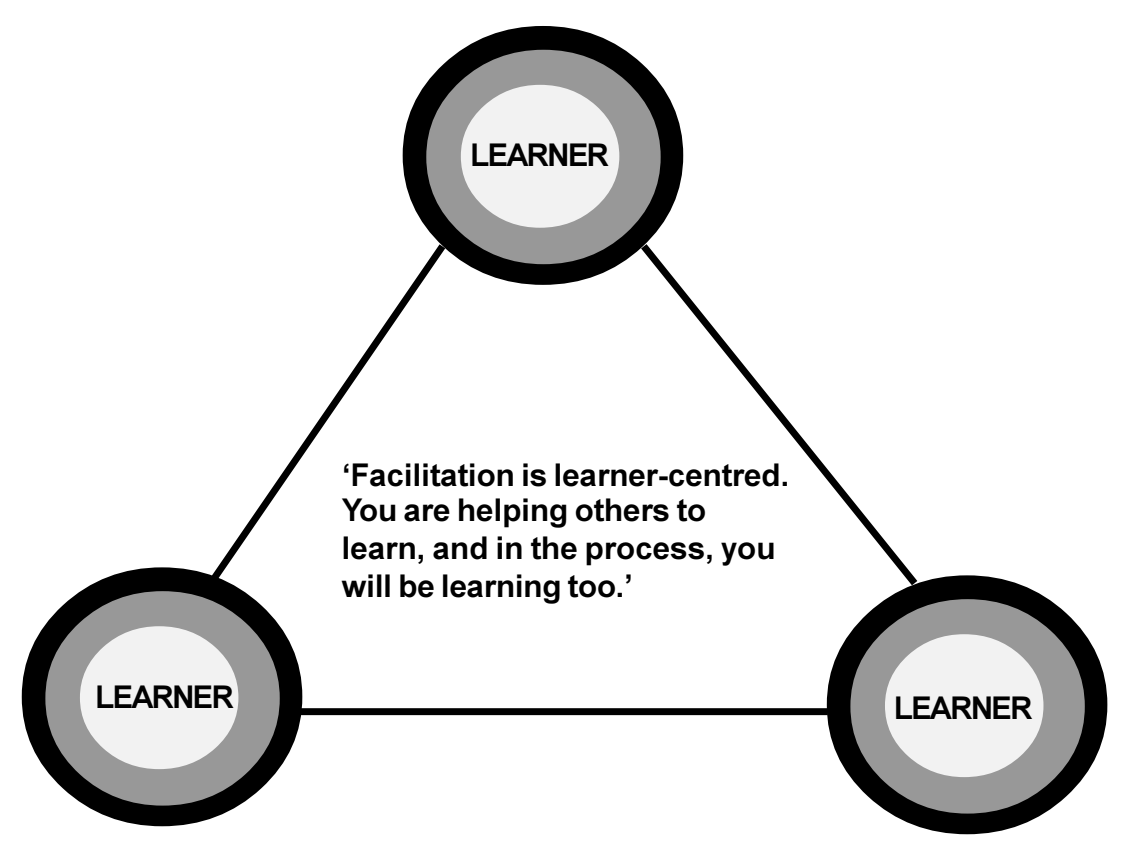

\section{Why is a facilitator's role crucial in the ACM process?}

The role of a facilitator in helping the local people and other stakeholders internalise ACM processes is very crucial. There are several reasons for this:

- ACM processes try to enhance social learning. Learning is not only an outcome of formal, classroom-based teaching. Learning usually comes from a process of selfdevelopment through experience.

- In facilitating ACM processes in community forestry, we are dealing with adults that have different learning styles, experience, attitudes, etc. Adults learn best 
when they are actively involved, if the context of learning can be applied directly to their tasks or jobs, and when they are in control of the learning process.

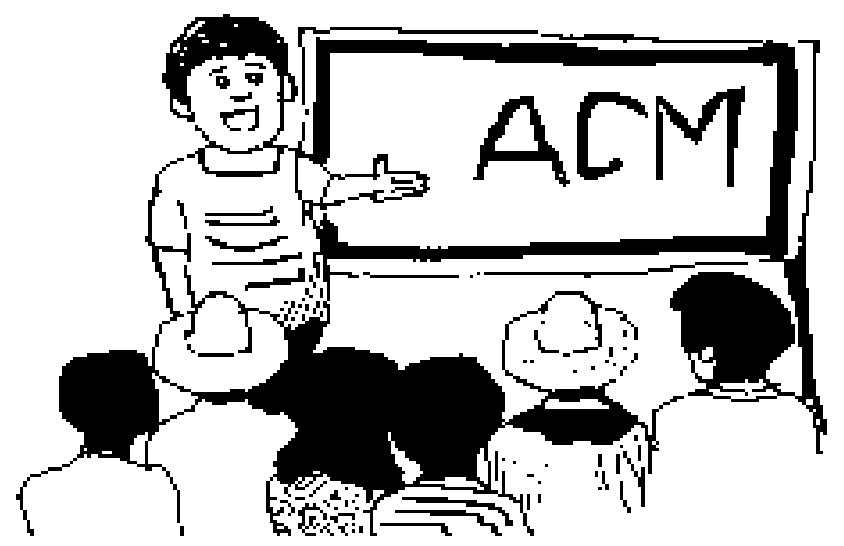

\section{What does an effective facilitator do?}

- Set the course of discussion right - exploring the participants' expectations from the discussion, summarising the agreed objectives of the discussion, and ensuring that the discussion processes are geared towards meeting the objectives.

- Set the atmosphere - making sure that the atmosphere is friendly and encouraging.

- Keep the discussion focused.

- Keep the pace - making sure that the pace of the discussions is neither too fast nor too slow for most of the participants.

- Keep the time - keeping track of time and promoting progress.

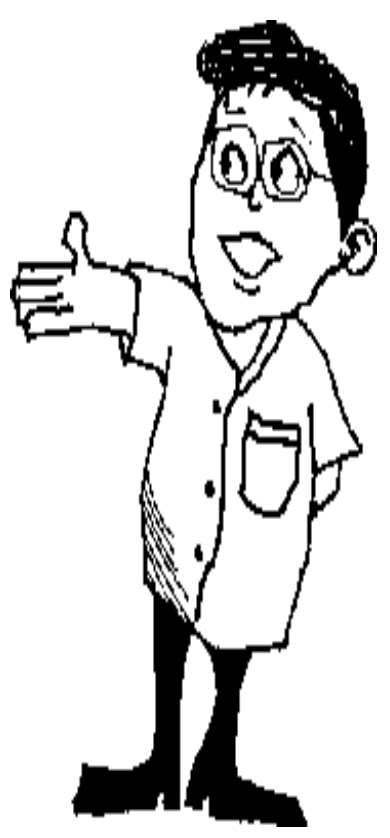

- Make space for everyone to participate - ensuring that everyone is given a chance to participate and that the discussions are not dominated by certain people. 
- Guide the discussions - asking questions to deepen the discussions, clarifying participants' ideas, and paraphrasing to make these ideas clearer for others.

- Test the waters - checking participants' feelings and whether everyone can follow the discussions and processes.

- Provide feedback - providing comments and acting as a mirror against which the participants can reflect on their own performance.

- Sum it up - at the end of the discussion, summarising the processes and the agreed actions.

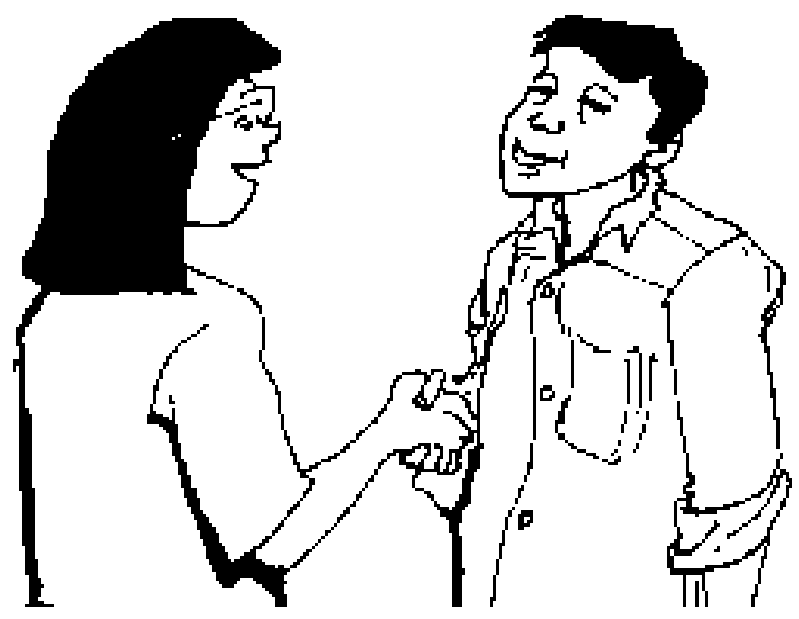

'Effective listening skills are basic facilitation skills required of all leaders and managers.'

\section{What kind of skills must a facilitator have?}

- Social skills - to bring the group together and provide structure without controlling the discussion.

- Organising skills - to sort out administrative and logistic arrangements, such as booking the rooms, preparing necessary documents for distribution, making sure invitations are sent beforehand, etc.

- Technical skills - knowledge of the subject matter.

- Analytical skills - to help participants identify, understand and analyse the problems clearly, and synthesise the information in a logical way. 
- Communication skills - to explain relevant issues clearly in simple language that can be understood by participants with different levels of literacy and education.

- Listening skills - to gauge people's level of understanding, to capture new ideas or perspectives, not only to listen to what is expressed explicitly but also to discern ideas between the lines, be sensitive to underlying tensions or confusion, gauge people's feelings.

- Interpersonal skills - to be warm, supportive, accessible, enthusias tic, flexible, and responsive to people's needs.

\section{What kind of attitude and behaviour should a facilitator have?}

- Open

- Honest

- Just

- Sensitive to culture

- Attentive to people and process.

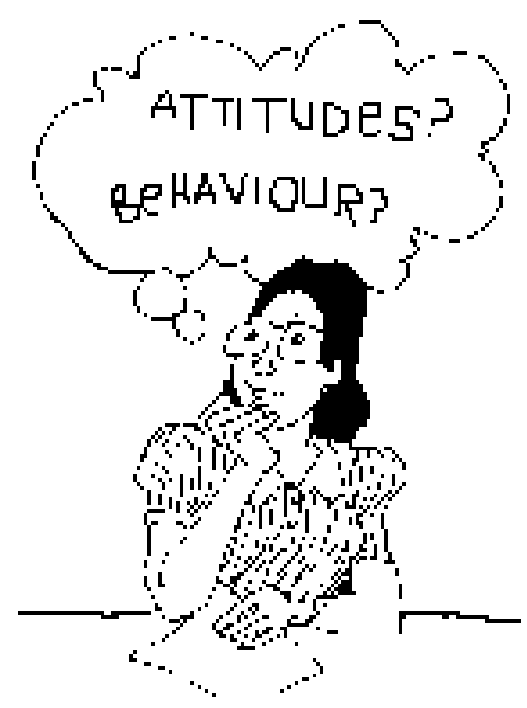

In the context of ACM, with the appropriate skills, behaviour, and attitude described above, the facilitators create conditions and processes that improve communication among different stakeholders. This improved communication generates a clear common vision and purpose that allow them to learn and work together to improve their lives and natural resources.

ACM facilitators should create 'space' that allows local people and stakeholders' creativity, innovation, and novelty to emerge. In facilitating ACM process, it is important for facilitators to keep in mind that suprise should be expected and failure and mistakes should be treated positively as opportunities for learning and improving. Lastly, always remember that facilitation is effective only if it is empowering! 


\section{ENDNOTES AND REFERENCES}

1. Lynch, O.J. 1993 Securing community-based tenurial rights in the tropical forests in Asia: An overview of current and prospective strategies. In: Waner, K. and Wood, H. (eds.) Policy and legislation in community forestry. RECOFTC, Bangkok. p. 27-34.

2. Pulhin, J.M. 1996 Community forestry: Paradoxes and perspective and development practices. PhD. Dissertation. The Australian National University, Canberra, Australia.

Guiang, E.S., Borlagdan, S.B. and Pulhin, J.M. 2001 Community-Based Forest Management in the Philippines: A preliminary assessment period. Institute of Philippine Culture, Ateneo de Manila University, Manila.

3. Gilmour, D.A. and Fisher, R.J. 1997 Evolution in community forestry: Contesting forest resources. In: Victor, M., Lang, C., and Bornemeier, J. (eds.) Community forestry at a crossroads: Reflections and future directions in the development of community forestry. Proceedings of an International Seminar, Bangkok, Thailand. 17-19 July 1997. p. 27-44.

4. Poffenberger, M. 1990 The evolution of forest management systems in Southeast Asia. In: Poffenberger, M. (ed.) Keepers of the forest: Land management alternatives in Southeast Asia. Kumarian Press, Connecticut. p. 7-26.

5. Ibid.

6. Gibbs, C., Payuan, E., del Castillo, R. 1990 The growth of the Philippine social forestry program. In: Poffenberger, M. (ed.) Keepers of the forest: Land management alternatives in Southeast Asia. Kumarian Press, Connecticut. p. 253-265.

Poffenberger, M. 1990 The evolution of forest management systems in Southeast Asia. In: Poffenberger, M. (ed.) Keepers of the forest: Land management alternatives in Southeast Asia. Kumarian Press, Connecticut. p. 7-26.

7. Office of the President. 1982 Launching Programme for Forest Ecosystem Management II (PROFEM II), also known as the Integrated Social Forestry programme. Manila. 
8. Magno, F. 2001 Forest devolution and social capital: State-civil society relations in the Philippines. Environmental History 6(2): 264-286.

Diaz, C.P. and Bacalla, D.T. 2002 ACM research in the Philippines: Implications for Community-Based Forest Management. A paper presented at the workshop on Adaptive Collaborative Management of Community Forests: An Option for Asia, organised by FAO RAP, Bangkok, 26-27 September 2002.

9. The figure was put together based on the information that we collected from various sources. Among others are the following:

Poffenberger, M. 1990 The evolution of forest management systems in Southeast Asia. In: Poffenberger, M. (ed.) Keepers of the forest: Land management alternatives in Southeast Asia. Kumarian Press, Connecticut. p. 7-26.

Department of Environment and Natural Resources. 1996 Basic community organizing handbook for community-based forest management programs. Department of Environment and Natural Resources, Manila, Philippines. $143 \mathrm{p}$.

Magno, F. 2001 Forest devolution and social capital: State-civil society relations in the Philippines. Environmental History 6(2): 264-286.

10. Department of Environment and Natural Resources. 1996 DENR Administrative Order No. 96-29. Rules and Regulations for the implementation of Executive Order No. 263, otherwise known as the Community Based Forest Management Strategy (CBFMS). Manila.

11. Diaz, C.P. and Bacalla, D.T. 2002 ACM Research in the Philippines: Implications for Community-Based Forest Management. A paper presented at the workshop on Adaptive Collaborative Management of Community Forests: An Option for Asia, organised by FAO RAP, Bangkok, 26-27 September 2002.

12. Department of Environment and Natural Resources. 1998 How to participate in the CBFM program. DENR Natural Resources Management Program (NRMP), Manila.

13. Office of the President. 1987 Executive Order No. 192. Reorganisation of the Department of Energy, Environment and Natural resources, renaming it as the Department of Environment and Natural Resources. Manila. 
14. Office of the President. 1991 Republic Act No. 7160. The new Local Governance Code (LGC). Manila.

It is worth pointing out that the Local Goverment Code was implemented way before CBFM became a national programme.

15. Magno, F. 1993 The growth of Philippine environmentalism. Kasarinlan: A Philippine Quarterly of Third World Studies 9(1):7-18.

16. Lynch, O.J. 1993 Securing community-based tenurial rights in the tropical forests in Asia: An overview of current and prospective strategies. In: Waner, K. and Wood, H. (eds.) Policy and legislation in community forestry. RECOFTC, Bangkok. p. 27-34.

Colchester, M. 1994 Sustaining the forests: The Community-based approach in South and South-East Asia. Development and Change 25(1): 3-31.

17. Geollegue, R.T. 2000 A Tale of two provinces: An assessment of the implementation of decentralized forestry functions by two provinces in the Philippines. In: Enters, T., Durst, P.B. and Victor, M. Decentralisation and devolution of forest management in Asia and the Pacific. RECOFTC Report No. 18 and RAP Publication 2000/1. Bangkok, Thailand. p. 210-222.

Tiongson, V. 2000 Experiences and challenges of local government units in co-managing forest resources: The case of Lower Magat Forest Reserve. In: Enters, T., Durst, P.B., and Victor, M. Decentralisation and devolution of forest management in Asia and the Pacific. RECOFTC Report No. 18 and RAP Publication 2000/1. Bangkok, Thailand. p. 205-209.

Magno, F. 2001 Forest devolution and social capital: State-civil society relations in the Philippines. Environmental History 6(2): 264-286.

18. Tiongson, V. 2000 Experiences and challenges of local government units in co-managing forest resources: The case of Lower Magat Forest Reserve. In: Enters, T., Durst, P.B. and Victor, M. Decentralisation and devolution of forest management in Asia and the Pacific. RECOFTC Report No. 18 and RAP Publication 2000/1. Bangkok, Thailand. p. 205-209.

19. Sabban, M.V.M. 1997 Community forestry and decentralization policies: Reflections on experiences from the Philippines. In: Victor, M., Lang, C., and Bornemeier, J (eds.) Community forestry at a crossroads: Reflections and future directions in the development of community forestry. Proceedings of an International Seminar, Bangkok, Thailand, 17-19 July 1997. p. 27-44. 
20. Geollegue, R.T. 2000 A tale of two provinces: An assessment of the implementation of decentralized forestry functions by two provinces in the Philippines. In: Enters, T., Durst, P.B., and Victor, M. Decentralisation and devolution of forest management in Asia and the Pacific. RECOFTC Report No. 18 and RAP Publication 2000/1. Bangkok, Thailand. p. 210-222.

21. Gauld, R. 2000 Maintaining centralized control in community-based forestry: Policy construction in the Philippines. In: Doorbos, M., Saith, A. and White, B. (eds.) Forests: Nature, people, power. Blackwell Publishers Ltd, Oxford. p. 223-248.

Edmunds, D. and Wollenberg, E. 2001 Historical perspectives on forest policy change in Asia. Environmental History 6(2): 190-212.

22. Vitug, M. 1996 A tortuous trek to community forestry. In: Coronel, S.S. (ed.) Patrimony: politics and the environment in the Philippines. Philippine Center for Investigative Journalism, Manila. p. 121-142.

Broad, R. 1995 The poor and the environment: Friends or foes. World Development 22(6): 811-822.

Revilla, A.V. 1986 A critical review of Philippine forestry policies. Policy paper No.19. Forestry Development Center, University of the Philippines Los Baños, College, Laguna, Philippines.

23. Castro, C.P. and Garcia, V.U. 2002 Pump-priming the LGU powerhouse: Emerging trends in the CBRMP. In: Hartanto, H. \& Evangelista, R. (eds.) Building partnerships, strengthening capacities and developing forest resources thru Community-Based Forest Management. Proceedings of a national workshop organised by Center for International Forestry Research (CIFOR) and Department of Environment and Natural Resources (DENR), Angeles City, Philippines, 6-7 August 2002.

Ignacio, D.B and Woell, H. 2002 Building partnerships, strengthening capacities and developing forest resources thru Community Based Forest Management: The CFPQ example. In: Hartanto, H. \& Evangelista, R. (eds.) Building partnerships, strengthening capacities and developing forest resources thru Community-Based Forest Management. Proceedings of a national workshop organised by Center for International Forestry Research (CIFOR) and Department of Environment and Natural Resources (DENR), Angeles City, Philippines, 6-7 August 2002. 
Tandug, E.T. 2002 A review of NRMP framework for sustainable forest management in the Philippines. In: Hartanto, H. \& Evangelista, R. (eds.) Building partnerships, strengthening capacities and developing forest resources thru Community-Based Forest Management. Proceedings of a national workshop organised by Center for International Forestry Research (CIFOR) and Department of Environment and Natural Resources (DENR), Angeles City, Philippines, 6-7 August 2002.

24. Mercado, E.S. 2000 Decentralisation and devolution of forest management in the Philippines: Uneasy steps to institutional maturity. In: Enters, T., Durst, P.B. and Victor, M. (eds.) Decentralisation and devolution of forest management in Asia and the Pacific. RECOFTC Report No. 18 and RAP Publication 2000/1. Bangkok, Thailand. p. 205-209.

25. Ibid.

26. Gilmour, D.A. and Fisher, R.J. 1997 Evolution in community forestry: Contesting forest resources. In: Victor, M., Lang, C., and Bornemeier, J. (eds.) Community forestry at a crossroads: Reflections and future directions in the development of community forestry. Proceedings of an International Seminar, Bangkok, Thailand, 17-19 July 1997. p. 27-44.

27. Hartanto, H., Lorenzo, M.C., Valmores, C., Burton, L. and Arda-Minas, L. 2002 Adaptive collaborative management: A value-adding approach to CBFM in the Philippines. In: Hartanto, H. \& Evangelista, R. (eds.) Building partnerships, strengthening capacities and developing forest resources thru Community-Based Forest Management. Proceedings of a national workshop organised by Center for International Forestry Research (CIFOR) and Department of Environment and Natural Resource (DENR), Angeles City, Philippines, 6-7 August 2002.

Ignacio, D.B and Woell, H. 2002 Building partnerships, strengthening capacities and developing forest resources thru Community-Based Forest Management: The CFPQ example. In: Hartanto, H. \& Evangelista, R. (eds.) Building partnerships, strengthening capacities and developing forest resources thru Community-Based Forest Management. Proceedings of a national workshop organised by Center for International Forestry Research (CIFOR) and Department of Environment and Natural Resources (DENR), Angeles City, Philippines, 6-7 August 2002.

Villanueva, T. 2002 Experiences in implementing the Water Resources Development Project in Region 4. In: Hartanto, H. \& Evangelista, R. (eds.) 
Building partnerships, strengthening capacities and developing forest resources thru Community-Based Forest Management. Proceedings of a national workshop organised by Center for International Forestry Research (CIFOR) and Department of Environment and Natural Resources (DENR), Angeles City, Philippines, 6-7 August 2002.

28. O'Hara, P. 2002 Community forestry in the Philippines: Release through scaling down our failures. In: Hartanto, H. \& Evangelista, R. (eds.) Building partnerships, strengthening capacities and developing forest resources thru Community-Based Forest Management. Proceedings of a national workshop organised by Center for International Forestry Researc (CIFOR) and Department of Environment and Natural Resource (DENR), Angeles City, Philippines, 6-7 August 2002.

29. Bryant, R.L. 2002 False prophets? Mutant NGOs and Philippine environmentalism. Society and Natural Resources 15:629-639.

30. Diaz, C.P. and Bacalla, D.T. 2002 ACM research in the Philippines: Implications for Community-Based Forest Management. A paper presented in the workshop on Adaptive Collaborative Management of Community Forests: An Option for Asia. FAO RAP, Bangkok, 26-27 September 2002.

Cayatoc, F.B. 2002 Community-Based Forest Management Program: Palawan experience. In: Hartanto, H. \& Evangelista, R. (eds.) Building Partnerships, Strengthening Capacities and Developing Forest Resources thru CommunityBased Forest Management. Proceedings of a national workshop organised by Center for International Forestry Research (CIFOR) and Department of Environment and Natural Resources (DENR), Angeles City, Philippines, 6-7 August 2002.

31. Hartanto, H., Lorenzo, M.C. and Frio, A.L. 2002 Collective action and learning in developing a local monitoring system. International Forestry Review 4(3): 184-195.

32. Fisher, R.J. 1995 Collaborative management of forests for conservation and development. IUCN \& WWF, Gland. 65p.

33. Lee, K.N. 1993 Compass and gyroscope: Integrating science and politics for the environment. Island Press, Washington, D.C. 243p.

34. Holling, C.S. 1978 Adaptive environmental assessment and management. Wiley International Series on Applied Systems Analysis, Vol.3. Wiley, Chichester. 507p. 
Walters, C. 1986 Adaptive management of renewable resources. McMillan, New York. 374p.

Lee, K.N. 1993 Compass and gyroscope: Integrating science and politics for the environment. Island Press, Washington, D.C. 243p.

35. Bosch, O.J.H., Allen, W.J. and Gibson, R.S. 1996 Monitoring as an integral part of management and policy making. Proceedings of Symposium on "Resource Management: Issues, Visions, Practice". Lincoln University, New Zealand, 5-8 July 1996. p. 12-21.

Taylor, B., Kremsater, L. and Ellis, R. 1997 Adaptive management of forests in British Columbia. British Columbia Ministry of Forests, Victoria. 93p.

Salafsky, N., Margoluis, R. and Redford, K. 2001 Adaptive management: A tool for conservation practitioners. Biodiversity Support Program. World Wildlife Fund, Inc., Washington D.C. 100p.

36. This definition was formulated by ACM Group in the $3^{\text {rd }}$ International Steering Committee meeting which was held in the Philippines, October 2001. The group consists of all the researchers from CIFOR and its partners who implement ACM approach and processes in various parts of the world. The group members exchange their experience at workshops and in internet-based communication (email interactions, ACM-interactive website, etc.).

37. The definition was formulated by ACM Group in a workshop held at CIFOR Headquarters, Bogor, November 2001.

38. This definition was formulated by ACM Group in the $3^{\text {rd }}$ International Steering Committee meeting, October 2001.

39. Ruitenbeek, J. and Cartier, C. 2001 The invisible wand: Adaptive comanagement as an emergent strategy in complex bio-economic systems. CIFOR Occasional Paper No. 35. CIFOR, Bogor.

40. Buck, L.E., Wollenberg, E. and Edmunds, D. 2001 Social learning in the collaborative management of community forests: Lessons from the field. In: Wollenberg, E., Edmunds, D., Buck, L., Fox, J. and Brodt, S. (eds.) Social learning in community forestry. Center for International Forestry Research, Bogor, p. 1-20.

41. Ibid. 
42. Maarleveld, M. and Dangbégnon, C. 2002 Social learning: Major concepts and issues. Lessons from natural resource management in 'terroirs' and 'landelijke gebieden'. In: Leeuwis, C. and Pyburn, R. (eds.) Wheelbarrows full of frogs: Social learning in rural resource management. Koninklijke van Gorgum, Assen, p. 67-84.

43. Maarleveld, M. and Dangbégnon, C. 1999 Managing natural resources: A social learning perspective. Agriculture and Human Values 16: 267-280.

44. Guerrero, L.H., Holling, C.S. and Light, S.S. (eds.). 1995 Barriers and bridges to the renewal of ecosystems and institutions. Columbia University Press, New York.

45. There are many studies that showed PAR to be an effective methodology to increase participation and to empower local people. Among others: Maclure, R. and Bassey, M. 1991 Participatory action research in Togo: An inquiry into maize storage systems. In: Whyte, W.F. (ed.) Participatory action research. Sage Publications, London. p. 190-209.

Sriskandarajah, N. and Fisher, R.J. 1992 A participatory approach to improving rural livelihoods of people in the Goilala District of Papua New Guinea. A report on a research project funded by the Australian International Development Aid Bureau (AIDAB) under the Development Research Grants Scheme. DRGS No. 196.

Fisher, R.J. and Jackson, W.J. 1998 Action research for collaborative management of protected Areas. A paper presented at "Collaborative Management of Protected Areas in the Asian Region" workshop, Nepal, 25. 28 May 1998.

Opatpatanakit, A. 1998 Collaborative action research: An alternative methodology to create sustainable rural development. A paper presented at the "Participatory Action research" workshop, Samarinda, 4-9 May 1998.

On the other hand, participatory processes can be harmful, if not used properly, as pointed out by Cooke \& Kothari (2001):

Cooke, B. and Kotahri, U. 2001 Participation: The new tyranny? Zed Books, London. 207p.

46. Fisher, R.J. and Jackson, W.J. 1998 Action research for collaborative management of protected areas. A paper presented at "Collaborative 
Management of Protected Areas in the Asian Region" workshop, Nepal, 25 28 May 1998.

47. Selener, D. 1997 Participatory action research and social change. The Cornell Participatory Action Research Network. Cornell University, Ithaca. 384p.

48. DENR-IPAS. 2000 Mt. Kitanglad Range Natural Park: Management plan. Malaybalay, Bukidnon.

49. Colfer, C.J.P., Prabhu, R., Gunther, M., McDougall, C., Porro, N.M. and Porro, R. 1999 Who counts most? Assessing human well-being in sustainable forest management. C\&I Toolbox No. 8. CIFOR, Bogor. 62p.

50. Esguerra, E. and Hartanto, H. 2002 Stakeholders' collaboration and learning: The implications of devolution and decentralisation in Palawan. A paper presented at "Rebuilding Indonesia, a Nation of 'Unity in Diversity': Towards a Multicultural Society” workshop, 16-19 July 2002.

51. Office of the President. 1992 Republic Act 7611. Strategic Environmental Plan (SEP) for Palawan. Manila.

52. Esguerra, E. and Hartanto, H. 2002 Stakeholders' collaboration and learning: The implications of devolution and decentralisation in Palawan. A paper presented at "Rebuilding Indonesia, a Nation of 'Unity in Diversity': Towards a Multicultural Society” workshop, 16-19 July 2002.

53. Environmental Science for Social Change, Inc., year of publication unknown. Decline of the Philippine Forest. ESSC, Manila. 45 pp.

54. Swedish Space Corporation (SSC). 1988 Mapping of the natural conditions of the Philippines. Report submitted to the World Bank. World Bank, Washington DC.

55. This is the result of the analysis done by Palawan Tropical Forest Protection Programme, a special project of the Palawan Council for Sustainable Development.

56. Hartanto, H., Villanueva, T., Malabrigo, P. and Sapin, N. 2000 Criteria and Indicator-based biophysical assessment. CIFOR ACM Internal Research Report. CIFOR, Bogor.

57. Ibid. 
58. Office of the President. 1967 Presidential Proclamation No. 219. Declaring the entire province of Palawan as game refuge and bird sanctuary, and the small islands off Palawan as natural reserves. Manila.

59. Devanadera, M.D., Devanadera, N., Canete, E., Rodriquez, D. and Robles, M. 2002 People's initiatives to influence change: The experience of a community in Palawan, Philippines. A paper presented at "Rebuilding Indonesia, a Nation of 'Unity in Diversity': Towards a Multicultural Society" workshop, 16-19 July 2002.

60. Villanueva, T., Hartanto, H. and Sapin, N. 2000 Criteria and Indicatorbased forest management assessment. CIFOR ACM Internal Research Report. CIFOR, Bogor.

61. Department of Environment and Natural Resources. 1998 DENR Administrative Order No. 98-42. Production sharing agreement with People's Organisation in the harvest of forest plantations owned by the government inside CBFM area. Manila.

62. The basis of the forest charge calculation was DENR Administrative Order No. 80 (1987) stating that forest charges for manufactured and squared timber should be based on their round or log form exclusive of allowable defects. This basis was not appropriate in the case of STCMPC who extracted fallen trees as many parts were rotten already. The exchange rate used was US $\$ 1$ equals to $\mathrm{PhP} 50$.

63. This is an average rate. Different rates are applied for different tree species.

64. Wollenberg, E. with Edmunds, D. and Buck, L. 2000 Anticipating change: Scenarios as a tool for adaptive forest management. A Guide. CIFOR Publication, Bogor. 38p.

65. Prabhu, R., Colfer, C.J.P., Venkateswarlu, P., Tan, L.C., Soekmadi, R. and Wollenberg, E. 1996 Testing criteria and indicators for the sustainable management of forests: Phase I final report. CIFOR Special Publication, Bogor. 217p.

Lammerts van Bueren, E. and Blom, E. 1997 Hierarchical framework for formulation of sustainable forest management standards: Principles, criteria, indicators. The Tropenbos Foundation, Wageningen. 82p.

Prabhu, R. Colfer, C., and Shepherd, G. 1998 Criteria ad indicators for sustainable forest management: New findings from CIFOR's Forest 
Management Unit level research. Rural Development Forestry Network Paper No. 23. Rural Development Forestry Network, London.

66. Colfer, C.J.P., Prabhu, R., Gunther, M., McDougall, C., Porro, N.M. and Porro, R. 1999 Who counts most? Assessing human well-being in sustainable forest management. C\&I Toolbox No. 8. CIFOR, Bogor. 62p.

67. Pretty, J.N., Guijt, I., Thompson, J., and Scoones, I. 1995 A Trainer's guide for participatory learning and action. IIED Participatory Methodology Series, London. 267p.

68. Modified from a method suggested in:

Colfer, C.J.P., Brocklesby, M.A., Diaw, C., Etuge, P., Gunther, M., Harwell, E., McDougall, C., Porro, N.M., Prabhu, R., Salim, A., Sarjono, M.A., Tchikangwa, B., Tiani, A.M., Wadley, R.L., Woelfel, J. and Wollenberg, E. 1999 The BAG (Basic Assessment Guide for Human Well-Being). C\&I Toolbox No. 5. CIFOR, Bogor. 79p.

69. Wollenberg, E. with Edmunds, D. and Buck, L. 2000 Anticipating change: Scenarios as a tool for adaptive forest management. A guide. CIFOR Publication, Bogor. 38p.

70. These symbols were used by a group of communities in Nepal in developing their local monitoring system.

71. Johnson, T.R. 1998 Measuring the impact of Community-Based Forest Management in the Philippines. Natural Resource Management Program, Community-Based Forest Management Office, Manila.

Paz, R.R. 1999 Community-based environmental performance monitoring: Field manual. Community-Based Forest Management Office, Manila.

72. Borrini-Feyerabend, G., Farvar, M.T. and Ndangang, V. 2000 Co-management of natural resources: Organising, negotiating and learning-by-doing. Kasparek Verlag, Heidelberg. p.76.

73. We used the book written by Pretty et al. (1995) as the main source of information for this annex, including the two quotations cited. We would like to suggest that you also read the manual written by Braakman \& Edwards (2002) if you want to know more about facilitation and improve your skills in this area. Their complete citations are: 
Pretty, J.N., Guijt, I., Thompson, J., and Scoones, I. 1995 A Trainer's guide for participatory learning and action. IIED Participatory Methodology Series. IIED, London. p. 1-37.

Braakman, L. \& Edwards, K. 2002 The art of building facilitation capacities: A training manual. RECOFTC, Bangkok. 269p. 
Community forestry in the Philippines has gone through a long process of change over the last thirty years. Efforts to promote community forestry have reached the highest achievement with the creation of a comprehensive and integrated programme called Community-Based Forest Management (CBFM) in 1995. In this programme, local people are recognised as partners in the management and protection of the country's forests and forest resources. Nevertheless, local people, the Department of Environment and Natural Resources, and other local stakeholders still face problems in implementing the programme effectively. Indeed, managing a complex system, such as a forest, in the ever-changing socio-economic and political situations is not an easy task.

This book introduces a learning-based approach called Adaptive Collaborative Management $(\mathrm{ACM})$ as a potential approach to deal with the challenges of CBFM. It draws on the experience and lessons learnt from CIFOR's collaborative research in two CBFM sites in the Philippines. It also describes how local people and stakeholders in the two sites applied the ACM approach and process to address their local issues, the outcomes of these efforts, and the challenges that remain.

This book is intended for field officers of the Department of Environment and Natural Resources, local government units, field-based NGO and extension workers, trainers, and others who are in need of new approaches, new references, and new ways of thinking about community forestry. The accompanying guide provides the readers with key phases and steps that they can follow and adapt in incorporating the ACM approach and process in their work.

\section{ISBN 979-3361-10-7}
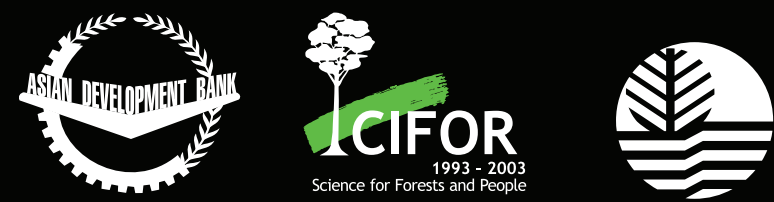

Republic of the Philippines

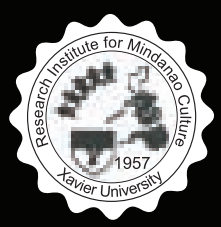

